\title{
Consumer and technological insights for improving the quality of osmo-dehydrated mango
}
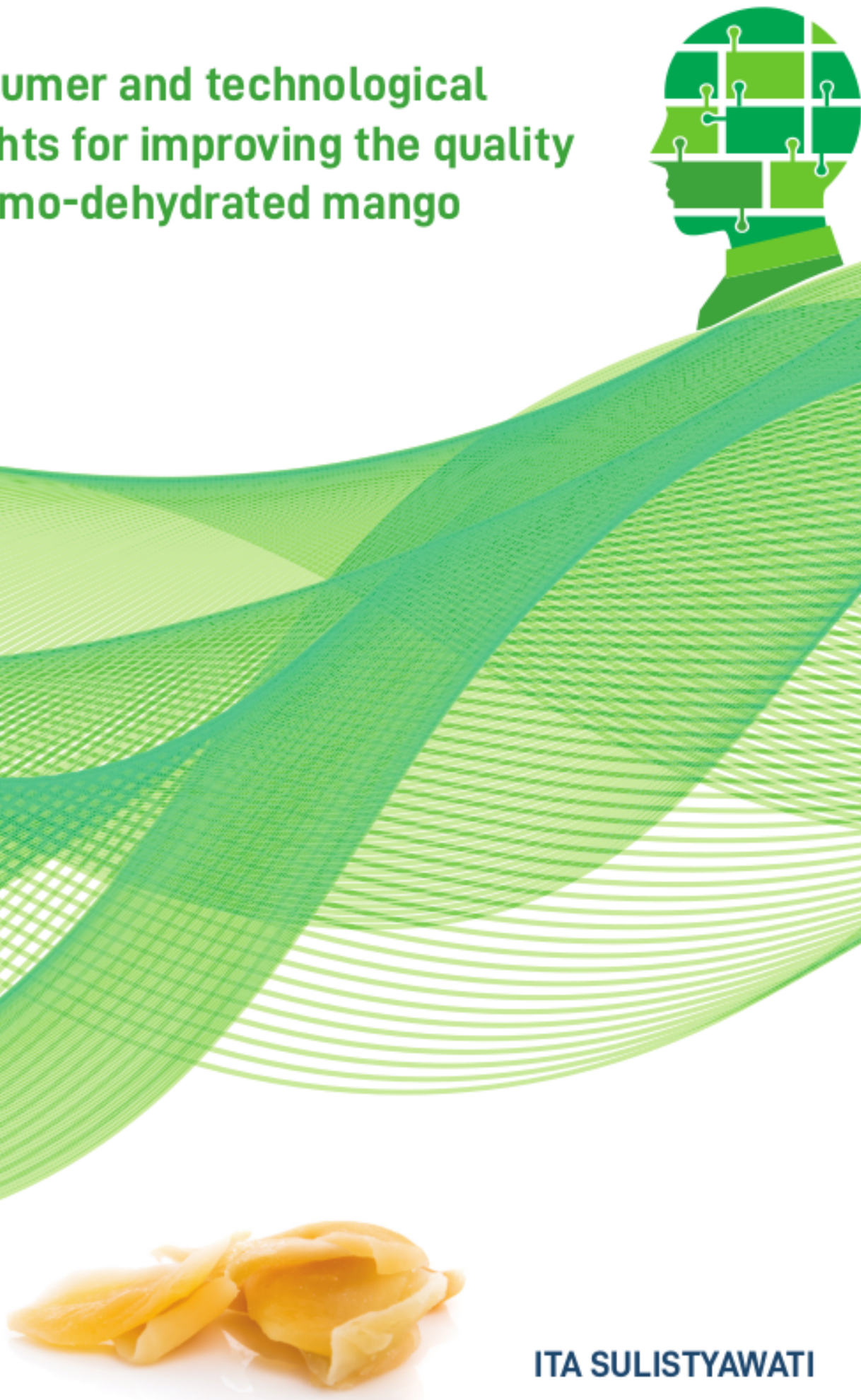


\section{PROPOSITIONS}

1. A successful consumer-oriented food product design should be started with a collaboration between consumer scientists and food technologists.

(this thesis)

2. Ripening of mango reduces the effect of high-pressure or vacuum impregnation treatments prior to osmo-dehydration on the mass transfer of sucrose.

(this thesis)

3. The statement of Blaise Pascal (The Provincial Letters, Letters XVI, 1657): "I have only made this letter longer because I have not had the time to make it shorter," supports the fact that finishing a $\mathrm{PhD}$ within four years to yield a high quality concisely written thesis is rather challenging.

4. Food innovation in edible packaging and utensils supports the importance of ultraprocessed foods for well-being and a sustainable environment.

5. Edible flowers are the key value-added product to revive floriculture business.

6. Social distancing policy stimulates the use of virtual and remote laboratories for engineering education.

7. Uncertainty amidst a public health crisis reveals how precious yet vulnerable human life is.

Propositions belonging to the thesis, entitled

'Consumer and technological insights for improving the quality of osmo-dehydrated mango'

Ita Sulistyawati

Wageningen, 20 May 2020 



\section{Consumer and technological insights for improving the quality of osmo-dehydrated mango}

Ita Sulistyawati 
Thesis committee

\section{Promotor}

Prof. Dr V. Fogliano

Professor of Food Quality and Design

Wageningen University \& Research

\section{Co-promotors}

Dr M. Dekker

Associate professor, Food Quality and Design Group

Wageningen University \& Research

Dr R. Verkerk

Associate professor, Food Quality and Design Group

Wageningen University \& Research

\section{Other members}

Prof. Dr H.J. Wichers - Wageningen University \& Research

Dr P.W. van Kleef - Wageningen University \& Research

Dr L.M. Sánchez-Siles - Hero Group, Murcia, Spain

Dr P. Pittia - University of Teramo, Italy

This research was conducted under the auspices of the Graduate School VLAG (Advanced Studies in Food Technology, Agrobiotechnology, Nutrition and Health Sciences) 


\title{
Consumer and technological insights for improving the quality of osmo-dehydrated mango
}

\author{
Ita Sulistyawati
}

\section{Thesis}

submitted in fulfilment of the requirements for the degree of doctor at Wageningen University

by the authority of the Rector Magnificus,

Prof. Dr A.P.J. Mol,

in the presence of the

Thesis Committee appointed by the Academic Board

to be defended in public

on Wednesday 20 May 2020

at 11 a.m. in the Aula. 


\section{Ita Sulistyawati}

Consumer and technological insights for improving the quality of osmo-dehydrated mango,

214 pages.

$\mathrm{PhD}$ thesis, Wageningen University, Wageningen, NL (2020)

With references, with summary in English, Dutch and Indonesian

ISBN : 978-94-6395-336-8

DOI : https://doi.org/10.18174/516716 


\section{Table of contents}

$\begin{array}{ll}\text { Chapter } 1 & 7\end{array}$

General introduction

Chapter 2

29

Exploring consumers' health perception across cultures in the early stages of new product development: Dried mango as a case study

Chapter 3

59

Consumer preference for dried mango attributes: A conjoint study among Dutch, Chinese and Indonesian consumers

Chapter 4

85

Osmotic dehydration of mango: Effect of vacuum impregnation, high

pressure, pectin methylesterase and ripeness on quality

\section{Chapter 5}

115

Modelling the kinetics of osmotic dehydration of mango: optimizing process conditions and pre-treatment for health aspects

Chapter 6

General discussion

Summary

Samenvatting

Ringkasan

Acknowledgements 



\section{Chapter 1 \\ General introduction}





\subsection{Background information}

Consumption of fruit supports a healthy life and wellbeing as well as contributes to a decrease in risk of major non-communicable diseases such as cardiovascular diseases because i) they are rich in vitamins, minerals and health promoting phytochemicals, ii) they are an important source of dietary fibers, and iii) they are generally low in energy density (Boeing et al., 2012; Angelino et al., 2019). Besides its healthfulness, fruit is consumed for its tastefulness being sweet and rich in a variety of flavors (Sabbe et al., 2009). However, consumption of fruit and vegetables is globally suboptimal (approx. $300 \mathrm{~g} /$ day) compared with the WHO-recommended amount of at least $400 \mathrm{~g} /$ day (A Joint WHO/FAOE Consultation, 2003; Afshin et al., 2019). Therefore, consumption of fresh and processed fruits should be stimulated (Boeing et al., 2012).

The increasing demand toward healthy convenient foods has triggered the development of minimally processed food aiming at maintaining health-promoting compounds and overall quality of fruits with a longer shelf life (Ahmed et al., 2016). This development increases the product availability in the market, e.g. dried fruits and vegetables, and their semi dried form like jams offers alternative fruit products to consumers (Siddiqui et al., 2011). In fact, dried and dehydrated fruit and vegetables gained $10 \%$ of the global market share of processed fruit and vegetables between 2011-2016 (IBISWorld Industry Report, 2016). However, increasing fruit consumption by eating these products did not receive much scientific attention yet.

Among the minimal processing technologies applied to fruit, drying gets less scientific attention compared to non-thermal processing as production of fresh-cut or high-pressure processed fruits. These non-thermal technologies produce relatively costly minimal processed fruits (MPFs) compared to drying. Recently, there has been a renewed scientific interest in the application of advanced drying technologies like combined drying techniques to produce dried/semi-dried fruits and vegetables (Qiu et al., 2019). In particular, fresh tropical fruits with high perishability and seasonal availability can benefit from these technologies to increase the fruit availability over a longer period and increase its versatility in food products (Prasad et al., 2013). 
Nevertheless, processing of fruit alters the perception of the final product quality, which usually is defined by a set of characteristics. When choosing fruits, a consumer assesses both the intrinsic and extrinsic quality characteristics, i.e., color, aroma, firmness, appearance, packaging, brand and country of origin. The consumer uses pieces of these information, called 'cues' to form an inference about its quality (e.g. good taste) (Grunert, 2005). This thesis focuses on consumer perception and preference in early stages of New Product Development (NPD) for product and process design of dehydrated mango, in which intrinsic quality characteristics of the product predominate.

Product and process design and optimizing the quality of dried mango are central in this thesis, because of growing interest in adding value to mango. Mango fruit ranked second in the global market of tropical fruit after banana and its sensory features are widely appreciated by consumers (UNCTAD, 2016; Altendorf, 2017). The research on dehydrated mango that will be discussed in this thesis is based on both consumer perception and food technology especially in terms of health, sensory and processing aspects.

\subsection{Tropical fruit}

Global trade in major tropical fruits reached the highest peak of 7.1 million tons (based on provisional figures for 2018), of which around 60\% was yielded in the Asian region, followed by USA, Africa, Oceania and Europe. Aside from banana, mango (Mangifera indica L.) is the predominant tropical fruit with a yearly production (approx. 39.1 million tons) accounting for more than half of the total major tropical fruit produced in 2018 (FAO, 2019). Interestingly, although mangoes are grown in several parts of the world (Matheyambath et al., 2015), more than $70 \%$ of the global production is in the Asian region, namely India, Thailand, Indonesia, Pakistan and China. Almost all the commercial cultivars of mango belong to Mangifera indica, among others Kent, Tommy Atkins, Haden, Keitt, Ataulfo, and Alphonso (Litz, 2009). Moreover, the majority of mango's total production is destined for domestic consumption and only $1.5 \%$ is traded globally (FAO, 2019). 

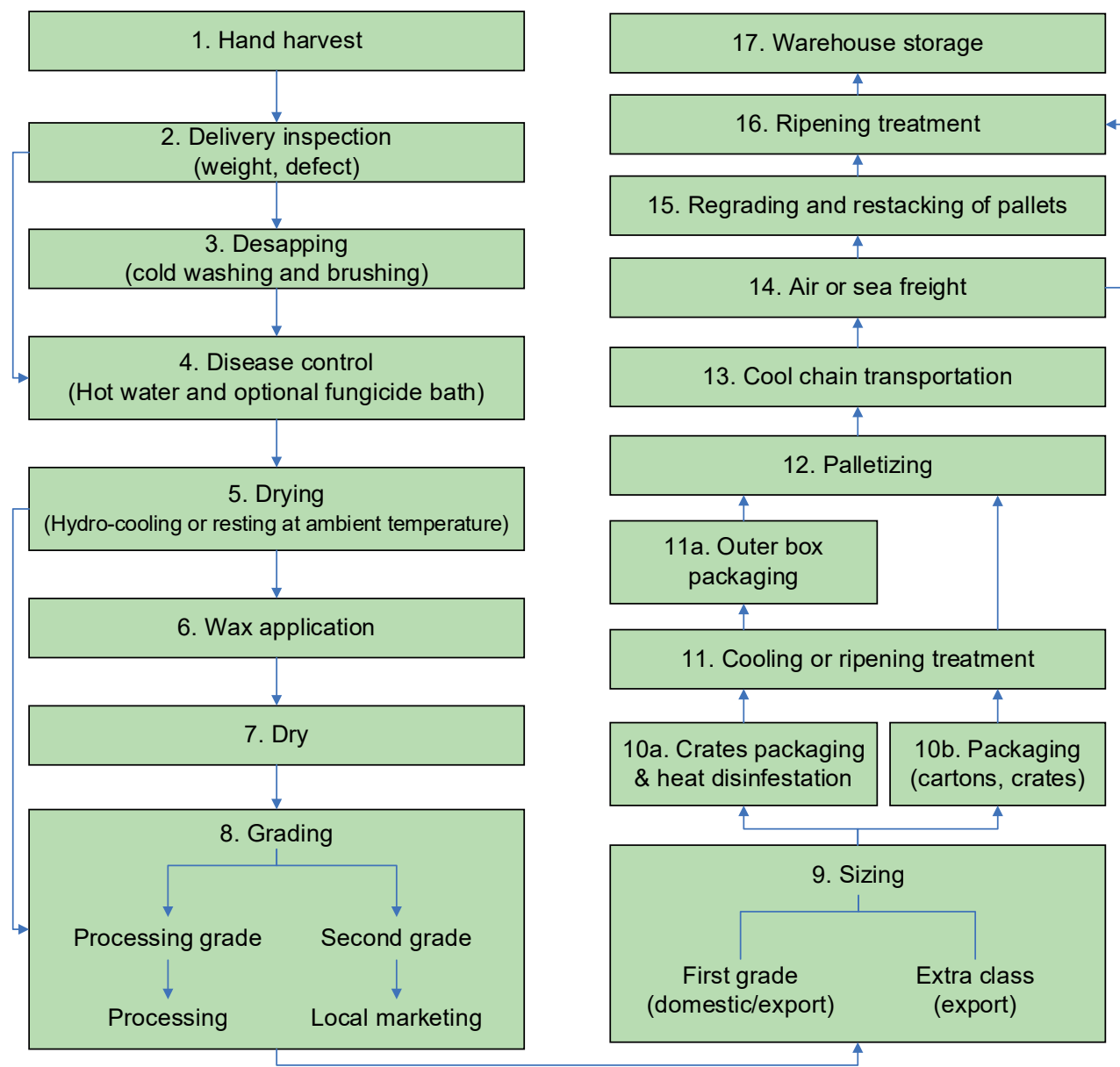

Fig 1.1 Harvest and post-harvest processing of fresh mango for the domestic and export chain. Adapted from Litz (2009) and National Mango Board (2010).

Fruits undergo several steps before reaching the consumers. Fig 1.1 summarizes the harvest and post-harvest process of commercial fresh mango. This starts with hand harvesting the mango at the appropriate picking date. After harvest, several postharvest treatments are applied: inspection, desapping, disease control, wax application, grading and sizing, packaging, cold chain transportation until warehouse storage.

Following this storage, the retailing process of the mango starts until reaching the consumers or mango processing industries. In the case of processed fruits, the raw 
material and the processing conditions, among others, will result in the final quality of the product at the time of consumption. Consumers have an important role in the food supply chain, therefore consumer research is a significant part of this thesis. Some elements of consumer-oriented product development are explored to acquire insights into consumers' perceived quality and preference as an input for product and process design.

\subsubsection{Quality perception}

In general European consumers have a positive appreciation towards tropical fruit consumption. They perceive tropical fruits and their products as healthy, nutritious, attractive, special and tasteful (Sabbe et al., 2009; Sijtsema et al., 2012). Two major aspects that positively influence tropical fruit consumption are the type and availability of the fruits. These aspects have placed banana, pineapple, mango, papaya, litchi, and passion fruit as the most common tropical fruits in the European market (Sabbe et al., 2008).

From a consumer perspective, food quality should meet the needs and preferences of consumers, providing characteristics (attributes), cues and benefits (Steenkamp, 1986; Grunert \& van Trijp, 2014). Relative to the needs and wishes, consumers differ in their quality assessment of a product, thus differ in their perceived quality of food.

Consumer perception is shaped by many variables which are closely related to each other, namely the individual (e.g. culture, personality, health cognitions), environment (e.g. society, family, food availability), product (product characteristics, production system) and the context or situation in which the interaction occurs (e.g. time, place) (Sijtsema et al., 2002; Stok et al., 2017). One example from a previous consumer perception study on fresh and dried fruits revealed that fresh fruits generally were perceived to be healthier and less convenient than dried fruits. Dried fruits were also perceived as containing more energy, and generally preferred in situations in which convenience is important like during sport (Jesionkowska et al., 2008). Some cross-cultural perception studies also reported cultural variation in 
perceiving quality of food, e.g. organic foods (Naspetti \& Zanoli, 2009), meat (Grunert et al., 2004), minimally processed vegetables (Ragaert et al., 2004).

While health undoubtedly contributes greatly to the consumer perception of food, it is not the only quality dimensions of importance. In fact, three other dimensions which overall represents perceived quality of food are taste (covers all sensory aspects), process (at primary production and processing level, e.g. organic production, processing technologies), and convenience (easy to be consumed) (Grunert et al., 1996). The first three dimensions are emphasized in this thesis. Relatedly, consumers differ in attribute weights to the quality dimensions (Bruns $\varnothing$ et al., 2002). As a consequence, not only differences between consumers in the relative importance of the quality attributes will exist, but also in how they infer from the available cues, how they choose and thus are exposed to various quality cues.

Summarizing, insights into consumers' perceived quality and their preference is necessary in early stages of consumer-oriented NPD to create products with the desired quality (Grunert, 2005).

\subsubsection{Nutrition and health}

Fruits in a diet have an important role for the well-being of humans. They contribute a wide range of nutrients and phytochemicals (Lule \& Xia, 2012). Also, the fruits' flavor, color and texture catch attention and add enjoyment to the food upon consumption (Wismer, 2014).

Tropical fruits, as other fruits have a relatively high carbohydrate, low protein, and, with a few exceptions, low fat content (Vicente et al., 2009). The fruits are also a rich source of vitamins $(\mathrm{C}, \mathrm{E})$, pro-vitamins, minerals $(\mathrm{K}, \mathrm{Fe}, \mathrm{Cu}, \mathrm{Mg})$, and dietary fiber (Yahia et al., 2019). In addition to the essential nutrients, most tropical fruits contain considerable amounts of phytochemicals, non-nutrient chemical compounds that are known to have biological significance, such as antioxidant activity (Dembitsky et al., 2011). Examples of fruits which have fairly high content of phytochemicals are mango with polyphenol content ranging from 9 to $208 \mathrm{mg} / 100 \mathrm{~g} \mathrm{FW}$ (Ribeiro \& Schieber, 2010); guava 
with total flavonoids ranging from 35 to $100 \mathrm{mg} / \mathrm{g} \mathrm{FW}$ (Biegelmeyer et al., 2011); papaya with total carotenoids ranging from 5.4 to $6.2 \mathrm{mg} / 100 \mathrm{~g} \mathrm{FW}$ (Schweiggert et al., 2011).

The content of nutritional and phytochemical compounds in fresh fruits depends on several inherent factors, e.g. species, cultivar and ripening stage (Vicente et al., 2009). In order to derive healthy products from the fruit these factors should be taken into consideration.

\subsubsection{Sensory aspects}

The first sensory characteristic assessed by consumers is appearance (e.g., color, shape, size), which is a major factor in the quality assessment of fruits and is an important determinant in the purchase of fruits and vegetables in the grocery store (Barrett et al., 2010). Appearance and (hand-assessed) texture are quality cues assessed by the consumer prior to purchase and consumption, while flavor (taste and aroma) and oral texture are experience quality characteristics assessed at the time of consumption (Wismer, 2014). As part of the intrinsic quality characteristics of fruits, these sensory characteristics are variable as they are also greatly influenced by the similar inherent factors as content of nutritional and phytochemical compounds.

\subsection{Minimally processed food}

Growing consumer demand for new products with fresh-like sensory and nutritional qualities yet convenient has led to the development of minimally processed food.

Globally, in the last five years, the production of ready-to-eat fruits and vegetables (e.g. table fruits, fresh-cut products) as well as the derived processed products (e.g. packaged fruit snacks, organic juices) has increased in recent years, and further increase is predicted (Nielsen, 2017; Sloan, 2018). In the same period, European imports of processed fruits and vegetables were increasing both in value and in volume (Sloan, 2018; CBI, 2019b). This increasing global demand was also applied to dried fruit, which can be seen from the increasing availability of dried fruit and its products in the international market (INC, 2018; CBI, 2019a). The dried fruit containing products include among others, baked goods, breakfast cereals, snack 
mixes (Sadler et al., 2019). Owing to the high versatility, consumer demand on dried fruit rises with the increasing consumer demand for healthy, convenient, natural, minimally processed, and functional food products (Nielsen, 2017; Sloan, 2018; Wyatt, 2018). Some examples of current trends of dried fruit products are nondairy probiotic dried fruits, air-dried organic fruit crisps, and 'clean label' dried fruits (Wyatt, 2018; Morrison, 2020).

Consumer preferences of fruit and vegetable products are shaped by several factors, but of increasing importance are nutritional attributes and disease prevention effects related to eating fruits and vegetables (Florkowski, 2019). Consumers demand for food products that are 'free from' artificial additives/ingredients, without any additives (E-numbers), "natural", and with functional benefits (Asioli et al., 2017). These diverse drivers challenge food manufacturers to be taken into account when developing new products.

Dried fruits have a long shelf-life, but the drying process often poses challenges in reaching desired nutritional and sensory characteristics (e.g., fresh-like characteristics). Table 1.1 shows several types of dried fruit products with different intrinsic characteristics due to, among others, type of processing and added ingredients. In general, there can be a trade-off between some quality characteristics and (the degree of) processing. 


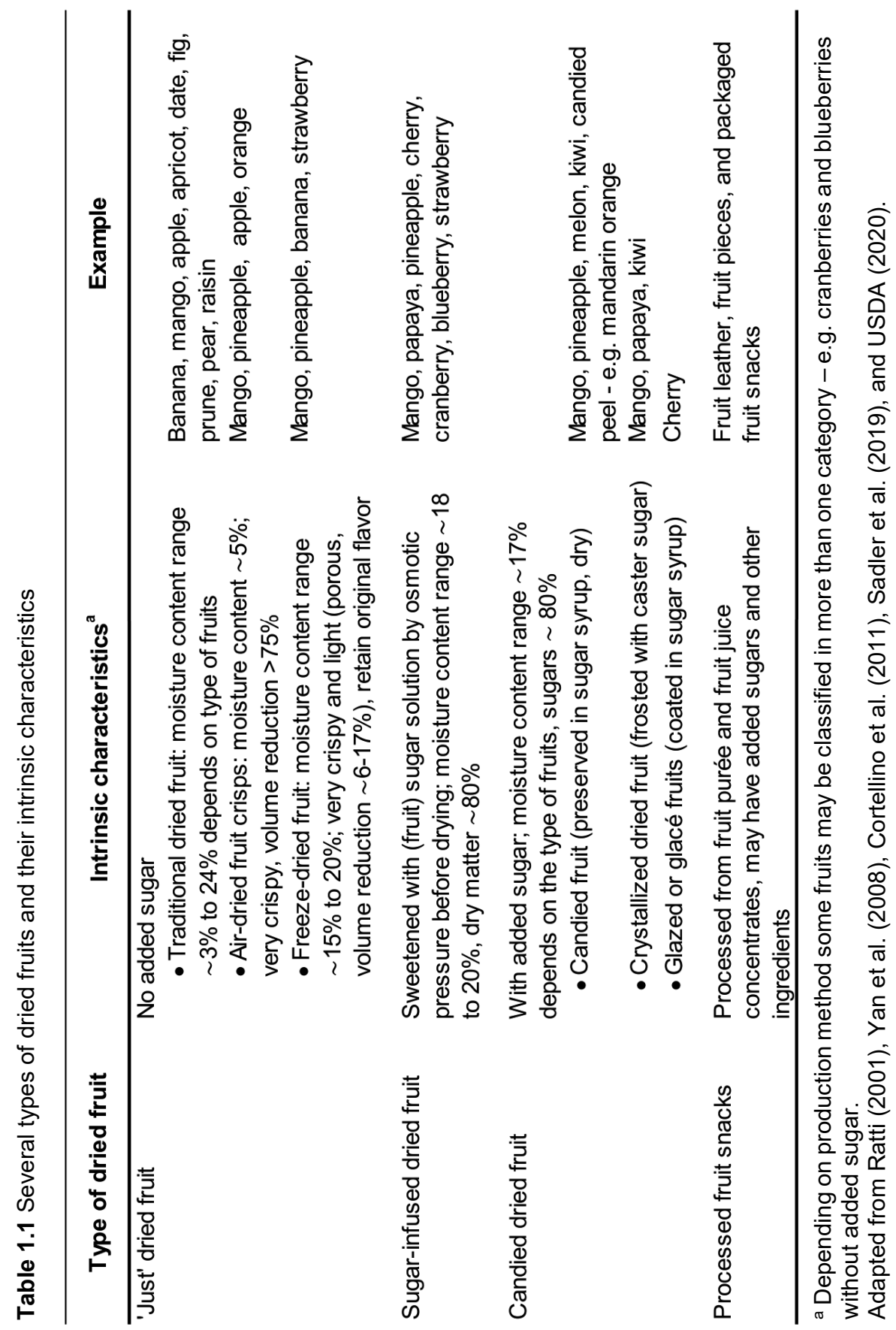




\subsubsection{Minimal processing by osmotic dehydration}

Minimal processing by osmotic dehydration (OD) is commonly applied to fruits to produce fresh-like processed fruits with an extended shelf-life while maintaining nutritional and health-promoting compounds. OD is a simple and effective conventional method to reduce the amount of water in fresh foods for the preparation of dried/semi-dried food products. As a partial water removal process, OD involves immersion of fruit in hypertonic sugar and/or salt solution that removes water and simultaneously increases the soluble solid content of the fruit (Torreggiani, 1993), as illustrated in Fig 1.2. Osmotic agents used for OD are osmotic solutions (OS) of sucrose, glucose, corn syrup, sorbitol, sodium chloride, or other agents acceptable to consumers. Depending on the process conditions and properties of fruit material, an OD process can remove $20-50 \%$ of water from the material (Ahmed et al., 2016). After OD, depending on the type of products, other processing such as drying or freezing can be applied more efficiently (Ciurzyńska et al., 2016).

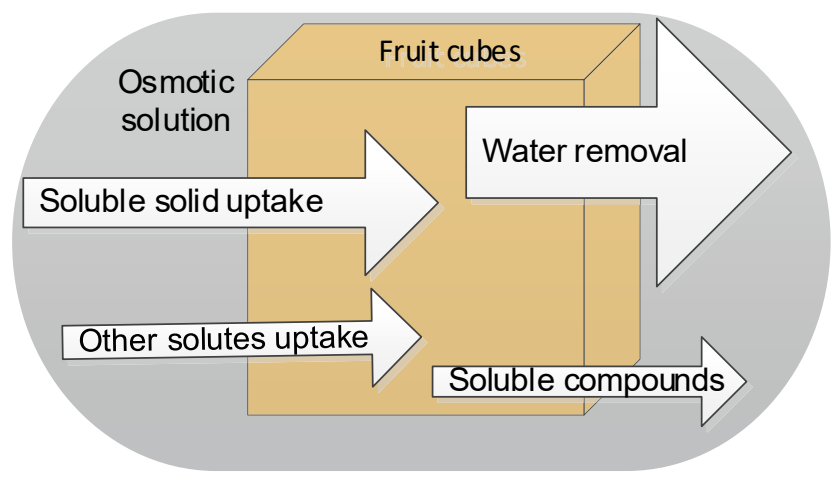

Soluble solid: the osmotic agents, e.g. salts, sugars, or its combination Other solutes: added compounds, e.g. minerals, vitamins

Fig 1.2 Mass transfer of fruit tissue during osmotic dehydration. The bigger arrow indicates the bigger volumetric flow of the respective compound.

\subsubsection{Innovative osmotic dehydration}

As a well-established partial water removal process, OD has been vastly developed to improve its process efficiency, that is, higher water removal with lower soluble solid uptake in shorter OD time. The efficiency of osmotic dehydration is influenced 
by several process variables, including pretreatments, temperature, fruit to water ratio, osmotic solution properties, and additional compounds (Ahmed et al., 2016). It has previously been observed that applying OD in combination with pretreatments, such as vacuum impregnation (VI) and high pressure (HP) prior to OD demonstrated an enhancement of mass transfer (Fito et al., 2001; Rastogi et al., 2007).

Fruit materials have a porous structure in which gas and intercellular spaces are filled with gas and endogenous fluids; its properties (e.g. pore size, number of pores) differ depending on several factors, e.g. maturity (Cantre et al., 2014). Owing to the porous structure, a novel vacuum impregnation, so-called pulsed vacuum impregnation or applying VI prior to OD (hereafter OD-VI) can be applied to fruit tissue, this involves the application of short vacuum pressure in the osmotic solution at the beginning of an OD process (Qiu et al., 2019). This process results in partial exchange of the internal gas or liquid in the pores with an external liquid phase (e.g. osmotic solution) promoted by pressure gradients (Fito et al., 2001; Chiralt \& Fito, 2003). Aside from being an effective way to reduce water, several advantages of OD-VI have been reported, including minimize the quality loss (e.g. nutrition, texture), and shorten the processing time (Qiu et al., 2019).

High pressure processing (HPP) is one of the most used commercial non-thermal processing in the food industry, e.g. for producing fruit and vegetable juice and purée, meat and dairy products. HPP application aims at extending the product's shelf life by inactivating microorganisms and enzymatic activities while retaining nutritional and sensory properties of the products (Balasubramaniam et al., 2015; Huang et al., 2017). The application of HPP is usually performed in a batch system: food is hermetically sealed in a flexible pouch under a high pressure of 100-800 MPa, with or without heat application, using a liquid (e.g. water, osmotic solution) as the pressure transfer medium, subjecting the interior and surface of the food to even pressure to achieve pasteurization (Balasubramaniam et al., 2015). Currently, relatively low productivity and high initial equipment costs limit the application of HPP technology to high value-added products (Balasubramaniam et al., 2015; Huang et al., 2017). Applying HPP prior to OD (OD-HP) can enhance the reduction of water 
activity during OD, inactivate microorganisms, and extend product shelf life (Dash \& Balasubramaniam, 2018).

To predict and optimize the effects of OD on the behavior of compounds of interest in the osmo-dehydrated fruit, a mathematical model can be used. The model can be derived based on knowledge of the physical and chemical properties of the fruit. Kinetic modelling is a mathematical tool to describe and forecast changes in food properties (van Boekel, 2008; Sarvan et al., 2014). Kinetic modelling has been previously applied to study the effect of OD on the concentration of nutritional and health-promoting compounds, including OD mass transfer as reviewed by Chandra \& Kumari (2015) and Assis et al., (2016) and vitamin C, e.g., da Silva et al. (2012) and Alam et al. (2010). In this thesis, a mathematical model was applied to quantitatively describe the effects of osmotic dehydration on kinetics of mass transfer and vitamin $\mathrm{C}$ loss in mango.

\subsection{Interdisciplinary approach for product and process design and optimizing quality of dried mango}

In this thesis, an interdisciplinary approach incorporating consumer science and food technology is proposed to design and optimize the product and process design to achieve the desired quality of dried mango, Fig 1.3.

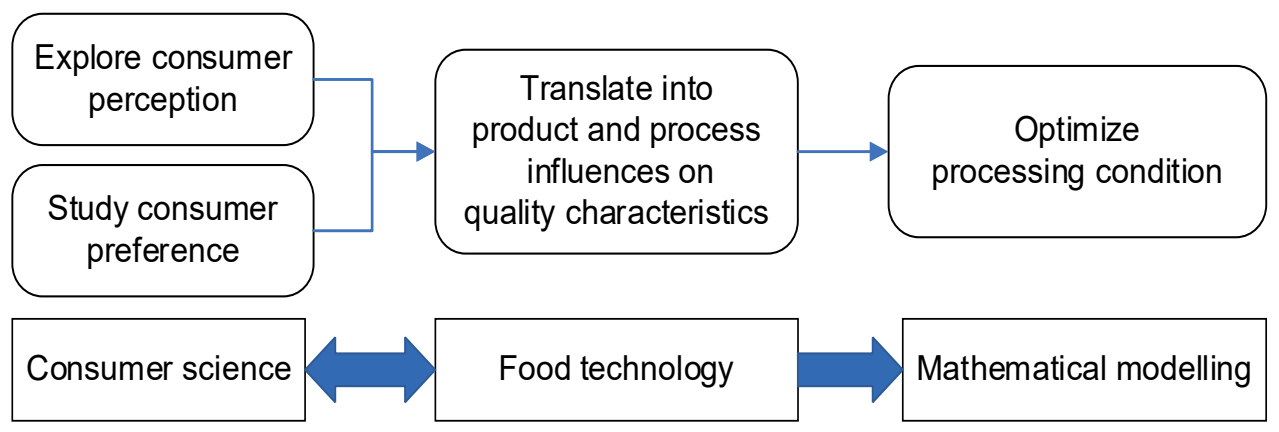

Fig 1.3. Interdisciplinary approach for designing and optimizing quality of dried mango

The consumer studies were used to provide relevant insights on quality perception towards dried mango. Subsequently, a transformation of the insights was built upon an interdisciplinary approach between consumer science and food technology to 
achieve technical product specifications (i.e. raw material and additional ingredients) and process specifications (i.e. pretreatment and main processing technologies). In addition, understanding of consumer preferences for the intrinsic quality of dried mango in relation to health and sensory was acquired. Besides, food technologists examined the influences of different processing conditions on quality changes in sensory (texture, color, etc.) and health properties (vitamin C, sucrose, etc.) during drying, e.g. osmotic dehydration. Mathematical models were applied to apprehend these quality changes (mass transfer and loss of vitamin $\mathrm{C}$ ) into equations containing parameters describing the quality change during processing. In particular, kinetic modeling was used to design the OD process conditions and choice of raw material to produce the optimum sucrose content and vitamin $C$ retention in an osmodehydrated mango. Thus, the model can be used to compare scenarios - by changing the parameter(s) -, to predict and optimize health properties as a function of applied processing conditions such as pre-treatment, time; as well as to optimize the osmotic dehydration process.

\subsection{Objectives and outline of the thesis}

The general objective of this thesis was to optimize the quality of dried mango using an interdisciplinary approach and contribute to the knowledge about the qualitybased product and process design. For this, some elements of consumer-oriented product development are explored to acquire insights into consumers' perceived quality and preference. These insights were translated into technological aspects of product design. Thus, the specific objectives of this thesis were to:

a. Explore consumer's health perception among different cultures and demonstrate its relevance for product and process design in the early stages of new product development;

b. Study consumer preference of dried mango among different cultures to contribute to adding value to dried mango products;

c. Study the effect of pre-treatment with vacuum impregnation (VI), high pressure (HP), and adding pectin methylesterase (PME) in combination with ripeness on the quality of dried mango; 
d. Describe the kinetics of osmotic dehydration of mango to optimize water loss, sugar uptake, vitamin $\mathrm{C}$ retention and treatment time.

This thesis comprises of six chapters in which four discuss the mentioned objectives. The four chapters are preceded by a general introduction addressing background, rationale and objectives (Chapter 1 ) and concluded by general discussion addressing key findings, implications and recommendations (Chapter 6) as shown in Fig 1.4. An interdisciplinary approach was used to transform in-depth insights in consumer perception of product and process characteristics toward dried mango and to apply it for product and process design (Fig 1.2). This interdisciplinary approach, involving participants of three countries, China, The Netherlands, and Indonesia, is described in Chapter 2. The results of this qualitative study - several key intrinsic quality attributes and their levels of dried mango - were tested in a quantitative setting, which is described in Chapter 3. A method to measure consumer preference using Adaptive Choice-Based Conjoint Analysis in the three countries is described. This analysis provided insights into the influence of the degree of familiarity and health consciousness toward the intrinsic quality attributes of dried mango.

Chapter 4 describes the effect of vacuum impregnation, high pressure processing and adding pectin methylesterase (PME) with calcium on the sucrose gain, texture and color of mango during osmotic dehydration (OD). These quality changes are compared between two different ripeness of mango to gain insight into tailoring $\mathrm{OD}$ efficiency and achieve the desired quality of OD mango. Subsequently, Chapter 5 describes the fate of ascorbic acids (AAs) concentration during a long duration of osmotic dehydration of mango. The water/sucrose mass transfer and changes of AAs during $O D$ are mathematically modelled to gain insight into the important mechanisms involved and to optimize sugar content, vitamin $\mathrm{C}$ retention and processing time of $\mathrm{OD}$ mango.

In Chapter 6, the key findings are summarized and discussed. Along with methodological considerations of the study, the implications of the findings for product development are elaborated. Finally, recommendations for further research are given. 


\section{Chapter 1}

Background, rationales \& objectives

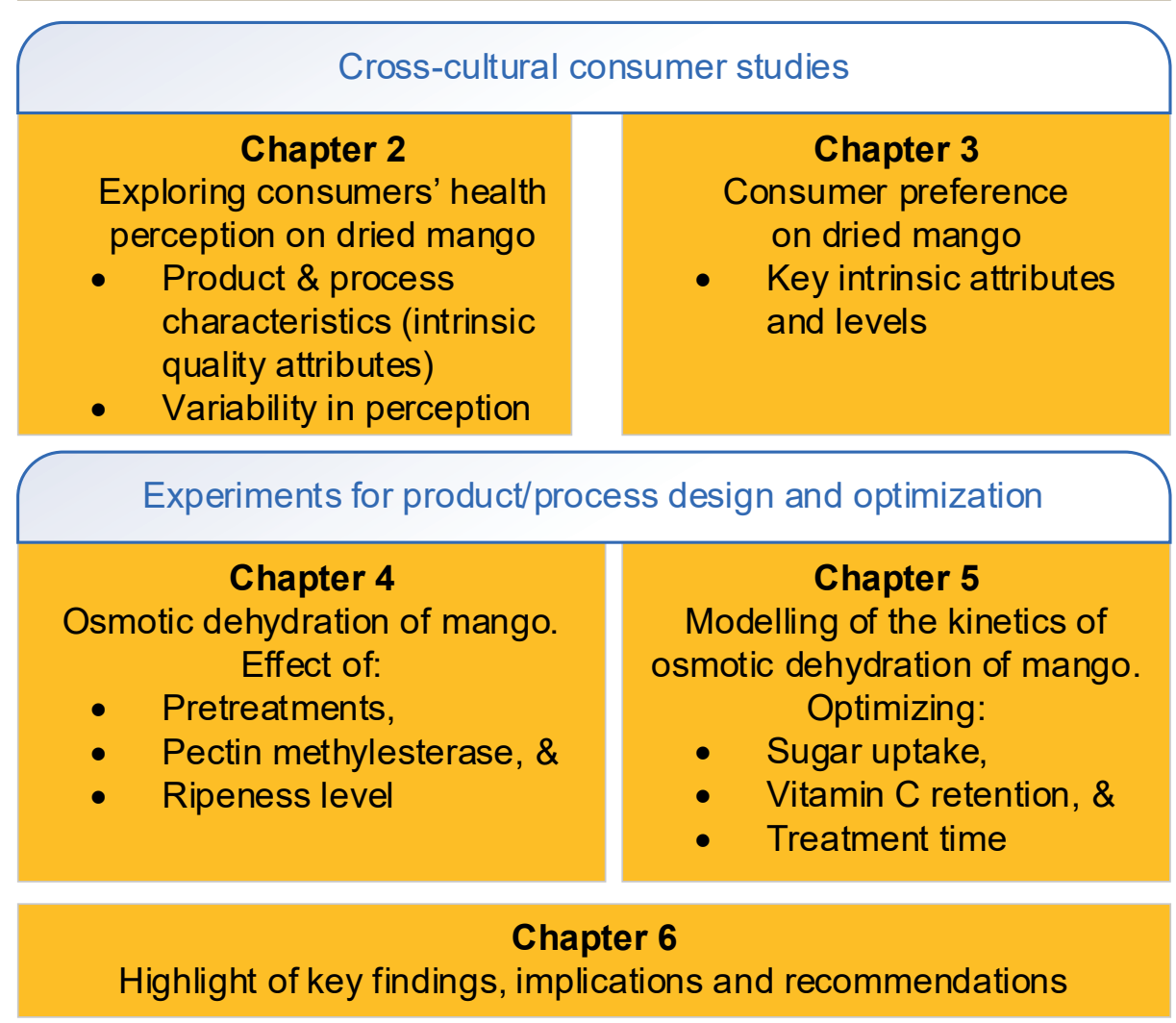

Fig 1.4. Schematic overview of the thesis chapters

\section{References}

A Joint WHO/FAOE Consultation. (2003). Diet, Nutrition and the Prevention of Chronic Diseases.

Afshin, A., Sur, P. J., Fay, K. A., Cornaby, L., Ferrara, G., Salama, J. S., Mullany, E. C., Abate, K. H., Abbafati, C., Abebe, Z., Afarideh, M., Aggarwal, A., Agrawal, S., Akinyemiju, T., Alahdab, F., Bacha, U., Bachman, V. F., Badali, H., Badawi, A., ... Murray, C. J. L. (2019). Health effects of dietary risks in 195 countries, 1990-2017: a systematic analysis for the Global Burden of Disease Study 2017. The Lancet, 393(10184), 19581972. https://doi.org/10.1016/S0140-6736(19)30041-8

Ahmed, I., Qazi, I. M., \& Jamal, S. (2016). Developments in osmotic dehydration technique for the preservation of fruits and vegetables. Innovative Food Science and Emerging Technologies, 34, 29-43. https://doi.org/10.1016/j.ifset.2016.01.003 
Alam, M. S., Amarjit, S., \& Sawhney, B. K. (2010). Response surface optimization of osmotic dehydration process for aonla slices. Journal of Food Science and Technology, 47(1), 47-54. https://doi.org/10.1007/s13197-010-0014-4

Altendorf, S. (2017). Global prospects for major tropical fruits: short-term outlook, challenges and opportunities in a vibrant global marketplace. In Food Outlook: Biannual Report on Global Food Markets (pp. 69-81). FAO Trade and Markets Division. http://www.fao.org/3/a-i6198e.pdf

Angelino, D., Godos, J., Ghelfi, F., Tieri, M., Titta, L., Lafranconi, A., Marventano, S., Alonzo, E., Gambera, A., Sciacca, S., Buscemi, S., Ray, S., Galvano, F., Del Rio, D., \& Grosso, G. (2019). Fruit and vegetable consumption and health outcomes: an umbrella review of observational studies. International Journal of Food Sciences and Nutrition, 70(6), 652-667. https://doi.org/10.1080/09637486.2019.1571021

Asioli, D., Aschemann-Witzel, J., Caputo, V., Vecchio, R., Annunziata, A., Næs, T., \& Varela, P. (2017). Making sense of the "clean label" trends: A review of consumer food choice behavior and discussion of industry implications. Food Research International, 99(July), 58-71. https://doi.org/10.1016/j.foodres.2017.07.022

Assis, F. R., Morais, R. M. S. C., \& Morais, A. M. M. B. (2016). Mass Transfer in Osmotic Dehydration of Food Products: Comparison Between Mathematical Models. Food Engineering Reviews, 8(2), 116-133. https://doi.org/10.1007/s12393-015-9123-1

Balasubramaniam, V. M. (Bala), Martínez-Monteagudo, S. I., \& Gupta, R. (2015). Principles and Application of High Pressure-Based Technologies in the Food Industry. Annual Review of Food Science and Technology, 6(1), 435-462. https://doi.org/10.1146/annurev-food-022814-015539

Barrett, D. M., Beaulieu, J. C., \& Shewfelt, R. (2010). Color, Flavor, Texture, and Nutritional Quality of Fresh-Cut Fruits and Vegetables: Desirable Levels, Instrumental and Sensory Measurement, and the Effects of Processing. Critical Reviews in Food Science and Nutrition, 50(5), 369-389. https://doi.org/10.1080/10408391003626322

Biegelmeyer, R., Andrade, J. M. M., Aboy, A. L., Apel, M. A., Dresch, R. R., Marin, R., Raseira, M. do C. B., \& Henriques, A. T. (2011). Comparative Analysis of the Chemical Composition and Antioxidant Activity of Red (Psidium cattleianum) and Yellow (Psidium cattleianumvar.lucidum) Strawberry Guava Fruit. In Journal of Food Science (Vol. 76, Issue 7). https://doi.org/10.1111/j.1750-3841.2011.02319.x

Boeing, H., Bechthold, A., Bub, A., Ellinger, S., Haller, D., Kroke, A., Leschik-Bonnet, E., Mü Ller •, M. J., Oberritter, H., Schulze, M., Stehle, P., \& Watzl, B. (2012). Critical review: vegetables and fruit in the prevention of chronic diseases. European Journal of Nutrition, 51, 637-663. https://doi.org/10.1007/s00394-012-0380-y 
Brunsø, K., Fjord, T. A., \& Grunert, K. G. (2002). Consumers' food choice and quality perception (Working Paper No. 77).

Cantre, D., Herremans, E., Verboven, P., Ampofo-Asiama, J., \& Nicolaï, B. (2014). Characterization of the 3-D microstructure of mango (Mangifera indica L. Cv. Carabao) during ripening using $\mathrm{X}$-ray computed microtomography. Innovative Food Science and Emerging Technologies, 24, 28-39. https://doi.org/10.1016/j.ifset.2013.12.008

CBI. (2019a). Exporting dried tropical fruit to Europe. CBI - Centre for the Promotion of Imports from Developing Countries. https://www.cbi.eu/node/2767/pdf/

CBI. (2019b). What is the demand for processed fruit and vegetables in the European market? $\mathrm{CBI}$ - Centre for the Promotion of Imports from Developing Countries.

Chandra, S., \& Kumari, D. (2015). Recent Development in Osmotic Dehydration of Fruit and Vegetables: A Review. Critical Reviews in Food Science and Nutrition, 55(4), 552-561. https://doi.org/10.1080/10408398.2012.664830

Chiralt, A., \& Fito, P. (2003). Transport Mechanisms in Osmotic Dehydration: The Role of the Structure. Food Science and Technology International, 9, 179-186. https://doi.org/10.1177/108201303034757

Ciurzyńska, A., Kowalska, H., Czajkowska, K., \& Lenart, A. (2016). Osmotic dehydration in production of sustainable and healthy food. Trends in Food Science and Technology, 50, 186-192. https://doi.org/10.1016/j.tifs.2016.01.017

Cortellino, G., Pani, P., \& Torreggiani, D. (2011). Crispy air-dried pineapple rings: optimization of processing parameters. Procedia Food Science, 1, 1324-1330. https://doi.org/10.1016/j.profoo.2011.09.196

da Silva, T. M., Argandoña, E. J. S., Madrona, G. S., Moraes, I. C. F., Haminiuk, C. W. I., \& Branco, I. G. (2012). Influence of osmotic dehydration on ascorbic acid loss in pickled dry peppers (Capsicum Chinense). Brazilian Archives of Biology and Technology, 55(5), 763-769. https://doi.org/10.1590/S1516-89132012000500016

Dash, K. K., \& Balasubramaniam, V. M. (2018). Effect of high pressure on mass transfer kinetics of granny smith apple. Drying Technology, 36(13), 1631-1641. https://doi.org/10.1080/07373937.2017.1421218

Dembitsky, V. M., Poovarodom, S., Leontowicz, H., Leontowicz, M., Vearasilp, S., Trakhtenberg, S., \& Gorinstein, S. (2011). The multiple nutrition properties of some exotic fruits: Biological activity and active metabolites. In Food Research International (Vol. 44, Issue 7, pp. 1671-1701). https://doi.org/10.1016/j.foodres.2011.03.003

FAO. (2019). Major tropical fruits: Market review 2018. http://www.wipo.int/amc/en/mediation/rules 
Fito, P., Chiralt, A., Barat, J. M., Andrés, A., Martínez-Monzó, J., \& Martínez-Navarrete, N. (2001). Vacuum impregnation for development of new dehydrated products. Journal of Food Engineering, 49(4), 297-302. https://doi.org/10.1016/S0260-8774(00)00226-0

Florkowski, W. J. (2019). Consumers and consumption of fruits and vegetables: Who wants more of a good thing? In M. Swainson (Ed.), Swainson's Handbook of Technical and Quality Management for the Food Manufacturing Sector (pp. 411-432). Woodhead Publishing. https://doi.org/10.1016/b978-1-78242-275-4.00016-2

Grunert, K. G., \& van Trijp, H. C. M. (2014). Consumer-Oriented New Product Development. Encyclopedia of Agriculture and Food Systems, 2, 375-386. https://doi.org/10.1016/B978-0-444-52512-3.00062-0

Grunert, Klaus G. (2005). Food quality and safety: consumer perception and demand. European Review of Agricultural Economics, 32(3), 369-391. https://doi.org/10.1093/eurrag/jbi011

Grunert, Klaus G., Bredahl, L., \& Brunsø, K. (2004). Consumer perception of meat quality and implications for product development in the meat sector - A review. Meat Science, 66(2), 259-272. https://doi.org/10.1016/S0309-1740(03)00130-X

Grunert, Klaus G., Hartvig Larse, H., Madsen, T. K., \& Baadsgaard, A. (1996). Market orientation in food and agriculture. Kluwer Academic Publisher. https://doi.org/10.1007/978-1-4613-1301-4

Huang, H. W., Wu, S. J., Lu, J. K., Shyu, Y. T., \& Wang, C. Y. (2017). Current status and future trends of high-pressure processing in food industry. Food Control, 72(Part A), 18. https://doi.org/10.1016/j.foodcont.2016.07.019

IBISWorld Industry Report. (2016). Global Fruit and Vegetables Processing.

INC. (2018). Nuts \& Dried Fruits: Statistical Yearbook 2018/2019. https://www.nutfruit.org

Jesionkowska, K., Sijtsema, S., Simoneaux, R., Konopacka, D., \& Plocharski, W. (2008).

Preferences and consumption of dried fruit and dried fruit products among Dutch, French and Polish consumers. Journal of Fruit and Ornamental Plant Research, 16, 261-274. http://www.insad.pl/jofaop.html

Litz, R. E. (Ed.). (2009). The Mango: Botany, production and uses (2nd Ed.). CAB Internatonal.

Lule, S. U., \& Xia, W. (2012). Phytochemicals and Bioactive Compounds in Tropical and Subtropical Fruits. In Tropical and Subtropical Fruits (pp. 53-69). Wiley-Blackwell. https://doi.org/10.1002/9781118324097.ch4

Matheyambath, A. C., Subramanian, J., \& Paliyath, G. (2015). Mangoes. In Encyclopedia of Food and Health (pp. 641-645). Elsevier Inc. https://doi.org/10.1016/B978-0-12384947-2.00442-6 
Morrison, O. (2020). NPD Trend Tracker: From organic kids snacks to more vegan innovation. NPD Group. https://www.foodnavigator.com/ARTICLE/2020/01/06/NPD-TRENDTRACKER-FROM-ORGANIC-KIDS-SNACKS-TO-MORE-VEGAN-INNOVATION

Naspetti, S., \& Zanoli, R. (2009). Organic food quality and safety perception throughout europe. Journal of Food Products Marketing, 15(3), 249-266. https://doi.org/10.1080/10454440902908019

National Mango Board. (2010). Mango: Postharvest Best Mangement Practices Manual.

Nielsen. (2017). On-The-Go Produce Snacking: A Billion Dollar Industry and Growing.

Prasad, K. N., Azlan, A., \& Yusof, B. N. M. (2013). Neutraceutical Properties of Dried Tropical Fruits: Guavas and Papayas. In Dried Fruits (pp. 444-456). Blackwell Publishing Ltd. https://doi.org/10.1002/9781118464663.ch24

Qiu, L., Zhang, M., Tang, J., Adhikari, B., \& Cao, P. (2019). Innovative technologies for producing and preserving intermediate moisture foods: A review. Food Research International, 116, 90-102. https://doi.org/10.1016/j.foodres.2018.12.055

Ragaert, P., Verbeke, W., Devlieghere, F., \& Debevere, J. (2004). Consumer perception and choice of minimally processed vegetables and packaged fruits. Food Quality and Preference, 15(3), 259-270. https://doi.org/10.1016/S0950-3293(03)00066-1

Rastogi, N. K., Raghavarao, K. S. M. S., Balasubramaniam, V. M., Niranjan, K., \& Knorr, D. (2007). Opportunities and Challenges in High Pressure Processing of Foods. Critical Reviews in Food Science and Nutrition, 47(1), 69-112. https://doi.org/10.1080/10408390600626420

Ratti, C. (2001). Hot air and freeze-drying of high-value foods: A review. In Journal of Food Engineering (Vol. 49, Issue 4, pp. 311-319). Elsevier Ltd. https://doi.org/10.1016/S0260-8774(00)00228-4

Ribeiro, S. M. R., \& Schieber, A. (2010). Bioactive compounds in mango (Mangifera indica L.). Bioactive Foods in Promoting Health, 507-523. https://doi.org/10.1016/B978-0-12374628-3.00034-7

Sabbe, S., Verbeke, W., \& Damme, P. Van. (2008). Familiarity and purchasing intention of Belgian consumers for fresh and processed tropical fruit products. British Food Journal, 110(8), 805-818. https://doi.org/10.1108/00070700810893331

Sabbe, S., Verbeke, W., \& Van Damme, P. (2009). Perceived motives, barriers and role of labeling information on tropical fruit consumption: Exploratory findings. Journal of Food Products Marketing, 15(2), 119-138. https://doi.org/10.1080/10454440802316750 
Sadler, M. J., Gibson, S., Whelan, K., Ha, M. A., Lovegrove, J., \& Higgs, J. (2019). Dried fruit and public health-what does the evidence tell us? International Journal of Food Sciences $\quad$ Nutrition, 675-687. https://doi.org/10.1080/09637486.2019.1568398

Sarvan, I., Verkerk, R., Van Boekel, M., \& Dekker, M. (2014). Comparison of the degradation and leaching kinetics of glucosinolates during processing of four Brassicaceae (broccoli, red cabbage, white cabbage, Brussels sprouts). Innovative Food Science and Emerging Technologies, 25(C), 58-66. https://doi.org/10.1016/j.ifset.2014.01.007

Schweiggert, R. M., Steingass, C. B., Mora, E., Esquivel, P., \& Carle, R. (2011). Carotenogenesis and physico-chemical characteristics during maturation of red fleshed papaya fruit (Carica papaya L.). Food Research International, 44, 1373-1380. https://doi.org/10.1016/j.foodres.2011.01.029

Siddiqui, W., Chakraborty, I., Ayala-Zavala, J. F., \& Dhua, R. S. (2011). Advances in minimal processing of fruits and vegetables: a review. Journal of Scientific \& Industrial Research, 70, 823-834.

Sijtsema, S. J., Zimmermann, K., Cvetković, M., Stojanovic, Z., Spiroski, I., Milosevic, J., Mora, C., Butigan, R., Mugosa, B., Esteve, M., \& Pohar, J. (2012). Consumption and perception of processed fruits in the Western Balkan region. LWT - Food Science and Technology, 49(2), 293-297. https://doi.org/10.1016/j.lwt.2012.07.025

Sijtsema, S., Linnemann, A., Van Gaasbeek, T., Dagevos, H., \& Jongen, W. (2002). Variables influencing food perception reviewed for consumer-oriented product development. Critical Reviews in Food Science and Nutrition, 42(6), 565-581. https://doi.org/10.1080/20024091054256

Sloan, A. E. (2018). Produce: New Priorities and Preferences. Food Technology. https://www.ift.org/news-and-publications/food-technology-magazine

Steenkamp, J. E. M. (1986). Perceived quality of food products and its relationship to consumer preferences: theory and measurement. Journal of Food Quality, 9(6), 373373. https://doi.org/10.1111/j.1745-4557.1986.tb00807.x

Stok, F. M., Hoffmann, S., Volkert, D., Boeing, H., Ensenauer, R., Stelmach-Mardas, M., Kiesswetter, E., Weber, A., Rohm, H., Lien, N., Brug, J., Holdsworth, M., \& Renner, B. (2017). The DONE framework: Creation, evaluation, and updating of an interdisciplinary, dynamic framework 2.0 of determinants of nutrition and eating. PLOS ONE, 12(2), e0171077. https://doi.org/10.1371/journal.pone.0171077

Torreggiani, D. (1993). Osmotic dehydration in fruit and vegetable processing. Food Research International, 26, 59-68. https://doi.org/10.1016/0963-9969(93)90106-S

UNCTAD. (2016). Mango: An INFOCOMM commodity profile. 
USDA. (2020). https://fdc.nal.usda.gov/

van Boekel, M. A. J. S. (2008). Kinetic Modeling of Reactions In Foods. In Kinetic Modeling of Reactions In Foods. CRC Press. https://doi.org/10.1201/9781420017410

Vicente, A. R., Manganaris, G. A., Sozzi, G. O., \& Crisosto, C. H. (2009). Nutritional Quality of Fruits and Vegetables. In Postharvest Handling (pp. 57-106). Elsevier Inc. https://doi.org/10.1016/B978-0-12-374112-7.00005-6

Wismer, W. V. (2014). Consumer Eating Habits and Perceptions of Fresh Produce Quality. In W. J. Florkowski, R. L. Shewfelt, B. Brueckner, \& S. E. Prussia (Eds.), Postharvest Handling: A Systems Approach (3rd ed., pp. 31-52). Academic Press. https://doi.org/10.1016/B978-0-12-408137-6.00003-X

Wyatt, S. L. (2018). New and Emerging SnackingTrends. https://www.iriworldwide.com/IRI/media/2018-New-and-Emerging-Snack-

Trends_SNAXPO.pdf

Yahia, E. M., García-Solís, P., \& Celis, M. E. M. (2019). Contribution of Fruits and Vegetables to Human Nutrition and Health. In E. M. Yahia (Ed.), Postharvest Physiology and Biochemistry of Fruits and Vegetables (pp. 19-45). Woodhead Publishing. https://doi.org/10.1016/b978-0-12-813278-4.00002-6

Yan, Z., Sousa-Gallagher, M. J., \& Oliveira, F. A. R. (2008). Shrinkage and porosity of banana, pineapple and mango slices during air-drying. Journal of Food Engineering, 84(3), 430 440. https://doi.org/10.1016/j.jfoodeng.2007.06.004 


\section{Chapter 2}

Exploring consumers' health perception across cultures in the early stages of new product development: Dried mango as a case study

\section{Published as:}

Sulistyawati, I., Sijtsema, S., Dekker, M., Verkerk, R., \& Steenbekkers, B. (2019). Exploring consumers' health perception across cultures in the early stages of new product development: Dried mango as a case study. British Food Journal, 121(9), 2116-2131. 



\begin{abstract}
Purpose - This study aimed at exploring consumers' health perception and demonstrating its relevance in product and process design in early stages of NPD.

Design/methodology/approach - Dried mango was used as a case study involving three countries: Indonesia, China, and The Netherlands. Data were collected from nine focus groups ( $n=53$ participants) and were content analyzed to acquire indepth insights.
\end{abstract}

Findings - Four themes of health perception emerged, namely nutrition, naturalness, taste, and wellbeing, which were all expressed on different levels of abstractness. Participants' health perception of dried mango varied, it is related to (1) the product category it is compared with, e.g. candy or fresh fruit; and (2) the eating context, e.g. position in the diet either as a snack or a meal. In extension participants mentioned product and process characteristics. Application of the insights into product and process design was performed through iterative interactions between consumer scientists and food technologists. The development of two product concepts was elaborated to transform the insights into technical product and process specifications for a natural dried mango product.

Originality/value - This transformation suggests that iterative interactions are necessary to achieve relevant product and process characteristics in the simultaneous design of the technical product and process specifications based on consumer perceptions.

\title{
2.1. Introduction
}

Success of New Product Development (NPD) is determined by degree of fit of the newly developed product to the needs and wishes of consumers (Grunert et al., 1997). Consumers are not attracted to products per se, but rather to perceived benefits that the products deliver when consumed (Grunert and Van Trijp, 2014). So the attractiveness of a product depends on how consumers perceive characteristics of a food product, its quality, and its benefits. Understanding this perception in early stages of consumer-oriented NPD is necessary to create products with the desired quality (Grunert, 2005b). 
Health is one of the often mentioned motives related to consumer's food choice (Cunha et al., 2018). Its importance is also represented as one of the four interrelated dimensions of food quality; sensory (taste and appearance), convenience (easy to be consumed), health and process (at primary production and processing level) (Grunert et al., 1996). There are many consumer perception studies about sensory, convenience, and health (Sijtsema et al., 2012, Johansen et al., 2011) and their interrelation, e.g. how do consumers link healthy food to tastiness. Some consumers implicitly associated unhealthy food to tastiness like German and US-Americans consumers, but some others have a 'healthy $=$ tasty' intuition such as French consumers (Werle et al., 2013, Mai and Hoffmann, 2015). Regarding the process dimension, there are also several studies at the primary production level, e.g. organic production (Lee and Yun, 2015), while there seems less attention to the link between consumer perception and the processing level. A few studies reported consumers' perception of innovative technologies (Perrea et al., 2015, Rollin et al., 2011). Even less attention is given to consumers' perception for low-technology processing. Therefore, we want to explore how consumers perceive product quality related to processing technology as it could provide new and relevant insights for NPD.

Consumer insights need a transformation to be a useful input for designing food products (Grunert et al., 1996). Insights on perceived product quality can consist of both product and process characteristics. It would be valuable for consumer oriented NPD if the transformation is carried out to guide the design of both product and process specifications. So based on desired product characteristics, a technology is chosen to realize the characteristics (Moskowitz, 2000). Also, the third generation model of product innovation suggests that along with consumer oriented NPD, a more balanced input from both the consumer and the technology side is necessary throughout the NPD process (Grunert and Van Trijp, 2014). To support these approaches, we focus on transformation of consumer perceptions in early stages of NPD to be used in product and process design, which is predominated by intrinsic characteristics of the product. This transformation requires interaction between consumer science and food technology expertise (Jacobsen et al., 2014). 
Average daily consumption of fruit is generally much lower than the WHOrecommended level. Therefore, consumption of fresh and processed fruits should be stimulated (Geeroms et al., 2008). However, increasing fruit consumption by eating dried fruit did not receive much scientific attention yet. Among fresh tropical fruits, mango has the second largest portion in the world market after banana (Altendorf, 2017). It has an attractive color and flavor and is an important source of micronutrients (e.g. vitamins and minerals) and phytochemicals (Ribeiro et al., 2010). Yet, mango has a high perishability and seasonal availability, thus in its dried form it could be a potential product to increase the fruit consumption. Therefore we focus on the health perception of dried mango as a case in our study.

Perception of food is influenced by many variables, one of which is cultural food customs (Stok et al., 2017). Due to differences in availability and exposure, individuals of different cultures differ in experience and familiarity with specific food products (Wang and Somogyi, 2018). Both product-related experience and product familiarity have been shown to affect how consumers use product characteristics to form their product quality judgment (Frez-Muñoz et al., 2016). Therefore, in the present study, health perception is investigated involving three countries differing in familiarity with dried mango: two from Asia (China and Indonesia) and one from Europe (The Netherlands). Levels of the product familiarity between those countries were assessed based on knowing the product, frequency of consumption, and product availability on the respective markets. Chinese and Indonesian consumers are most likely to have a higher familiarity than Dutch consumers. In China a wide range of dried fruits is commonly consumed and is also available as additional ingredients, a.o. in breakfast porridge or baked goods (Wei et al., 2017) or snack. In Indonesia, dried mango is one of the popular dried tropical fruits that is commonly produced by small scale industries and is widely available in the local markets. The Dutch are less familiar with dried mango compared to the Asians and small numbers of dried fruit products are available in the Dutch supermarkets and greengrocers. 


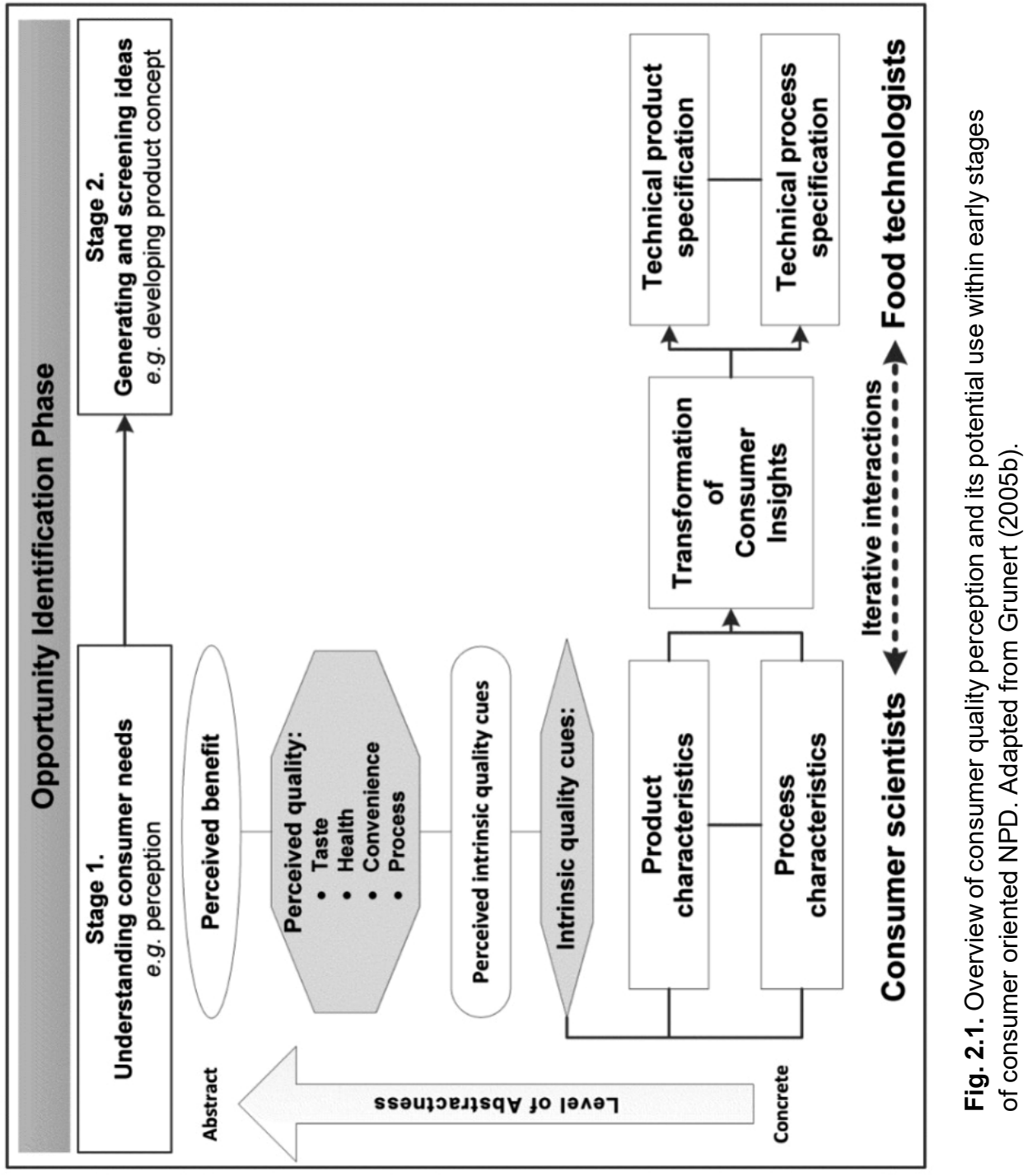


The Total Food Quality Model (TFQM) links concrete product characteristics, with perceived quality cues, expected or experienced quality and benefits (Grunert, 2005b), Figure 2.1. This hierarchical way of defining quality is represented on different levels of abstractness, e.g. a concrete product characteristic "crunchy" links to a perceived intrinsic quality cue at an intermediate level (e.g. has a bite) and perceived benefit at a rather abstract level (enjoying the food).

Within the TFQM, benefits are defined as pleasant consequences perceived when consuming a product, which reflects what the product does for consumers (Van Kleef et al., 2005). Consumers assess benefits from a combination of product cues including intrinsic and extrinsic quality cues (Grunert, 2005a, Van Trijp and Steenkamp, 2005). Intrinsic quality cues are pieces of information about a product (e.g. one or more intrinsic characteristics) which consumers use to form an inference or an expectation about its quality, such as good taste, natural, healthy (Grunert, 2005a, Lähteenmäki et al., 2010). So products have cues while consumers perceive benefits. Intrinsic characteristics are concrete physical and physiological characteristics of products (Van Trijp and Steenkamp, 2005, Grunert, 2005a), which can be linked to not only product characteristics but also process characteristics. These characteristics are evaluated through the senses, i.e. bright colour but can also be inferred from other cues, such as information like "does not contain fiber". These characteristics need a transformation to set up technical product and process specifications for product and process design, which requires involvement of consumer science and food technology expertise.

This study aims to explore consumers' health perceptions and transform them into technical product and process specifications for product and process design. We used dried mango as a case study and involved participants from three countries (The Netherlands, China, and Indonesia). The questions related to this aim are:

(1) What are consumers' perceived benefits, intrinsic quality cues, and concrete characteristics of dried mango?

(2) What consumers' health perceptions of dried mango give relevant insights for product and process specification? 


\subsection{Method}

Focus group was selected to collect data on quality perception of dried mango. Focus groups can be used to explore and identify consumers' perception of product characteristics and accompanying consumer benefits, as well as other potentially relevant issues (Van Kleef et al., 2005).

\subsubsection{Participants}

Nine focus groups were held ( $n=53$ participants), three for each of the three countries: Indonesia, China, and The Netherlands. Each focus group consisted of 57 participants (aged 20 - 40 years). Participants were recruited via email and social media. They were mostly students of Wageningen University, The Netherlands and were not from food science and nutrition-related programs. All participants had experience in eating dried fruits at least once a year. In addition, Chinese and Indonesian participants were shortly living in the Netherlands (maximum of four months). The participants were: 18 Indonesian/INA (7M, 11F; average age 26 years); 20 Chinese/CHN (6M, 14F; 23 years), and 15 Dutch/NL (5M, 10F; 25 years).

\subsubsection{Focus group protocol}

A semi-structured focus group protocol was developed in English, translated into three respective languages and rechecked by a native speaker. The protocol consisted of two main parts: (1) perception of dried tropical fruit and (2) perception of dried mango, both parts included questions about expected and experienced quality related to health. To ensure commitment to individual opinions, for some questions, participants first recorded their responses in individual booklets, and were asked to read it out to the group before discussing it. The protocol was tested in one focus group pilot for each country and minor adjustments were made. The focus groups were conducted in the native language of the participants and led by a native speaker. The first author was present as an observer in each session to ensure consistency in conducting the protocol. Focus groups were held in November 2015 in Wageningen, lasted approximately 2 hours each, were audiotaped for further analysis. Note takers and observers made field notes. 


\subsubsection{Data analysis}

Data were transcribed verbatim by a native speaker of the language and verified by a second person. Transcripts were translated into English and checked by a second person for translation-accuracy and content-analyzed using ATLAS.ti 7.5.12 for Windows. Transcripts were grouped by country and coded according to predetermined coding categories of dried tropical fruit and dried mango. Secondlevel categories were defined, being reasons to eat or not to eat the products. All quotes related to health perception were put together for further analysis. Four main themes related to perceived quality emerged and were applied as additional coding: nutrition, naturalness, taste, and wellbeing.

Participants of each country were used as one sample to be compared across countries because the results are generally similar across focus groups within each country. These findings, therefore indicated data saturation as it shows its reliability (Krueger and Casey, 2000).

The main findings are presented and illustrated with quotes by the themes. When the results were similar between countries, results are described in general terms; country-specific differences are mentioned explicitly.

Next, results are graphically presented by level of abstractness to show how consumers link concrete characteristics of dried mango with their perceived quality cues and perceived benefits.

Finally, to demonstrate the transformation of consumers' perception into technical product and process specifications, we give an example of two product concepts of natural dried mango.

\subsection{Results}

\subsubsection{Nutrition}

Mentioned benefits of eating dried fruit were increasing nutritional intake and satisfying hunger. Regarding the first benefit, some participants linked it to calories and nutrients like sugar, fiber, vitamins, minerals, and antioxidants. Others linked it 
to the more abstract 'healthiness' of dried fruit. Meanwhile, satisfying hunger was associated with amount of sugar in it:

"It's [dried fruit] quite suitable for satisfying hunger because it contains a lot of sugar, using it as a snack..." (INA/FG2-P2F)

At one hand, some participants perceived eating dried mango as healthier than eating other sugars like candy, honey or syrup because they perceived it to have fewer calories and it was made of fruit.

On the other hand, some other participants assessed the nutritional value of eating dried fruit by linking it to water or juice content while comparing it with eating fresh fruit. Some participants perceived dried mango with less moisture negatively because they expect that when the juice evaporated from the fruit during drying some nutrients were also gone. These participants - who compared dried mango with fresh mango - seem to expect fresh mango's characteristics in dried mango.

Meanwhile, some others perceived dried mango positively by stating that some nutrients still remained in dried fruit and they can get more nutrients from it. The drying process seemed to be one of the considerations taken into account when assessing healthiness of eating dried fruit:

"I can imagine that if the juice leaves the [fresh] fruit, some nutritional value is lost." (NL/FG3-P4F)

“...when you eat dried fruits... you will double the [amount of] nutrients. ... vitamins, fibers,..." (CHN/FG3-P1M)

\subsubsection{Naturalness}

Participants linked eating dried fruit with the naturalness of the ingredients or with processing, and they all related it to health (Figure 2). They felt more positive and less worried toward the healthiness of eating dried fruit compared to eating other snack foods, like potato crisps, since they are familiar with ingredients of dried fruit or they perceive it as having no additives: 
“...For candied fruit or fruit crisps, we know what the ingredients are, unlike for example for potato crisps..." (INA/FG1-P6F)

Additional ingredients that they often mentioned were food additives such as preservatives, colorants, flavor enhancers, and sweeteners. They inferred these ingredients from perceived characteristics of dried fruit like colour, smell or taste. Furthermore, some participants experienced the sweetness of dried fruit as artificial because they perceived it to contain added sugar or additives like artificial sweeteners:

"P6F: But somehow when I eat candied fruit, there is something that you can feel in your throat, so I want to eat candied fruit with fewer additives.

P2F: Colorants, I think?... Artificial sweeteners." (INA/FG2)

Some participants used colour (e.g. faded colour, too light colour, colorful) or dryness resulting from drying process of fruit to make inferences about the presence of colorants and preservatives. Both perceived characteristics seem to influence their health perception especially regarding the presence of food additives:

"I think the colour of dried tropical fruits shall not be too light or too colorful. It will make me feel that there are too much additives." (CHN/FG1-P1M)

"The colors [of dried fruit] will fade, but that's the real colour of the fruits which are dried." (INA/FG2-P5M)

\subsubsection{Taste}

Some participants related the taste of dried fruit to health. Participants considered eating dried mango as tasty and they made an inference about healthiness from several intrinsic characteristics such as specific nutrients, taste, smell, dryness, and chewiness. Dutch participants expressed that eating dried fruit as such was tastier when sugar was not added. They also mentioned that rather plain food products (e.g. yogurt and muesli) became tastier when dried fruit was added as a healthier choice than other sugars like syrup or honey. They also expressed the taste together with inferred (e.g. presence of natural sugar and flavor) and perceived (e.g. sweet taste) characteristics:

"P2F: Without the [added] sugar it [dried fruit] is tastier. 
P5M: They contain a lot of natural sugars." (NL/FG1)

"...If I eat muesli I think it is tasty that there are dried [fruit] pieces in it for the taste. Otherwise, you are inclined to add syrup or honey to the yogurt. Then I would consider it [dried fruit] to be healthier than other additions ..." (NL/FG2P2F)

Different from Dutch participants, some Chinese and Indonesian participants linked perceived characteristics like sweet taste and flavor of dried mango to the presence of additives. They expressed the characteristics in both positive and negative ways: "I think the sweetness [of dried fruit] is artificial, due to adding more sugar or something else [sweeteners]. I dislike food being too sweet." (CHN/FG1-P7F)

"It [dried salted mango] contains a lot of preservatives so I can't really taste the real [mango] flavor." (INA/FG3-P3F)

Indonesian participants only mentioned their experience of eating dried fruit as a snack, while some Dutch and Chinese participants also mentioned eating it as an ingredient of a product or by adding it into a meal, such as yoghurt, mixed with nuts, muesli, porridge (as a snack or a meal, e.g. breakfast). These results suggest that participants from different countries have different perceptions due to different consumption situations of dried fruit.

\subsubsection{Wellbeing}

Participants mentioned that eating dried mango would influence their body weight that they assessed as either positive or negative:

"It [dried mango] contains too much sugar... Sugar will make people fat." (CHN/FG2-P7F)

"I often buy candied fruit with the thought of "Ah I want to gain weight". So I bought candied fruit, like that." (INA/FG2) 
Some participants also mentioned other physical concerns of eating dried fruits such as causing toothache, mouth pain, and inflamed throat. They inferred these concerns from the presence of added sugar and perceived characteristics like hardness, dryness and a sweet taste. It is very likely that the mentioned concerns were perceived based on past experience of eating dried fruit in general:

"But will you get shang huo ${ }^{1}$ if you eat too much dried fruit?" (CHN/FG2P6F)

"For the candied fruit... because you add sugar to it, it's too sweet and causes a toothache." (INA/FG2-P2F)

Participants also expressed their emotional experience of eating dried mango both in a positive and negative way. Some Indonesian participants mentioned that eating fruit crisps were for their enjoyment; in contrast, some Chinese participants perceived the less juicy characteristic of dried mango - due to drying process - as less healthy than eating fresh fruit, which leads to a guilty feeling:

"If it's [fruit] crisps then it's something for you to enjoy your life."(INA/FG3P6M)

"But actually I prefer fresh mango.... [It is] juicy. This gives you a feeling of healthiness. While [eating] dried mango makes me feel guilty."(CHN/FG2-P2F)

\subsubsection{Representation of consumer's health perception of dried mango}

Figure 2.2 shows that health was perceived at each level of abstractness in each emerged theme. The figure also shows that consumers' thinking about the healthiness of dried mango not only covers nutrition, which commonly influences health perception, but also naturalness, taste, and wellbeing.

\footnotetext{
${ }^{1}$ Shang huo is defined as inadaptability symptom of the body e.g. inflamed throat, bleeding gums, etc. which can be caused by consuming certain foods (Rongrong and Hiroshi, 2008).
} 


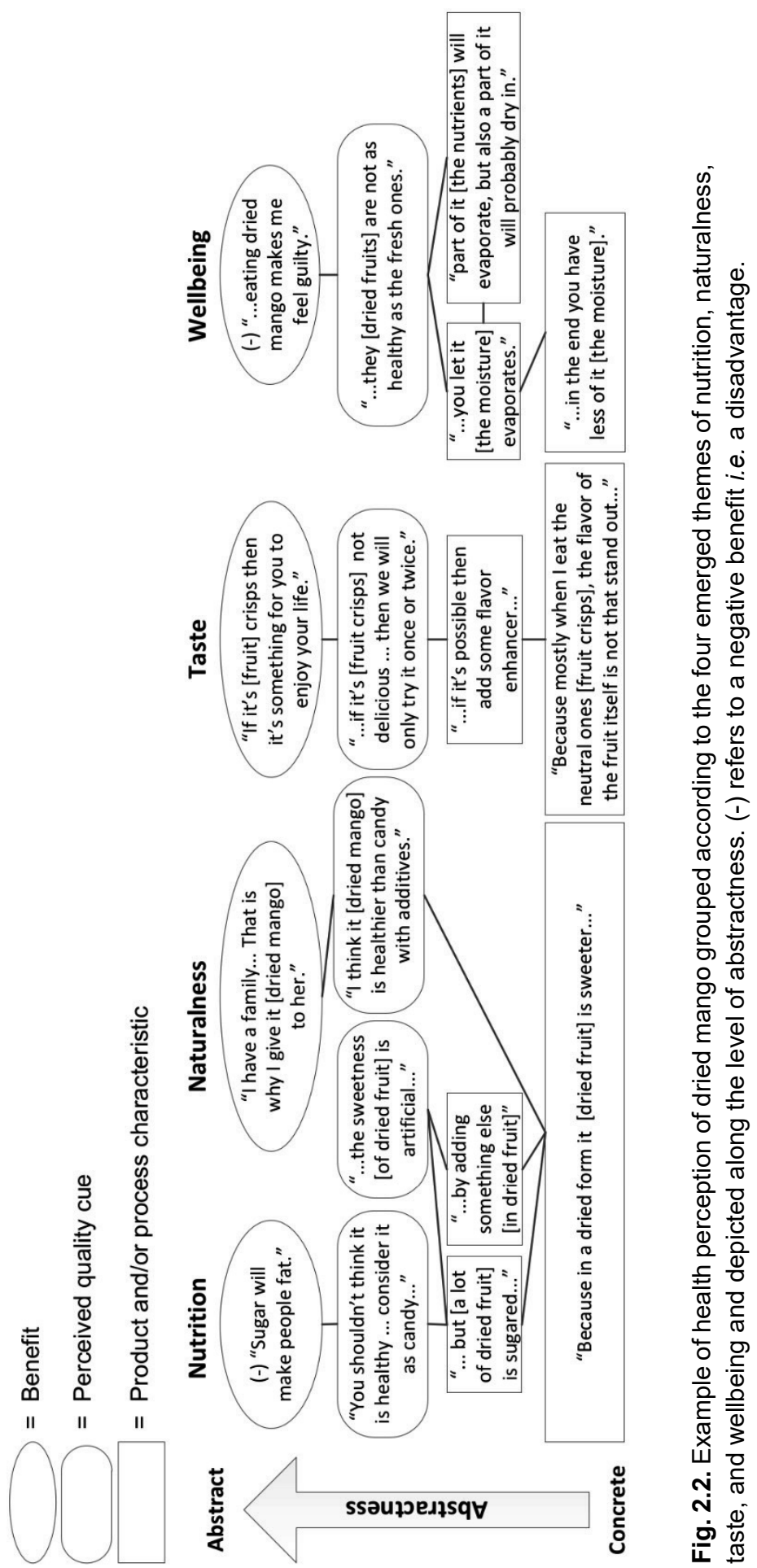




\subsection{Transformation of the results and its application for new product and process design}

This section demonstrates how the in-depth consumer insights of product and process characteristics could be applied to achieve technical product and process specifications. This demonstration is built upon a multidisciplinary approach between consumer science and food technology.

As shown in the results, naturalness was one of the often mentioned themes. Therefore, we choose a 'natural dried mango' product concept for this demonstration. Participants discussed naturalness in terms of two definitions (Figure 2.3), (1) what does the product contain (hereafter, product characteristics), and (2) how does processing affect the expected beneficial nutrients (hereafter, process characteristics). These definitions become relevant in product and process design of the product concept.

In all three involved countries, participants often mentioned product characteristics like the flavor or the sweet taste of dried mango and linked them with "contains natural sugar" or "no added sugar" (section 2.3.3 and Figure 2.3). Others linked flavor or sweet taste with "does not contain artificial substances" or "fewer additives". Chinese and Indonesian participants also linked product colour like "too light or too colorful" with "too much additives". These results show that perception of natural dried mango was influenced by the perceived presence of sugar and additives. It implies that natural dried mango should contain mango material with natural sugar, and should not contain added sugar and no or fewer additives.

Chinese and Indonesian participants related the colour of dried mango also to processing such as "the colour will fade but that's the real colour of fruits which are dried" (section 2.3.5 and Figure 2.3). This implies that colour changes due to drying process are one of the considerations taken into account to assess naturalness of dried mango. 


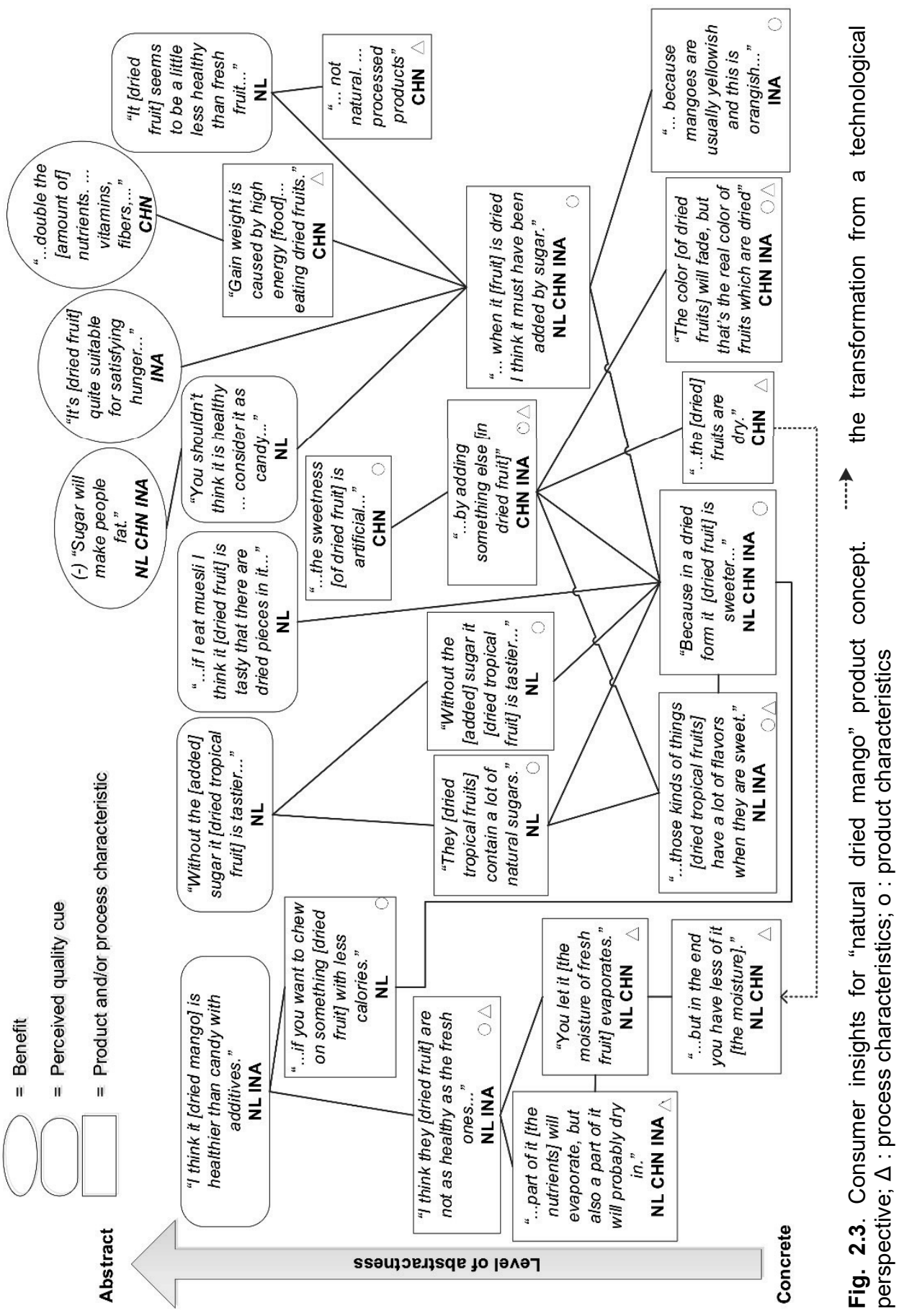


At one hand, some Chinese participants mentioned a perceived characteristic "dry" and linked it with the absence of preservatives in the product: "there won't be many preservatives in dried fruits ... the fruits are dry" (Figure 3). On the other hand, from a technological perspective, the term "dry" of dried fruit could also mean a lack of juice or moisture. Some Chinese and Dutch participants linked "juice" or "moisture" with how the drying reduced vitamins and antioxidants in dried fruit (section 2.3.1 and Figure 2.3).

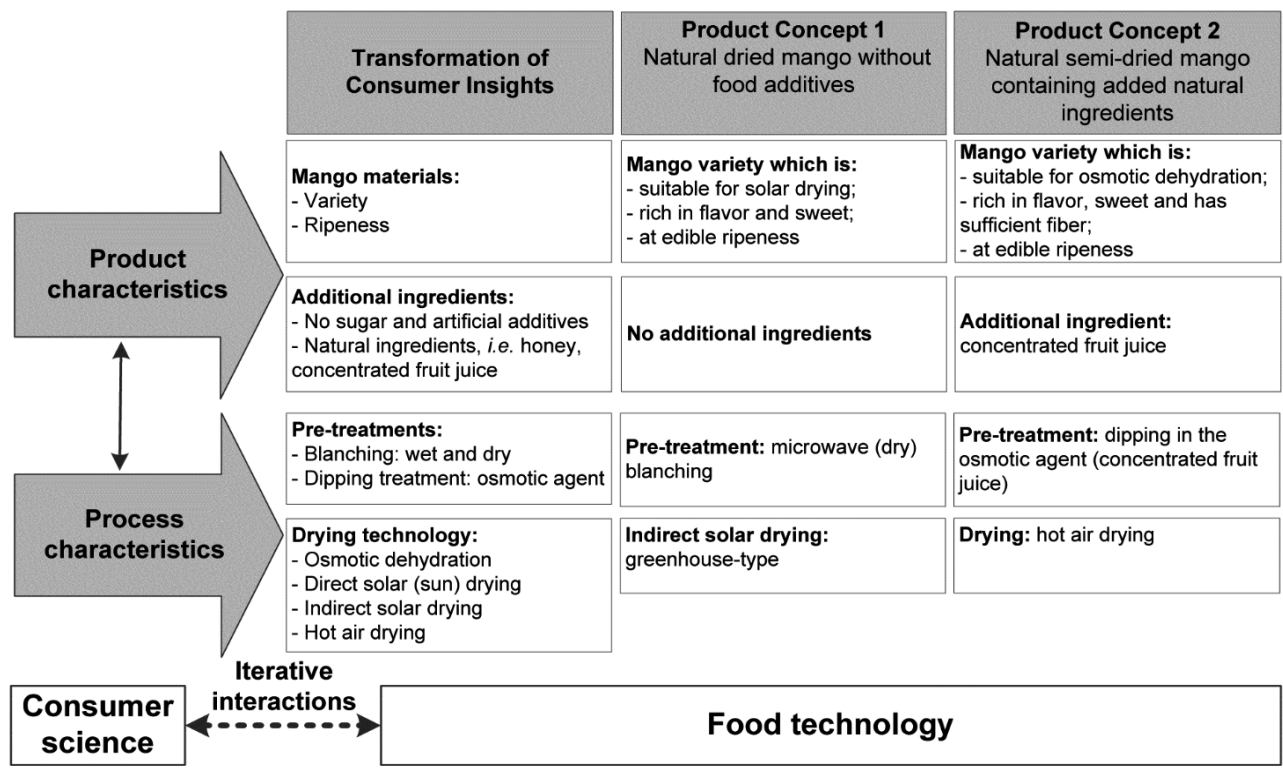

Fig. 2.4. Development of two natural dried mango concepts in which consumer insights and technological insights are combined: (1) Natural dried mango without food additives; (2) Natural semi-dried mango containing added natural ingredients.

The abovementioned transformation of the results was used to develop technical product and process specifications for the 'natural dried mango' product concept (Figure 2.4).

\subsubsection{Technical product specification}

The technical product specification was set up from product characteristics covering all possible ingredients to be used for product formulation:

a. Mango material. To have a sweet taste, a lot of flavor and a preferred colour for dried mango, variety and ripeness of the mango should be taken into account (Van 
Buggenhout et al., 2009). Varieties of mango that have the ascribed characteristics when ripe should be used for providing the preferred flavor and appearance (e.g. colour, texture).

b. Additional ingredients. Sugar and artificial additives should not be added to the product. Alternatively, both taste and colour of the product could be tailored to the consumer perceptions using natural ingredients like concentrated fruit juice (contains vitamin $C$ and natural sugar) or honey (contains antioxidants and natural sugar) (Chen et al., 2000, Konopacka et al., 2009).

\subsubsection{Technical process specification}

The technical process specification was set up from the mentioned process characteristics into possible processing technologies to be applied to produce dried mango. To have a lesser processing effect on dried mango which is not too dry but juicier and having a preferred colour, some processing technologies are preferred, including:

\section{a. Pre-treatment technology prior to drying}

Prior to drying, sliced fruits are pretreated to inactivate enzymes responsible for undesirable changes and to modify the tissue. This pretreatment improves drying performance, colour, flavor, and texture of the products (Reis, 2017). The pretreatment technologies include among others wet and dry blanching, and dipping treatment, e.g. using osmotic agents (Pan et al., 2003). Dry blanching such as using a microwave is preferred over wet blanching for fruit processing due to its high nutrient retention capacity (Guiamba et al., 2018).

\section{b. Drying technology}

Several drying technologies are available for drying fruits, including solar drying, osmotic dehydration, and hot air drying. Solar drying technology covers direct and indirect solar drying (Belessiotis and Delyannis, 2011). Indirect solar drying results in improved product quality in terms of sensorial characteristics and improved shelflife, compared to direct solar drying (Patil and Gawande, 2016). 
Osmotic dehydration (OD) can provide fruit with fresh-like characteristics for colour, texture, and flavor (Sulistyawati et al., 2018, Ciurzyńska et al., 2016). OD involves partial water removal from fruit by soaking it in a concentrated solution which may contain natural ingredients (Shi and Xue, 2009). OD could serve as a treatment preceding drying or can be used as the main dehydration processing technology (Chandra and Kumari, 2015). OD followed by hot air drying can preserve the desired texture and colour of the fruit (Rodríguez et al., 2015, Roopa et al., 2014).

From the above described technical product and process specifications can be learned that various combinations can be made to develop a natural dried mango product concept. We elaborated two product concepts as examples: (1) natural dried mango without food additives and (2) natural semi-dried mango containing added natural ingredients.

\section{Product concept 1 - Natural dried mango without food additives}

This concept would suit consumers who consider dried mango as a healthy snack or a healthy ingredient for yogurt or muesli. They have an interest in health and avoid products which have added sugar and additives. They prefer dried mango which is sweet, dry, rich in flavor and has a natural colour. Insights used for this product concept are no use of added sugar and additives. Based on these preferences, the product concept uses solely ripe mango material. Mango varieties with a sweet taste and rich flavor are preferred. No additional ingredients are used, and to preserve the colour, pretreatment using microwave (dry) blanching is chosen (Guiamba et al., 2018). Subsequently, greenhouse solar drying is used as drying technology with mango varieties Amélie and Kent as the most suitable to realize a natural dried mango (Dissa et al., 2011).

Product concept 2 - Natural semi-dried mango containing added natural ingredients This product would suit consumers who consider dried mango as a sweet, healthy candy when consuming it as a snack. They have an interest in health and want to get beneficial nutrients especially vitamins and fiber from dried mango. They prefer a sweet taste and moisty characteristic. Based on these preferences, mango 
varieties with sufficient ripeness, a sweet taste, rich in flavor and sufficient fiber are preferred.

Insights used for this product concept are no use of added sugar and artificial additives, and the use of natural ingredients. So, in addition to the mango material, natural de-acidified concentrated apple juice containing healthy compounds was chosen to tailor the taste (Konopacka et al., 2009). Subsequently, mild processing should be applied to maintain fresh fruit's colour and flavor (Kowalski and Mierzwa, 2013). Ideally, osmotic dehydration as pre-treatment using the concentrated juice as an osmotic agent, followed by hot air drying at a relatively low temperature.

\subsection{Discussion}

Participants expressed their health perception of dried mango in relation to four themes: nutrition, naturalness, taste, and wellbeing, all on each level of abstractness and interrelated. These different levels of expressing quality perceptions gave valuable insights into the concrete product and process characteristics, as elaborated for two 'natural dried mango' product concepts. The results confirm previous findings that health-related quality perception of food included themes such as nutrition, naturalness, and wellbeing (Asioli et al., 2017, Sijtsema et al., 2007). Moreover, health perception is interrelated with taste, e.g. naturalness was frequently linked to sweet taste and mango flavor. This supports the fact that quality dimensions are interrelated and exchangeably used by consumers to build their perceptions (Grunert et al., 1996). The acquired data from the focus groups gave more insights into how participants perceived healthiness of dried mango from its concrete characteristics, quality cues, and benefits and how they are interrelated.

\subsubsection{Variability in consumers' health perception of dried mango}

Participants vary in health perception of dried mango, linked to (1) product category and (2) the eating context.

On the one side, they compared dried mango either with fresh mango or with high sugar products, see Section 2.3.1 and Fig. 2.2. When compared with fresh fruit, participants expect to find fresh-like characteristics, e.g. yellow-orange colour, sweet 
taste, and fruity flavor. They link these concrete sensorial characteristics to the presence of nutrients like vitamins, minerals, and antioxidants, and use them as a cue to define healthiness of the product. Those participants who tend to search freshlike characteristics in processed fruits think that the dried mango product should have characteristics as close as possible to fresh mango. This results supports a previous perception study on vegetables which found that 'sensory oriented' consumers require for product to be very close to their original form in terms of sensory properties, like appearance and freshness (Dinnella et al., 2014). Thus this should be taken into consideration when choosing a processing technology for products for targeting these consumers.

On the other side, participants considered the eating context, e.g. the position of dried mango in the diet, either as a snack or as part of a meal (see Section 2.3.3 and Fig. 2.2). When eaten as a snack, it was perceived as healthier than other nonfruit based snack foods, but less healthy than fresh fruits, in accordance with Jesionkowska et al. (2007). In this regard, there also seems to be a difference in health perception between countries. Indonesian participants mentioned more often negative quality cues and characteristics. This might be owing to Indonesian participants regarded dried mango only as a snack which often is perceived as indulgence and comfort food (Jack et al., 1997).

When using dried mango as part of a meal (an ingredient in muesli or added to yogurt or porridge), it was perceived as healthier by Chinese and Dutch participants than adding syrup or honey because it was perceived to contain vitamins and minerals. In this respect, dried mango appears to be regarded as a healthier replacement of sugar to sweeten muesli or yoghurt. This supports Adams and Savage (2017) who revealed that difference in the categorization of a food product in the diet could influence the perceived healthiness of the product. This implies that product and process designers should be aware of where consumers position a product in their diet. Moreover, these results suggest that consumers may differ in their health perception, depending on the type of food product they compare with and the eating context they think of. 
We chose three countries (NL, CHN, and INA) differing in the amount and variety of dried fruits products on their market, assuming that these countries have a different familiarity with eating dried fruit. In accordance with the expectation Chinese and Indonesian participants were more familiar and mentioned more concrete characteristics than Dutch participants. This suggests that consumers who are more familiar with the product might be more helpful to provide characteristics for product and process design.

Taken together, these results suggest that variability in consumers' health perception in terms of intrinsic characteristics, quality cues and benefits are relevant to be taken into account in the early stages of NPD.

\subsubsection{Application of insights from consumers' health perception of dried mango into product and process design}

The Total Food Quality Model of Grunert (2005b) provides a tool to structure and level the perceptions expressed by the participants. We added to this tool interrelation between product and process characteristics and showed how consumer perception is linked to this. Using natural dried mango product concepts as examples, we demonstrated the usefulness of insights in consumer perception for product and process design. Specifically, we were able to address how participants defined healthiness of dried mango in terms of what the product can or should contain and how processing affects the expected beneficial nutrients. The latter is in agreement with a previous study which found that consumers with a higher product familiarity has been associated to having a more informed product evaluation, its characteristics, quality and benefit (Banović et al., 2012). In this study, the information includes processing technology applied to the product which were used by consumers to perceive healthiness of the product (Deliza et al., 2003).

The two presented product concepts show that consumer insights can be used in different ways to select product formulations and processing technologies and combine these when targeting specific consumers perceptions. Based on the rich data, different selections and combinations could be made in order to develop 
several product concepts. Food manufacturers should further test, develop and optimize these concepts towards specific target groups.

The demonstrated transformation and application of the acquired product and process characteristics show the relevance of consumer insights on health perception to guide the design of the interrelated technical product and process specification in NPD. Using the guidance from consumer insights - instead of just trial and error- a product and process design team which ideally consists of consumer scientists and food technologists can 'mix and match' the options for product formulation and processing technology to develop new product concepts.

\subsubsection{Methodological considerations and future research}

To the best of our knowledge, previous consumer perception studies scarcely explored the relevance of consumers' health perception of products in association with process design, especially in terms of established processing technology. Understanding how consumers perceive healthiness of a food product, from its product and process characteristics, quality cues and benefits might result in a more effective way to take the relevant characteristics for product and process design into account in NPD. Further research is required to assess whether the application of these insights increases the effectiveness of NPD. Follow up research is needed to confirm that the developed product concepts are perceived as more healthy than the current products on the market.

\subsection{Conclusions}

This exploratory qualitative study illustrates an approach to identify differences in health perceptions among consumers having different familiarity levels with dried mango and how to apply this knowledge in early stages of NPD. Healthiness of dried mango was perceived in four themes (nutrition, naturalness, taste, and wellbeing) and on different levels of abstractness. At the same time, this perception is linked to and depending on the product category it is compared with (e.g. candy or fresh fruit) and to the eating context (e.g. position of the product in the diet). Chinese and Indonesian participants - whom are relatively more familiar with dried mango mentioned more concrete characteristics than the Dutch participants. 
It was shown that consumer insights in health perception of a product not only relates to product characteristics but also to processing and its characteristics. Natural dried mango product concepts were used to demonstrate the relevance of these insights into product and process design. Transformation of consumer insights and its application into product and process design requires iterative interactions between consumer scientists and food technologists.

\section{Conflict of interest}

All authors report no conflict of interest.

\section{Acknowledgements}

I. Sulistyawati received a PhD scholarship from the Directorate General of Resources for Science, Technology and Higher Education, Indonesia (RISTEKDIKTI) [grant number 391/E4.4/K/2014]. The authors appreciated Stefani Amanda Harmani, Changyun Zhang and Martijn van Oirschot for their kind assistance with data collection.

\section{References}

Adams, E. L. and Savage, J. S. (2017). From the children's perspective: What are candy, snacks, and meals? Appetite, Vol. 116 No. 9, pp. 215-222.

Altendorf, S. (2017). Global prospects for major tropical fruits: Short-term outlook, challenges and opportunities in a vibrant global marketplace. Food outlook: Biannual report on global food markets. Rome: FAO Trade and Markets Division.

Asioli, D., Aschemann-Witzel, J., Caputo, V., Vecchio, R., Annunziata, A., Næs, T. and Varela, P. (2017). Making sense of the "clean label" trends: A review of consumer food choice behavior and discussion of industry implications. Food Research International, Vol. 99, pp. 58-71.

Belessiotis, V. and Delyannis, E. (2011). Solar drying. Solar Energy, Vol. 85 No. 8 , pp. 1665-1691.

Chandra, S. and Kumari, D. (2015). Recent development in osmotic dehydration of fruit and vegetables: A review. Critical Reviews in Food Science and Nutrition, Vol. 55 No. 4, pp. 552-561. 
Chen, L., Mehta, A., Berenbaum, M., Zangerl, A. R. and Engeseth, N. J. (2000). Honeys from different floral sources as inhibitors of enzymatic browning in fruit and vegetable homogenates. Journal of Agricultural and Food Chemistry, Vol. 48 No. 10, pp. 4997-5000.

Ciurzyńska, A., Kowalska, H., Czajkowska, K. and Lenart, A. (2016). Osmotic dehydration in production of sustainable and healthy food. Trends in Food Science and Technology, Vol. 50, pp. 186-192.

Cunha, L. M., Cabral, D., Moura, A. P. and de Almeida, M. D. V. (2018). Application of the Food Choice Questionnaire across cultures: Systematic review of cross-cultural and single country studies. Food Quality and Preference, Vol. 64, pp. 21-36.

Deliza, R., Rosenthal, A. and Silva, A. L. S. (2003). Consumer attitude towards information on non conventional technology. Trends in Food Science and Technology, Vol. 14 No. 1, pp. 43-49.

Dinnella, C., Torri, L., Caporale, G. and Monteleone, E. (2014). An exploratory study of sensory attributes and consumer traits underlying liking for and perceptions of freshness for ready to eat mixed salad leaves in Italy. Food Research International, Vol. 59, pp. 108-116.

Dissa, A. O., Bathiebo, D. J., Desmorieux, H., Coulibaly, O. and Koulidiati, J. (2011). Experimental characterisation and modelling of thin layer direct solar drying of Amelie and Brooks mangoes. Energy, Vol. 36 No. 5, pp. 2517-2527.

Frez-Muñoz, L., Steenbekkers, L. and Fogliano, V. (2016). The choice of canned whole peeled tomatoes is driven by different key quality attributes perceived by consumers having different familiarity with the product. Journal of Food Science, Vol. 81 No. 12, pp. S2988-S2996.

Geeroms, N., Verbeke, W. and Kenhove, P. V. (2008). Health advertising to promote fruit and vegetable intake: Application of health-related motive segmentation. Food Quality and Preference, Vol. 19 No. 5, pp. 481-497.

Grunert, K. and Van Trijp, H. (2014). Consumer-oriented new product development. In Alfen, N. K. v. (ed.) Encyclopedia of Agriculture and Food Systems. Academic Press, San Diego, CA, pp. 375-386.

Grunert, K. G. (2005a). Consumer behaviour with regard to food innovations: quality perception and decision-making. In Jongen, W. M. \& Meulenberg, M. T. 
(eds.) Innovation in Agri-food Systems: Product Quality and Consumer Acceptance. Wageningen Academic Publishers, Wageningen, pp. 57-85.

Grunert, K. G. (2005b). Food quality and safety: consumer perception and demand. European Review of Agricultural Economics, Vol. 32 No. 3, pp. 369-391.

Grunert, K. G., Harmsen, H., Larsen, H. H., Sørensen, E. and Bisp, S. (1997). New areas in agricultural and food marketing. In Wierenga, B., van Tilburg, A., Grunert, K., Steenkamp, J.-B. E. M. \& Wedel, M. (eds.) Agricultural Marketing and Consumer Behavior in A Changing World. Springer, Boston, MA, pp. 3-30.

Grunert, K. G., Larsen, H. H., Madsen, T. K. and Baadsgaard, A. (1996). Market orientation in food and agriculture Boston, MA, Kluwer Academic Publishers Guiamba, I. I., Ahrne, L. and Svanberg, U. (2018). Enhancing the retention of $\beta$ carotene and vitamin $\mathrm{C}$ in dried mango using alternative blanching processes. African Journal of Food Science, Vol. 12 No. 7, pp. 165-174.

Jack, F. R., O'Neill, J., Piacentini, M. G. and Schröder, M. J. A. (1997). Perception of fruit as a snack: A comparison with manufactured snack foods. Food Quality and Preference, Vol. 8 No. 3, pp. 175-182.

Jacobsen, L. F., Grunert, K. G., Søndergaard, H. A., Steenbekkers, B., Dekker, M. and Lähteenmäki, L. (2014). Improving internal communication between marketing and technology functions for successful new food product development. Trends in Food Science \& Technology, Vol. 37 No. 2, pp. 106-114.

Jesionkowska, K., Konopacka, D., Płocharski, W., Sijtsema, S. and Zimmermann, K. (2007). What do Polish and Dutch consumers think about dried fruit and products with them - Creative group discussions as a means of recognition consumers perceptions? Polish Journal of Natural Sciences, Suppl. No. 4, pp. 169-175.

Johansen, S. B., Næs, T. and Hersleth, M. (2011). Motivation for choice and healthiness perception of calorie-reduced dairy products. A cross-cultural study. Appetite, Vol. 56 No. 1, pp. 15-24.

Konopacka, D., Jesionkowska, K., Klewicki, R. and Bonazzi, C. (2009). The effect of different osmotic agents on the sensory perception of osmo-treated dried 
fruit. The Journal of Horticultural Science and Biotechnology, ISAFRUIT Special Issue, pp. 80-84.

Kowalski, S. J. and Mierzwa, D. (2013). Influence of Osmotic Pretreatment on Kinetics of Convective Drying and Quality of Apples. Drying Technology, Vol. 31 No. 15 , pp. 1849-1855.

Krueger, R. A. and Casey, M. A. (2000). Focus groups: A practical guide for applied research, Thousand Oaks, CA, Sage Publications, Inc.

Lähteenmäki, L., Lampila, P., Grunert, K., Boztug, Y., Ueland, Ø., Åström, A. and Martinsdóttir, E. (2010). Impact of health-related claims on the perception of other product attributes. Food Policy, Vol. 35 No. 3, pp. 230-239.

Lee, H.-J. and Yun, Z.-S. (2015). Consumers' perceptions of organic food attributes and cognitive and affective attitudes as determinants of their purchase intentions toward organic food. Food Quality and Preference, Vol. 39 No. 1, pp. 259-267.

Mai, R. and Hoffmann, S. (2015). How to combat the unhealthy = tasty intuition: The influencing role of health consciousness. Journal of Public Policy \& Marketing, Vol. 34 No. 1, pp. 63-83.

Moskowitz, H. (2000). Inter-relating data sets for product development: the reverse engineering approach. Food Quality and Preference, Vol. 11 No. 1-2, pp. 105-119.

Pan, Y. K., Zhao, L. J., Zhang, Y., Chen, G. and Mujumdar, A. S. (2003). Osmotic dehydration pretreatment in drying of fruits and vegetables. Drying Technology, Vol. 21 No. 6, pp. 1101-1114.

Patil, R. and Gawande, R. (2016). A review on solar tunnel greenhouse drying system. Renewable and Sustainable Energy Reviews, Vol. 56, pp. 196-214.

Perrea, T., Grunert, K. G. and Krystallis, A. (2015). Consumer Value perceptions of food products from emerging processing technologies: A cross-cultural exploration. Food Quality and Preference, Vol. 39, pp. 95-108.

Reis, F. R. (2017). Impact of blanching on the performance of subsequent drying. In Reis, F. R. (ed.) New Perspectives on Food Blanching. Springer, Cham, pp. 123-136. 
Ribeiro, S. M. R., Schieber, A. and Preedy, V. R. (2010). Bioactive compounds in mango (Mangifera indica L.). In Watson, R. R. \& Preedy, V. R. (eds.) Bioactive Foods in Promoting Health. Academic Press, London, pp. 507-523. Rodríguez, M. M., Rodriguez, A. and Mascheroni, R. H. (2015). Color, Texture, Rehydration Ability and Phenolic Compounds of Plums Partially Osmodehydrated and Finish-Dried by Hot Air. Journal of Food Processing and Preservation, Vol. 39 No. 6, pp. 2647-2662.

Rollin, F., Kennedy, J. and Wills, J. (2011). Consumers and new food technologies. Trends in Food Science \& Technology, Vol. 22 No. 2, pp. 99-111.

Rongrong, H. and Hiroshi, K. (2008). Shanghuo syndrome in traditional Chinese medicine. World Science and Technology, Vol. 10 No. 5, pp. 37-41.

Roopa, N., Chauhan, O. P., Raju, P. S., Das Gupta, D. K., Singh, R. K. R. and Bawa, A. S. (2014). Process optimization for osmo-dehydrated carambola (Averrhoa carambola L.) slices and its storage studies. Journal of Food Science and Technology, Vol. 51 No. 10, pp. 2472-2480.

Shi, J. and Xue, J. (2009). Application and development of osmotic dehydration technology in food processing. In Ratti, C. (ed.) Advances in food dehydration. CRC Press, Boca Raton, FL, pp. 187-208.

Sijtsema, S., Linnemann, A., Backus, G., Jongen, W., van Gaasbeek, T. and Dagevos, H. (2007). Exploration of projective techniques to unravel health perception. British Food Journal, Vol. 109 No. 6, pp. 443-456.

Sijtsema, S. J., Jesionkowska, K., Symoneaux, R., Konopacka, D. and Snoek, H. (2012). Perceptions of the health and convenience characteristics of fresh and dried fruits. LWT - Food Science and Technology, Vol. 49 No. 2, pp. 275-281.

Stok, F. M., Hoffmann, S., Volkert, D., Boeing, H., Ensenauer, R., Stelmach-Mardas, M., Kiesswetter, E., Weber, A., Rohm, H., Lien, N., Brug, J., Holdsworth, M. and Renner, B. (2017). The DONE framework: Creation, evaluation, and updating of an interdisciplinary, dynamic framework 2.0 of determinants of nutrition and eating. PLoS One, Vol. 12 No. 2, p. e0171077.

Sulistyawati, I., Dekker, M., Fogliano, V. and Verkerk, R. (2018). Osmotic dehydration of mango: Effect of vacuum impregnation, high pressure, pectin 
methylesterase and ripeness on quality. LWT - Food Science and Technology, Vol. 98, pp. 179-186.

Van Buggenhout, S., Sila, D. N., Duvetter, T., Van Loey, A. and Hendrickx, M. (2009). Pectins in processed fruits and vegetables: Part III - Texture engineering. Comprehensive Reviews in Food Science and Food Safety, Vol. 8 No. 2, pp. 105-117.

Van Kleef, E., Van Trijp, H. C. M. and Luning, P. (2005). Consumer research in the early stages of new product development: a critical review of methods and techniques. Food Quality and Preference, Vol. 16 No. 3, pp. 181-201.

Van Trijp, J. and Steenkamp, J. (2005). Consumer-oriented new product development: principles and practice. In Jongen, W. M. \& Meulenberg, M. T. (eds.) Innovation in Agri-food Systems: Product Quality and Consumer Acceptance. Wageningen Academic Publishers, Wageningen, pp. 87-124.

Wang, O. and Somogyi, S. (2018). Chinese consumers and shellfish: Associations between perception, quality, attitude and consumption. Food Quality and Preference, Vol. 66, pp. 52-63.

Wei, D. Z., Wang, Y., Jiang, D. M., Feng, X. Y., Li, J. and Wang, M. (2017). Survey of alternaria toxins and other mycotoxins in dried fruits in China. Toxins, Vol. 9 No. 7 , p. 200.

Werle, C. O. C., Trendel, O. and Ardito, G. (2013). Unhealthy food is not tastier for everybody: The "healthy=tasty" French intuition. Food Quality and Preference, Vol. 28 No. 1, pp. 116-121. 



\section{Chapter 3}

Consumer preference for dried mango attributes:

A conjoint study among Dutch, Chinese and Indonesian consumers

\section{Submitted as:}

Sulistyawati, I., Dekker, M., Verkerk, R., \& Steenbekkers, B. Consumer preference for dried mango attributes: A conjoint study among Dutch, Chinese and Indonesian consumers 



\begin{abstract}
One way to add value to tropical fruit and increase its availability in the global market is to develop new, less perishable, products from fresh fruit. The purpose of this study is to compare the perception of key quality attributes and preferences of dried mango between consumers with different familiarity and health consciousness. This study surveyed respondents from China, Indonesia and the Netherlands via an Adaptive Choice-Based Conjoint method $(n=483)$ to evaluate intrinsic quality attributes that influenced consumer preference for dried mango. Consumers in different countries have different texture, taste and color preferences for dried mango. The most important attribute for the Dutch and Chinese was 'free from extra ingredients', while for Indonesians it was the texture. Familiarity with dried mango and health consciousness do not influence consumer preference of intrinsic attributes of dried mango. Different preferences of intrinsic attributes of dried mango between countries are related to cultural differences. This study provides useful insights for food manufacturers into the significance of key intrinsic quality attributes in developing dried mango.
\end{abstract}

Keywords: Consumer preference; Conjoint analysis; Intrinsic attribute; Healthy; Familiarity; Dried fruits

\title{
3.1. Introduction
}

The demand for healthy and convenient food has increased, and consumers more often choose for available processed fruits, e.g. dried fruits, jam, fruit snacks (Jesionkowska et al., 2008; Sadler et al., 2019). To increase the value of this food and its availability in the global market it is necessary to create new products that meet consumer wishes and preferences of the intended markets. This study contributes to the understanding of European and Asian consumer preferences for dried mango. The study assesses especially consumer preferences for the intrinsic quality of dried mango in relation to health and sensory.

The quality preference of some dried tropical fruits has been investigated in European (Bower \& Ferguson, 2008; Alphonce et al., 2015) and Asian countries (Precoppe et al., 2014; Cinar, 2018) on health or sensory properties. To our 
knowledge, no studies so far compared the quality preferences of dried tropical fruit between both regions. Asia is one of the predominant producers and suppliers of major traded tropical fruits, i.e., mango, guava, pineapple (FAO, 2019). The majority of these fruits is destined for domestic markets, thus fresh tropical fruits are widely available. The European Union meanwhile, is one of the largest import markets of fresh tropical fruits. The fruits are highly appreciated for their exotic appearance, health benefits and tastefulness (Wismer, 2014; Yahia et al., 2019), yet most tropical fruits are seasonal. Having the fruits as dried fruit is of global market interest since the product has longer availability and high versatility in various food products including breakfast cereals, fruit bars, mixed with nuts (CBI, 2019; Sadler et al., 2019). Therefore, this study identified consumer preferences for health and sensory properties, especially at understanding which attributes might help to increase the value of dried mango for the intended markets. Both types of information are essential for consumer-oriented product development to be successful (Grunert, 2005).

Consumers' preference of food is influenced by what they perceive from "experienced" intrinsic quality attributes (color, taste, flavor, texture). This perception is used to assess other more "hidden" intrinsic quality attributes of the product such as health (nutritional value, vitamins content) and to determine the overall quality of a food product (Asioli et al., 2017).

In European countries, a potential market especially for dried tropical fruit arises (CBI, 2019). In Asian countries like China and Indonesia, demand for processed fruits also rises as a result of rapid industrialization and greater participation of developing countries in global export-import activities. Moreover, the annualized growth rate in global fruit and vegetables processing industry was at $2 \%$ (2011-2016), with $10 \%$ gain for dried and dehydrated fruit and vegetables of the total market share (IBISWorld Industry Report, 2016). Amongst dried tropical fruits, dried mango poses an interesting case. Mango is one of the top three most consumed tropical fruits due to its attractive color, unique flavor and its nutritional value. One way to increase the availability of and to add value to mango is by developing mango products, e.g. dried mango. Product features like an extended shelf-life, convenience and "fresh-like" 
characteristics, are provided by dried fruit with maintained nutrients and healthpromoting value (Ciurzyńska et al., 2016).

Beside sensory and health properties of the product, product familiarity and health consciousness play a key role in consumers' food choice, including fresh fruit (Pollard et al., 2002) and processed tropical fruits choice (Sabbe et al., 2008). Familiarity has been associated with personal product-related experience such as knowledge, purchase, consumption, and product typicality, i.e. to what extent the product represents its overall category (Park \& Lessig, 1981; Bredahl, 2003; FrezMuñoz et al., 2016). A higher familiarity with the product has been associated with a higher understanding of its attributes, which is translated to more informed product evaluations (Banović et al., 2012). Consumers with different familiarity levels asses both intrinsic and extrinsic attributes in different ways (Bredahl, 2003; Banović et al., 2012; Frez-Muñoz et al., 2016).

Healthiness of the product is one of the main motives in consumers' food choice (Januszewska et al., 2011; Milošević et al., 2012). Healthiness is often associated with sensory (flavor, taste, color, texture) and natural content characteristics (no additives, natural ingredients) (Puska \& Luomala, 2016; Chambers et al., 2018). According to literature, health consciousness could influence how consumers assess the importance of attributes in a food product (Schifferstein \& Ophuis Oude, 1998; Chen, 2013). The aim of this study is to compare perception on key quality attributes and their preferences for intrinsic characteristics of dried mango between consumers with different familiarity levels to support consumer-oriented product development of dried mango. It is hypothesized that perceptions of key quality attributes are different among different familiarity levels. Secondly, it is hypothesized that the intrinsic quality attributes of dried mango are perceived differently by consumers with different levels of health consciousness.

\subsection{Methods}

In this study, conjoint analysis was applied to identify the importance of different intrinsic quality attributes and the preference for the attribute levels of dried mango, 
as well as to evaluate if these attributes vary due to nationality, demographic data and health consciousness of respondents.

\subsubsection{Conjoint analysis}

\subsubsection{Selection of attributes and levels by focus groups}

To determine the attributes and levels to be evaluated in the conjoint analysis, our previously obtained focus groups results were used by selecting the intrinsic attributes that were mentioned most often by participants as relevant to eat dried mango (Sulistyawati et al., 2019), Table 3.1. The focus groups showed that sweetening agents and (the absence of) extra ingredients were the most often mentioned intrinsic attributes related to perceived healthiness of dried mango, followed by taste, flavor, color and texture.

Table 3.1 Intrinsic attributes and their levels of dried mango used in the conjoint analysis

\begin{tabular}{|c|c|c|}
\hline Extra ingredients & Sweetener & Texture \\
\hline Salt & High calorie, sugar/honey & Chewy \\
\hline Spices (e.g. chili, ginger) & Low calorie, natural sweetener & Soft \\
\hline Combination of salt and spices & No calorie, artificial sweetener & Crispy \\
\hline Color & Taste & Mango Flavor \\
\hline Yellow & More sweet than sour & Weaker than fresh mango \\
\hline Light orange & Balanced sweet and sour & Similar to fresh mango \\
\hline Orange & More sour than sweet & Stronger than fresh mango \\
\hline Intense orange & & \\
\hline
\end{tabular}

\subsubsection{Design of conjoint analysis}

An Adaptive Choice-Based Conjoint Analysis (ACBC) method was used in this study. This method has been suggested to be more accurate at measuring consumer response involving five or more attributes and may require fewer respondents than a traditional CBC to obtain similar results (Orme, 2010; Jervis et al., 2012).

The ACBC survey was developed in English, translated into the three respective languages and rechecked by a native speaker. The survey was pre-tested by respondents for each country after which minor adjustments were made. The online surveys were conducted in the native language of the participants and were held in 
November-December 2016. The survey began with a short introduction of the research and followed by questions on demographic information and experience in eating fresh and dried mango, e.g. frequency of consumption. According to Pollard et al. (2002) experience in consuming a certain food is related to familiarity with that food. Next, the survey comprised three main sections; the first section was designed with one Build-Your-Own (BYO) questionnaire in which respondents were introduced to the attributes and levels while they were asked to identify the product closest to their ideal. In the second section, five screening tasks with four product concepts per task with the possible responses of "a must-have" or "an unacceptable" attribute were created for each product concept. A minimum of two and a maximum of three attributes varied from the BYO selections for each product concept. Two "unacceptable" questions and one "must-have" question were built into the survey. In the third section - a choice task tournament-, they were asked to select the concept that best fitted their preferences from a maximum of 14 product concepts and with a minimum of three concepts per choice task.

Following the conjoint survey, an additional section was added to measure the health consciousness of the respondents. The health-consciousness questionnaire (Schifferstein \& Ophuis Oude, 1998) assesses whether individuals are aware of the influence of lifestyle on health (Wardle \& Steptoe, 2003), and ready to take health actions (Becker et al., 1977). Respondents rated 11-items of health consciousness on a 5-point scale ranging from 1 = strongly disagree, 2 = disagree, 3 = neutral, 4 = agree to 5 = strongly agree, see Appendix 3.A. Upon completion of the entire survey respondents were entered into a lottery to receive one of the five $€ 15$ voucher cards for each country.

\subsubsection{Data collection and respondents}

The online survey was created using Sawtooth Software Lighthouse Studio 9.2 (Sawtooth Software Inc., USA) and carried out for each country separately. A total of 638 respondents participated, of which 483 respondents gave valid answers. Answers of respondents who completed the survey too fast, gave repetitive answers, and/or did not complete the survey were removed from the database. 


\subsubsection{Statistical analysis}

The data were analyzed by Hierarchical Bayesian (HB) estimation and rescaled with the zero-centered difference method using Sawtooth Software Lighthouse Studio 9.2 (Sawtooth Software Inc., Utah, USA). The results - e.g. importance scores and utility values within a country, importance scores per attribute between countries - were compared by applying one way ANOVA with post hoc Hochberg-GT2 using IBM SPSS Statistics 25 (IBM Corp, NY, USA).

The internal consistency reliability of the health consciousness scale was measured with Cronbach's Alpha. The overall reliability was 0.78 , which is above the 0.70 level that is generally considered to be satisfactory (Tavakol \& Dennick, 2011). The reliability values for each country were also satisfactory: China (0.78), The Netherlands (0.83) and Indonesia (0.71).

\subsection{Results and Discussion}

\subsubsection{Socio-demographic characteristics}

Table 3.2 shows the socio-demographic characteristics of the three respondent groups: Chinese, Indonesians, and Dutch and their health consciousness scores. Most of the respondents were females comprising $70.6 \%$ of the sample. The age distribution is skewed with $61.7 \%$ of the sample population between $18-25$ years. The respondents were well-educated with $78.3 \%$ of them holding an undergraduate or post graduate qualification.

\subsubsection{Health consciousness scores}

Indonesian respondents were on average more health-conscious than Chinese and Dutch respondents $(P<0.05)$, Table 3.2. It is worth to note that the average healthconscious score of the total respondents $(n=483)$ was rather high, on average 3.3 on a 5-point scale. This value suggests that the sample population in this study considered themselves as health-conscious individuals.

In the total sample, no significant difference on the average health consciousness score was found for gender (Table 3.2). The youngest respondents appeared to be 
more health-conscious than the oldest respondents $(P<0.05)$. This can't be attributed to differences within countries since no differences between age groups within the three countries were found, but it seems due to the high number of young Indonesians in the sample. There is no significant difference in health consciousness scores between educational backgrounds within a country, except for the Chinese respondents, where lower educated respondents have lower health consciousness scores. However, some caution is necessary due to the small number of Chinese respondents in the sample with lower educational background.

A significant correlation exists between the health consciousness score and being a dried mango eater $(P<0.05)$, as shown in Table 3.2. This result might be because the number of Indonesian respondents contributed to more than half of the total respondents. Indonesian groups who are less health-conscious (as compared with those who have higher health-conscious scores) tend to be dried mango eaters ( $P$ $<0.05)$. This result is in line with our previous health perception study which found that Indonesian participants ate dried mango as a snack and their reasons for eating were often unrelated to health (Sulistyawati et al., 2019). Nevertheless, it should be noted that the Indonesian groups have the highest health consciousness scores among the three respondent groups. For Dutch and Chinese respondents, no significant difference in the health consciousness between dried mango eaters and non-eaters was found, implying that for these groups dried mango consumption might not be associated with a healthy diet and lifestyle. This result is contradictory to previous consumer studies which found that high health-conscious consumers show greater preference toward certain foods (as compared to that of low healthconscious consumers), e.g. willingness to use functional food (Chen, 2013), frequency of olive oil consumption (Gámbaro et al., 2013).

\subsubsection{Familiarity levels}

This study involved respondents from the Netherlands, China and Indonesia. These countries show large differences in quantity and variety of dried fruit products available on their market, so participants from these countries are expected to have different familiarity with eating dried fruit, specifically dried tropical fruit. As expected, Chinese participants were most familiar with dried mango, reflected in $94.9 \%$ of the 
respondents being dried mango eaters, followed by Indonesian (64.3\%) and Dutch participants (50\%), Table 3.2. These results are in line with the consumer perception study on dried mango in which Chinese and Indonesian participants mentioned more intrinsic characteristics (Sulistyawati et al., 2019), implying a higher product familiarity than the Dutch participants.

For the Indonesians is $35.7 \%$ of non-eaters of dried mango remarkably low. This might be due to the fact that various alternatives of fruit snacks are available in the Indonesian market ranging from various fresh tropical fruits (Altendorf, 2017, 2018) to processed fruit products, including semi-dried/dried fruits.

It is worth to note that although Dutch respondents were least familiar in eating dried mango among the groups studied, the proportion of the eaters is still rather high $(50 \%)$. This can be explained by the recent increase in semi-dried/dried mango popularity and higher availability as snack and ingredient in breakfast cereals and patisseries. Nevertheless, half of the Dutch respondents - who do not eat dried mango - might be hampered by the limited availability of dried mango in the Dutch supermarkets and greengrocers. According to the Europe Health Interview Survey conducted between 2013-2015 more than $85 \%$ Dutch people regularly consume fresh fruits and vegetables, respectively (EUROSTAT, 2018), which might also contribute to lower dried fruit consumption.

\subsubsection{Relative importance of intrinsic quality attributes}

This study measured the relative importance of six intrinsic attributes for choosing dried mango and compared the significant differences among the three respondent groups: Chinese, Indonesians, and Dutch (Fig 3.1). The relative importance scores reflect the importance of each attribute in the decision-making process for a preferred product concept by the respondents. The attribute (no) extra ingredients had the greatest importance in determining consumers' preference for Chinese and Dutch groups, while for Indonesians, it was the third most importance attribute (but not significantly different from sweetener), as shown in Fig 3.S1. 


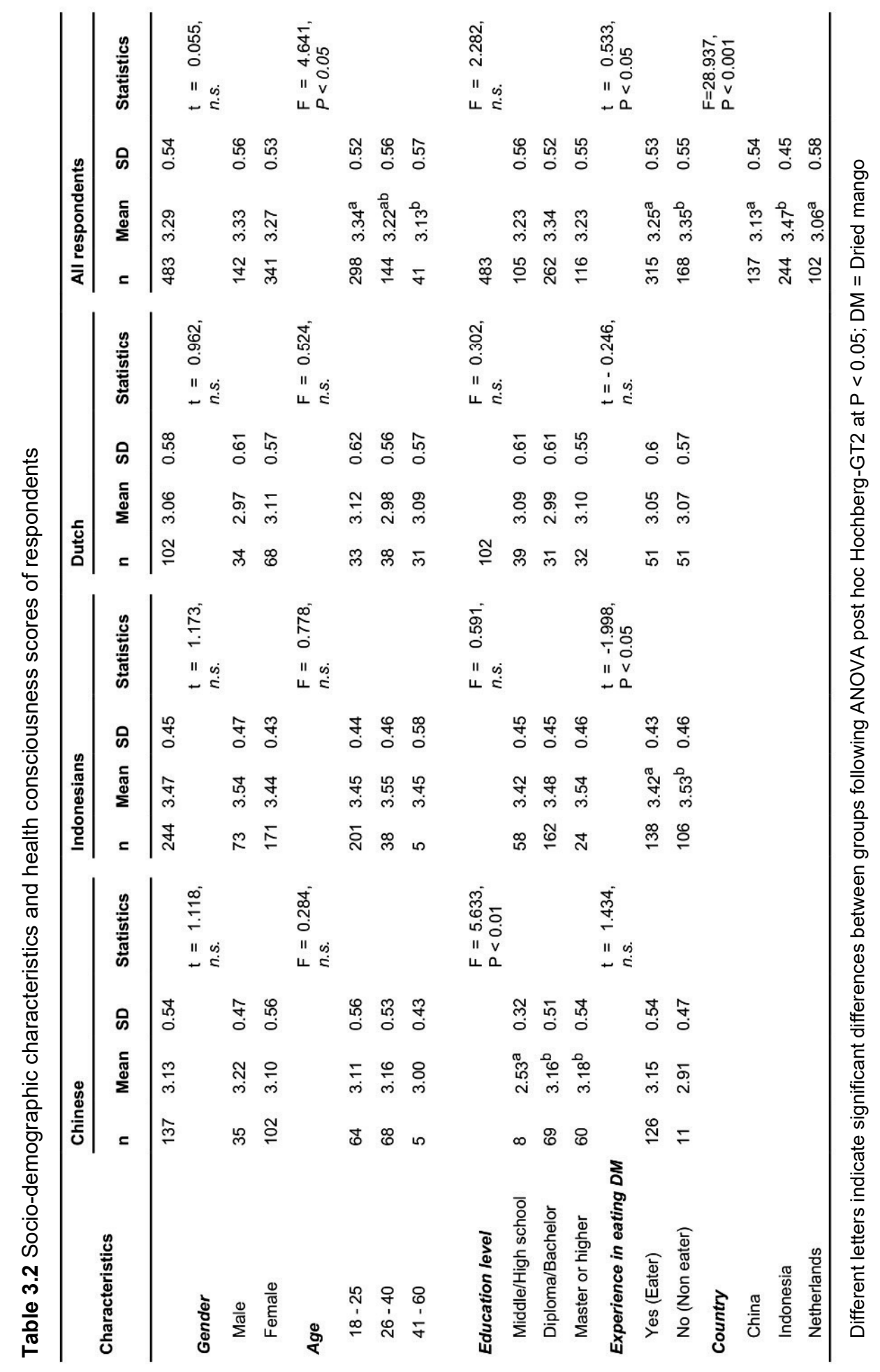




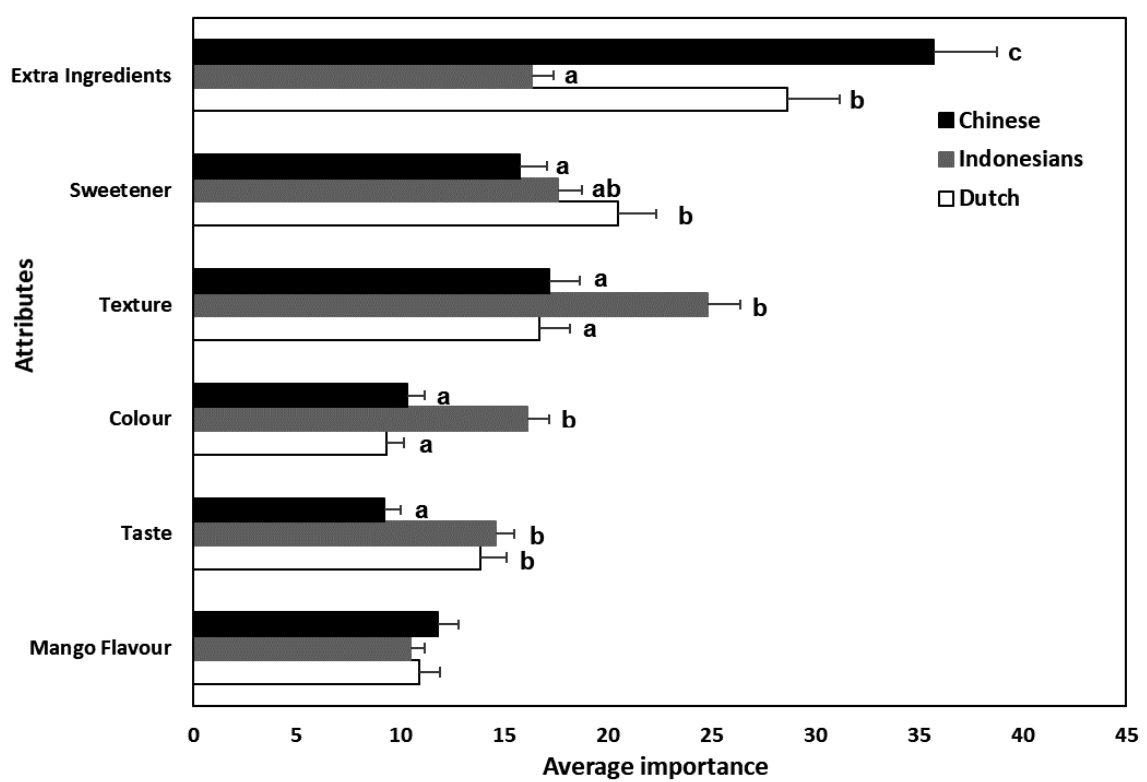

Fig 3.1 Relative importance of intrinsic attributes (mean \pm SE) contributing to consumer preference in dried mango in three countries. Different letters show significant differences per attribute between respondent groups $(P<0.05)$.

Texture was the most important attribute for selecting and consuming dried mango for Indonesians, being 'crispy' as the preferred level (Table 3.3, Fig 3.S1). This finding seems contradictory to the health consciousness scores in which Indonesians had higher scores than other groups, but they weighed texture - a sensory attribute - as the most important attribute in choosing dried mango. For the Chinese and Dutch this attribute was the second most important intrinsic quality attribute, but not significantly different from sweetener $(P<0.05)$.

The least important attribute of dried mango was different for the three groups; it was taste for the Chinese, mango flavor for the Indonesians and color for Dutch respondents (Fig 3.S1). Taste usually falls within the top three most important sensory attributes of a food (Prescott, 1998). This result is in line with the relatively high health consciousness of the samples which can drive a health-related food choice behavior, i.e. making food choice by considering health-related attributes over the non-health-related attributes (Mai \& Hoffmann, 2012). 


\subsubsection{Utility values for different levels of each attribute of dried mango}

Fig 3.2 shows the utility values for different levels of each intrinsic quality attribute shown in Fig 3.1. The values reflect contribution of the respective level to the consumers' preference of choosing dried mango. 'No extra ingredients' was the preferred level for extra ingredients in all respondent groups (Fig 3.2, Table 3.3). 'No extra ingredients' might be interpreted as a preference for a 'natural' product. This finding is in line with a thorough review study on the importance of food naturalness for consumers that revealed that to the majority of consumers, food naturalness is crucial (Román et al., 2017). Gomez et al. (2015) also found that consumers differed in their perception of food naturalness and the difference influenced their consumption of fresh dairy products. This result implies that it can be relevant to take naturalness into account when developing dried mango.

All respondent groups distinctly less preferred adding 'salt' or 'salt and spices' or 'spices'. Adding salt could be seen as turning healthy fruit into unhealthy dried fruit, as it is also recommended to reduce dietary salt intake for prevention of cardiovascular disease (Hooper et al., 2004). Moreover, for the Dutch group, as for other European consumers, dried fruit is commonly consumed as 'just' dried fruit (e.g. raisin) or incorporated in sweet products like breakfast cereals, muesli bars, mixed with nuts as reported by Jesionkowska et al. (2007), implying that adding salt or spices into dried fruit is not a common practice for these consumers.

Despite the rather similar preference among the three groups on 'no extra ingredients', adding salt showed a positive utility value only for the Chinese group. This might be related to the availability of dried salted fruit made of sour plum, mango and tangerine/orange peel in the local market in China (Liu \& Yin, 2015) and a high salt intake of the Chinese on a regular basis (Hvistendahl, 2014), implying their preference for salty foods including dried fruit. 

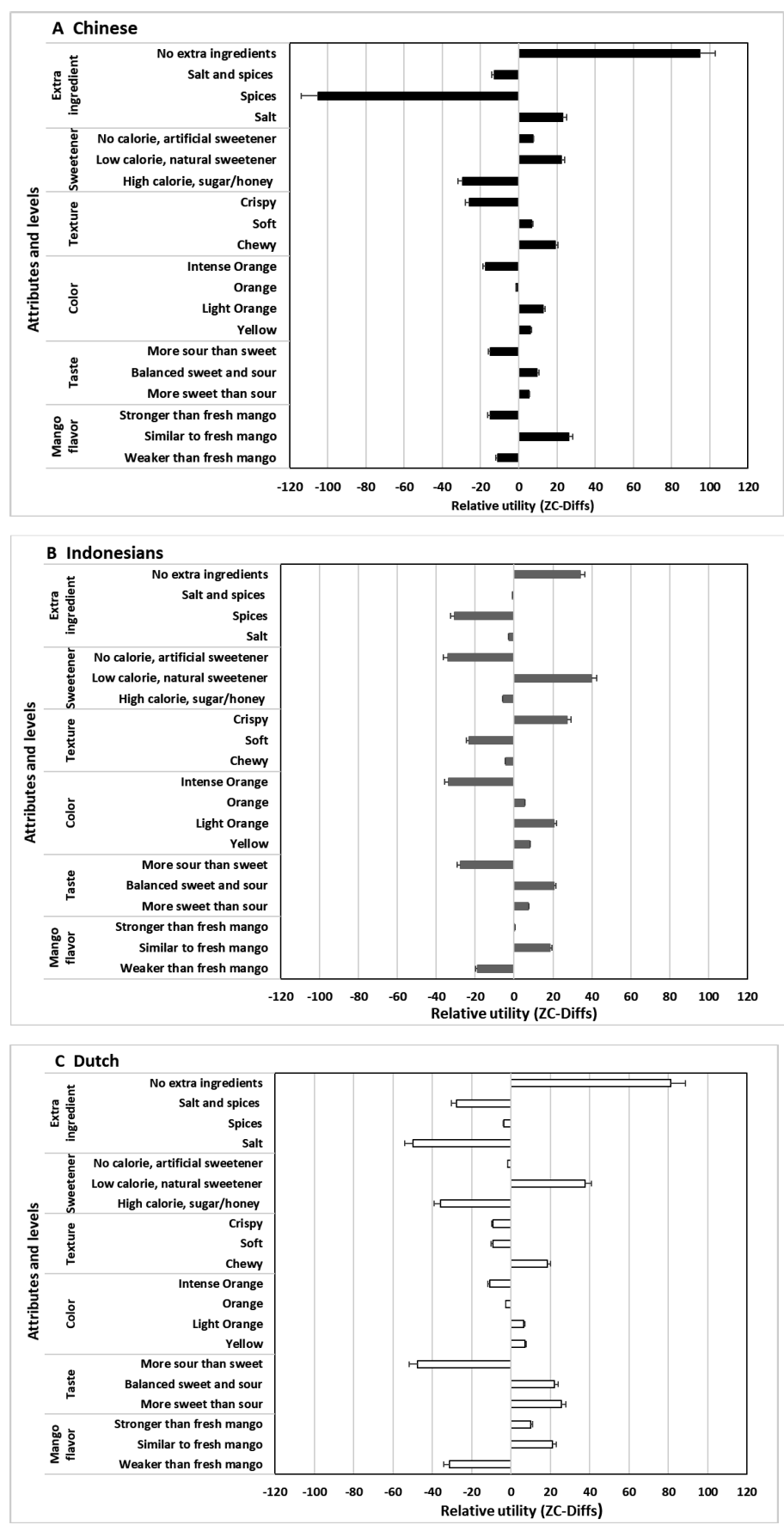

Fig 3.2. Preference for intrinsic quality attributes and their levels of dried mango in each group of respondents. 
'Low calorie, natural sweetener' is the most preferred sweetener for all respondent groups (Fig 3.2, Table 3.3). This is followed by 'no calorie, artificial sweetener' for Chinese and Dutch groups, and 'high calorie, natural sugar/honey' for the Indonesian group. Following that, the Chinese and Dutch groups significantly preferred 'no calorie, artificial sweetener' over 'high calorie, natural sugar/honey', while the Indonesian group preferred the opposite. This could imply that respondents give different importance weights to level of calorie and type of sweetener, which however was not studied here.

Table 3.3. The most preferred levels per intrinsic attribute of dried mango among respondent groups.

\begin{tabular}{|c|c|c|c|}
\hline Intrinsic attributes & Chinese & Indonesians & Dutch \\
\hline Extra Ingredients & No Extra Ingredients & No Extra Ingredients & No Extra Ingredients \\
\hline Sweetener & \multicolumn{3}{|c|}{ Low calorie, natural sweetener } \\
\hline Texture & Chewy & Crispy & Chewy \\
\hline Colour & \multicolumn{2}{|c|}{ Light orange } & Yellow \\
\hline Taste & \multicolumn{2}{|c|}{ Balanced sweet and sour } & More sweet than sour \\
\hline Mango Flavour & \multicolumn{3}{|c|}{ Similar to fresh mango } \\
\hline
\end{tabular}

${ }^{*}$ The levels in bold are the key intrinsic quality attributes based on the relative importance of the attributes from the conjoint analysis.

A significant difference in texture preferences was found between the groups. The Indonesians really appreciated crispy dried mango over a chewy or soft texture, as reflected in the distinct positive utility value (Fig 3.2, Table 3.3). Dutch and Chinese had negative utility values for 'crispy', they preferred 'chewy' over the other textures. It is likely that the Indonesian group considers dried mango only as a snack as also reported by Sulistyawati et al. (2019), which is often regarded as indulgence and comfort food (Jack et al., 1997). Moreover, this finding is in agreement with Oddo, Maehara, \& Rah (2019) who revealed that $65 \%$ of Indonesian adults consume fried snacks for 4 days/week, suggesting that they repeatedly consume food with a crispy texture. In the study of Sulistyawati et al. (2019) some Indonesian participants reasoned eating dried fruit crisps was for enjoyment and then they preferred adding flavor enhancer. Dutch groups preferred a 'chewy' texture perhaps due to their frequent consumption (weekly of more often) of chewy dried fruits, e.g. raisin and dried apricot (Jesionkowska et al., 2008). In addition, the Dutch are used to consume 
dried fruits including dried mango as a chewy snack or in breakfast cereals, as can be found in the supermarkets and greengrocers. In China, a wide variety of dried fruit is commonly consumed and is also available as additional ingredient, like in breakfast porridge or baked goods (Wei et al., 2017), thus it could be assumed the dried fruit eaten by the Chinese usually has a 'chewy' texture. These findings give an important market insight regarding texture of dried mango.

Regarding color, the Chinese and the Indonesians preferred light orange, while the Dutch preferred yellow dried mango (Fig 3.2, Table 3.3). With regard to taste, Dutch respondents preferred a 'more sweet than sour' taste, while Indonesian and Chinese respondents preferred a 'balanced sweet and sour' taste (Fig 3.2, Table 3.3). As expected, a 'more sour than sweet' taste gave negative utility values for all respondent groups. Intense yellow orange or orange mango flesh indicates a full ripened mango (Medlicott et al., 1990) and a sweeter taste due to ripening (Yashoda et al., 2006). In relation to this, the results on color preferences imply that all respondents favored dried mango which resembled the color and taste characteristics of ripe mango.

No significant difference in relative importance of attributes was found between men and women $(P>0.05)$. To our surprise, also no significant differences on the relative importance of attributes were found between dried mango eaters and non-eaters, which was hypothesized influencing product familiarity. Consumers having different frequency of consuming a certain food are likely to differ in their assessment of that food attributes (Hersleth et al., 2011). Results of the present study also differed from a previous consumer study on fresh fruit which found that high-frequency fruit consumers (as compared to those of low-frequency fruit consumers) tended to attach more value to many intrinsic fruit attributes, e.g. freshness, nutritional value (Heng \& House, 2018).

The results of taste preference of the Chinese and Indonesians are similar to a previous preference study on dried mango which revealed that Norwegian respondents mostly appreciated a sweet and sour balance of dried mango (Alphonce et al., 2015). 
In the present study, preferences of dried mango attributes differ between the three countries studied (Table 3.3). The key intrinsic attribute in dried mango for the Indonesians is texture, while for the Chinese and the Dutch it is (not adding) extra ingredients. Nevertheless, this difference seems not to be influenced by familiarity nor health consciousness. The different preferences for intrinsic attributes of dried mango between groups might be due to factors of cultural differences and individual preferences. As reported by Pollard et al. (2002) these two factors contributed in affecting food choice in relation to fruit and vegetable intake.

\subsubsection{Limitations}

One limitation of this study is the use of social media and e-mail to recruit the respondents. As such the respondents were self-selected and are not necessarily representative of the general population because they were not divided according to age, gender or health consciousness.

Another limitation of this study was that we only examined the frequency of dried mango consumption to represent product familiarity. Furthermore, while the health consciousness scale has been tested and applied in several studies (e.g. Sijtsema et al., 2012; Gámbaro et al., 2013; Chen, 2013), this self-reported health consciousness may be assessed differently by consumers across countries due to variability in health perception.

\subsection{Conclusions and recommendations}

According to this study, consumer preferences toward intrinsic attributes of dried mango differ between respondent groups from China, Indonesia, and the Netherlands. The key quality attribute considered by the Indonesians is texture, with crispy as the preferred texture, the Dutch and Chinese consider the lack of extra ingredients as the key attribute. Apparently they prefer a pure mango product, without 'extra ingredients'. This is one of the key intrinsic attributes of dried mango and interpreted to be related to naturalness, suggesting that naturalness needs to be taken into account in product development. The results of this study suggest that adding value to dried mango by addressing different intrinsic quality attributes is relevant. In reality, consumers choose products considering also extrinsic quality 
attributes, e.g. origin, price, nutritional information (Rodrigues et al., 2017), therefore further studies are recommended, addressing both type of attributes, intrinsic and extrinsic, for a more comprehensive understanding in choosing dried fruit. The results relate to the preference of intrinsic attributes of dried mango consumed as a single product; not as an ingredient of a food product. Further studies are needed to shed additional light on the understanding preference of dried fruit products such as protein bar, on-the-go dried fruit/nut mixes.

Both familiarity toward dried mango - operationalized as ever/never ate it and local availability - as well as health consciousness do not influence the preference. To identify factors influencing the consumers' preference toward dried mango or comparable types of products, a case-specific approach is necessary in which product familiarity can be investigated involving more indicators (e.g. product knowledge, taste preference).

This study demonstrates the application of conjoint analysis in multiple countries as a valuable tool in product development. Results of this study contributes particularly to explaining variations in key quality attributes and preferences; supporting the development of dried mango and product variety that meet consumer wishes and preferences of the intended markets.

\section{Acknowledgements}

The authors appreciated Stella Alinneshia, Dangyiqi Wu and Claire Setjadiningrat for their assistance with data collection from the Indonesian, Chinese and Dutch participants, respectively.

\section{Conflict of interest}

All authors report no conflict of interest.

\section{Funding}

I. Sulistyawati received a Ph.D. scholarship from the Directorate General of Resources for Science, Technology and Higher Education, Indonesia (DIKTI) [grant number 391/E4.4/K/2014]. 


\section{References}

Alphonce, R., Temu, A., \& Almli, V. L. (2015). European consumer preference for African dried fruits. British Food Journal, 117(7), 1886-1902. https://doi.org/10.1108/BFJ-10-2014-0342

Altendorf, S. (2017). Global prospects for major tropical fruits: short-term outlook, challenges and opportunities in a vibrant global marketplace. In Food Outlook: Biannual Report on Global Food Markets (pp. 69-81). FAO Trade and Markets Division. http://www.fao.org/3/a-18080e.pdf

Altendorf, S. (2018). Minor tropical fruits: Mainstreaming a niche market. In Food Outlook: Biannual Report on Global Food Markets (Issue July, pp. 69-78). FAO Trade and Markets Division. http://www.fao.org/3/CA0239EN/ca0239en.pdf

Asioli, D., Aschemann-Witzel, J., Caputo, V., Vecchio, R., Annunziata, A., Næs, T., \& Varela, P. (2017). Making sense of the "clean label" trends: A review of consumer food choice behavior and discussion of industry implications. Food Research International, 99(Part 1), 58-71. https://doi.org/10.1016/j.foodres.2017.07.022

Banović, M., Fontes, M. A., Barreira, M. M., \& Grunert, K. G. (2012). Impact of product familiarity on beef quality perception. Agribusiness, 28(2), 157-172. https://doi.org/10.1002/agr.21290

Becker, M. H., Maiman, L. A., Kirscht, J. P., Haefner, D. P., \& Drachman, R. H. (1977). The health belief model and prediction of dietary compliance: A field experiment. Journal of Health and Social Behavior, 18(4), 348-366. https://doi.org/10.2307/2955344

Bower, J. A., \& Ferguson, J. (2008). Children's perception of fresh fruit and fruit snacks. Nutrition \& Food Science, 38(3), 256-263. https://doi.org/10.1108/00346650810871948

Bredahl, L. (2003). Cue utilisation and quality perception with regard to branded beef. Food Quality and Preference, 15(1), 65-75. https://doi.org/10.1016/S09503293(03)00024-7

CBI. (2019). Exporting dried tropical fruit to Europe. https://www.cbi.eu/node/2767/pdf/

Chambers V, E., Chambers IV, E., \& Castro, M. (2018). What Is "Natural"? 
Consumer Responses to Selected Ingredients. Foods, 7(65). https://doi.org/10.3390/foods7040065

Chen, M. F. (2013). Influences of health consciousness on consumers' modern health worries and willingness to use functional foods. Journal of Applied Social Psychology, 43, E1-E12. https://doi.org/10.1111/jasp.12033

Cinar, G. (2018). Consumer perspective regarding dried tropical fruits in Turkey. Italian Journal of Food Science, 30(4), 809-827. https://doi.org/10.14674/IJFS1131

Ciurzyńska, A., Kowalska, H., Czajkowska, K., \& Lenart, A. (2016). Osmotic dehydration in production of sustainable and healthy food. Trends in Food Science and Technology, 50, 186-192. https://doi.org/10.1016/j.tifs.2016.01.017

EUROSTAT. (2018). Fruit and vegetable consumption statistics. http://ec.europa.eu/eurostat/statisticsexplained/

FAO. (2019). Major tropical fruits: Market review 2018. http://www.fao.org/3/ca5692en/ca5692en.pdf

Frez-Muñoz, L., Steenbekkers, B. L. P. A., \& Fogliano, V. (2016). The choice of canned whole peeled tomatoes is driven by different key quality attributes perceived by consumers having different familiarity with the product. Journal of Food Science, 81(12), S2988-S2996. https://doi.org/10.1111/17503841.13539

Gámbaro, A., Ellis, A. C., \& Prieto, V. (2013). Influence of subjective knowledge, objective knowledge and health consciousness on olive oil consumption-A case study. Food and Nutrition Sciences, 4, 445-453. https://doi.org/10.4236/fns.2013.44057

Gomez, P., Schneid, N., \& Delaere, F. (2015). How often should I eat it? Product correlates and accuracy of estimation of appropriate food consumption frequency. Food Quality and Preference, 40(1), 1-7. https://doi.org/10.1016/j.foodqual.2014.07.018

Grunert, K. G. (2005). Food quality and safety: consumer perception and demand. European Review of Agricultural Economics, 32(3), 369-391. https://doi.org/10.1093/eurrag/jbi011

Heng, Y., \& House, L. A. (2018). Cluster analysis for fruit consumption patterns: an 
international study. British Food Journal, 120(9), 1942-1952. https://doi.org/10.1108/BFJ-01-2018-0014

Hersleth, M., Lengard, V., Verbeke, W., Guerrero, L., \& Næs, T. (2011). Consumers' acceptance of innovations in dry-cured ham: Impact of reduced salt content, prolonged aging time and new origin. Food Quality and Preference, 22(1), 31 41. https://doi.org/10.1016/j.foodqual.2010.07.002

Hooper, L., Bartlett, C., Davey Smith, G., \& Ebrahim, S. (2004). Advice to reduce dietary salt for prevention of cardiovascular disease. Cochrane Database of Systematic Reviews, 1 , CD003656. https://doi.org/10.1002/14651858.cd003656.pub2

Hvistendahl, M. (2014). China tries to kick its salt habit. Science, 345(6202), 12681269. https://doi.org/10.1126/science.345.6202.1268

IBISWorld Industry Report. (2016). Global Fruit and Vegetables Processing.

Jack, F. R., O'Neill, J., Piacentini, M. G., \& Schröder, M. J. A. (1997). Perception of fruit as a snack: A comparison with manufactured snack foods. Food Quality and Preference, 8(3), 175-182. https://doi.org/10.1016/s0950-3293(96)000468

Januszewska, R., Pieniak, Z., \& Verbeke, W. (2011). Food choice questionnaire revisited in four countries. Does it still measure the same? Appetite, 57(1), 9498. https://doi.org/10.1016/j.appet.2011.03.014

Jervis, S. M., Ennis, J. M., \& Drake, M. A. (2012). A comparison of adaptive choicebased conjoint and choice-based conjoint to determine key choice attributes of sour cream with limited sample size. Journal of Sensory Studies, 27(6), 451462. https://doi.org/10.1111/joss.12009

Jesionkowska, K, Sijtsema, S., Simoneaux, R., Konopacka, D., \& Plocharski, W. (2008). Preferences and consumption of dried fruit and dried fruit products among Dutch, French and Polish consumers. Journal of Fruit and Ornamental Plant Research, 16, 261-274.

Jesionkowska, Katarzyna, Konopacka, D., Płocharski, W., Sijtsema, S., \& Zimmermann, K. (2007). What do Polish and Dutch consumers think about dried fruit and products with them - Creative group discussions as a means of recognition consumers' perceptions. Polish Journal of Natural Sciences, Supplement No.4, 169-175. 
Liu, J., \& Yin, F. (2015). Prunus mume (Sieb.) Sieb. et Zucc. 乌梅 (Wumei, Japanese Apricot). In Dietary Chinese Herbs (pp. 483-494). Springer Vienna. https://doi.org/10.1007/978-3-211-99448-1_55

Mai, R., \& Hoffmann, S. (2012). Taste lovers versus nutrition fact seekers: How health consciousness and self-efficacy determine the way consumers choose food products. Journal of Consumer Behaviour, 11(4), 316-328. https://doi.org/10.1002/cb.1390

Medlicott, A. P., N'Diaye, M., \& Sigrist, J. M. M. (1990). Harvest maturity and concentration and exposure time to acetylene influence initiation of ripening in mangos. Journal of the American Society for Horticultural Science, 115(3), 426-430. https://doi.org/10.21273/jashs.115.3.426

Milošević, J., Žeželj, I., Gorton, M., \& Barjolle, D. (2012). Understanding the motives for food choice in Western Balkan Countries. Appetite, 58(1), 205-214. https://doi.org/10.1016/j.appet.2011.09.012

Oddo, V. M., Maehara, M., \& Rah, J. H. (2019). Overweight in Indonesia: An observational study of trends and risk factors among adults and children. $B M J$ Open, 9, e031198. https://doi.org/10.1136/bmjopen-2019-031198

Orme, B. K. (2010). Getting Started with Conjoint Analysis: Strategies for Product Design and Pricing Research (2nd ed.). Research Publishers LLC.

Park, C. W., \& Lessig, V. P. (1981). Familiarity and its impact on consumer decision biases. Journal of Consumer Research, 8(2), 223-231. https://doi.org/10.1086/208859

Pollard, J., Kirk, S. F. L., \& Cade, J. E. (2002). Factors affecting food choice in relation to fruit and vegetable intake: A review. Nutrition Research Reviews, 15(2), 373-387. https://doi.org/10.1079/NRR200244

Precoppe, M., Nagle, M., Mahayothee, B., Udomkun, P., Janjai, S., \& Müller, J. (2014). Optimal physicochemical properties of dried litchis for Thai consumers. International Journal of Agricultural and Biological Engineering, 7(5), 103-110. https://doi.org/10.25165/IJABE.V7I5.1151

Prescott, J. (1998). Comparisons of taste perceptions and preferences of Japanese and Australian consumers: Overview and implications for cross-cultural sensory research. Food Quality and Preference, 9(6), 393-402. https://doi.org/10.1016/S0950-3293(98)00021-4 
Puska, P., \& Luomala, H. T. (2016). Capturing qualitatively different healthfulness images of food products. Marketing Intelligence and Planning, 34(5), 605-622. https://doi.org/10.1108/MIP-06-2015-0119

Rodrigues, D. M., Ferreira Rodrigues, J., Rios De Souza, V., De Deus, J., Carneiro, S., \& Borges, S. V. (2017). Consumer preferences for Cerrado fruit preserves: a study using conjoint analysis. British Food Journal, 120(4), 827-838. https://doi.org/10.1108/BFJ-03-2017-0187

Román, S., Sánchez-Siles, L. M., \& Siegrist, M. (2017). The importance of food naturalness for consumers: Results of a systematic review. Trends in Food Science and Technology, 67, 44-57. https://doi.org/10.1016/j.tifs.2017.06.010

Sabbe, S., Verbeke, W., \& Van Damme, P. (2008). Familiarity and purchasing intention of Belgian consumers for fresh and processed tropical fruit products. British Food Journal, 110(8), 805-818. https://doi.org/10.1108/00070700810893331

Sadler, M. J., Gibson, S., Whelan, K., Ha, M. A., Lovegrove, J., \& Higgs, J. (2019). Dried fruit and public health-what does the evidence tell us? International Journal of Food Sciences and Nutrition, 70(6), 675-687. https://doi.org/10.1080/09637486.2019.1568398

Schifferstein, H. N. J., \& Ophuis Oude, P. A. M. (1998). Health-related determinants of organic food consumption in the Netherlands. Food Quality and Preference, 9(3), 119-133. https://doi.org/10.1016/S0950-3293(97)00044-X

Sijtsema, S. J., Jesionkowska, K., Symoneaux, R., Konopacka, D., \& Snoek, H. (2012). Perceptions of the health and convenience characteristics of fresh and dried fruits. LWT - Food Science and Technology, 49(2), 275-281. https://doi.org/10.1016/j.Iwt.2012.04.027

Sulistyawati, I., Sijtsema, S., Dekker, M., Verkerk, R., \& Steenbekkers, B. (2019). Exploring consumers' health perception across cultures in the early stages of new product development: Dried mango as a case study. British Food Journal, 121(9), 2116-2131. https://doi.org/10.1108/BFJ-02-2019-0091

Tavakol, M., \& Dennick, R. (2011). Making sense of Cronbach's alpha. International Journal of Medical Education, 2, 53-55. https://doi.org/10.5116/ijme.4dfb.8dfd Wardle, J., \& Steptoe, A. (2003). Socioeconomic differences in attitudes and beliefs about healthy lifestyles. J Epidemiol Community Health, 57, 440-443. 
https://doi.org/10.1136/jech.57.6.440

Wei, D., Wang, Y., Jiang, D., Feng, X., Li, J., \& Wang, M. (2017). Survey of Alternaria toxins and other mycotoxins in dried fruits in China. Toxins, 9(7), 200. https://doi.org/10.3390/toxins 9070200

Wismer, W. V. (2014). Consumer Eating Habits and Perceptions of Fresh Produce Quality. In W. J. Florkowski, R. L. Shewfelt, B. Brueckner, \& S. E. Prussia (Eds.), Postharvest Handling: A Systems Approach (3rd ed., pp. 31-52). Academic Press. https://doi.org/10.1016/B978-0-12-408137-6.00003-X

Yahia, E. M., García-Solís, P., \& Celis, M. E. M. (2019). Contribution of Fruits and Vegetables to Human Nutrition and Health. In E. M. Yahia (Ed.), Postharvest Physiology and Biochemistry of Fruits and Vegetables (pp. 19-45). Woodhead Publishing. https://doi.org/10.1016/b978-0-12-813278-4.00002-6

Yashoda, H. M., Prabha, T. N., \& Tharanathan, R. N. (2006). Mango ripening: Changes in cell wall constituents in relation to textural softening. Journal of the Science of Food and Agriculture, 86(5), 713-721. https://doi.org/10.1002/jsfa.2404 
Appendix 3.A. The health consciousness scale (Schifferstein \& Ophuis Oude, 1998) and internal consistency reliability

\begin{tabular}{|c|c|}
\hline \multicolumn{2}{|l|}{ Item } \\
\hline \multicolumn{2}{|c|}{ 1. I have the impression that I sacrifice a lot for my health } \\
\hline \multicolumn{2}{|c|}{ 2. I consider myself to be very health conscious } \\
\hline \multicolumn{2}{|c|}{ 3. I am prepared to leave a lot, to eat as healthy as possible } \\
\hline \multicolumn{2}{|c|}{ 4. I think I take health into account a lot in my life } \\
\hline \multicolumn{2}{|c|}{ 5. I think it is more important to know how to eat in a more healthy way } \\
\hline \multicolumn{2}{|c|}{ 6. My health is so valuable to me that I am prepared to sacrifice many things for it } \\
\hline \multicolumn{2}{|c|}{ 7. I have the impression that the other people pay more attention to health than I do } \\
\hline \multicolumn{2}{|c|}{ 8. I do not continually ask myself whether something is good for me } \\
\hline \multicolumn{2}{|c|}{ 9. I do not often think about whether everything I do is healthy } \\
\hline \multirow{2}{*}{\multicolumn{2}{|c|}{$\begin{array}{l}\text { 10. I do not want to ask myself all the time whether the things I eat are good for me } \\
\text { 11. I often dwell on my health }\end{array}$}} \\
\hline & \\
\hline Cronbach's Alpha Overall (all 3 countries) & 0.78 \\
\hline The Netherlands & 0.85 \\
\hline China & 0.78 \\
\hline Indonesia & 0.71 \\
\hline
\end{tabular}


Chapter 3

\section{Appendix 3.B}

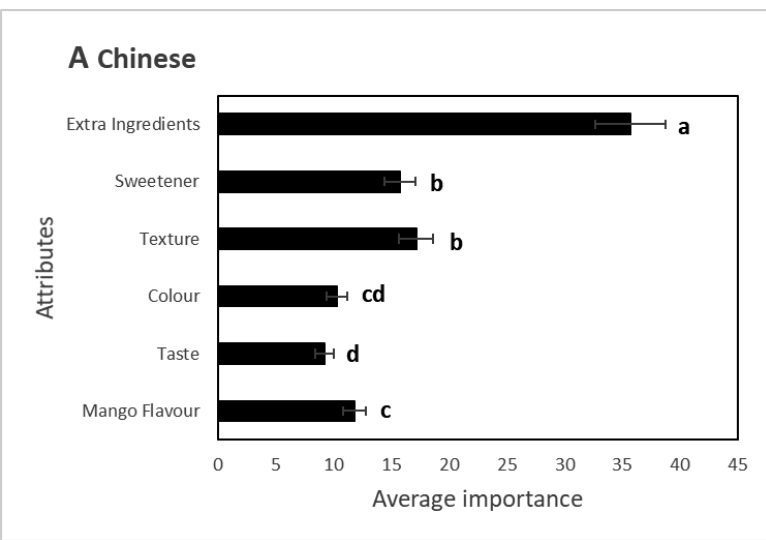

\section{B Indonesians}
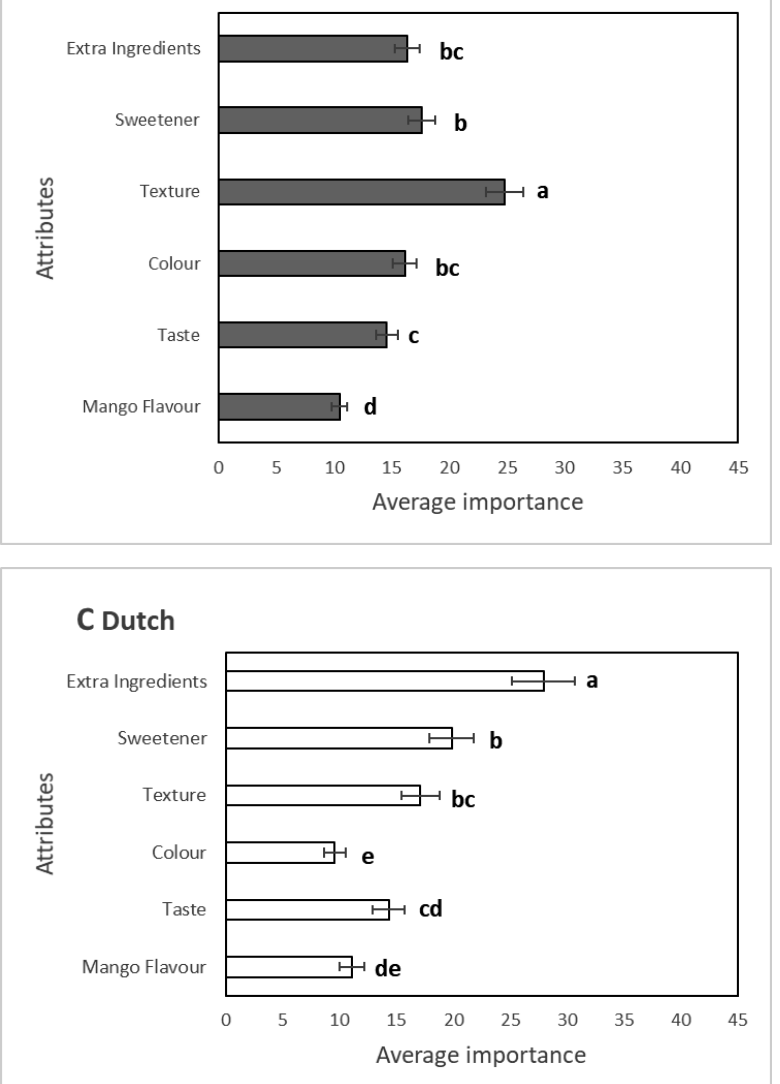

Fig 3.S1. Relative importance attributes (mean \pm SE) contributing to consumer preference of dried mango in each respondent groups. Different letters show significant differences of an attribute within a group $(P<0.05)$. 


\section{Chapter 4}

Osmotic dehydration of mango:

Effect of vacuum impregnation, high pressure, pectin methylesterase and ripeness on quality

\section{Published as:}

Sulistyawati, I., Dekker, M., Fogliano, V., \& Verkerk, R. (2018). Osmotic dehydration of mango: Effect of vacuum impregnation, high pressure, pectin methylesterase and ripeness on quality. LWT, 98, 179-186. 



\begin{abstract}
The effects of pretreatment with vacuum impregnation (VI) and high pressure (HP) and adding pectin methylesterase (PME) with calcium on the quality of osmotic dehydrated mango of different ripeness were investigated. Unripe and ripe 'Kent' mango cubes were osmotic dehydrated (OD at $50^{\circ} \mathrm{C}$ in $60^{\circ}$ Brix sucrose solution containing $2 \mathrm{~g}$ calcium lactate $/ 100 \mathrm{~g}$ and 0 or $0.48 \mathrm{~mL}$ PME/100 g), preceded either by VI (OD-VI) or HP (OD-HP). Use of unripe mango in OD showed two to five-fold higher soluble solid gain (SSG) compared to ripe mango for all treatments. Unripe mango pretreated with OD-VI showed the lowest water loss (WL) and the highest SSG. OD-HP had a similar but less pronounced effect as OD-VI on WL and SSG. Hue $\left(h^{*}\right)$ were generally preserved and color intensity $\left(C^{*}\right)$ were maintained or only slightly increased in both ripeness in all treatments. Lightness $\left(L^{*}\right)$ was greatly reduced in unripe mango but stable in ripe mango. In general, firmness and work of shear slightly increased when adding PME.
\end{abstract}

Keywords: mango fruit; maturity; osmotic dehydration; vacuum impregnation; high pressure

\title{
4.1. Introduction
}

Mango (Mangifera indica L.) is the second most important tropical fruit in the world after banana (Altendorf, 2017). Mango, as most fruits, is an important source of macro-, micronutrients, and a broad range of phytochemicals (Ribeiro, Schieber, \& Preedy, 2010). There has been an increase in world demand for minimally processed mango products with a prolonged shelf-life, though maintaining the healthy and tasty experience (Hanemann, 2017). Osmotic dehydration (OD) can provide such added value to the product. OD could be applied before drying or freezing to creating new, less perishable food products or ingredients with high nutritional and sensory properties (Ciurzyńska, Kowalska, Czajkowska, \& Lenart, 2016).

OD is a mass transfer process which removes partially water and simultaneously increases the soluble solid content of fruit in an osmotic solution (OS) (Torreggiani, 1993). The process results in modification of the fruit tissue which can be tailored towards the compositional, textural and sensorial quality of dehydrated fruit. The OD 
mass transfer can be influenced by the fruit properties (ripeness, variety, physicochemical properties, and tissue structure). As mango is often harvested at mature-green stage, a full sized but unripe state, it has different characteristics from ripe mango, a fully developed, ripe and ready to eat product (Brecht \& Yahia, 2009). During ripening mango undergoes biochemical changes causing tissue softening because of extensive pectin solubilization (Muda, Seymour, Errington, \& Tucker, 1995) and progressive depolymerization (Yashoda, Prabha, \& Tharanathan, 2005) in the middle lamella of cell walls, involving cell wall hydrolases (Yashoda, Prabha, \& Tharanathan, 2007).

Several process variables affect OD mass transfer rates such as pretreatments, temperature, OS properties, agitation, fruit to OS ratio, and additives (Ahmed, Qazi, \& Jamal, 2016). Combination of OD with pretreatments, such as vacuum impregnation $(\mathrm{VI})$ and high pressure (HP) have been shown to enhance the mass transfer (Rastogi, Raghavarao, Balasubramaniam, Niranjan, \& Knorr, 2007; Fito et al., 2001). The main driving forces during OD of fruit have been illustrated in Fig. 4.1. In OD, flux of OS into cellular tissue is induced by initial capillary pressure (Seguí, Fito, \& Fito, 2012). Meanwhile, three other mechanisms concurrently occur throughout the process: (i) cell dehydration caused by $a_{w}$ gradients leading to water loss; both (ii) soluble solid diffusion and (iii) cell impregnation caused by cellular volume changes that generate pressure gradients related to mechanical deformation. In OD-VI, the capillary impregnation was combined with VI-induced impregnation which expands internal gas and liquid in pores (when vacuum is applied) and followed by compression (when atmospheric pressure is restored). The gas partially flows out causing additional internal volume changes (Chiralt \& Fito, 2003). Instead, in OD-HP, the imposed pressure changes are caused by high pressure and the following decompression increase cell membrane permeability (Rastogi, Raghavarao, Niranjan, \& Knorr, 2002). In this study, the response was also influenced by the tissue features of mango which change during ripening. 
Osmotic dehydration of mango

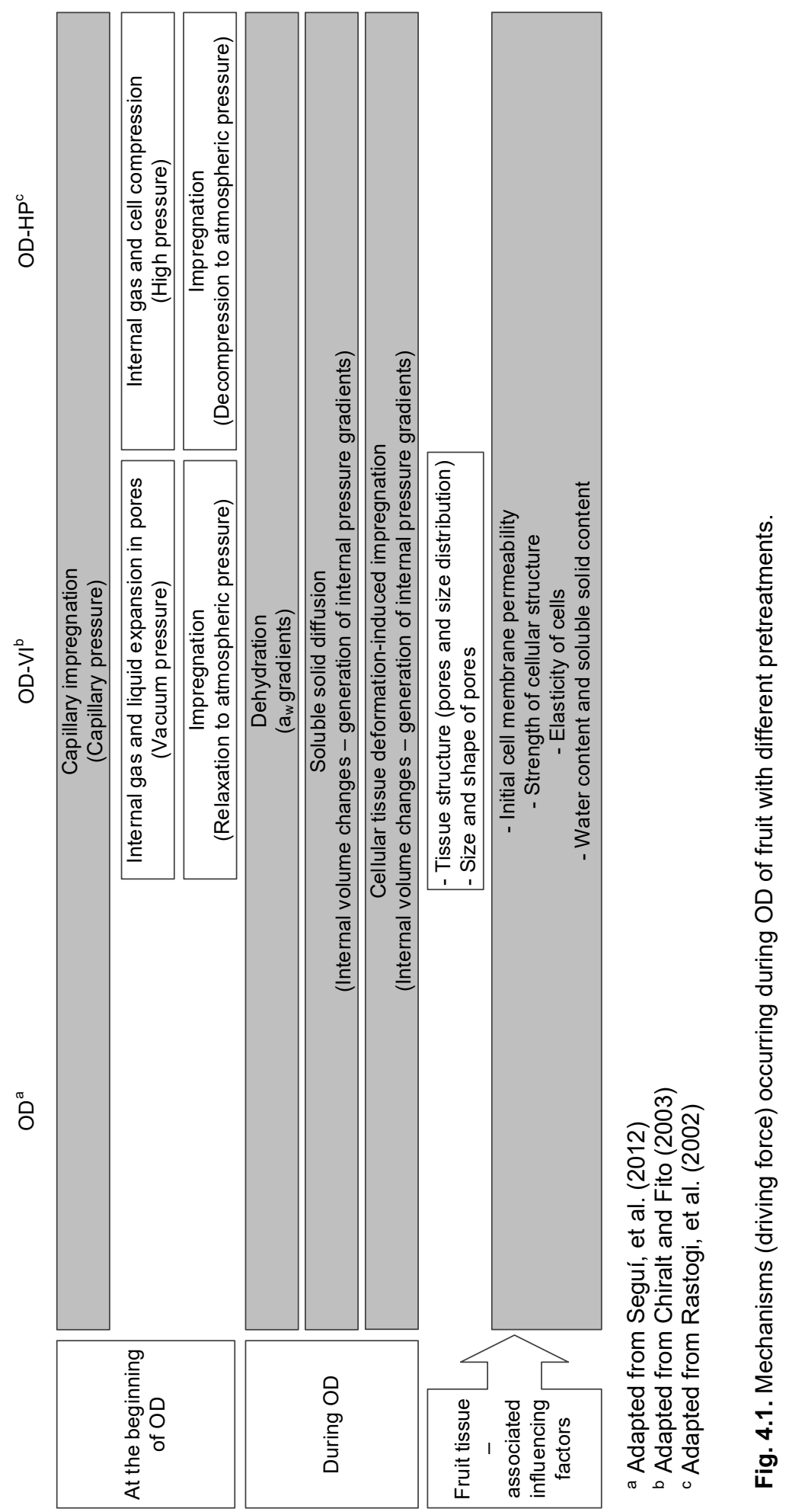


Mass transfer and a mild temperature $\left(30-50^{\circ} \mathrm{C}\right)$ applied during $O D$ result in tissue modification without damaging the fruit structure (Shi \& Xue, 2009). Product firmness can be improved by incorporating texture modifying agents, such as pectin methylesterase (PME) (Guillemin et al., 2008), calcium (Silva, Fernandes, \& Mauro, 2014a) or a combination of these agents (Sirijariyawat, Charoenrein, \& Barrett, 2012). PME is able to de-methylate fruit pectin which can subsequently be bound by the available endogenous and/or added calcium into a calcium-pectin gel (Van Buggenhout, Sila, Duvetter, Van Loey, \& Hendrickx, 2009). Incorporation of these agents can be enhanced by applying VI or HP (Sirijariyawat et al., 2012; Sila, Smout, Vu, \& Hendrickx, 2004) prior to OD.

Understanding the effect of fruit ripeness is essential to improve the process as well as the sensory and nutritional quality of osmotic dehydrated fruit. Many studies investigated OD mass transfer rates and its efficiency in different fruits under different conditions, a.o. Torreggiani and Bertolo (2004); Rastogi et al. (2002). The effects of OD process variables have been thoroughly investigated and reviewed (Ahmed et al., 2016; Ciurzyńska et al., 2016). However, the effect of fruit ripeness with PME addition and using different pretreatments for OD has not been reported. Therefore, the objective of this study is to investigate the effects of pretreatments ( $\mathrm{HP}$ and $\mathrm{VI}$ ) and PME as additives in the presence of calcium on OD efficiency and on quality parameters of osmotic dehydrated mango of different ripeness.

\subsection{Materials and methods}

\subsubsection{Materials}

Unripe and ripe mango (Mangifera indica L. cv. Kent) from Brazil was provided by Nature's Pride (Maasdijk, The Netherlands) and stored at $11{ }^{\circ} \mathrm{C}$ and used within three days after arrival. After being selected based on the firmness (Table 4.1), mango was peeled and the flesh was cut into cubes (approximately $1.2 \mathrm{~cm} \times 1.2 \mathrm{~cm}$ $x 1.2 \mathrm{~cm}$ ) using a potato cutter and a knife. Approximately $150 \mathrm{~g}$ of mango cubes were used for each replicate per treatment. 
Table 4.1. Characteristics of mango samples

\begin{tabular}{lll}
\hline Characteristics & Unripe mango & Ripe mango \\
\hline Average weight $(\mathrm{g})^{\mathrm{a}}$ & $403.9 \pm 25.7$ & $700.3 \pm 56.7$ \\
${\text { Firmness }(\mathrm{kg})^{\mathrm{a}}}^{\text {Total soluble solid }\left({ }^{\circ} \text { Brix }\right)^{\mathrm{b}}}$ & $9.0 \pm 0.9$ & $2.6 \pm 0.3$ \\
Titratable acidity $(\mathrm{g} \text { citric acid } / 100 \mathrm{~g})^{\mathrm{b}}$ & $13.2 \pm 0.2$ & $15.7 \pm 0.3$ \\
Moisture $(\mathrm{g} / 100 \mathrm{~g})^{\mathrm{b}}$ & $0.80 \pm 0.05$ & $0.58 \pm 0.02$ \\
Number of mangoes used & $80.44 \pm 0.05$ & $84.87 \pm 1.76$ \\
\hline
\end{tabular}

a Values represent mean $\pm S D$ of all selected mango within the same ripeness.

b Values represent mean $\pm S D$ of two batches per pretreatment that were each analyzed in duplicate.

Pectin methylesterase from a recombinant Aspergillus oryzae (Novoshape ${ }^{\circledR}$ Novozymes, Denmark) with a declared activity of 10 Pectin Esterase Units (PEU)/ml, and calcium-L-lactate pentahydrate (Merck KGaA, Darmstadt, Germany) were used. Osmotic solutions (OS) were prepared with commercial sucrose in demineralized water.

\subsubsection{Experimental setup}

OD was carried out with a 1:4 (w/w) mango to OS ratio (Fig. 4.2) at $50^{\circ} \mathrm{C}$ in $60^{\circ} \mathrm{Brix}$ sucrose, $2 \mathrm{~g}$ calcium lactate/100 $\mathrm{g}$ and 0 or $0.48 \mathrm{~mL}$ PME/100 $\mathrm{g}$ for 0.5, 2 and $4 \mathrm{~h}$ under continuous stirring (Silva, Fernandes, \& Mauro, 2014b; Torres, Talens, Escriche, \& Chiralt, 2006). OD time started from the immersion in the OS (aided with an adjustable metal plate) which included the pretreatment time. Afterward, the cubes were separated, quickly rinsed with demineralized water, gently blotted with tissue papers and kept at $4{ }^{\circ} \mathrm{C}$ prior to analysis. Untreated mango was used as a control. Each treatment was performed in duplicate.

VI was carried out in a vacuum chamber with a pump (VD53, Binder GmbH and SC950, Knf-Neuberger, Inc., Germany) at $30{ }^{\circ} \mathrm{C}$ and $5 \mathrm{KPa}$ for $15 \mathrm{~min}$ and $10 \mathrm{~min}$ for pressure recovery. After VI, samples completed the OD time.

HP was carried out in a Resato FPU-100-50 (Resato International B.V., Roden, The Netherlands). OS at $35^{\circ} \mathrm{C}$ and mango cubes were packed in a sealed polyethylene bag after removal of air. The packed sample was subjected to HP condition (300 MPa for 3-5 min) using water as the pressure medium. Pressure build-up rate was 
about $6.7 \mathrm{MPa} / \mathrm{s}$. The processing time was counted after the solutions reached 300 $\mathrm{MPa}$. Due to the adiabatic heating, a maximum temperature of $50{ }^{\circ} \mathrm{C}$ was obtained (de Heij et al., 2003). Decompression time was about $10 \mathrm{~s}$. After HP, samples completed the OD time.

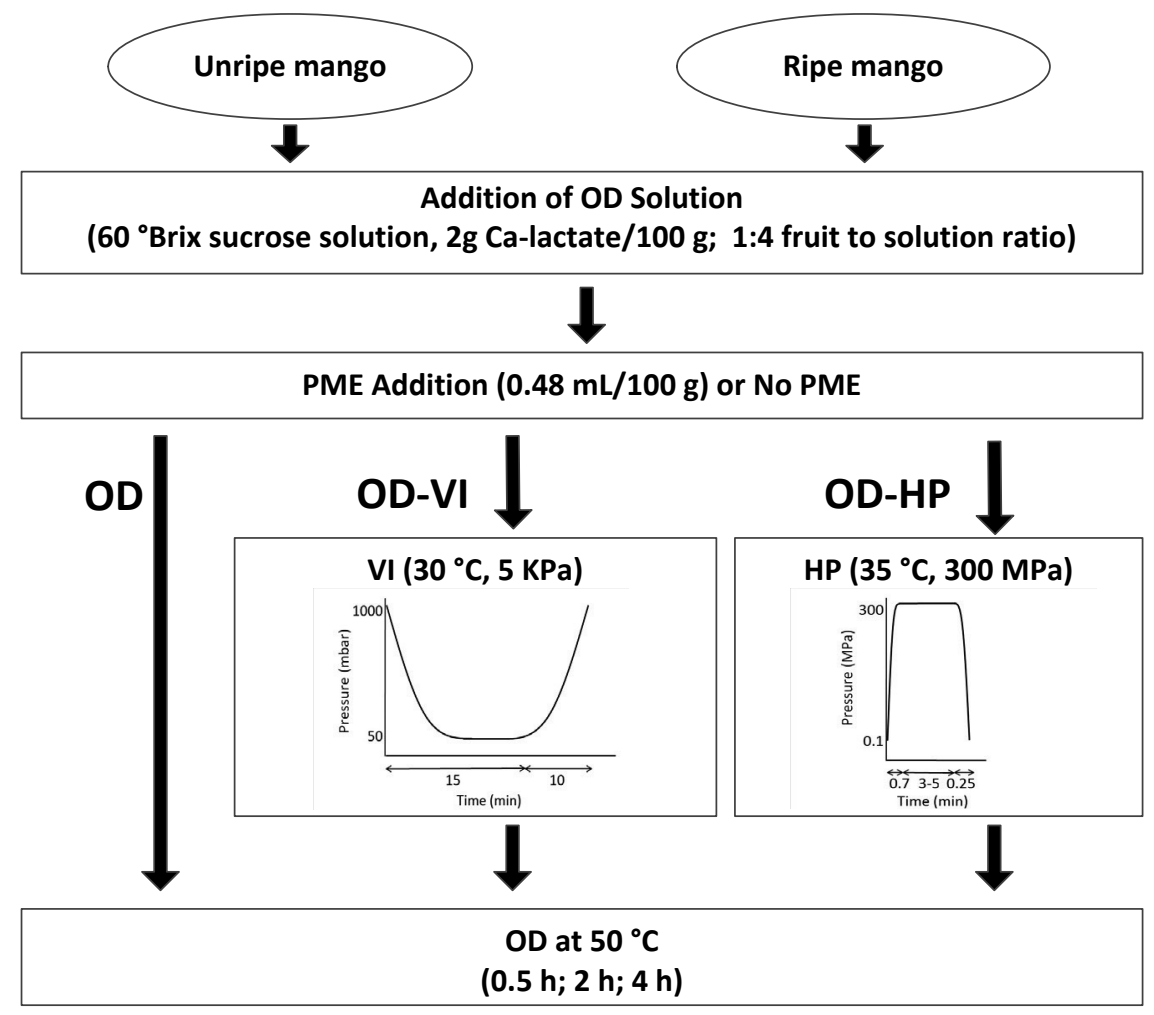

Fig. 4.2. Experimental setup of the study.

\subsubsection{Physicochemical analyses}

The firmness of intact mango was measured at four equatorial points using a penetrometer with $8 \mathrm{~mm}$ tip (FT 327, Effegi, Italy). Titratable acidity (g citric acid/100 g) was measured by titrating supernatant of mango juice with $0.1 \mathrm{~mol} / \mathrm{L} \mathrm{NaOH}$ to $\mathrm{pH}$ 8.1 using a $\mathrm{pH}$ meter (pHenomenal pH1000L, VWR, Germany).

Total soluble solid (TSS, 'Brix) was determined with a digital refractometer (HI 96801, Hanna Instruments, USA). Water activity (aw) was measured with a LabMaster-aw (Novasina AG, Switzerland). Moisture content (g water/100 g) was measured by 
drying in an oven at $103 \pm 2{ }^{\circ} \mathrm{C}$ until reaching a constant weight. All physicochemical analyses were measured in duplicate before and after each treatment.

Water loss (WL), soluble solid gain (SSG), weight reduction (WR) and OD efficiency in mango cubes was calculated according to equations below:

$W L=\frac{\left(M_{t}\right)\left(x_{W, t}\right)-\left(M_{0}\right)\left(x_{W, 0}\right)}{M_{0}}$

$S S G=\frac{\left(M_{t}\right)\left(x_{S, t}\right)-\left(M_{0}\right)\left(x_{S, 0}\right)}{M_{0}}$

$W R=\frac{M_{t}-M_{0}}{M_{0}}$

$O D$ efficiency $=\frac{W L}{S S G}$

Where $M_{0}$ is the initial weight of the sample $(\mathrm{g}), M_{t}$ is the weight of the sample at time $\mathrm{t}(\mathrm{g}), x_{w, 0}$ is the initial mass fraction of water, $x_{w, t}$ is the mass fraction of water at time $\mathrm{t}, x_{s, 0}$ is the initial mass fraction of soluble solids and $x_{s, t}$ is the mass fraction of soluble solids at time $t$.

\subsubsection{Colorimetric analysis}

Color was determined by measuring the CIE $L^{*}$ (lightness), $a^{*}$ (redness/greenness), $b^{*}$ (yellowness/blueness) scale using Hunterlab ColorFlex ${ }^{\circledR}$ (Hunter Associates Laboratory Inc., USA), standard illuminant $D_{65}$ and observer $10^{\circ}$. Color intensity (chroma, $C^{*}$ ), visual color perceived by humans (hue angle, $h^{*}$ ) and total color difference $\left(\Delta E^{\star}\right)$ were calculated, as follow:

$C^{*}=\left(a^{*}+b^{* 2}\right)^{\frac{1}{2}}$

$h^{*}=\tan ^{-1}\left(\frac{b^{*}}{a^{*}}\right)$ when $+a^{*}$ and $+b^{*}$ (quadrant I)

$\Delta E^{*}=\left(\Delta L^{*}+\Delta a^{* 2}+\Delta b^{* 2}\right)^{\frac{1}{2}}$

where $\Delta x^{*}=x^{*}-x_{0}^{*}$ (fresh mango) and $x^{*}$ represents $L^{*}, a^{*}$ and $b^{*}$. 


\subsubsection{Textural attributes of mango cubes}

A bulk shear test was performed in a TA-TX2 texture analyzer (SMS, Surrey, UK) equipped with Texture Exponent 32 and mini-Kramer shear cell and a $50 \mathrm{~kg}$ load cell. Maximum force (firmness, $N$ ) and total force to shear the bulk sample which is the total area under the curve of firmness (work of shear (WOS), N.s) of a single layer of four and a double layer of eight mango cubes were measured before and after each treatment for unipe and ripe mango, respectively. Test speed of $1.5 \mathrm{~mm} / \mathrm{s}$; post-test speed of $1.5 \mathrm{~mm} / \mathrm{s}$; target distance of $39 \mathrm{~mm}$ were used.

\subsubsection{Statistical analysis}

Data were statistically evaluated using analysis of variance (ANOVA) combined with Duncan's multiple range test (IBM SPSS Statistics version 23, Chicago, USA).

\subsection{Results and discussion}

\subsubsection{Mass transfer during OD process}

The main mass transfer phenomena during osmotic dehydration involve water loss (WL) and soluble solid gain (SSG), and effects of pretreatments are shown in Table 4.2 OD resulted in a WL of 45-51 $\mathrm{g}$ water/100 $\mathrm{g}$ in unripe and ripe mango. $\mathrm{VI}$ and $\mathrm{HP}$ clearly led to a lower $\mathrm{WL}$ in unripe mango compared to OD alone (26-32 g water/100 $g \mathrm{WL}, \mathrm{P}<0.05$ ), while no clear effect of pretreatments was observed in ripe mango. This could be caused by the strong cellular structure of unripe mango, so the imposed pressure changes removed most of the gas from the pores (in VI) or increased cell permeability (in HP) causing SSG exceeded WL. Similar results were obtained for OD ripe mango compared with OD-VI (Torres et al., 2006) and OD-HP (Tedjo, Taiwo, Eshtiaghi, \& Knorr, 2002). The observed OD-HP results on WL in mango differed from other fruits where OD-HP maintained or promoted WL compared with OD alone, a.o. banana, tomato (Dermesonlouoglou et al., 2017; Verma, Kaushik, \& Rao, 2014). 


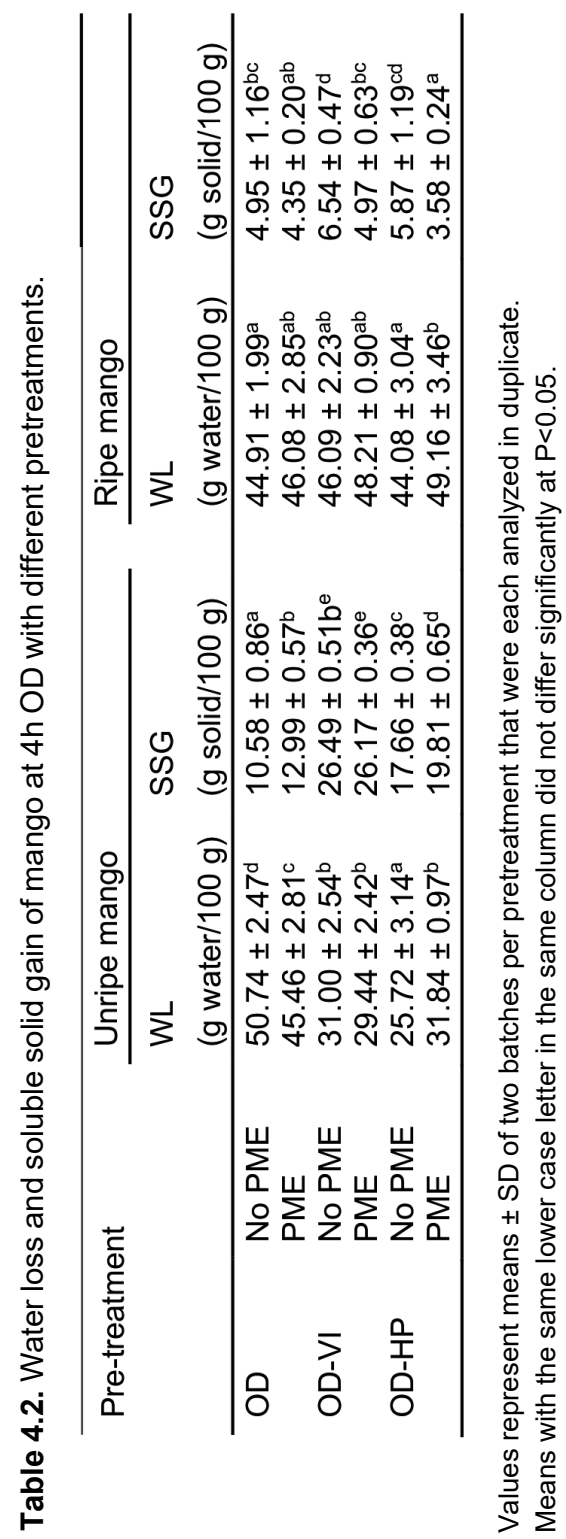



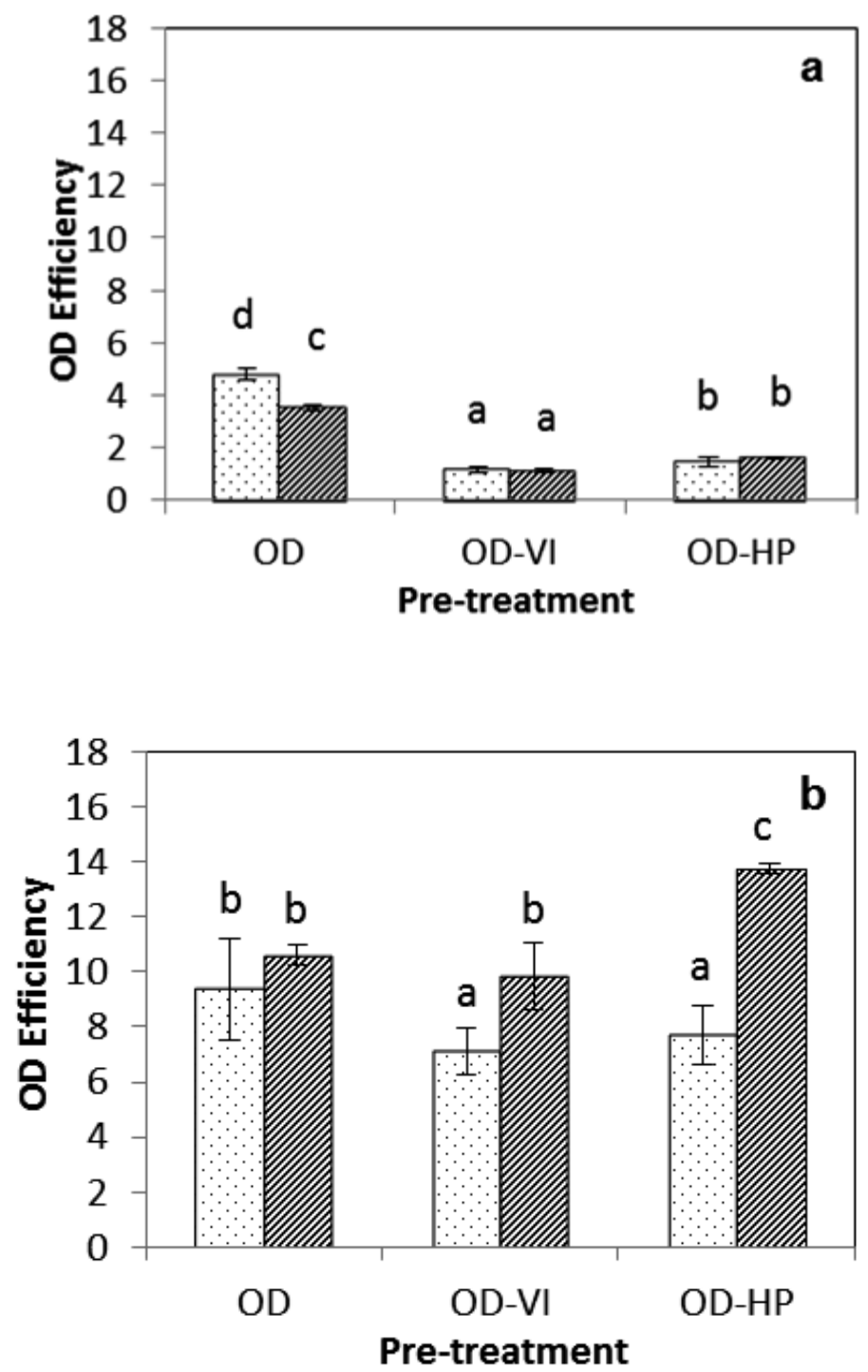

Fig. 4.3. OD efficiency of mango after $4 \mathrm{~h}$ treatment: (a) unripe mango; (b) ripe mango. Means with the same lower case letter did not differ significantly at $\mathrm{p}<0.05$ ( $\square$ No PME; $\mathbb{Z} \mathrm{PME}$ ).

The SSG of unripe OD-treated mango was $11-13 \mathrm{~g}$ solid/100 $\mathrm{g}$ and 4.3-5 $\mathrm{g}$ solid/100 $\mathrm{g}$ for the ripe mango. Also for unripe mango, the pretreatments showed a substantial effect; the SSG was up to 17.7-19.8 g solid/100 $\mathrm{g}$ for OD-HP and even up to 26.2$26.5 \mathrm{~g}$ solid/100 $\mathrm{g}$ for OD-VI mango $(\mathrm{P}<0.05)$. The imposed pressure changes by the 
pre-treatments seem to enhance the mass transfer mechanisms (Fig. 4.1) for unripe mango. For ripe mango, effects on SSG were just marginally, with $6.5 \mathrm{~g}$ solid/100 g SSG for OD-VI as the highest value (no PME). The higher SSG is favorable to having sweetened fruit but is less favorable to obtain a lower sugar content. SSG of unripe mango was two to five-fold higher compared to ripe mango for all treatments (Table 4.2, $\mathrm{P}<0.05)$. A similar result was also reported by Rincon and Kerr (2010).

Previous studies reported that OD-VI of ripe mango resulted in a more pronounced increase in SSG (up to two-fold) compared to OD (Torres et al., 2006; Giraldo, Talens, Fito, \& Chiralt, 2003). OD-HP was also reported to increase SSG in OD ripe mango about 1.5-fold compared to OD alone (Tedjo et al., 2002). OD-VI applied in the present study led to a remarkable enhancement of SSG in unripe mango, as was also observed in other fruits (Moraga, Moraga, Fito, \& Martínez-Navarrete, 2009; Deng \& Zhao, 2008).

A higher SSG in OD unripe mango compared to ripe mango could be explained by the fact that unripe mango has: (i) a stronger cellular structure (Brummell, 2006); (ii) a lower sugar content (Table 4.1). The stronger cell walls are because polysaccharide modification and turgor reduction have not occurred yet. Hence, when water is removed from the fruit tissue, structural changes might be limited leading to a higher SSG. In ripe mango cell wall softening has occurred (Yashoda, Prabha, \& Tharanathan, 2006), when water leaves the fruit, the tissue structure could collapse, thereby physically hindering OS penetration into the fruit (Giraldo et al., 2003). Lower initial sugar content in unripe mango results in higher concentration gradients during OD facilitating a higher SSG. In addition, ripe mango has a decreased intercellular pore size (Cantre, Herremans, Verboven, Ampofo-Asiama, \& Nicolaï, 2014), which could limit OS penetration into the fruit.

OD efficiency of ripe mango (7.1-13.1) was higher than unripe mango (1.1-4.8), as shown in Fig. 4.3, $P<0.05$. This is in line with the lower SSG of ripe mango compared to unripe, while they had a similar WL. In unripe mango, the pretreatments significantly decreased OD efficiency from 3.5-4.8 to 1.1 (OD-VI) and 1.5-1.6 (OD$H P)$, respectively $(P<0.05)$. Pretreated ripe mango without $P M E$ resulted in a $25 \%$ 
(OD-VI) and 18\% (OD-HP) lower OD efficiency. Similar results of a $20-30 \%$ OD efficiency reduction when mango was pretreated with $\mathrm{VI}$ were reported by Ito, Tonon, Park, and Hubinger (2007); Torres et al. (2006).

There was no clear effect of PME addition on OD efficiency at 0.5 and $2 \mathrm{~h}$ for unripe and ripe mango (Table 4.51 of Supplementary material). Though, after $4 \mathrm{~h}$ OD, PME addition significantly increased OD efficiency in both pretreated ripe mango $(P<0.05$, Fig. 4.3b). This result is due to an increased WL and reduced SSG led to a significant efficiency increase surpassing that of $O D(P<0.05$, Table 4.2 and Fig. 4.3). Both pretreatments could facilitate more rapid and homogenous penetration of PME and calcium into cells, forming a calcium-pectin gel leading to SSG reduction by these modified cells (Nuñez-Mancilla et al., 2011; Corrêa, Pereira, Vieira, \& Hubinger, 2010; Yashoda et al., 2006). In addition, the applied OD-HP seems to be a suitable combination of pressure $(300 \mathrm{MPa})$ and temperature $\left(50^{\circ} \mathrm{C}\right)$ to stimulate fungal PME activity (Duvetter et al., 2006) and to lower baro-sensitive polygalacturonase (PG) activity (Oey, Lille, Van Loey, \& Hendrickx, 2008).

Weight reduction of mango after OD was comparable to the observed WL although with much lower value especially for OD-VI and OD-HP of unripe mango (Table 4.2 and Fig. 4.4). This difference could be due to higher SSG of OD pretreated unripe mango compared to OD alone. In unripe mango, the highest WR occurred in OD, while pretreatment of HP and VI lowered the value $(P<0.05)$. Thus, HP and VI could be advantageous to limit great WR in unripe mango, but it is associated with a higher sugar content in the product.

In Fig. 4.5, a composed overview is presented on main OD effects on unripe/ripe mango and combined pretreatments on relevant variables, caused by different mass transfer phenomena. This overview gives an indication of suitable combinations of mango ripeness and pretreatment to produce desired quality characteristics. A complete overview of data representing effects of each pretreatment and ripeness of mango on WL, SSG, OD efficiency, and WR is given in Table 4.S1 (Supplementary material). 

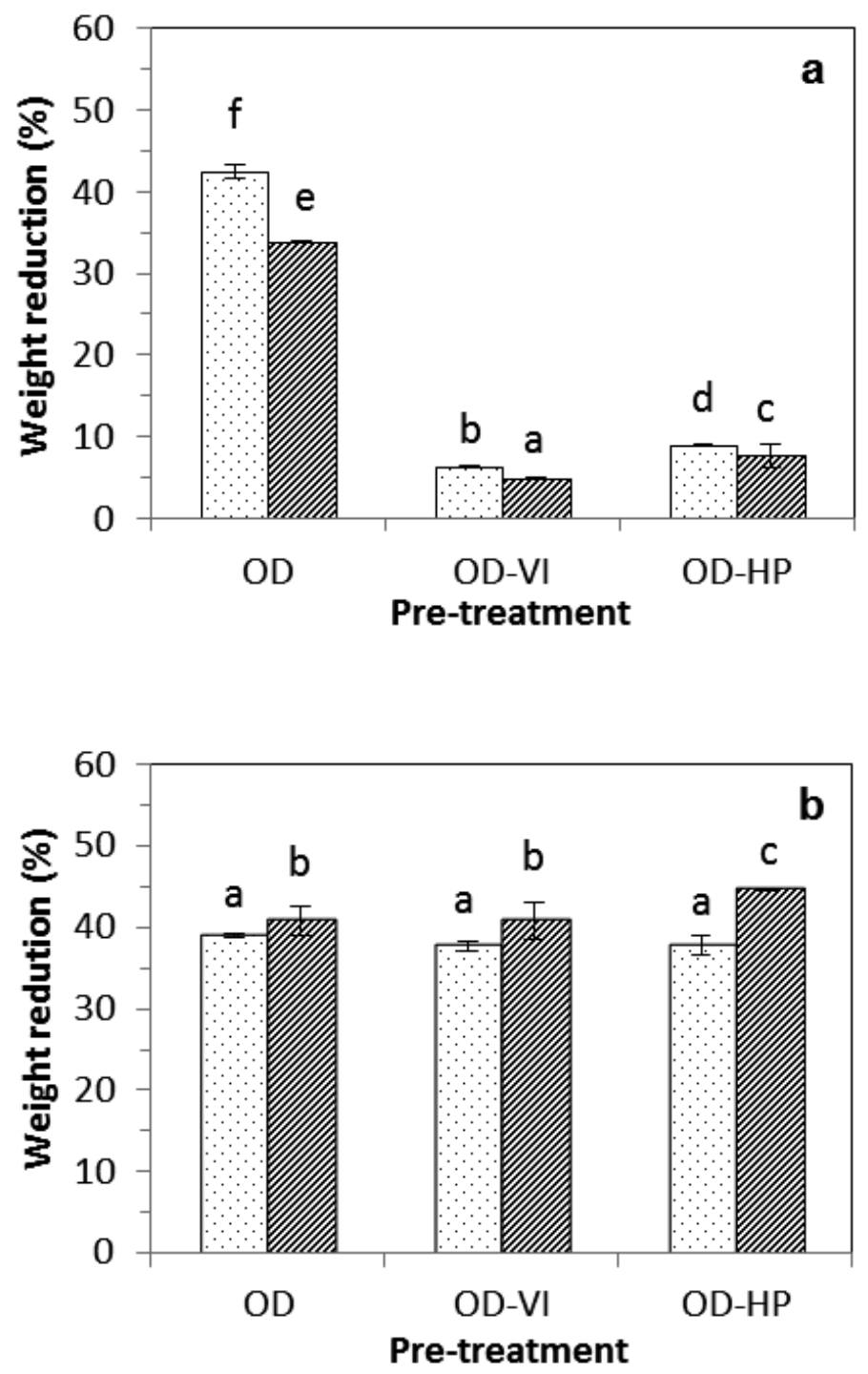

Fig. 4.4. Weight reduction of mango after $4 \mathrm{~h}$ OD: (a) unripe mango; (b) ripe mango. Means with the same lower case letter did not differ significantly at $\mathrm{p}<0.05$ ( $\square$ No PME; $\mathbb{Z} \mathrm{PME}$ ). 

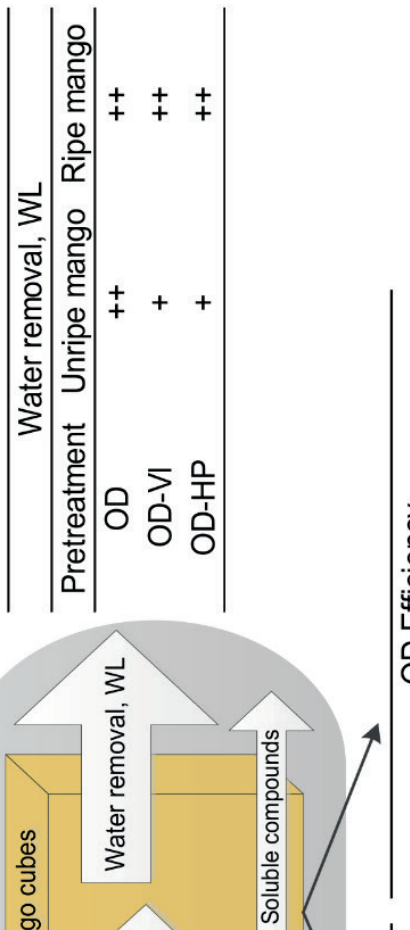

这

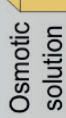

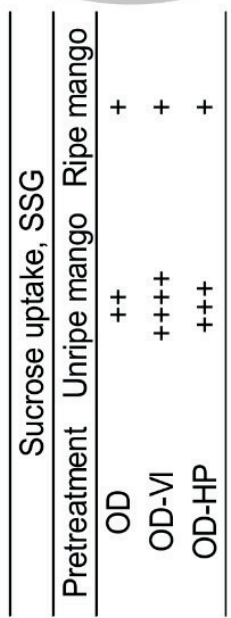

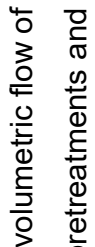

ปั

음 든

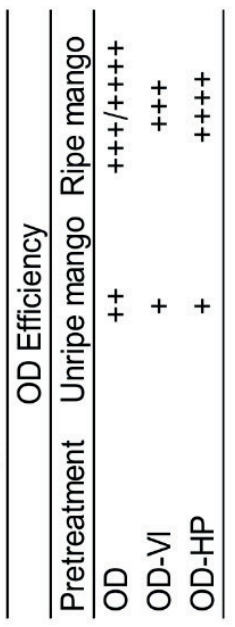

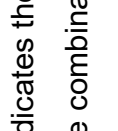

. $\stackrel{9}{=}$

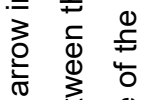

ฮั

응 \&

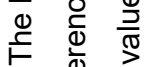

孪

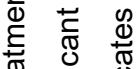

离 読

ㅎํ

艺

ब

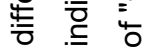

ঠे $=$

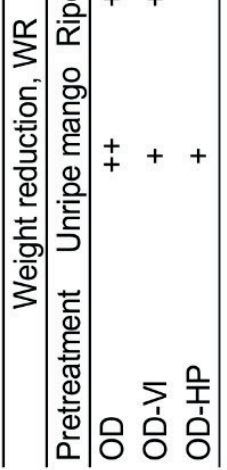

造

을 은

है

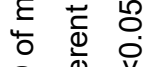

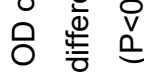

ㄷ $\frac{0}{0}$

त

这

离

की

更

मे के

×

ㅇํㄴ 은 


\subsubsection{Color changes}

In all treatments, after $4 \mathrm{~h}, h^{*}$ values were generally slightly reduced for both ripeness, except for OD-HP of unripe mango (Table 4.S2, Supplementary material). $C^{*}$ values were generally maintained between 50-60 in unripe mango implying carotenoid pigment stability, except for OD-VI of unripe mango, but were slightly increased in ripe mango (Table 4.S2, Supplementary material). The OD setting seems to be suitable for preservation of color quality of mango. An unchanged $C^{*}$ value was also found in OD pineapple (Silva et al., 2014a).

After $4 \mathrm{~h}$ OD, $L^{*}$ values of unripe mango were greatly reduced in all treatments $(P<0.01)$, but that of ripe mango were consistent between 48-51 (Fig. 4.6). For unripe mango, OD-VI mango had the highest $L^{*}$ reduction followed by OD and ODHP. This reduction is in a good agreement with a previous study on OD-VI mango (Torres et al., 2006). This could be attributed to increasing of translucency resulting from internal gas loss triggered by $\mathrm{VI}$ or OS penetration during OD as was also reported for other fruits (Yang, Wu, Ng, \& Wang, 2017; Igual, Castelló, Ortolá, \& Andrés, 2008). $L^{*}$ value of OD-VI unripe mango was similar to fresh ripe mango $(P<0.05)$, which might be preferred as it could contribute to the fresh-like appearance of the product. This OD-VI effect was not observed in ripe mango, the $L^{*}$ value of fresh ripe mango is already lower because of a lower internal gas. Total color differences $\left(\Delta E^{\star}\right)$ were calculated (Table 4.S2, Supplementary material). Changes in $\Delta E^{*}$ reflected the changes in $L^{*}$, due to the much smaller changes in $a^{*}$ and $b^{*}$. 

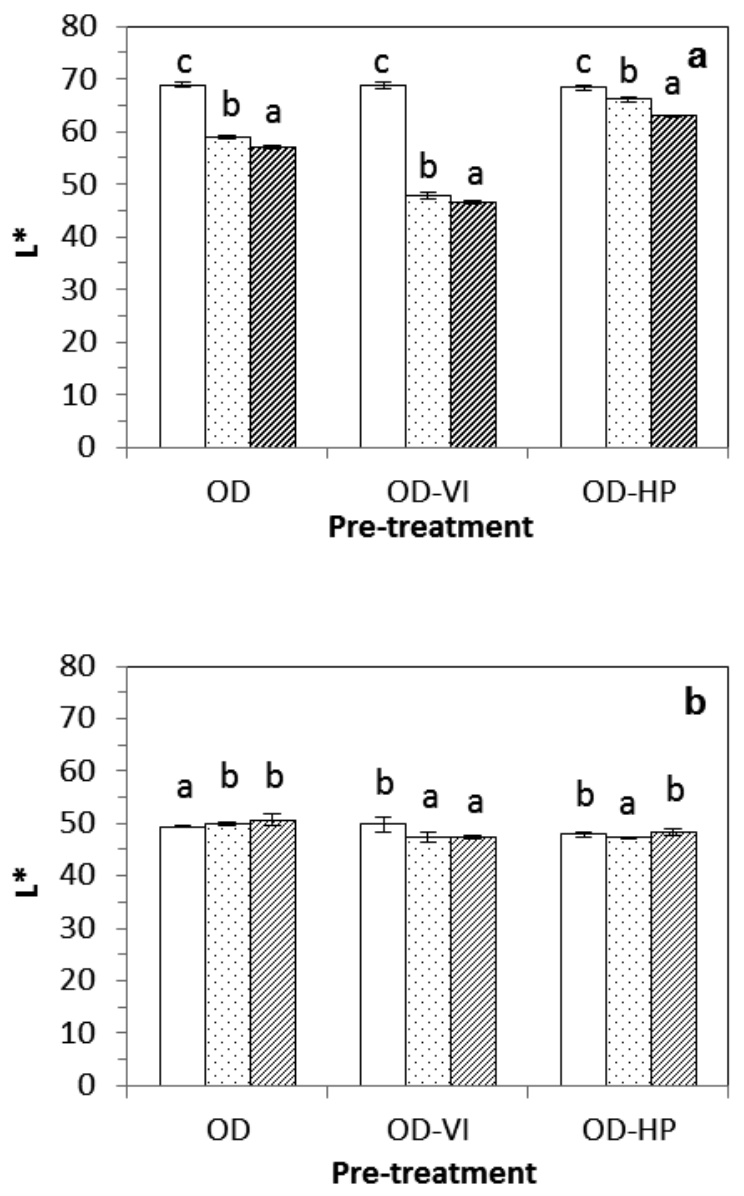

Fig. 4.6. $L^{*}$ of fresh and $4 \mathrm{~h}$ OD mango with different pretreatments: (a) unripe mango; (b) ripe mango. Means with the same lower case letter within similar pretreatment did not differ significantly at $\mathrm{p}<0.05$ ( $\square$ Fresh; $\square$ No PME; $\mathbb{Z}$ PME).

\subsubsection{Textural attributes}

Firmness and work of shear after $4 \mathrm{~h}$ OD of all treatments were consistently more reduced in ripe mango compared to unripe mango (Figs. 4.7 and 4.8). Fresh unripe mango had higher values than ripe mango. Effect of pretreatments on texture was only clear for WOS of unripe mango (Fig. 4.8a) which for all pretreatments resulted in a lower WOS after OD $(\mathrm{P}<0.05)$. Although $\mathrm{VI}$ and HP promote penetration of added calcium into fruit (Van Buggenhout et al., 2009; Sila et al., 2008), it seems the treatments reduced endogenous PME activity and the stronger structure of unripe 
mango might limit fungal PME penetration into cells. In addition, we found that the lower WR, the higher the WOS (Figs. 4.4 and 4.8). The cellular structure of fruit seems to be more preserved when the shrinkage due to the WR is minimized.
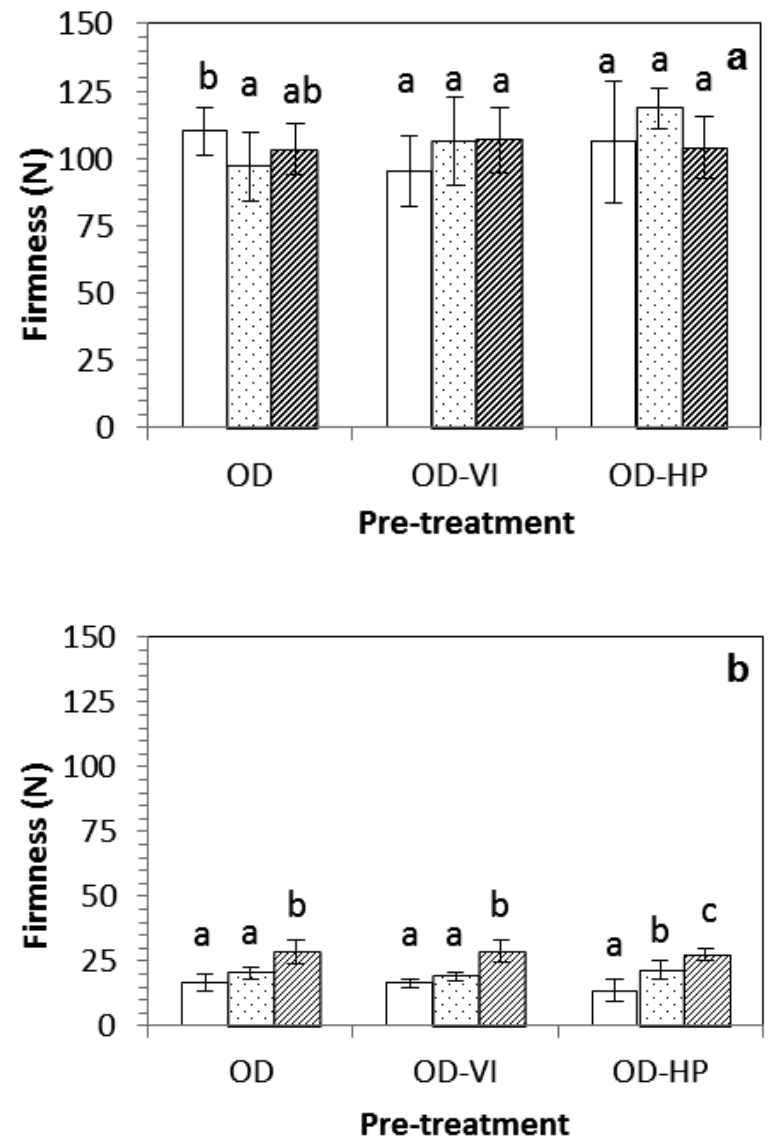

Fig. 4.7. The firmness of fresh and $4 \mathrm{~h}$ OD mango of different pretreatments: (a) unripe mango; (b) ripe mango. Means with the same lower case letter within similar pretreatment did not differ significantly at $\mathrm{p}<0.05$ ( $\square$ Fresh; $\square$ No PME; $\mathbb{R}$ PME).

Addition of PME with calcium had some influences on firmness and work of shear of ripe mango which generally increased $(P<0.05)$, except for WOS of OD-HP mango (Figs. 4.7b and 4.8b). Similar firming effects on ripe mango treated with HP were also reported in mango and pineapple (Tedjo et al., 2002; Rastogi \& Niranjan, 1998). Conversely, no textural effect of adding PME on OD unripe mango was observed $(P>0.05)$, Figs. 4.7a and 4.8a. In the presence of calcium, ripe mango of all 
treatments showed a more pronounced firming effect with added PME. Similar firming effects of VI with calcium and PME were also obtained in other pectin containing fruits such as papaya and apple (Yang et al., 2017; Guillemin et al., 2008). The effect of added PME on textural attributes might be enhanced by increasing the concentration of added PME and calcium to result in more pectin-calcium gels in the tissue.
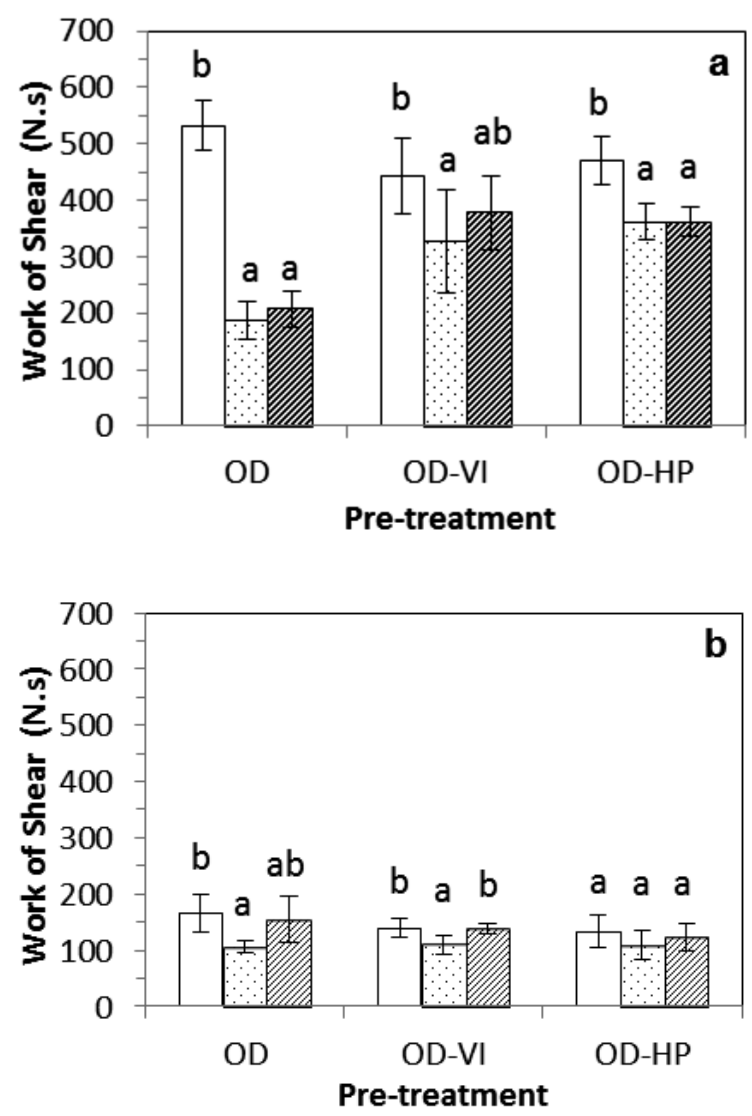

Fig. 4.8. Work of shear of fresh and $4 \mathrm{~h}$ OD mango of different pretreatments: (a) unripe mango; (b) ripe mango. Means with the same lower case letter within similar pretreatment did not differ significantly at $\mathrm{p}<0.05$ ( $\square$ Fresh; $\square$ No PME; $\mathrm{PME}$ ). 


\subsection{Conclusions}

Osmodehydrated unripe mango resulted in a remarkable two to five-fold higher SSG compared to ripe mango for all treatments. Unripe mango pretreated with OD-VI had the lowest WL and the highest SSG, while OD-HP had a similar but less pronounced effect. Fungal PME addition increased OD efficiency for OD-HP and OD-VI of ripe mango. Generally, $h^{*}$ were preserved and $C^{*}$ were maintained or only slightly increased in both ripeness in all treatments. Nevertheless, $L^{*}$ values of OD-VI unripe mango were greatly reduced and became similar to fresh ripe mango. A general trend in increasing firmness and WOS with added PME in OD unripe and ripe mango was observed.

This study thus demonstrates that using different ripeness of mango resulted in different quality of OD mango upon pretreatments in the presence of calcium. The observed effects of $\mathrm{VI}$ and $\mathrm{HP}$ applied to unripe and ripe mango are valuable to tailor OD efficiency and achieve the desired quality of OD mango. Two contrasting product of OD mango from this study could be candied mango and OD mango with minimal sugar uptake. For candied mango, it is favorable to use unripe mango and apply ODHP without PME to result in high SSG, the lowest $W L$, and $W R$, while minimizing color changes and maintaining fresh-like texture. To produce OD mango with minimal sugar uptake, it is favorable to use ripe mango and apply OD without PME to result in the lowest SSG and fresh-like $C^{*}$ and $h^{*}$ values as well as texture.

\section{Acknowledgements}

I. Sulistyawati received $\mathrm{PhD}$ scholarship from the Directorate General of Resources for Science, Technology and Higher Education, Indonesia (DIKTI) [grant number 391/E4.4/K/2014]. The authors appreciated Nature's Pride The Netherlands for providing the mango; Guizhao Hu, Peter van Grunsven, José Luis Ordóñes Alarcón and Yu Shen for the laboratory assistance. All authors report no conflict of interest. 


\section{References}

Ahmed, I., Qazi, I. M., \& Jamal, S. (2016). Developments in osmotic dehydration technique for the preservation of fruits and vegetables. Innovative Food Science and Emerging Technologies, 34, 29-43.

Altendorf, S. (2017). Global Prospects for Major Tropical Fruits: Short-term Outlook, Challenges and Opportunities in a Vibrant Global Marketplace. Food Outlook: Biannual Report on Global Food Markets. Rome: FAO Trade and Markets Division.

Brecht, J. K., \& Yahia, E. M. (2009). Postharvest Physiology. In R. E. Litz (Ed.), The mango: botany, production and uses. (pp. 484-528). Wallington, UK: CABI Publishing.

Brummell, D. A. (2006). Cell wall disassembly in ripening fruit. Functional Plant Biology, 33, 103-119.

Cantre, D., Herremans, E., Verboven, P., Ampofo-Asiama, J., \& Nicolaï, B. (2014). Characterization of the 3-D microstructure of mango (Mangifera indica L. cv. Carabao) during ripening using X-ray computed microtomography. Innovative Food Science and Emerging Technologies, 24, 28-39.

Chiralt, A., \& Fito, P. (2003). Transport Mechanisms in Osmotic Dehydration: The Role of the Structure. Food Science and Technology International, 9, 179186.

Ciurzyńska, A., Kowalska, H., Czajkowska, K., \& Lenart, A. (2016). Osmotic dehydration in production of sustainable and healthy food. Trends in Food Science and Technology, 50, 186-192.

Corrêa, J. L. G., Pereira, L. M., Vieira, G. S., \& Hubinger, M. D. (2010). Mass transfer kinetics of pulsed vacuum osmotic dehydration of guavas. Journal of Food Engineering, 96, 498-504.

de Heij, W. B., Van Schepdael, L., Moezelaar, R., Hoogland, H., Matser, A. M., \& van den Berg, R. W. (2003). High-pressure sterilization: maximizing the benefits of adiabatic heating. Food Technology, 57, 37-41.

Deng, Y., \& Zhao, Y. (2008). Effects of pulsed-vacuum and ultrasound on the osmodehydration kinetics and microstructure of apples (Fuji). Journal of Food Engineering, 85, 84-93. 
Dermesonlouoglou, E. K., Varvara, A., Zacharias, A., Katsaros, G. J., Giannakourou, M. C., \& Taoukis, P. S. (2017). The hurdle effect of osmotic pretreatment and high-pressure cold pasteurisation on the shelf-life extension of fresh-cut tomatoes. International Journal of Food Science \& Technology, 52, 916-926.

Duvetter, T., Fraeye, I., Sila, D. N., Verlent, I., Smout, C., Clynen, E., et al. (2006). Effect of temperature and high pressure on the activity and mode of action of fungal pectin methyl esterase. Biotechnology Progress, 22, 1313-1320.

Fito, P., Chiralt, A., Barat, J. M., Andrés, A., Martínez-Monzó, J., \& MartínezNavarrete, N. (2001). Vacuum impregnation for development of new dehydrated products. Journal of Food Engineering, 49, 297-302.

Giraldo, G., Talens, P., Fito, P., \& Chiralt, A. (2003). Influence of sucrose solution concentration on kinetics and yield during osmotic dehydration of mango. Journal of Food Engineering, 58, 33-43.

Guillemin, A., Guillon, F., Degraeve, P., Rondeau, C., Devaux, M.-F., Huber, F., et al. (2008). Firming of fruit tissues by vacuum-infusion of pectin methylesterase: visualisation of enzyme action. Food Chemistry, 109, 368378.

Hanemann, P., Velez, Julian, Arnoldus, Michiel. (2017). Fruit Company Assessments for Exporting to U.S. Market West Africa Trade and Investment Hub. Arlington, Virginia: J.E. Austin Associates, Inc.

Igual, M., Castelló, M. L., Ortolá, M. D., \& Andrés, A. (2008). Influence of vacuum impregnation on respiration rate, mechanical and optical properties of cut persimmon. Journal of Food Engineering, 86, 315-323.

Ito, A. P., Tonon, R. V., Park, K. J., \& Hubinger, M. D. (2007). Influence of process conditions on the mass transfer kinetics of pulsed vacuum osmotically dehydrated mango slices. Drying Technology, 25, 1769-1777.

Moraga, M. J., Moraga, G., Fito, P. J., \& Martínez-Navarrete, N. (2009). Effect of vacuum impregnation with calcium lactate on the osmotic dehydration kinetics and quality of osmodehydrated grapefruit. Journal of Food Engineering, 90, 372-379.

Muda, P., Seymour, G., Errington, N., \& Tucker, G. (1995). Compositional changes in cell wall polymers during mango fruit ripening. Carbohydrate Polymers, 26, 255-260. 
Nuñez-Mancilla, Y., Perez-Won, M., Vega-Gálvez, A., Arias, V., Tabilo-Munizaga, G., Briones-Labarca, V., et al. (2011). Modeling mass transfer during osmotic dehydration of strawberries under high hydrostatic pressure conditions. Innovative food science \& emerging technologies, 12, 338-343.

Oey, I., Lille, M., Van Loey, A., \& Hendrickx, M. (2008). Effect of high-pressure processing on colour, texture and flavour of fruit- and vegetable-based food products: A review. Trends in Food Science and Technology, 19, 320-328.

Rastogi, N., Raghavarao, K. S. M. S., Balasubramaniam, V. M., Niranjan, K., \& Knorr, D. (2007). Opportunities and challenges in high pressure processing of foods. Critical Reviews in Food Science and Nutrition, 47, 69-112.

Rastogi, N. K., \& Niranjan, K. (1998). Enhanced mass transfer during osmotic dehydration of high pressure treated pineapple. Journal of Food Science, 63, 508-511.

Rastogi, N. K., Raghavarao, K. S. M. S., Niranjan, K., \& Knorr, D. (2002). Recent developments in osmotic dehydration: methods to enhance mass transfer. Trends in Food Science and Technology, 13, 48-59.

Ribeiro, S. M. R., Schieber, A., \& Preedy, V. R. (2010). Bioactive compounds in mango (Mangifera indica L.). In R. R. Watson \& V. R. Preedy (Eds.), Bioactive foods in promoting health (pp. 507-523). London: Academic Press.

Rincon, A., \& Kerr, W. L. (2010). Influence of osmotic dehydration, ripeness and frozen storage on physicochemical properties of mango. Journal of Food Processing and Preservation, 34, 887-903.

Seguí, L., Fito, P. J., \& Fito, P. (2012). Understanding osmotic dehydration of tissue structured foods by means of a cellular approach. Journal of Food Engineering, 110, 240-247.

Shi, J., \& Xue, J. (2009). Application and development of osmotic dehydration technology in food processing. In C. Ratti (Ed.), Advances in food dehydration (pp. 187-208). Boca Raton, FL: CRC Press.

Sila, D. N., Duvetter, T., De Roeck, A., Verlent, I., Smout, C., Moates, G. K., et al. (2008). Texture changes of processed fruits and vegetables: potential use of high-pressure processing. Trends in Food Science and Technology, 19, 309-319. 
Sila, D. N., Smout, C., Vu, T. S., \& Hendrickx, M. E. (2004). Effects of high-pressure pretreatment and calcium soaking on the texture degradation kinetics of carrots during thermal processing. Journal of Food Science, 69, 205-211.

Silva, K. S., Fernandes, M. A., \& Mauro, M. A. (2014a). Effect of calcium on the osmotic dehydration kinetics and quality of pineapple. Journal of Food Engineering, 134, 37-44.

Silva, K. S., Fernandes, M. A., \& Mauro, M. A. (2014b). Osmotic dehydration of pineapple with impregnation of sucrose, calcium, and ascorbic acid. Food and Bioprocess Technology, 7, 385-397.

Sirijariyawat, A., Charoenrein, S., \& Barrett, D. M. (2012). Texture improvement of fresh and frozen mangoes with pectin methylesterase and calcium infusion. Journal of the Science of Food and Agriculture, 92, 2581-2586.

Tedjo, W., Taiwo, K. A., Eshtiaghi, M. N., \& Knorr, D. (2002). Comparison of pretreatment methods on water and solid diffusion kinetics of osmotically dehydrated mangos. Journal of Food Engineering, 53, 133-142.

Torreggiani, D. (1993). Osmotic dehydration in fruit and vegetable processing. Food Research International, 26, 59-68.

Torreggiani, D., \& Bertolo, G. (2004). Present and future in process control and optimization of osmotic dehydration. From unit operation to innovative combined process: An overview. Advances in Food and Nutrition Research, 48, 173-238.

Torres, J. D., Talens, P., Escriche, I., \& Chiralt, A. (2006). Influence of process conditions on mechanical properties of osmotically dehydrated mango. Journal of Food Engineering, 74, 240-246.

Van Buggenhout, S., Sila, D. N., Duvetter, T., Van Loey, A., \& Hendrickx, M. (2009). Pectins in processed fruits and vegetables: Part III - Texture engineering. Comprehensive Reviews in Food Science and Food Safety, 8, 105-117.

Verma, D., Kaushik, N., \& Rao, P. S. (2014). Application of High Hydrostatic Pressure as a Pretreatment for Osmotic Dehydration of Banana Slices (Musa cavendishii) Finish-Dried by Dehumidified Air Drying. Food and Bioprocess Technology, 7, 1281-1297.

Yang, H., Wu, Q., Ng, L. Y., \& Wang, S. (2017). Effects of Vacuum Impregnation with Calcium Lactate and Pectin Methylesterase on Quality Attributes and 
Chelate-Soluble Pectin Morphology of Fresh-Cut Papayas. Food and Bioprocess Technology, 10, 901-913.

Yashoda, H. M., Prabha, T. N., \& Tharanathan, R. N. (2005). Mango ripeningchemical and structural characterization of pectic and hemicellulosic polysaccharides. Carbohydrate Research, 340, 1335-1342.

Yashoda, H. M., Prabha, T. N., \& Tharanathan, R. N. (2006). Mango ripening: changes in cell wall constituents in relation to textural softening. Journal of the Science of Food and Agriculture, 86, 713-721.

Yashoda, H. M., Prabha, T. N., \& Tharanathan, R. N. (2007). Mango ripening - Role of carbohydrases in tissue softening. [Food Chemistry]. Food Chemistry, 102, 691-698. 


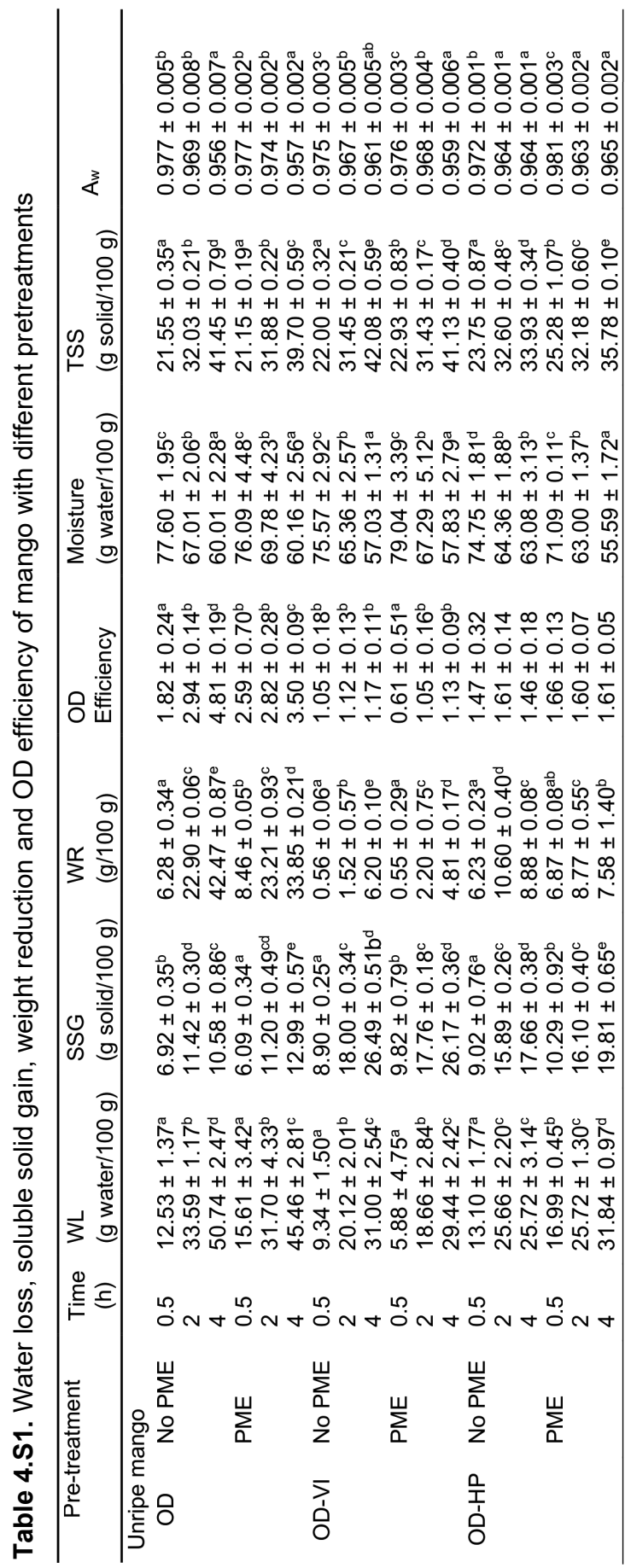




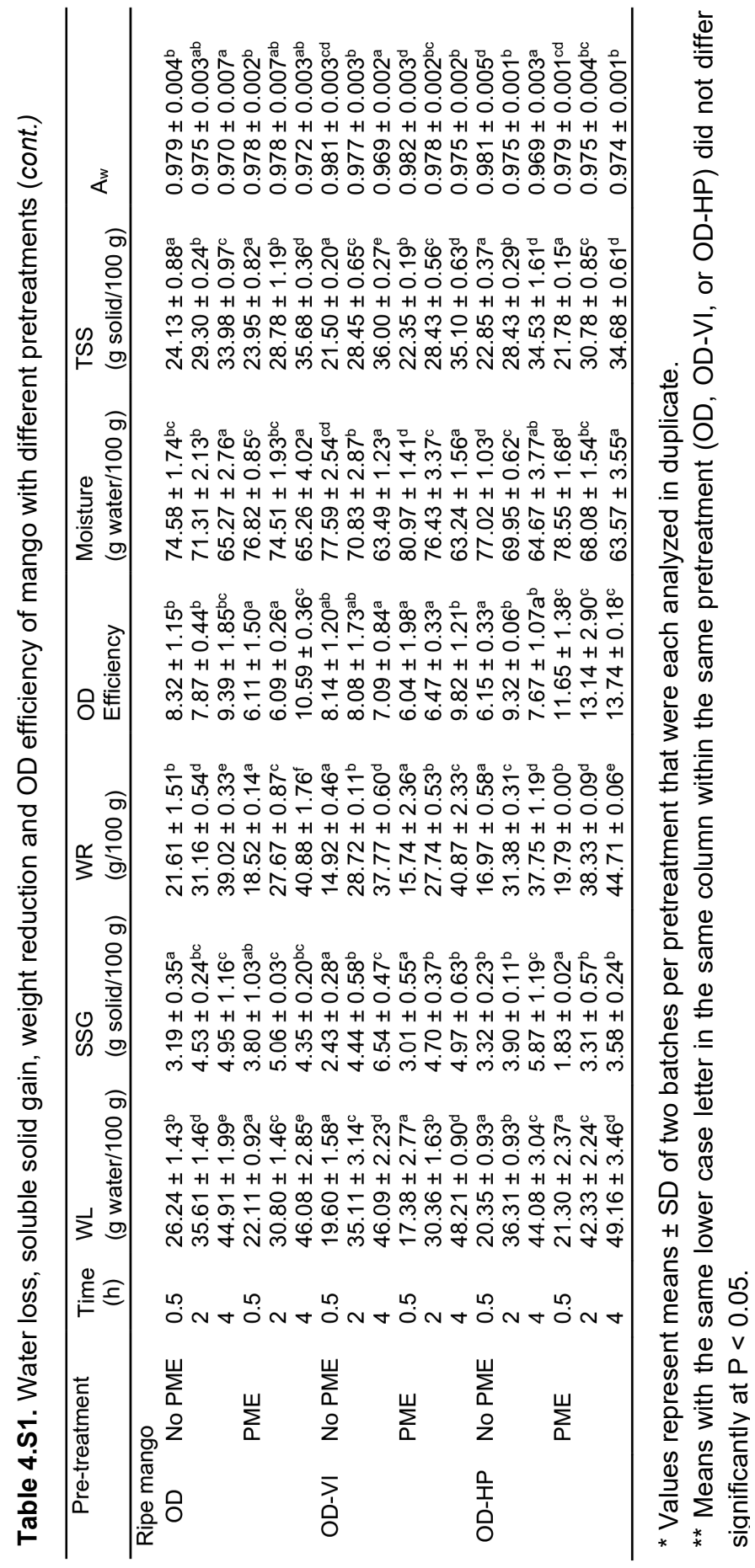




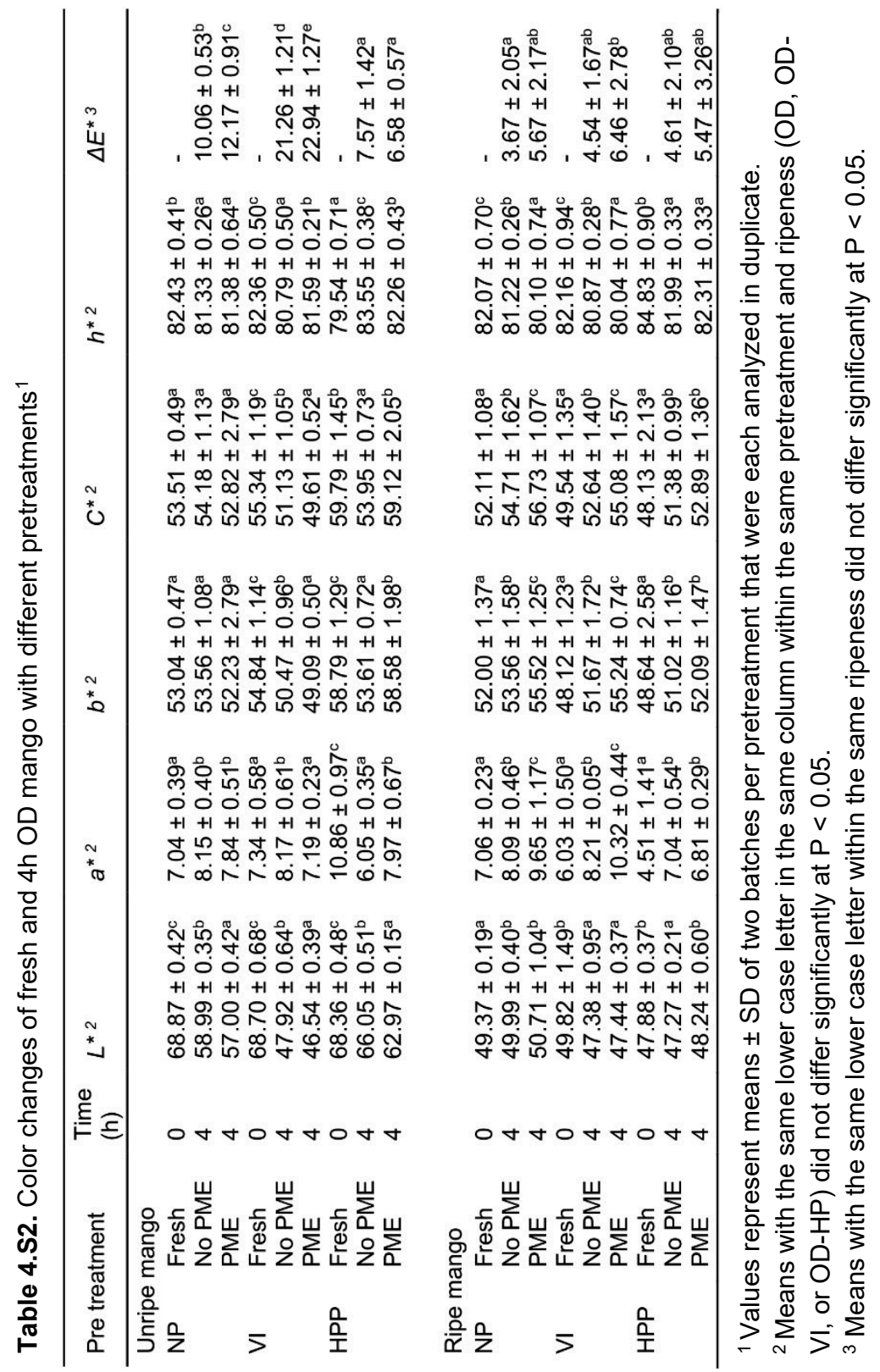





\section{Chapter 5}

Modelling the kinetics of osmotic dehydration of mango: optimizing process conditions and pre-treatment for health aspects

\section{Published as:}

Sulistyawati, I., Verkerk, R., Fogliano, V., \& Dekker, M. (2020). Modelling the kinetics of osmotic dehydration of mango: optimizing process conditions and pre-treatment for health aspects. Journal of Food Engineering, 280, 109985 



\begin{abstract}
The kinetics of mass transfer and vitamin C loss in mango during osmotic dehydration (OD) were described by mathematical models. Water loss (WL) and weight reduction (WR) was modelled by Weibull's model, soluble solid gain (SSG) was better described by Peleg's model. Vitamin C loss was described by a multiresponse model incorporating both degradation and leaching processes into the OD-solution. Effects of vacuum impregnation (VI) and pectin methylesterase (PME) addition on the model parameters were evaluated. VI increases SSG indicated by a $55 \%$ lower value of $k_{2}$ in the Peleg model $(P<0.05)$. PME addition showed no significant effect on the mass transfer kinetics. The major mechanism of vitamin $\mathrm{C}$ loss during OD was degradation. The pretreatments have no significant effect on degradation and leaching rate constants of vitamin $\mathrm{C}$. The combination of modelling the mass transfer and vitamin $C$ retention was shown to be valuable in optimizing the OD process design to enhance the health-promoting value of OD mango (sugar content, vitamin C) and processing time.
\end{abstract}

Keywords: Vacuum impregnation; Mass transfer; Ascorbic acid; Kinetic modelling; Multiresponse model

\title{
5.1. Introduction
}

Mango (Mangifera indica L.) ranks second among tropical fruits in global market after banana (Altendorf, 2017). The fruit is an important source of vitamin C (between 9.79 and $186 \mathrm{mg} / 100 \mathrm{~g}$ edible portion due to different varieties, and growing conditions) and it is rich in various phytochemicals, including carotenoids and phenolic compounds (Ribeiro et al., 2010). Along with fresh mango's trade expansion, the global demand for minimally processed mango products has been increasing (Hanemann, 2017). These mild treated products feature an extended shelf-life with fresh-like characteristics, while maintain a high nutritional and health-promoting value (Ciurzyńska et al., 2016).

New product design of dehydrated fruit range from the direct consumption as snacks to its use as ingredients in various foods such as dairy, breakfast cereals and confectionery products, e.g., Betoret et al. (2003); Talens et al. (2012); Threlfall et al. 
(2007). Different dehydration technologies like vacuum impregnation and osmotic dehydration $(O D)$ can be tailored to obtain these products. Over recent years, OD has received much appraisal from researchers as a minimal processing operation (Ahmed et al., 2016; Ciurzyńska et al., 2016; Ramya and Jain, 2017). OD is a mass transfer process involving immersion of fruit pieces in an OD-solution, which is a hyperosmotic solution inducing partial water removal from the tissue and soluble solid uptake in the tissue (Torreggiani, 1993), as illustrated in Fig. 5.1. Its application can precede drying or freezing and contributes to creating new and less perishable fruit products with health-promoting, nutritional and sensory properties (Ciurzyńska et al., 2016). Therefore, OD application should aim for a healthier OD fruit with a low soluble solid uptake and a high retention of nutrients. However, with a given fruit material, health quality of the products can be affected by the setting of OD process variables, e.g., pretreatments, temperature, additives, and time (Ahmed et al., 2016).

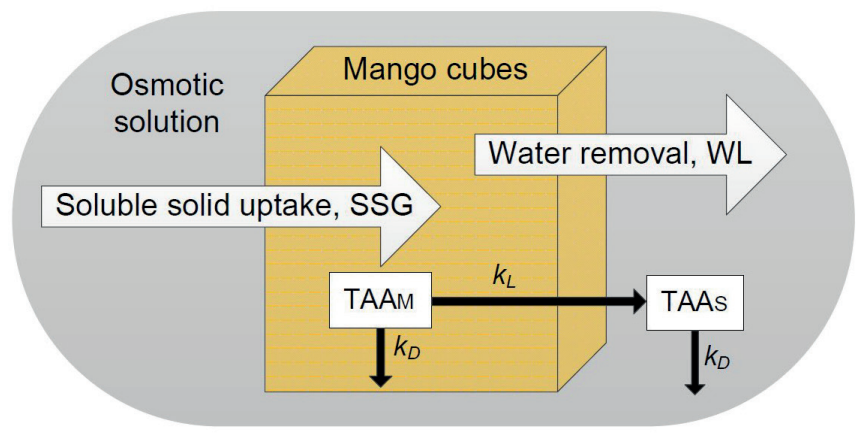

Fig. 5.1. Mass transfer of fruit during osmotic dehydration, e.g., mango cubes. TAAM - Total Ascorbic Acid content in mango, TAAs - Total Ascorbic Acid content in the OD-solution, $k_{D}$ degradation rate constant, $k L$ - leaching rate constant.

Due to a complex microstructure of a plant tissue, the OD should be explained as a process where several other mechanisms influence mass transfer (Chiralt and Fito, 2003). Right after a fruit tissue is immersed in OD-solution, the initial capillary pressure induced a flux of OD-solution into voids in the tissue (Seguí et al., 2012). During OD, three other mechanisms simultaneously occur: (i) cell dehydration caused by $a_{w}$ gradients; both (ii) soluble solid diffusion and (iii) deformed cell impregnation caused by cellular volume changes. In addition to the mass transfer, due to the viscoelastic properties of the cells, a structural shrinkage and relaxation 
also occur simultaneously; however, they have different rates (Oliver et al., 2012). Application of vacuum impregnation $(\mathrm{VI})$ prior to $\mathrm{OD}$, hereafter called OD-VI shows mass transfer kinetics (Fito and Chiralt, 1995; Fito et al., 2001). During OD-VI, the capillary impregnation and vacuum-induced impregnation concurrently occur. Both impregnations expand internal gas in pores triggering the gas partially flowing out of the pores (when vacuum is applied) and followed by compression sucking in the ODsolution into the pores (Chiralt and Fito, 2003).

A mild temperature $\left(30-50^{\circ} \mathrm{C}\right)$ applied during $O D$ result in tissue modification without damaging the fruit structure (Shi and Xue, 2009) and low thermal degradation of nutrients (Ciurzyńska et al., 2016). Previous studies has been reported that application of texturizing agents during $O D$ can enhance product firmness, e.g. calcium salts (Silva et al., 2014) or pectin methylesterase (PME) (Guillemin et al., 2008), or both agents (Sirijariyawat et al., 2012). The firmness enhancement by these agents can be augmented by OD-VI (Sirijariyawat et al., 2012). Nevertheless, during immersion of the fruit in OD-solution, water-soluble nutrients will partially leach from the tissue, such as vitamin $\mathrm{C}$, and phenolic compounds (Nowacka et al., 2018; Peiró et al., 2006).

Retention of nutrients in dehydrated plant material, e.g., by OD is generally inferred from the extent of vitamin C retention (Nowacka et al. (2018); Nuñez-Mancilla et al. (2013); Oladejo et al. (2017)). In literature conflicting results on leaching of vitamin $\mathrm{C}$ into the OD-solution have been reported; it has been considered as not relevant since some authors found it as a minor cause of vitamin C loss (Alam et al., 2010). Meanwhile other studies report significant amounts of vitamin $C$ appear in the reuse of OD-solutions, e.g., Germer et al. (2016); Moraga et al. (2011); Peiró et al. (2006)). Most OD studies addressed vitamin $C$ degradation kinetics without including the leaching mechanism, e.g., Alam et al. (2010); Dermesonlouoglou et al. (2016). This study aims to model the kinetics of mass transfer and vitamin $C$ loss during osmotic dehydration of mango and the effect of vacuum impregnation as pre-treatment and addition of PME on the model parameters, to contribute to optimizing process design towards maintaining health-promoting value of OD mango (i.e., optimum sugar content and vitamin C). 


\subsection{Materials and methods}

\subsubsection{Fruit material}

Ripe mango (Mangifera indica L. CV. Kent) fruit originated from Brazil was purchased from Bakker Barendrecht B.V. (Ridderkerk, The Netherlands), stored at $11^{\circ} \mathrm{C}$ - to prolong mango's shelf life (Tharanathan et al., 2006) - and used within four days after arrival. Mango was selected based on firmness (Table 5.1), then cut into cubes approximately $1.2 \mathrm{~cm} \times 1.2 \mathrm{~cm} \times 1.2 \mathrm{~cm}$ (Sulistyawati et al., 2018), mixed and kept on ice prior to treatment.

Table 5.1 Characteristics of mango samples

\begin{tabular}{lll}
\hline Characteristics & Ripe mango batch 1 & Ripe mango batch 2 \\
\hline Average weight $(\mathrm{g})^{1}$ & $678.2 \pm 71.3$ & $482 \pm 25.2$ \\
${\text { Firmness }(\mathrm{kg})^{1}}^{\text {Total soluble solid }\left({ }^{\circ} \text { Brix }\right)^{2}}$ & $2.9 \pm 0.6$ & $2.6 \pm 0.5$ \\
Titratable acidity $(\% \text { citric acid })^{2}$ & $13.0 \pm 0.9$ & $12.4 \pm 3.9$ \\
Moisture $(\%)^{2}$ & $0.69 \pm 0.08$ & $0.69 \pm 0.08$ \\
$\mathrm{pH}$ & $85.8 \pm 1.8$ & $83.6 \pm 1.82$ \\
Number of mangoes used & $4.67 \pm 0.7$ & $3.97 \pm 0.1$ \\
\hline
\end{tabular}

All physicochemical analyses were carried out based on Sulistyawati et al. (2018).

${ }^{1}$ Values represent mean \pm SD of all selected mango within the same ripeness.

${ }^{2}$ Values represent mean $\pm S D$ of two batches per pretreatment that were each analyzed in duplicate.

Pectin methylesterase (PME) from a recombinant Aspergillus oryzae (Novoshape ${ }^{\circledR}$ Novozymes, Denmark) and calcium-L-lactate pentahydrate (Merck KGaA, Darmstadt, Germany) were used. OD-solutions were prepared with commercial sucrose in demineralized water.

\subsubsection{Pretreatment and osmotic dehydration}

Osmotic dehydration (OD) was carried out at atmospheric pressure and in combination with a vacuum impregnation (OD-VI) according to Sulistyawati et al. (2018). Mango cubes (250 g) were immersed in $1 \mathrm{~L} \mathrm{OD-solution} \mathrm{of} 60^{\circ}$ Brix sucrose, $2 \%$ calcium lactate and 0 or $0.48 \% \mathrm{PME}$ at $50{ }^{\circ} \mathrm{C}$ for $0-29 \mathrm{~h}$ under continuous stirring.

$\mathrm{VI}$ was carried out at $30{ }^{\circ} \mathrm{C}$ in a vacuum chamber at $5 \mathrm{kPa}$ for 15 minutes and 10 minutes pressure recovery (Fito and Chiralt, 1995). Samples for water and soluble solid analyses were kept at $4{ }^{\circ} \mathrm{C}$, and samples for vitamin $\mathrm{C}$ analysis were frozen 
into liquid nitrogen and kept at $-20^{\circ} \mathrm{C}$ prior to analysis (Olivares-Tenorio et al., 2017). The experimental setup of this study is shown in Fig. 5.2, in which each treatment was done with two independent batches.

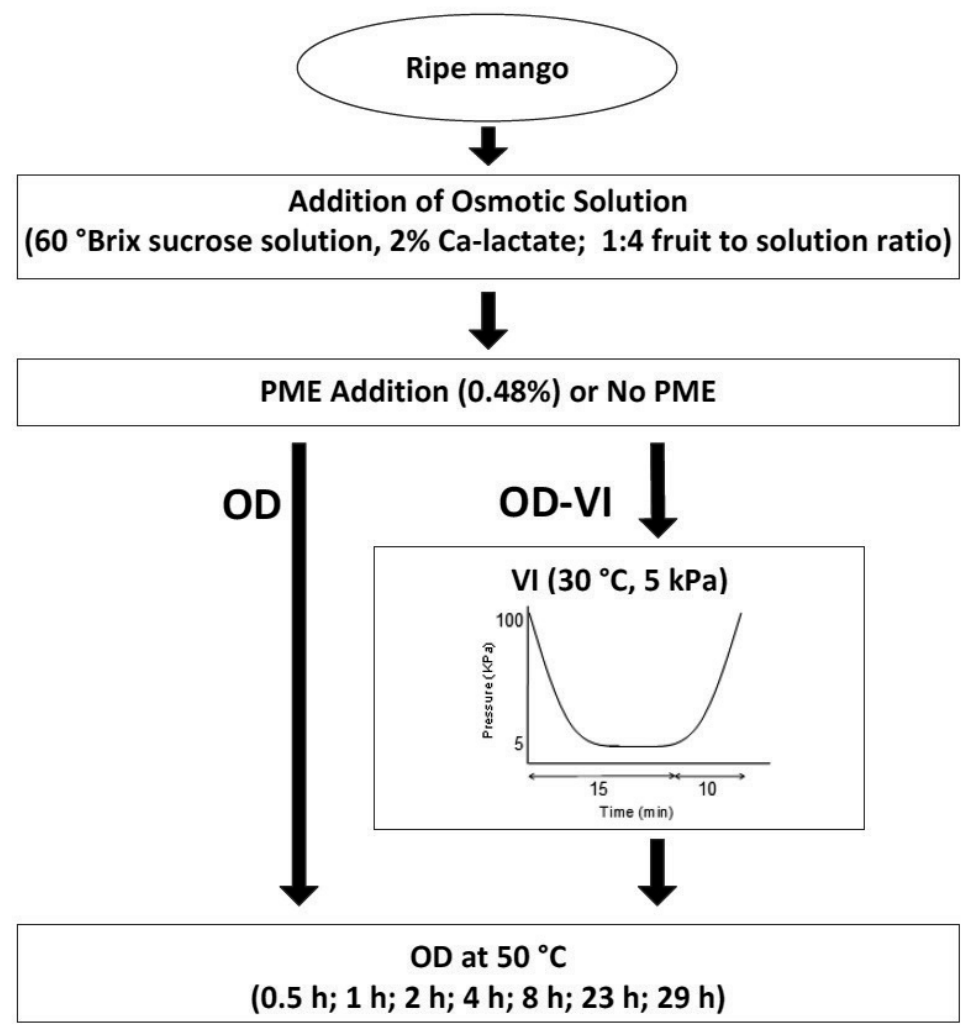

Fig. 5.2. Experimental setup for osmotic dehydration treatment (OD) of mango cubes treated with vacuum impregnation (VI) and pectin methylesterase (PME) (Sulistyawati et al., 2018).

Weight reduction (WR), water loss (WL) and soluble solids gain at time $t$ (SSG) were determined according to Sulistyawati et al. (2018) and were described using the equations:

$\Delta M_{t}=\frac{\left(M_{t}-M_{0}\right)}{M_{0}}$

$\Delta M_{t}^{W}=\frac{\left(M_{t}\right)\left(x_{t}^{W}\right)-\left(M_{0}\right)\left(x_{0}^{W}\right)}{M_{0}}$

$\Delta M_{t}^{S S G}=\frac{\left(M_{t}\right)\left(x_{t}^{S S G}\right)-\left(M_{0}\right)\left(x_{0}^{S S G}\right)}{M_{0}}$ 
Where $\Delta$ is the weight difference of component at time $t, M$ is the weight of sample $(\mathrm{g})$ and $x$ is the initial mass fraction of component $(\mathrm{g} / \mathrm{g})$, subscript $t$ refers to time and 0 to $t=0$ and superscript $W$ to water and $S S G$ to soluble solids.

\subsubsection{Vitamin $\mathrm{C}$ analysis}

\subsubsection{Sample preparation}

Frozen mango and OD-solution samples were freeze dried (GRI Vriesdroger, GR Instruments B.V., Wijk bij Duurstede, the Netherlands) connected to a two-stages vacuum pump (E2M18, Edward $\AA$, Crawley, UK) to a constant weight. Thereafter, samples were milled in liquid nitrogen (IKA A11 basic; IKA-Werke $\mathrm{GmbH}$, Staufen, Germany) and kept at $-20^{\circ} \mathrm{C}$ for vitamin $\mathrm{C}$ analysis.

\subsubsection{Measurement of vitamin C}

Vitamin $C$ was expressed as the Total Ascorbic Acid (TAA) content - includes two biologically active forms, which are ascorbic acid and its oxidized form, dehydroascorbic acid - and was determined according to Hernández et al. (2006) with modifications, using an HPLC system (a thermo separation products model with P-2000 Binary Gradient Pump and UV 2000 detector), see Supplementary data 5.1. Each sample was measured in duplicate - for mango and OD-solution samples and then was averaged to get one data set per batch (Olivares-Tenorio et al., 2017). Results were expressed in $\mathrm{mg}$ total ascorbic acid $100 \mathrm{~g}^{-1}$ fresh weight (FW).

\subsubsection{Kinetics modelling}

\subsubsection{Modelling of mass transfer}

In literature mainly empirical models have been applied on modelling the mass transfer in OD, the most widely applied models are the Peleg, Azuara, Page and Weibull model (Assis et al., 2017). These existing models are briefly described as the following.

Peleg Model. Peleg (1988) proposed a two-parameter sorption equation that can describe water loss (WL) and soluble solid gain (SSG) kinetics during OD: 
$x_{t}^{W}-x_{0}^{W}=-\frac{t}{k_{l}^{W}+k_{2}^{W} \cdot t}$

$x_{t}^{S S G}-x_{0}^{S S G}=+\frac{t}{k_{1}^{S S G}+k_{2}^{S S G} . t}$

with $x_{0}^{W}$ is the initial mass fraction of water $(\mathrm{g} / \mathrm{g}), x_{t}^{W}$ is the mass fraction of water at time $t(\mathrm{~g} / \mathrm{g}), x_{0}^{S S G}$ is the initial mass fraction of soluble solids $(\mathrm{g} / \mathrm{g})$ and $x_{t}^{S S G}$ is the mass fraction of soluble solids at time $t(\mathrm{~g} / \mathrm{g})$.

The water reduction (WR) kinetics was rewritten from the same Peleg's equation in the form:

$M_{t}-M_{0}=-\frac{t}{k_{1}+k_{2} \cdot t}$

where $M_{0}$ is the initial weight of sample $(\mathrm{g}), M_{t}$ is the weight of sample at time $t(\mathrm{~g})$.

The constant $k_{1}$ relates to the reciprocal of the rate of mass transfer and constant $k_{2}$ relates to the reciprocal of the equilibrium composition.

Azuara Model. Azuara et al. (1992) proposed a two-parameter model to estimate mass transfer coefficients and the equilibrium values:

$Y=\frac{\text { s.t. } Y_{\infty}}{1+\text { s.t }}$

Where $Y$ could be respectively: $W L$ or $S S G$ or $W R$. $Y_{\infty}$ indicates the respective $Y$ at equilibrium. $s$ is the rate parameter of the respective $Y$.

Weibull Model. The Weibull's model has been used to describe mass transfer coefficients and equilibrium values during OD (Cunha et al., 2001) by three parameters:

$$
Y=Y_{\infty}\left(1-\exp \left[-\left(\frac{t}{\tau}\right)^{\beta}\right]\right)
$$

where $Y$ could be respectively: $W L$ or $S S G$ or $W R$. $Y_{\infty}$ indicates the respective $Y$ at equilibrium. $\tau$ is the scale parameter related to the process rate, and $\beta$ is the shape parameter.

Page Model. Page (1949) proposed an empirical three-parameter model based on an exponential equation for mass transfer:

$Y=Y_{\infty}\left(1-\exp \left(-A \cdot t^{B}\right)\right)$ 
$A\left(\mathrm{~h}^{-1}\right)$ and $B$ are the Page's constants.

Although in literature these four models have been used to model OD, it is important to realize that the Peleg and Azuara model and the Page and Weibull model are mathematically identical. Therefore, the parameters of these models can be transformed into one another. In the Azuara model the Peleg's parameters can be expressed as: $k_{1}=1 /\left(s . Y_{\infty}\right)$ and $k_{2}=\left(1 / Y_{\infty}\right)$. While in the Page's model the Weibull's parameters can be expressed as: $\tau=1 / A^{-\beta}$ and $\beta=B$. Therefore, in this study, only the Peleg and Weibull models were considered for mass transfer.

\subsubsection{Modelling of vitamin C loss}

Vitamin C concentrations during OD was described by two mechanisms (1) leaching from mango cubes into the OD-solution; and (2) degradation of vitamin C (see Fig. $5.1)$.

In this study it was assumed that the leaching rate $r_{L}$ is proportional to the vitamin C concentration difference between mango $T A A_{M}$ and the OD-solution $T A A_{S}$ (Sarvan et al., 2012):

$r_{L}=k_{L} \cdot\left(T A A_{M}-T A A_{S}\right)$

The degradation rate of vitamin $\mathrm{C}$ in mango and in the $\mathrm{OS} r_{D}$ is described by a first order reaction (Dermesonlouoglou et al., 2016; Katsoufi et al., 2017):

$r_{D}=k_{D} \cdot T A A$

Vitamin $\mathrm{C}$ concentrations in time are described by combining the rate of leaching and that of degradation:

$\frac{d T A A_{M}}{d t}=-r_{L}-r_{D}$

$\frac{d T A A_{S}}{d t}=+r_{L} \cdot \frac{M_{M}}{M_{S}}-r_{D}$

Euler's method was used for the numerical integration of the two differential equations (12) and (13) (Butcher, 2016). 
For all models the parameters were estimated by minimizing the weighted residual sum of squares $S S_{\text {res }}$ between the data and model predictions (GRG Nonlinear algorithm) using Microsoft Excel 2010 Solver ${ }$.

\subsubsection{Statistical analysis}

Differences between the model parameters for the four OD treatments were evaluated using a two-way ANOVA (IBM SPSS Statistics version 23, Chicago, USA) with a confidence level of $95 \%$. Effects of $\mathrm{VI}$ and PME were evaluated by independent sample T-test. Statistical analysis of the model fits (SD values and correlation matrices of the parameter estimates) was done by using the 'SolverAid' macro (De Levie, 2004). Model discrimination was done by the corrected Akaike Information Criterion $\left(A I C_{C}\right)$ value (Hurvich and Tsai, 1995):

$A I C_{C}=n \ln \left(\widehat{\sigma}^{2}\right)+2(p+1) \frac{n}{n-p}$

where $n=$ the number of data, $p=$ the number of parameters, $\widehat{\sigma}^{2}=\left(S S_{\text {res }} / n\right)$ with $S S_{\text {res }}$ the residual sum of squares.

\subsection{Results and discussion}

\subsubsection{Mass transfer kinetics}

The observed WL, SSG, and WR for all treatments increased along with the osmotic dehydration time (Fig. 5.3). The Peleg and Weibull model showed a good fit of the data. Parameter standard deviations and parameter correlation coefficients were acceptable (<0.9). Since the two models had similar good fitting performances on mass transfer variables, a quantitative comparison using the Akaike Information Criterion $\left(A I C_{C}\right)$ was done (Table 5.2). The Weibull model was superior for $\mathrm{WL}$ and WR data while the Peleg model was better for the SSG. 


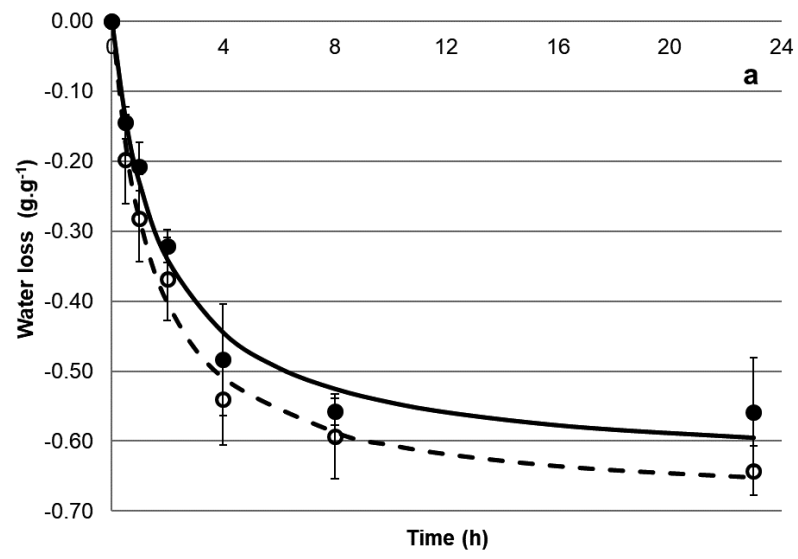

- OD Exp Data • OD-VI Exp Data - - OD Model —OD-VI Model

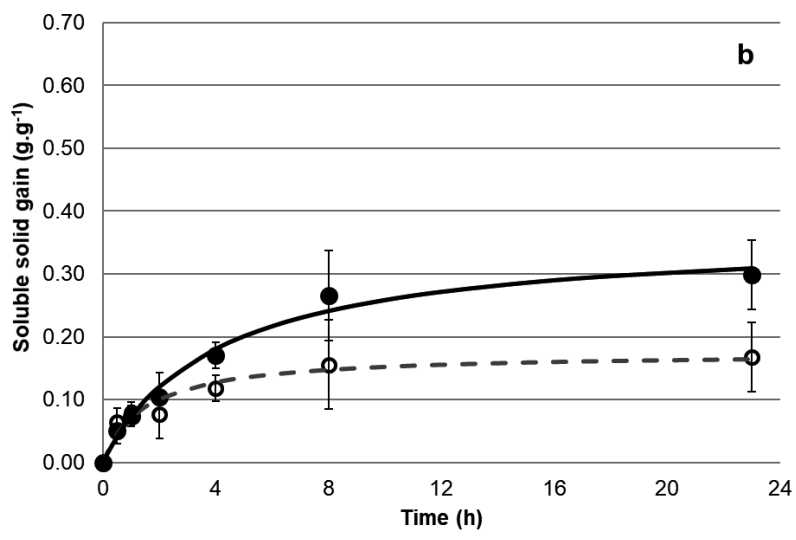

- OD Exp Data - OD-VI Exp Data - - OD Model —OD-VI Model

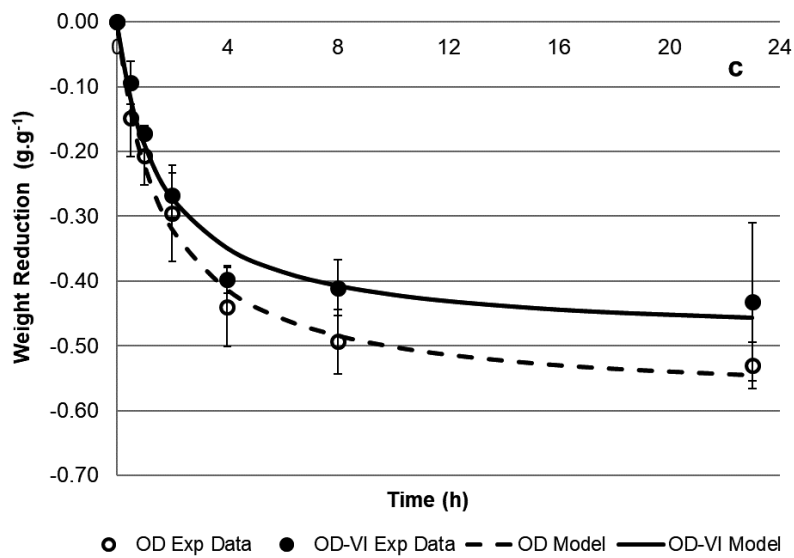

Fig. 5.3. Mass transfer of mango with different pretreatments during osmotic dehydration: (a) water loss, (b) soluble solid gain; (c) weight reduction. 
Table 5.2 Model discrimination of Peleg and Weibull models fitted to mass transfer $(n=14$ for each data set).

\begin{tabular}{lllllll}
\hline \multirow{2}{*}{ Model } & \multicolumn{2}{l}{$\begin{array}{l}\text { Sum of squares of residuals } \\
\left(S S_{\text {res }}\right)\end{array}$} & & & & \\
\cline { 2 - 7 } & Water & Soluble & Weight & Water & Soluble & Weight \\
& Loss & Solid Gain & Reduction & Loss & Solid Gain & Reduction \\
\hline Peleg $(p=2)$ & 0.004 & 0.001 & 0.003 & -91.51 & $\mathbf{- 1 0 7 . 4 3}$ & -95.26 \\
Weibull $(p=3)$ & 0.001 & 0.001 & 0.001 & $\mathbf{- 9 4 . 4 9}$ & -105.07 & $\mathbf{- 1 0 2 . 8 6}$ \\
$\Delta$ AIC $_{C}$ & - & - & - & 2.98 & 2.36 & 7.60 \\
\hline
\end{tabular}

Better $A I C_{C}$ values for each mass transfer variable are presented in bold.

Table 5.3 presents parameter values of the selected models for the OD mass transfer variables. A two-way ANOVA on the parameters of the mass transfer resulted in a significant effect of VI on $k_{2}$ values for SSG $(P<0.05)$ but no effect of PME or the interaction between $\mathrm{VI}$ and PME. The lacking effect of PME might be due to low pectin concentration of ripe mango - because of progressive depolymerization of pectin during ripening causing a significant decrease of pectin concentration (Prasanna et al., 2003; Yashoda et al., 2006) - which did not create sufficient calcium-pectin gels to affect the mass transfer kinetics. This result differed from Van Buggenhout et al. (2008) for OD strawberries who found that PME addition slightly decreased WR, which was correlated to a small increase of the SSG, although they did not model their data.

For WL and WR, applying VI resulted in an increase of shape-parameter $\beta$ associated with the mechanism of OD mass transfer -, but this increase was not significant $(P>0.05)$. In this study, the increasing $\beta$-values for $\mathrm{WL}$ by $\mathrm{VI}$ is in line with Assis et al. (2017) for OD of apple. However, Deng and Zhao (2008) found that pulse vacuum treatment reduced the $\beta$-value of WL for apple (0.46 vs 0.57 ). $\beta$ values for WL of OD-treated mango are in agreement with what was found by Khan et al. (2008). VI application did not change $\tau$ values for $\mathrm{WL}$ and WR $(P>0.05)$. For $\mathrm{WL}$, the estimated $\tau$-values - associated with the process rate - are similar to the values found in other OD studies, e.g., for mango and apple (Assis et al., 2017; Khan et al., 2008). 


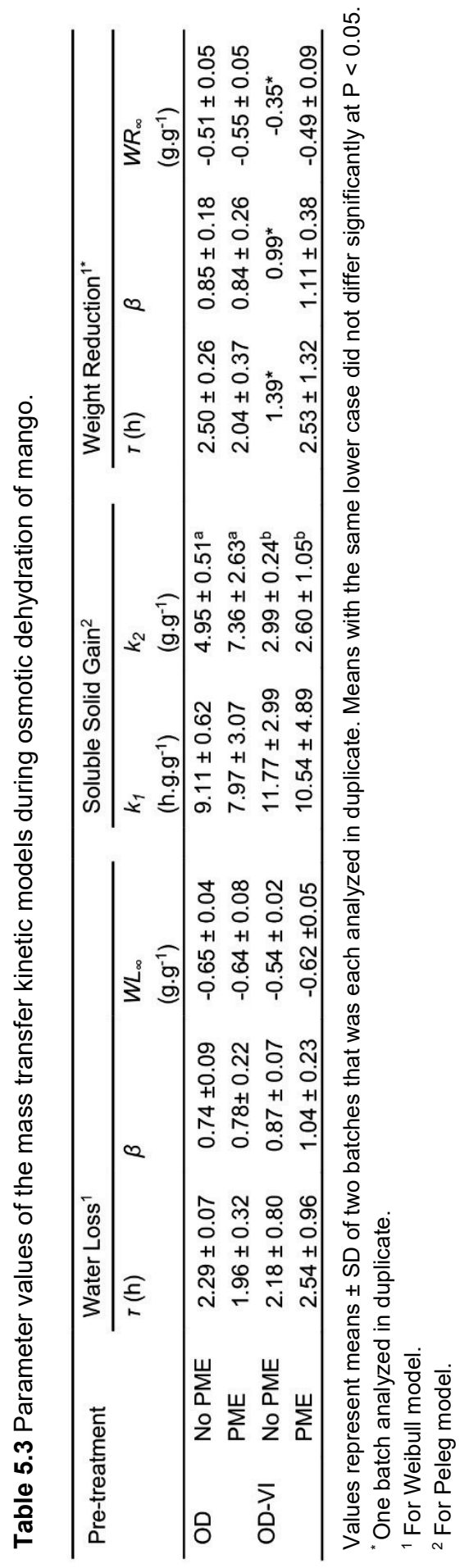


The equilibrium water loss $\left(W L_{\infty}\right)$ and weight reduction $\left(W R_{\infty}\right)$ values were similar in all treatments. The $W L_{\infty}$ of this study are in between those of Ganjloo et al. (2012) for OD of guava $\left(0.40-0.49 \mathrm{~g}^{-1}\right)$ and that of Mokhtarian et al. (2014) for pumpkin $\left(0.71-0.86 \mathrm{~g}^{-1} \mathrm{~g}^{-1}\right)$.

The $k_{1}$ values for SSG tends to increase by $\mathrm{VI}$ although they were not significantly different $(P>0.05)$ (Table 5.3), so VI did not significantly affect the initial mass transfer rate. These results could be explained by the fact that ripe mango has both a small pore size, porosity and number of pores (Cantre et al., 2014) which may cause no distinct effect of the imposed vacuum pressure in modifying the pore characteristics impregnating OD-solution into the tissue. The observed OD-VI results on SSG in this study differed from Lin et al. (2016) and Assis et al. (2017) who both found that VI significantly increased the initial rate of SSG in ripe mango and apple.

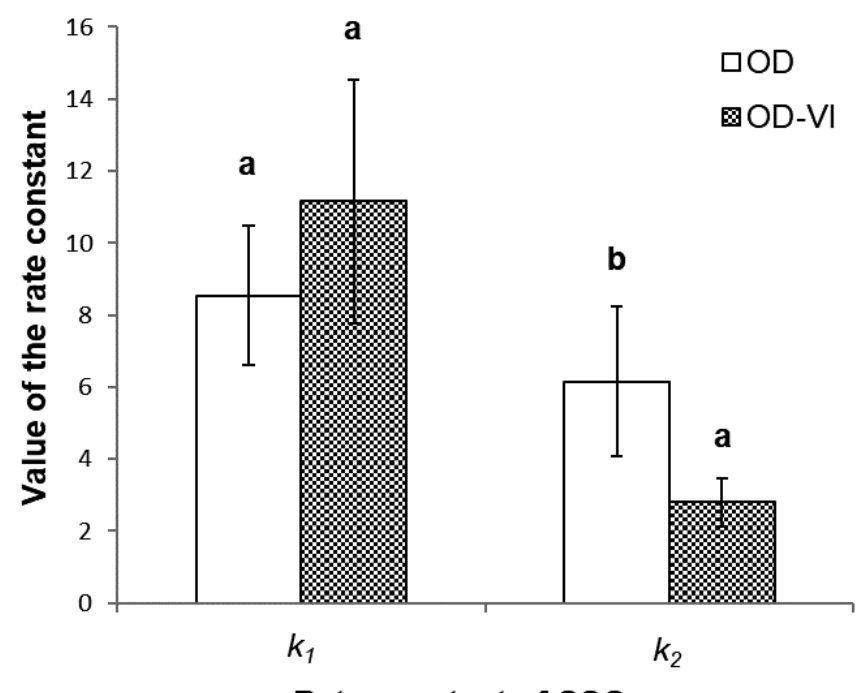

Fig. 5.4. Peleg parameters of soluble solid gain of mango during osmotic dehydration (different letters indicate significant differences $(P<0.05)$ for the parameter between pretreatments).

VI significantly increased the equilibrium of SSG (1/k2) two-fold, $P>0.05$ (Fig. 5.4). In the case of VI-treated mango, upon removal of some water the protoplast shrinks. 
This shrinkage causes retraction of protoplasm from the peripheral layers of the cell and/or detachment from the cell wall. Yet, deformation of the cell wall is scarce due to weaker interaction between cell wall and protoplast than that of OD-treated sample (Oliver et al., 2012). Consequently, cell filling (SSG) due to relaxation of cells and subsequent increase in total volume occurs at longer times throughout the equilibration time (Barat et al., 1999; Lin et al., 2016). This effect of VI on $k_{2}$ is also reported by Assis et al. (2017) for OD of apple.

\subsubsection{Kinetics of vitamin $C$ loss}

Applying Eqs. (10) and (11) for degradation and leaching of vitamin $C$ results in a continuous decrease of vitamin $C$ in mango and an initial increase in OD-solution followed by a decrease when degradation becomes more dominant than leaching (Fig. 5.5).

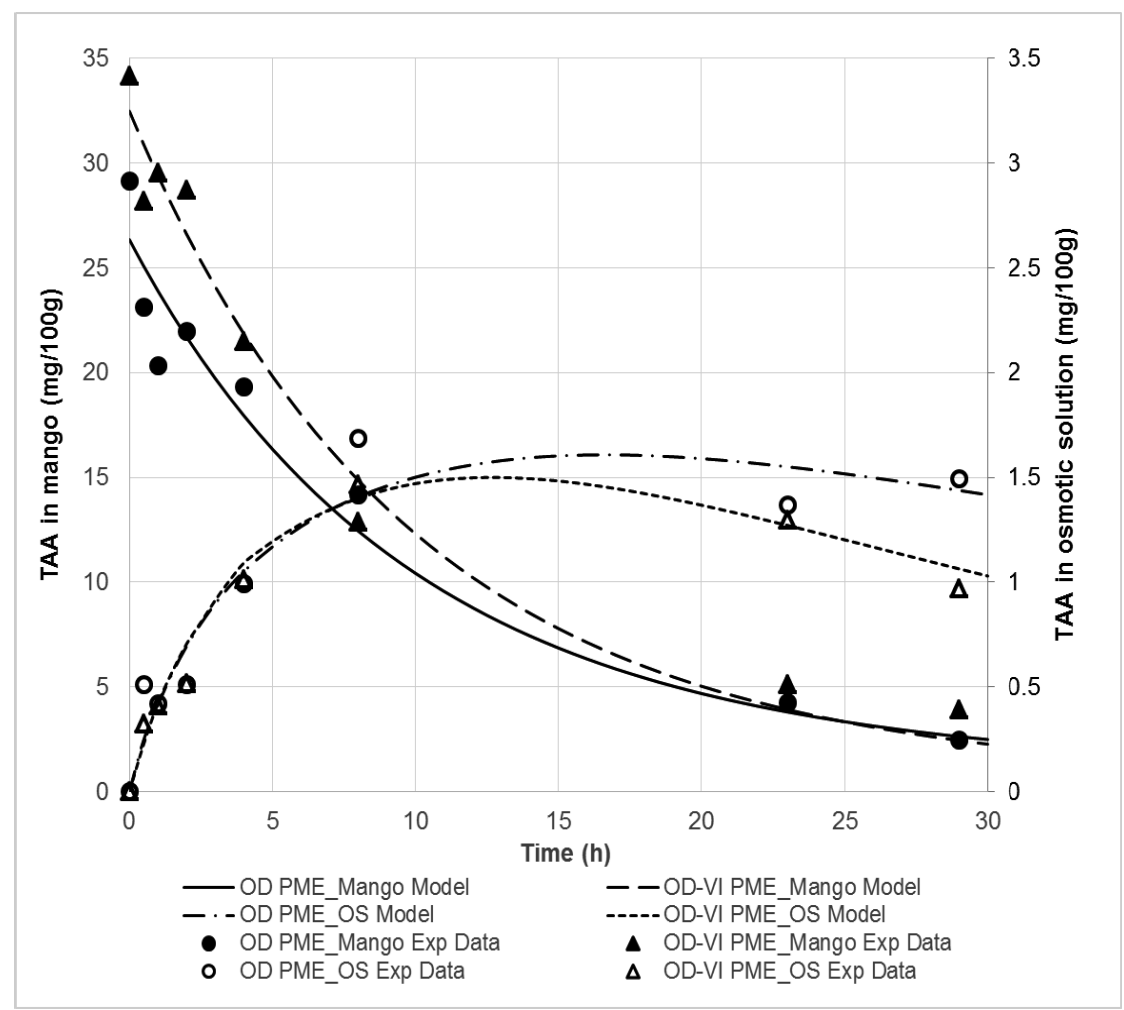

Fig. 5.5. Multiresponse modeling results of the total ascorbic acid loss in mango and ODsolution during osmotic dehydration: illustrated for OD with PME and OD-VI with PME. 
For all treatments, the multiresponse model fitted the observed data of mango and the OD-solution well (Fig. 5.5). Parameter standard deviations for some of the estimates were quite high, but parameter correlation coefficients were acceptable $(<0.9)$. see Table 5.4 .

Two way ANOVA showed no significant effects of VI, PME and their interaction on both $k_{L}$ and $k_{D}(\mathrm{P}>0.05)$. Although an effect of $\mathrm{VI}$ on OD during processing was not investigated, an OD study on frozen lotus root reported that applying VI gave higher vitamin $\mathrm{C}$ retention during storage at $-18^{\circ} \mathrm{C}$ (Song et al., 2017). Insignificant effect of adding PME in the presence of calcium on vitamin $\mathrm{C}$ loss was also found in an OD study on papaya (Germer et al., 2014).

Table 5.4 Parameter values of vitamin C loss during osmotic dehydration of mango with different treatments.

\begin{tabular}{|c|c|c|c|}
\hline \multicolumn{2}{|c|}{ Pretreatment } & \multicolumn{2}{|c|}{ Vitamin $C\left(h^{-1} \cdot 10^{-3}\right)$} \\
\hline & & $k_{L}$ & $k_{D}$ \\
\hline \multirow[t]{2}{*}{ OD } & No PME & $77.5 \pm 2.9$ & $16.0 \pm 9.1$ \\
\hline & PME & $48.2 \pm 37.9$ & $30.3 \pm 13.6$ \\
\hline \multirow[t]{2}{*}{ OD-VI } & No PME & $41.6 \pm 24.7$ & $41.4 \pm 12.8$ \\
\hline & PME & $52.2 \pm 5.0$ & $32.8 \pm 13.2$ \\
\hline
\end{tabular}

Values represent means \pm SD of two batches.

The average leaching rate constants $(54.9 \pm 15.7)$ are significantly higher than the degradation rate constants $(30.1 \pm 10.6), P=0.04, t_{\text {crit }}=2.617$. However the degradation mechanism is causing a higher loss of vitamin $C(81.7 \pm 7.2 \%)$ compared to leaching $(5.1 \pm 2.8 \%)$ at the end of the process. The decreasing difference of vitamin C concentration between mango and OD-solution results in a lower $r_{L}$ compared to $r_{D}$. This main role of degradation on vitamin $C$ loss during OD was consistent with those of previous studies on papaya and kiwi fruits (Cao et al., 2006; Heng et al., 1990; Vial et al., 1991). Nevertheless, the OD solution still has significant amounts of vitamin C (around $1.5 \mathrm{mg} / 100 \mathrm{~g}$ ). Also previous studies report significant amounts of vitamin $\mathrm{C}$ in the OD-solutions especially after repeated cycles among others, for OD guava, reaching $95 \mathrm{mg} / 100 \mathrm{~g}$ in 15 cycles (Germer et al., 
2016); for grapefruit, up to $4 \mathrm{mg} / 100 \mathrm{~mL}$ in 5 cycles (Moraga et al., 2011) and up to $2 \mathrm{mg} / 100 \mathrm{~g}$ in 8 cycles (Peiró et al., 2006). Based on this study, use of longer OD times might have a practical interest if the OD-solutions were used repeatedly.

The ascribed first-order kinetic model for vitamin $\mathrm{C}$ degradation of this study supports evidence from previous OD observations (Dhakal et al., 2018; Marfil et al., 2008). Marfil et al. (2008) found that ascorbic acids degradation fitted by a first order reaction during drying of $O D$ peeled whole tomatoes at 50,60 and $70^{\circ} \mathrm{C}$ with similar $k_{D}$ values between $15.10^{-3} \mathrm{~h}^{-1}-48.10^{-3} \mathrm{~h}^{-1}$. Thermal processing of pineapple juice at $75{ }^{\circ} \mathrm{C}$ resulted in higher $k_{D}$ values of $252.10^{-3} \mathrm{~h}^{-1}$ (Dhakal et al., 2018). This value is approximately ten times higher than the degradation rate constant found in this study, which can be explained by the $25^{\circ} \mathrm{C}$ higher temperature.

\subsubsection{Scenario simulations}

To demonstrate the value of the models, the quality attributes (WR, WL, SSG and vitamin $\mathrm{C}$ contents) and processing time were predicted for two target settings based on practical applications (Table 5.5). Scenario 1: target value is $35 \% \mathrm{WR}$ of initial mango weight; Scenario 2: the target value is $50 \% \mathrm{WL}$ of initial mango weight. Based on these scenarios, the treatment time was calculated by the Weibull equation of the target variable WR for scenario 1 and WL for scenario 2 , using the estimated mass transfer parameters (Table 5.3). Based on this treatment time the other mass transfer variables were calculated by Eqs. (5) and (8). The vitamin C contents was calculated by Eqs. (12) and (13) with the estimated $k_{L}$ and $k_{D}$ (Table 5.4).

Both scenarios resulted in the lowest vitamin $\mathrm{C}$ concentration in mango treated with OD-VI/No PME, which is mainly a consequence of the longest process time needed to achieve the WL/WR targets. The other three treatments result in quite similar vitamin $C$ values, with OD/PME giving the highest retention for both scenarios (Table 5.5). For both scenarios the lowest SSG was obtained for OD/PME, while OD-VI/No PME gave the highest SSG $(P>0.05)$. Hence, depending on the desired quality attributes of OD mango (e.g., high vitamin $\mathrm{C}$ and high/low sugar content) different optimal process conditions can be recommended in a quantitative way based on the predictive models. 


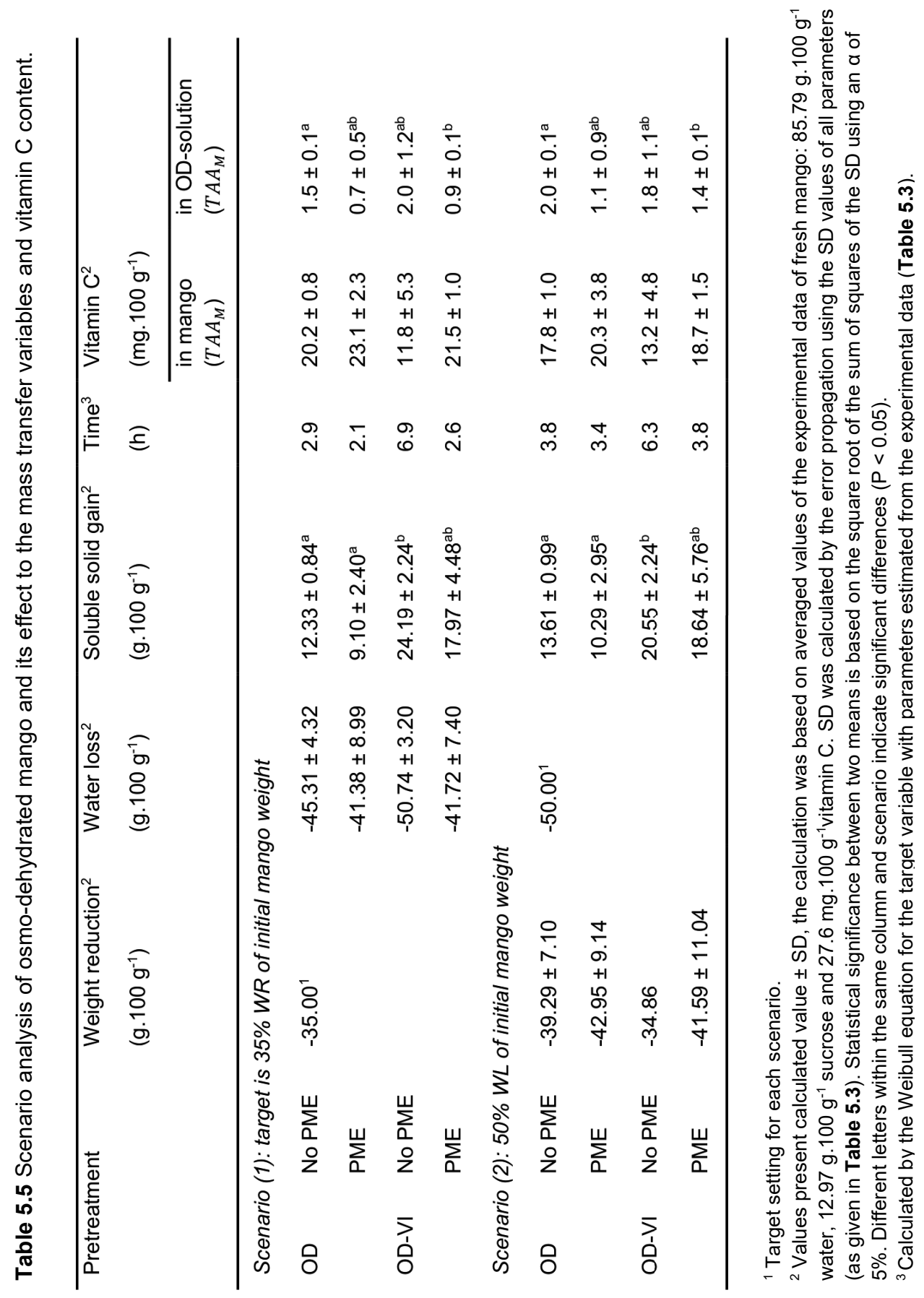




\subsection{Conclusions}

The soluble solid gain kinetics of osmo-dehydrated mango was described well by the Peleg model, while the Weibull model described the water loss and weight reduction better. Vacuum impregnation prior to osmotic dehydration of mango increased the soluble solid gain, reflected in the lower value of $k_{2}$ Peleg-parameter. For pectin methylesterase addition no effect on mass transfer parameters was found.

Vitamin C loss during osmotic dehydration of mango was well described by a multiresponse model including two mechanisms: leaching and degradation (in both mango and in the OD-solution). For all treatments, the major cause of vitamin $\mathrm{C}$ loss was degradation. The treatments have no significant effect on the degradation and leaching rate constants of vitamin $\mathrm{C}$ in mango.

This study indicates that applying VI and adding PME with calcium affected especially the SSG kinetics but did not affect the kinetics of vitamin C loss of osmodehydrated mango. The observed effects of $\mathrm{VI}$ applied to mango are valuable to modify OD mass transfer and therefore the required processing time. The predictive modelling of two scenarios suggested that OD with PME is favorable to produce OD mango with lowest sugar uptake, highest vitamin $C$ retention and shortest treatment time. OD-VI with PME is favorable to produce sweeter OD mango with moderate vitamin $C$ retention. Adding vitamin $C$ to the $O D$-solution could further increase the vitamin $\mathrm{C}$ content of the OD mango. The combination of modelling the mass transfer and vitamin C loss is a valuable tool to design OD processes for a specific product quality.

\section{Acknowledgements}

I. Sulistyawati received PhD scholarship from the Directorate General of Resources for Science, Technology and Higher Education, Indonesia (RISTEK-DIKTI) [grant number 391/E4.4/K/2014]. The authors appreciated Stefani Hartono for laboratory assistance. 


\section{References}

Ahmed, I., Qazi, I. M., \& Jamal, S. (2016). Developments in osmotic dehydration technique for the preservation of fruits and vegetables. Innovative Food Science and Emerging Technologies, 34, 29-43. http://dx.doi.org/10.1016/j.ifset.2016.01.003.

Alam, M. S., Amarjit, S., \& Sawhney, B. K. (2010). Response surface optimization of osmotic dehydration process for aonla slices. Journal of Food Science and Technology, 47(1), 47-54. http://dx.doi.org/10.1007/s13197-010-0014-4.

Altendorf, S. (2017). Global prospects for major tropical fruits: Short-term outlook, challenges and opportunities in a vibrant global marketplace. Rome: FAO Trade and Markets Division.

Assis, F. R., Morais, R. M. S. C., \& Morais, A. M. M. B. (2017). Mathematical modelling of osmotic dehydration kinetics of apple cubes. Journal of Food Processing and Preservation, 41(3), e12895. http://dx.doi.org/10.1111/jpp.12895.

Azuara, E., Beristain, C. I., \& Garcia, H. S. (1992). Development of a mathematicalmodel to predict kinetics of osmotic dehydration. Journal of Food Science and Technology-Mysore, 29(4), 239-242.

Barat, J., Albors, A., Chiralt, A., \& Fito, P. (1999). Equilibration of apple tissue in osmotic dehydration: microstructural changes. Drying Technology, 17(7-8), 1375-1386. https://doi.org/10.1080/07373939908917621

Betoret, N., Puente, L., Díaz, M. J., Pagán, M. J., García, M. J., Gras, M. L., MartínezMonzó, J., \& Fito, P. (2003). Development of probiotic-enriched dried fruits by vacuum impregnation. Journal of Food Engineering, 56(2), 273-277. https://doi.org/10.1016/S0260-8774(02)00268-6.

Butcher, J. C. (2016). Numerical differential equation methods. In J. C. Butcher (Ed.), Numerical methods for ordinary differential equations (3rd ed., pp. 55-142). Chichester: John Wiley \& Sons, Ltd. https://doi.org/10.1002/9781119121534.ch2.

Cantre, D., Herremans, E., Verboven, P., Ampofo-Asiama, J., \& Nicolaï, B. (2014). Characterization of the 3-D microstructure of mango (Mangifera indica L. cv. Carabao) during ripening using X-ray computed microtomography. 
Innovative Food Science and Emerging Technologies, 24, 28-39. http://dx.doi.org/10.1016/j.ifset.2013.12.008.

Cao, H., Zhang, M., Mujumdar, A. S., Du, W.-h., \& Sun, J.-c. (2006). Optimization of Osmotic Dehydration of Kiwifruit. Drying Technology, 24(1), 89-94. http://dx.doi.org/10.1080/07373930500538741.

Chiralt, A., \& Fito, P. (2003). Transport Mechanisms in Osmotic Dehydration: The Role of the Structure. Food Science and Technology International, 9(3), 179186. https://doi.org/10.1177/1082013203034757

Ciurzyńska, A., Kowalska, H., Czajkowska, K., \& Lenart, A. (2016). Osmotic dehydration in production of sustainable and healthy food. Trends in Food $\begin{array}{llll}\text { Science } \quad \text { and } & \text { 186-192. }\end{array}$ http://dx.doi.org/10.1016/j.tifs.2016.01.017.

Cunha, L. M., Oliveira, F. A., Aboim, A. P., Frías, J. M., \& Pinheiro-Torres, A. (2001). Stochastic approach to the modelling of water losses during osmotic dehydration and improved parameter estimation. International Journal of Food Science \& Technology, 36(3), 253-262. https://doi.org/10.1046/j.1365-2621.2001.t01-1-00447.x.

De Levie, R. (2004). Advanced Excel for scientific data analysis. New York: Oxford University Press.

Deng, Y., \& Zhao, Y. (2008). Effects of pulsed-vacuum and ultrasound on the osmodehydration kinetics and microstructure of apples (Fuji). Journal of Food Engineering, 85(1), 84-93. http://dx.doi.org/10.1016/j.jfoodeng.2007.07.016.

Dermesonlouoglou, E. K., Giannakourou, M., \& Taoukis, P. S. (2016). Kinetic study of the effect of the osmotic dehydration pre-treatment with alternative osmotic solutes to the shelf life of frozen strawberry. Food and Bioproducts Processing, 99, 212-221. http://dx.doi.org/10.1016/j.fbp.2016.05.006.

Dhakal, S., Balasubramaniam, V. M., Ayvaz, H., \& Rodriguez-Saona, L. E. (2018). Kinetic modeling of ascorbic acid degradation of pineapple juice subjected to combined pressure-thermal treatment. Journal of Food Engineering, 224, 62-70. https://doi.org/10.1016/j.jfoodeng.2017.12.016.

Fito, P., \& Chiralt, A. (1995). An update on vacuum osmotic dehydration. In G. V. Barbosa-Canovas \& J. Welti-Chanes (Eds.), Food preservation by moisture 
control: Fundamentals and applications (pp. 351-372). Lancaster, PA: Technomic Publishing Co., Inc.

Fito, P., Chiralt, A., Barat, J. M., Andrés, A., Martínez-Monzó, J., \& MartínezNavarrete, N. (2001). Vacuum impregnation for development of new dehydrated products. Journal of Food Engineering, 49(4), 297-302. https://doi.org/10.1016/S0260-8774(00)00226-0.

Ganjloo, A., Rahman, R. A., Bakar, J., Osman, A., \& Bimakr, M. (2012). Kinetics Modeling of Mass Transfer Using Peleg's Equation During Osmotic Dehydration of Seedless Guava (Psidium guajava L.): Effect of Process Parameters. Food and Bioprocess Technology, 5(6), 2151-2159. https://doi.org/10.1007/s11947-011-0546-2.

Germer, S. P. M., Ferrari, C. C., Lancha, J. P., Berbari, S. A. G., Carmello-Guerreiro, S. M., \& Ruffi, C. R. G. (2014). Influence of processing additives on the quality and stability of dried papaya obtained by osmotic dehydration and conventional air drying. Drying Technology, 32(16), 1956-1969. https://doi.org/10.1080/07373937.2014.924963.

Germer, S. P. M., Morgano, M. A., da Silva, M. G., Silveira, N. F. d. A., \& Souza, E. d. C. G. (2016). Effect of reconditioning and reuse of sucrose syrup in quality properties and retention of nutrients in osmotic dehydration of guava. Drying Technology, 34(8), 997-1008. https://doi.org/10.1080/07373937.2015.1090446.

Guillemin, A., Guillon, F., Degraeve, P., Rondeau, C., Devaux, M.-F., Huber, F., Badel, E., Saurel, R., \& Lahaye, M. (2008). Firming of fruit tissues by vacuum-infusion of pectin methylesterase: visualisation of enzyme action. Food Chemistry, 109(2), 368-378. https://doi.org/10.1016/j.foodchem.2007.12.050.

Hanemann, P., Velez, Julian, Arnoldus, Michiel. (2017). Fruit company assessments for exporting to U.S. market. Arlington, Virginia: J.E. Austin Associates, Inc. Heng, K., Guilbert, S., \& Cuq, J. (1990). Osmotic dehydration of papaya: influence of process variables on the product quality. Sciences des Aliments, 10(4), 831-848. 
Hernández, Y., Lobo, M. G., \& González, M. (2006). Determination of vitamin C in tropical fruits: A comparative evaluation of methods. Food chemistry, 96(4), 654-664. https://doi.org/10.1016/j.foodchem.2005.04.012.

Hurvich, C. M., \& Tsai, C. L. (1995). Model selection for extended quasi-likelihood models in small samples. Biometrics, 51(3), 1077-1084. https://doi.org/10.2307/2533006.

Katsoufi, S., Lazou, A. E., Giannakourou, M. C., \& Krokida, M. K. (2017). Mass transfer kinetics and quality attributes of osmo-dehydrated candied pumpkins using nutritious sweeteners. Journal of Food Science and Technology, 54(10), 3338-3348. https://doi.org/10.1007/s13197-017-27862.

Khan, M. A. M., Ahrné, L., Oliveira, J. C., \& Oliveira, F. A. R. (2008). Prediction of water and soluble solids concentration during osmotic dehydration of mango. Food and Bioproducts Processing, 86(1), 7-13. https://doi.org/10.1016/j.fbp.2007.10.012.

Lin, X., Luo, C., \& Chen, Y. (2016). Effects of Vacuum Impregnation with Sucrose Solution on Mango Tissue. Journal of Food Science, 81(6), E1412-E1418. https://doi.org/10.1111/1750-3841.13309.

Marfil, P. H. M., Santos, E. M., \& Telis, V. R. N. (2008). Ascorbic acid degradation kinetics in tomatoes at different drying conditions. $L W T$ - Food Science and Technology, 41(9), 1642-1647. http://dx.doi.org/10.1016/j.Iwt.2007.11.003.

Mokhtarian, M., Majd, M. H., Koushki, F., Bakhshabadi, H., Garmakhany, A. D., \& Rashidzadeh, S. (2014). Optimisation of pumpkin mass transfer kinetic during osmotic dehydration using artificial neural network and response surface methodology modelling. Quality Assurance and Safety of Crops \& Foods, 6(2), 201-214. https://doi.org/10.3920/qas2012.0121.

Moraga, M. J., Moraga, G., \& Martínez-Navarrete, N. (2011). Effect of the re-use of the osmotic solution on the stability of osmodehydro-refrigerated grapefruit. LWT - Food Science and Technology, 44(1), 35-41. https://doi.org/10.1016/j.lwt.2010.05.018.

Nowacka, M., Fijalkowska, A., Dadan, M., Rybak, K., Wiktor, A., \& Witrowa-Rajchert, D. (2018). Effect of ultrasound treatment during osmotic dehydration on 
bioactive compounds of cranberries. Ultrasonics, 83, 18-25. https://doi.org/10.1016/j.ultras.2017.06.022.

Nuñez-Mancilla, Y., Pérez-Won, M., Uribe, E., Vega-Gálvez, A., \& Di Scala, K. (2013). Osmotic dehydration under high hydrostatic pressure: Effects on antioxidant activity, total phenolics compounds, vitamin $\mathrm{C}$ and colour of strawberry (Fragaria vesca). LWT - Food Science and Technology, 52(2), 151-156. https://doi.org/10.1016/j.Iwt.2012.02.027.

Oladejo, A. O., Ma, H., Qu, W., Zhou, C., \& Wu, B. (2017). Effects of ultrasound on mass transfer kinetics, structure, carotenoid and vitamin $C$ content of osmodehydrated sweet potato (Ipomea batatas). Food and Bioprocess Technology, 10(6), 1162-1172. https://doi.org/10.1007/s11947-017-1890-7.

Olivares-Tenorio, M.-L., Verkerk, R., van Boekel, M. A. J. S., \& Dekker, M. (2017). Thermal stability of phytochemicals, HMF and antioxidant activity in cape gooseberry (Physalis peruviana L.). Journal of Functional Foods, 32, 46-57. https://doi.org/10.1016/j.jf.2017.02.021.

Oliver, L., Betoret, N., Fito, P., \& Meinders, M. B. J. (2012). How to deal with viscoelastic properties of cellular tissues during osmotic dehydration. Journal of Food Engineering, 110(2), 278-288. https://doi.org/10.1016/j.jfoodeng.2011.04.028.

Page, G. E. (1949). Factors influencing the maximum rates of air drying shelled corn in thin layers. (Doctoral dissertation). Purdue University, Purdue.

Peiró, R., Dias, V. M. C., Camacho, M. M., \& Martínez-Navarrete, N. (2006). Micronutrient flow to the osmotic solution during grapefruit osmotic dehydration. Journal of Food Engineering, 74(3), 299-307. https://doi.org/10.1016/j.jfoodeng.2005.03.022.

Peleg, M. (1988). An empirical model for the description of moisture sorption curves. Journal of Food Science, 53(4), 1216-1217. https://doi.org/10.1111/j.13652621.1988.tb13565.x|.

Prasanna, V., Yashoda, H., Prabha, T., \& Tharanathan, R. (2003). Pectic polysaccharides during ripening of mango (Mangifera indica $\mathrm{L}$ ). Journal of the Science of Food and Agriculture, 83(11), 1182-1186. https://doi.org/10.1002/jsfa.1522. 
Ramya, V., \& Jain, N. K. (2017). A review on osmotic dehydration of fruits and vegetables: An integrated approach. Journal of Food Process Engineering, 40(3), e12440. https://doi.org/10.1111/jpe.12440.

Ribeiro, S. M. R., Schieber, A., \& Preedy, V. R. (2010). Bioactive compounds in mango (Mangifera indica L.). In R. R. Watson \& V. R. Preedy (Eds.), Bioactive Foods in Promoting Health (pp. 507-523). London: Academic Press. https://doi.org/10.1016/B978-0-12-374628-3.00034-7.

Sarvan, I., Verkerk, R., \& Dekker, M. (2012). Modelling the fate of glucosinolates during thermal processing of Brassica vegetables. LWT-Food Science and Technology, 49(2), 178-183. https://doi.org/10.1016/j.Iwt.2012.07.005.

Seguí, L., Fito, P. J., \& Fito, P. (2012). Understanding osmotic dehydration of tissue structured foods by means of a cellular approach. Journal of Food Engineering, 110(2),

240-247. https://doi.org/10.1016/j.jfoodeng.2011.05.012.

Shi, J., \& Xue, J. (2009). Application and development of osmotic dehydration technology in food processing. In C. Ratti (Ed.), Advances in food dehydration (pp. 187-208). Boca Raton, FL: CRC Press.

Silva, K. S., Fernandes, M. A., \& Mauro, M. A. (2014). Effect of calcium on the osmotic dehydration kinetics and quality of pineapple. Journal of Food Engineering, 134, 37-44. http://dx.doi.org/10.1016/j.jfoodeng.2014.02.020.

Sirijariyawat, A., Charoenrein, S., \& Barrett, D. M. (2012). Texture improvement of fresh and frozen mangoes with pectin methylesterase and calcium infusion. Journal of the Science of Food and Agriculture, 92(13), 2581-2586. https://doi.org/10.1002/jsfa.5791.

Song, J., Meng, L., Li, D., Qian, M., \& Liu, C. (2017). Vacuum impregnation pretreatment with maltose syrup to improve the quality of frozen lotus root. International Journal of Refrigeration, 76, 261-270. https://doi.org/10.1016/j.ijrefrig.2017.02.018.

Sulistyawati, I., Dekker, M., Fogliano, V., \& Verkerk, R. (2018). Osmotic dehydration of mango: Effect of vacuum impregnation, high pressure, pectin methylesterase and ripeness on quality. LWT - Food Science and Technology, 98, 179-186. https://doi.org/10.1016/j.Iwt.2018.08.032. 
Talens, P., Pérez-Masía, R., Fabra, M. J., Vargas, M., \& Chiralt, A. (2012). Application of edible coatings to partially dehydrated pineapple for use in fruit-cereal products. Journal of Food Engineering, 112(1-2), 86-93. https://doi.org/10.1016/j.jfoodeng.2012.03.022.

Tharanathan, R., Yashoda, H., \& Prabha, T. (2006). Mango (Mangifera indica L.),"The king of fruits"-An overview. Food Reviews International, 22(2), 95123.

Retrieved from

http://www.tandfonline.com/doi/pdf/10.1080/87559120600574493.

Threlfall, R., Morris, J., \& Meullenet, J.-F. (2007). Product development and nutraceutical analysis to enhance the value of dried fruit. Journal of Food Quality, 30(4), 552-566. https://doi.org/10.1111/j.1745-4557.2007.00142.x.

Torreggiani, D. (1993). Osmotic dehydration in fruit and vegetable processing. Food Research International, 26(1), 59-68. https://doi.org/10.1016/09639969(93)90106-S.

Van Buggenhout, S., Grauwet, T., Van Loey, A., \& Hendrickx, M. (2008). Use of pectinmethylesterase and calcium in osmotic dehydration and osmodehydrofreezing of strawberries. European Food Research and Technology, 226(5), 1145-1154. https://doi.org/10.1007/s00217-007-06437.

Vial, C., Guilbert, S., \& Cuq, J. L. (1991). Osmotic dehydration of kiwi fruits: Influence of process variables on the color and ascorbic-acid content. Sciences des Aliments, 11(1), 63-84.

Yashoda, H. M., Prabha, T. N., \& Tharanathan, R. N. (2006). Mango ripening: changes in cell wall constituents in relation to textural softening. Journal of the Science of Food and Agriculture, 86(5), 713-721. https://doi.org/10.1002/jsfa.2404. 


\section{Supplementary data 5.1. Measurement of vitamin C}

Vitamin C was expressed as the Total Ascorbic Acid (TAA) content and was determined according to Hernández et al. (2006) with modifications, using an HPLC system (a thermo separation products model with P-2000 Binary Gradient Pump and UV 2000 detector). To obtain the extract, $0.5-0.7 \mathrm{~g}$ lyophilized powder mango sample was mixed with $3.5 \mathrm{~mL}$ of an extraction solution (mixture of $3 \%$ metaphosphoric acid (MPA) and $0.1 \%$ tert-butylhydroquinone (TBHQ)). The mixture was homogenized at high speed for $1 \mathrm{~min}$. The supernatant was centrifuged for 5 min at $1,790 \mathrm{~g}$ and $4{ }^{\circ} \mathrm{C}$. This procedure was repeated thrice and the supernatants were combined, centrifuged for $10 \mathrm{~min}$ at $11,700 \mathrm{~g}$ and $4{ }^{\circ} \mathrm{C}$ and filtered through 0.2 $\mu \mathrm{m}$ CA filter into amber vials and added with $1 \mathrm{M}$ tris-2-carboxyethyl phosphine (TCEP) solution. For OD-solution samples, approximately $5 \mathrm{~g}$ of lyophilized powder sample was mixed with $10.5 \mathrm{~mL} 3 \% \mathrm{MPA}-0.1 \%$ THBQ solution. The rest of the procedure was similar to mango samples. Vitamin $C$ concentrations were determined using an HPLC system (a thermo separation products model with P2000 Binary Gradient Pump and UV 2000 detector) with a Varian Polaris 5 C18-A column (150 x $4.6 \mathrm{~mm}, 5 \mu \mathrm{m})$. The mobile phase employed was $0.2 \%$ orthophosphoric acid (Merck $®)$ in Milli-Q Water $(\mathrm{v} / \mathrm{v})$. Ascorbic acid eluted after 5.5 min at a flow rate of $1.0 \mathrm{~mL} \mathrm{~min}{ }^{-1}$ which was monitored at a wavelength of $245 \mathrm{~nm}$. For identification and quantification of vitamin $\mathrm{C}$, a standard calibration was prepared using L-ascorbic acid (Sigma-Aldrich $囚, \geq 99 \%$ ) dissolved in 3\% MPA-0.1\% THBQ solution. Measurements were performed in duplicate of both samples and supernatants and then averaged to get one data set per batch. Results were expressed in mg total ascorbic acid $100 \mathrm{~g}^{-1}$ fresh weight (FW). 


\section{Chapter 6 \\ General discussion}





\subsection{Introduction}

This thesis provides consumer and technological insights for improving the quality of dried mango, especially in terms of health and sensory aspects. The obtained findings from this research resulted from combining perception and preference insights learned from two consumer studies, from investigating osmotic dehydration (OD) as an innovative drying technology in a food technological study and optimizing the OD process design in a mathematical modelling study.

Food drying is a method of food preservation by removal of water. Water is traditionally removed through evaporation in low-technology operations (e.g. air drying, sun drying, smoking or wind drying), while nowadays more advanced technologies (e.g. freeze drying) are used to accelerate the drying process, ensure a more consistent process and deliver high quality food products. Dried food has been an important source of foods in the human diet since about 20,000 BC because drying is one of the oldest preservation technologies (Hayashi, 1989). Dried food has a high versatility and a longer availability throughout the year. In particular dried and semi-dried fruits are often consumed as a convenient snack, as an ingredient of food products, or as a replacement of unavailable fresh fruits, e.g. outside its season or not being produced in the area (Sijtsema et al., 2012).

Consumption of dried fruit has a high potential to meet the recommended level of daily fruit and vegetable consumption to supports a healthy life. The relevance has been addressed in some epidemiological studies, on aspects like general health benefits (Chang et al., 2016); dental health (Sadler, 2016); modulating effects on common cancer risk factors (Mossine et al., 2019); improved diet quality (Keast et al., 2011), and public health (Sadler et al., 2019). Dried fruits are not only contain high levels of nutritional and health-promoting compounds (Alasalvar \& Shahidi, 2013; Chang et al., 2016), but also are perceived by consumers as very tasteful.

The current increasing demand for processed fruit (CBI, 2019b) has made dried fruit products more available in the global market. Dried fruit with its high versatility addresses consumers' trends toward healthy and nutritional, convenient, natural, minimally processed, and functional food products (Nielsen, 2017; Sloan, 2018; Wyatt, 2018). Some examples of current trends of dried fruit products are; 
1. Individual dried fruit/nut mixes as on-the-go snacks representing a convenient nutrient-dense snack with relatively low carbohydrates and sugar (Olayanju, 2019);

2. Dried fruit snacks enriched with probiotics (Wyatt, 2018) which represent minimally processed functional foods (Rodgers, 2016);

3. So-called natural foods like dried organic tropical fruit (Alphonce et al., 2015) and dried fruit pieces in exotic tea bags representing products with a natural image (Sloan, 2018), and a 'clean label' dried fruit (Asioli et al., 2017).

In 2018/2019, the world production of dried fruits - which only covered raisins, dates, prunes, apricots, cranberries, and figs - represented an $11 \%$ increment over the prior 5-year average (INC, 2018). In Europe, between 2014-2018, dried tropical fruits grew in value at an average annual rate of $11 \%$, but decreased in quantity at an average annual rate of $7 \%$, which reached $€ 43$ million and 16 thousand tons (CBI, 2019a). When adding dried mangoes, dried pineapples and candied tropical fruit which were excluded in previous data -the total European imports of dried tropical fruit is estimated to be just above 30 thousand tons. Dried mango is one of the important dried tropical fruits in European countries like the United Kingdom and Germany which both are the major importers (CBI, 2019a).

The high versatility of dried fruit is shown by its multiple uses ranging from industrial applications (e.g., as ingredient for confectionery, bakery, breakfast cereals, cereal bars), domestic purposes (e.g., home baking or cooking) and to food to be consumed as such (Sadler et al., 2019).

Drying (dehydration) technology can be considered as one of the technologies favorable to produce minimally processed fruit (MPF) to preserve its sensory quality, nutrition and health-promoting compounds, as well as to provide extended shelf life. In the literature, the vast development of this technology in the last few decades brings out improvement in quality (intrinsic attributes or characteristics, maintained nutritional and health-promoting compounds) and a wide range of differently minimally processed fruits (as shown in Fig 6.1). Nevertheless, drying, as most processes, changes the fresh fruit quality characteristics, thus changes the 
consumer perception toward the end product, also in terms of expected health benefits and sensory quality attributes.

The term "minimally processed fruits", to some extent, was used deliberately by different authors for different types of processed fruits, e.g. Qiu et al. (2019), Siddiqui et al. (2011), Pasha et al. (2014), Monteiro et al. (2016). In the following, an attempt to distinguish types of MPF is proposed, as illustrated in Fig 6.1. The focus, in particular, is on the distinction between the production process and degree of processing, which is relevant when addressing dried fruit in this thesis.

Production process (in vertical alignment in Fig. 6.1). - After being selected, fruits are generally processed in small, medium up to large scale production in which several processing steps take place. The steps start with pre-processing which involves washing, removal of inedible/unwanted parts, and if necessary size reduction, e.g. halving, slicing, dicing (Alasalvar \& Shahidi, 2013). Depending on the type of MPF - depicted in green boxes in Fig 6.1 -, this will be followed by several steps of processing. Minimally fresh-cut processed (fresh-cut) fruit requires distinct steps - special preparation techniques - as compared to other MPF in order to optimize the (microbial) quality and extend product shelf life, e.g. applying good hygienic practices and specific temperatures during processing, packaging techniques like Modified Atmosphere Packaging (MAP) (Artés \& Allende, 2005). Aside from the fresh cut fruit, depending on the applied processing, other types of MPF can have different moisture contents, as followed:

a. Intermediate moisture fruit/semi-dried fruit (IMF/SDF) contains 20 to 50 weight- $\%$ moisture and the $a_{w}$ is between 0.70 and 0.85 ; generally considered as microbiologically stable at room temperature (Ahmed et al., 2016).

b. Low moisture dried fruit (LMF) contains 2 to 20 weight-\% moisture content and the $a_{w}$ is between $0.20-0.40$ or could be higher than 0.40 with added preservatives to extend its shelf life (Perera, 2005).

These MPFs can be produced by one or more types of processing technologies, as shown in Fig 6.1. In particular, osmotic dehydration (OD) represents an 
interesting case. While this technology often used as a pre-treatment prior to drying or freezing, other technologies (e.g. vacuum impregnation and high pressure processing) can also precede OD application (Ahmed et al., 2016). Combination of OD with pre-treatments, often called as "innovative osmotic dehydration" have been shown to improve the final food product. Therefore, in this thesis, the food technological study involves the application of innovative osmotic dehydration in combination with high pressure or vacuum impregnation.

Degree of processing (in horizontal alignment in Fig. 6.1). - Minimally processed fruits are subjected to a different degree of processing (Siddiqui et al., 2011). The relative order of MPF from the least to the most processed is: fresh-cut fruits; IMF/SMF (non-thermal < mild temperature < high temperature processing); and LMF (low temperature (freezing) < freeze-drying < high temperature processing). The relative order is made based on both processing temperature and the degree of water removal of the products. Yet, application of the processing technology can vary from one, two to more processing operations, varying in process conditions, namely temperature and duration, which can lead to highly varied end product quality.

The method and degree of processing of dried fruit and its consumption is relevant to health and its perception. Regarding the public health, a general misconception that most dried fruits contain added sugars exists among consumers (Sadler et al., 2019) although there are "just" dried fruits and other "no added sugar" dried fruit products available in the market. This misconception poses a challenge in increasing consumers' fruit intake through dried fruit consumption.

For consumer perception of the quality of dried fruit products, the intrinsic characteristics of the product as well as the way of processing, is highly relevant. Therefore, the understanding of the perception of intrinsic and extrinsic attributes is of value for product and process design of dried mango. 


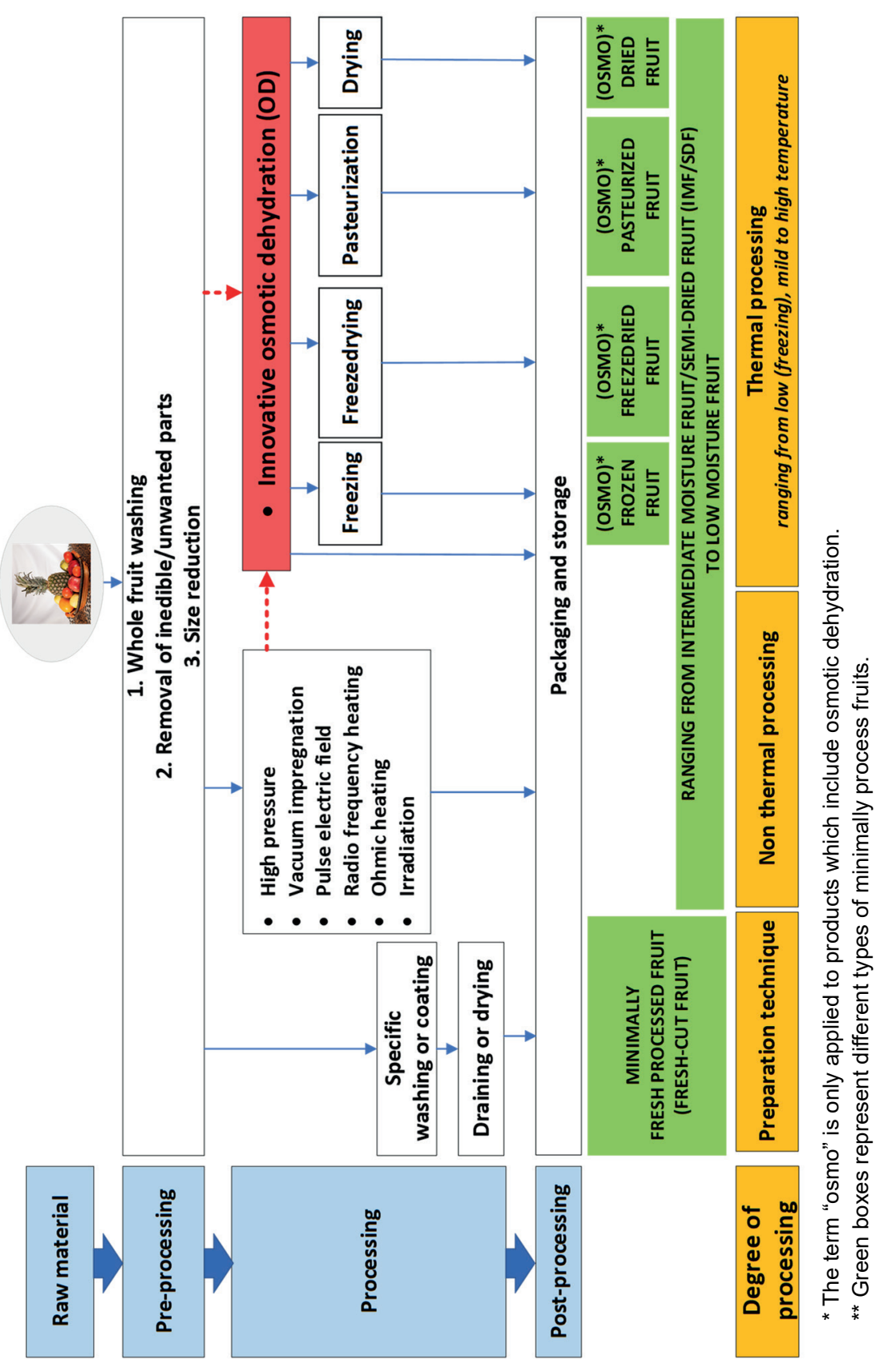

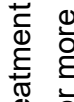

齐

힐

त

으 등 웅

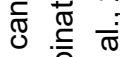

으 है ๘

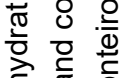

त्रे के

응 흥

放 은

○ $\overline{\bar{z}} \frac{\dot{0}}{\mathrm{\sigma}}$

จ่ $\cong$

के $\frac{0}{0}$

บ ญ

늠

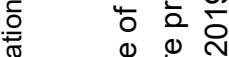

ఖ

ठ্ঠ क त

유

음 站 五 응

ลิ $\frac{c}{0}$

\& $\bar{\Phi}$ क

N. 은

ㅎํㅇ $\frac{\vdots}{\overline{0}}$

ब्ष

ชั 응 음

旁

क त

कू

은

응 党

高 要

.

넝 응

ํํㅇำ

단 을

은 음

$\varangle \stackrel{0}{\square}$

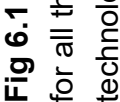


To add value to mango suitable for the intended market (i.e. healthy dried mango), this thesis explored insights from consumers and connected them to technological optimization of the product quality during product and process design. An interdisciplinary approach is used to acquire more knowledge about the effect of processing on the dried mango quality and how it is perceived by consumers. The specific objectives of this thesis were to:

a. Explore consumer's health perception among different cultures and demonstrate its relevance for product and process design in the early stages of new product development;

b. Study consumer preference of dried mango among different cultures to contribute to adding value to dried mango products;

c. Study the effect of pre-treatment with vacuum impregnation (VI), high pressure (HP), and adding pectin methylesterase (PME) in combination with ripeness on the quality of dried mango;

d. Describe the kinetics of osmotic dehydration of mango to optimize water loss, sugar uptake, vitamin $\mathrm{C}$ retention and treatment time.

This discussion chapter addresses the relevance of the thesis findings (see Table 6.1) and the extent to which the objectives were achieved. The contribution of the current research to the improvement of dried mango quality is also addressed. Finally, recommendations for further research are given. 


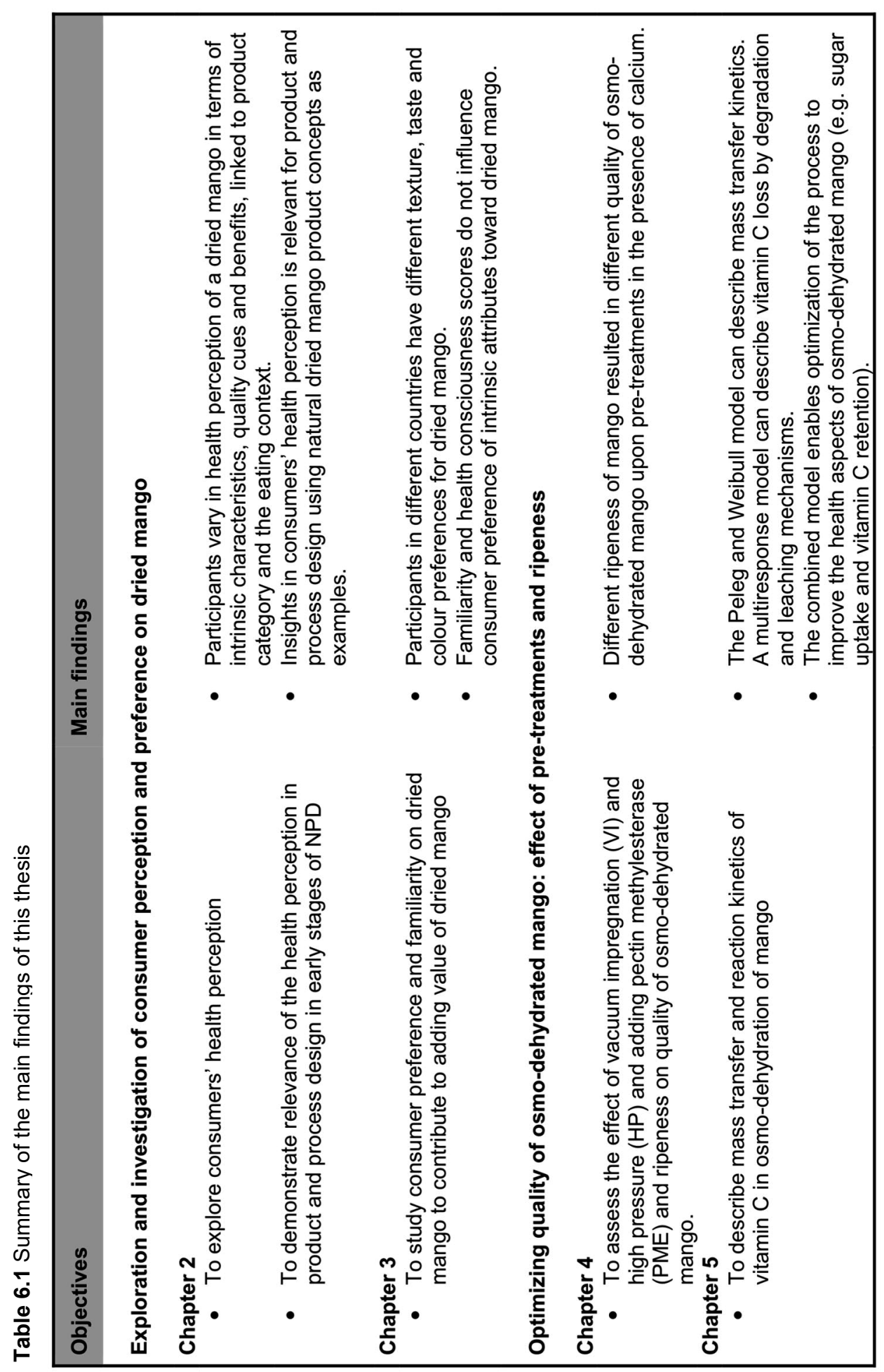




\subsection{Discussion and interpretation of findings}

As explained in Chapter 1, an interdisciplinary approach has been used to optimize quality of dried mango and to contribute to the knowledge about quality based process and product design. This section discusses chosen methodologies and interprets findings of the four studies presented in this thesis.

\subsubsection{Consumer perception and preference studies}

\subsubsection{Focus groups and conjoint analysis: Methodological considerations}

The choice for collecting consumer data depends on the purpose, which in this thesis to acquire input from consumers for product and process design (Chapter $\mathbf{2}$ and $\mathbf{3}$ ).

Several methods for consumer research in the early stages of New Product Development (NPD) have been described in the literature, e.g., laddering, category appraisal, lead user technique, focus group, and conjoint analysis (van Kleef et al., 2005). For the work of this thesis, studies with focus groups and conjoint analysis were used. The focus group method was chosen to explore consumers' health perception of dried mango. The interaction between participants in the focus group allows for greater accessibility of shared ideas and experiences (Bruseberg \& McDonagh-Philp, 2002) and enables for a better understanding of cultural differences (Brunsø et al., 2009; Tan et al., 2016). This method has been successfully applied in our research for three cultures (Dutch, Chinese and Indonesian) to gain more insights into differences in the way consumers think about the healthiness of dried mango. Four main themes related to perceived quality emerged - nutrition, naturalness, taste, and well-being - containing useful product and process characteristics. Based on the rich data, the relevance of consumer insights for product and process design of natural dried mango product concepts as examples was well demonstrated.

To explore consumers' perception across cultures, translation of the focus group protocol was required, while the translation accuracy depends on the vocabulary of the respected language. In the Indonesian language, the term 'dried fruit' cannot be equally translated and a proper definition was given, yet this still resulted in some participants mentioning several fried fruits, despite the fact frying is not included as 
a type of drying technology (Ratti, 2009). Nevertheless, the revealed misconception might have a practical relevance for making appropriate messages for consumers, i.e. crispy dried fruit as compared to crispy fried fruit.

Unfortunately, the focus group in this study only included an optional tasting session of one commercially available dried mango. The method may be improved by combining it with the use of compulsory tasting of different types of dried fruit as stimulus to obtain richer data for NPD (Bruseberg \& McDonagh-Philp, 2002), for example concerning characteristics, cues and quality of the various types of dried fruit.

Relatedly, the valuable insights obtained from the focus group data was useful for the further quantitative consumer research in which a conjoint analysis method was applied in order to explain variations in key intrinsic quality attributes and preferences of dried mango. An adaptive choice-based conjoint (ACBC) analysis via an online survey was used. This survey was not intended to represent the general population of the participating countries. However, the data of 483 respondents (comprised of 137 Chinese, 244 Indonesian and 102 Dutch respondents) could provide a pointer on the implication of different key intrinsic attributes and preferences of dried mango between countries in product development. However, the uneven number of respondents between groups posed a challenge in interpreting the data for between groups comparison. Further work is required to establish consumer segmentation for dried mango which needs a higher number of respondents, at least 200 or 250 respondents per participating country (Jervis et al., 2012; Orme, 2010).

Both consumer studies in this thesis involved respondents from three countries, The Netherlands, China and Indonesia. The Netherlands is the leading European importer of processed fruits including dried fruit from outside the EU such as from Africa and Asia (CBI, 2019b). Regarding fresh mango, China and Indonesia contribute approximately $10 \%$ and $7 \%$ of the global mango production in 2018 , respectively (FAO, 2019b). However, China is also the largest Asian importer of fresh mango. In Indonesia, as also in some other Southeast Asian countries, mangoes are used in salads and pickles when green and unripe, and when ripe, they are used in a variety of desserts (Van Esterik, 2008), thus ripeness is considered as relevant. 


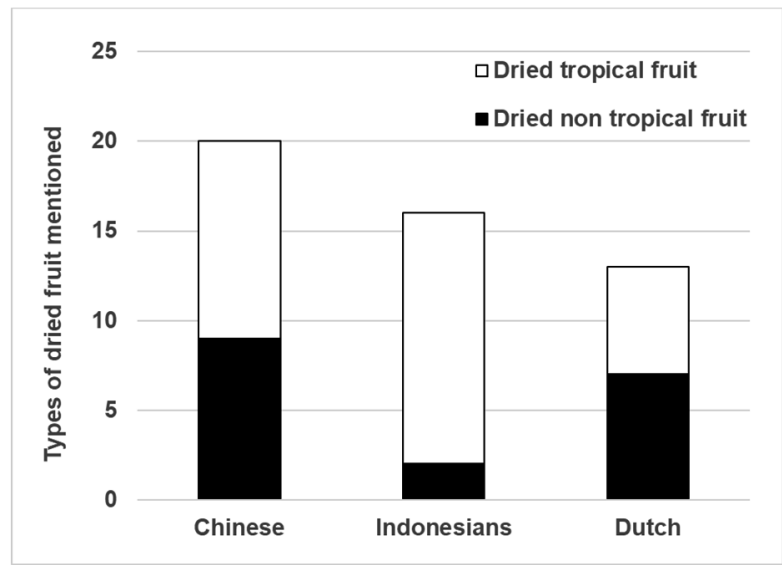

Fig 6.2 Number of types of dried fruits mentioned by participants during the focus groups.

Consumption of dried fruit is part of the culture in China and Indonesia. China has a long history of usage of various types of dried fruit both as food and for medicinal purposes (Liu et al., 2015). Some examples are dried goji berry, dried plum, dried jujube (Chinese red date). For Indonesia, various types of dried fruit are known and used in the form of semi-dried fruit or candied fruit; mainly made of tropical fruit (e.g., papaya, mango, banana, snake fruit) and produced domestically or in small and medium sized enterprises. Based on the available information, as expected, focus group participants from both countries mentioned more types of dried tropical and non-tropical fruits than the Dutch participants (Fig 6.2). Moreover, differences in perception and preference of dried mango between countries were found which are useful for product and process design.

\subsubsection{Exploration of consumers' health perception of dried mango: findings and interpretation}

Consumers' health perception of food is influenced by four closely related determinants, food, individual, environment and context, which have to be taken into consideration during NPD (Sijtsema et al., 2002). An explorative consumer study in this thesis showed the benefit of unveiling that perceived healthiness of dried mango varied between consumers (Chapter 2). The variation of their perceptions was linked to (perceived) product category and the eating context. These results are in agreement with Ronteltap et al. (2012) who revealed that healthy eating is not as 
clear-cut for consumers, and is not similarly understood and interpreted by consumers.

Product categorization. On the one hand, some of the focus group participants in this study classified products based on their "own" categorization which varied among them (Chapter 2). For example, some consumers positioned dried mango more towards fresh mango (for health and nutritional aspects), others positioned dried mango towards a more processed high sugar product.

Table 6.2 Categorization of dried fruit ${ }^{\mathrm{a}}$.

\begin{tabular}{|c|c|c|}
\hline Category of dried fruit & Characteristics & Examples \\
\hline Traditional dried fruit & $\begin{array}{l}\text { No added sugar; removal of some water } \\
\text { content; moisture content range } \sim 14 \% \\
\text { (sultanas) to } 24 \% \text { (dried apricots) }\end{array}$ & $\begin{array}{l}\text { Apples, apricots, dates, figs, prunes, } \\
\text { pears, raisins }\end{array}$ \\
\hline Sugar-infused dried fruit & $\begin{array}{l}\text { Sweetened with fruit sugar solution by } \\
\text { osmotic pressure before drying; moisture } \\
\text { content } 18-20 \% \text { a, dry matter } \sim 80 \%\end{array}$ & $\begin{array}{l}\text { Blueberries, cherries, cranberries, } \\
\text { mangoes, strawberries }\end{array}$ \\
\hline Candied dried fruit & $\begin{array}{l}\text { Includes candied (preserved in sugar syrup, } \\
\text { dry), crystallized (frosted with caster sugar) } \\
\text { and glazed or glacé (coated in sugar syrup) } \\
\text { fruits }\end{array}$ & $\begin{array}{l}\text { Melon, papaya, pineapple, kiwi, glacé } \\
\text { cherries, candied peel - e.g. mandarin } \\
\text { oranges }\end{array}$ \\
\hline Processed fruit snacks & $\begin{array}{l}\text { Processed from fruit purée and fruit juice } \\
\text { concentrates, may have added sugars and } \\
\text { other ingredients }\end{array}$ & $\begin{array}{l}\text { Fruit leathers, fruit pieces, packaged fruit } \\
\text { snacks }\end{array}$ \\
\hline
\end{tabular}

a Depending on production method some fruits may be classified in more than one category - e.g. cranberries and blueberries without added sugar.

Source: Sadler et al. (2019).

On the other hand, among the various stakeholders (producers, scientists, governmental agencies like $\mathrm{FAO} / \mathrm{WHO}$, and consumers), a substantial discrepancy exists about the understanding and interpretation of various food processing classification systems (Bleiweiss-Sande et al., 2019). While the NOVA system divides processing of foods into four categories (Monteiro et al., 2010), the IFIC systems identifies five categories (International Food Information Council Foundation, 2010), and the UNC divides it even into seven categories of processing (Poti et al., 2015). Interestingly, Sadler et al. (2019) proposed a classification system specifically for dried fruit based on the intrinsic characteristics (i.e., nutritional content, added ingredients) and processing methods and divided dried fruits into four categories: dried traditional, sugar-infused, candied and processed fruit snacks (Table 6.2). Though the latter system is fairly useful to represent different types of dried fruits, it did not (explicitly) cover several types of dried fruit such as freeze-dried 
fruit and low moisture dried fruit. To add to the complexity of the discrepancy, some focus group participants in this thesis (Chapter 2) also applied another way of categorizing products, e.g. in type of application in their consumption pattern, like a snack or an ingredient. Therefore, the categorization of Sadler et al. (2019) - as shown Table 6.2 - was adapted in this thesis.

Some critical reflections on the dried fruit categorization presented by Sadler et al. (2019):

1. The categorization simplifies the sugar content of dried fruits into several classes, yet it does not cover the range of the available dried fruits. Also it neglects the fact that sugars have a functional feature in food processing, e.g. sugars as osmotic agents to improve flavor, texture, and to incorporate functional compounds.

2. Dried fruit is consumed not only for its sugars. Consumers perceived its healthiness as found in this thesis. There are many health-promoting compounds present in the dried products and the possibilities and potentials to apply various processing technologies are numerous to meet the needs and wishes of consumers.

3. The categorization neglects the fact that dried fruit is not only consumed as a single product, it is consumed in the form of various food products - dried fruit-containing products - as an ingredient, both in home-made cooking or in manufactured products. These products thus contain different amount of sugars compared to that of dried fruit alone, regardless the type.

It is therefore proposed to include the point of view of consumers regarding the healthiness of dried fruit - as given in the above-mentioned considerations - in the categorization of dried fruit and products containing dried fruit as an ingredient.

It is complicated to assess the quality of a food and to determine what factors should be included. Assessment of the dried fruit quality can follow the healthy diet assessment proposed by The EAT-Lancet Commission on healthy diets from sustainable food systems (Willett et al., 2019). The Commission proposed that healthy diets have an appropriate caloric intake and consist of a diversity of plantbased foods, low amounts of animal source foods, unsaturated rather than saturated 
fats, and small amounts of refined grains, highly processed foods, and added sugars. Following that the assessment of a food depends on three aspects:

1. Criteria. - Set of desirable criteria to which quality dried fruit is produced. For dried fruit, the criteria could be sensory and nutritional quality (according to consumers \& technical product and process specifications).

2. Indicators. - Set of concrete indicators to meet the stated criteria, consisting of multiple variables which can be measured, incl. objective and subjective assessment. These will differ for various processing technologies, degree of processing - as illustrated in Fig 6.1 - and different fruits.

3. Reference values. - Reference values for each individual indicator, for instance desired target values or threshold levels, i.e. based on similar types of dried fruits.

The above-proposed assessment could be used to reduce the gap between the way consumers perceive dried fruit products and how other stakeholders classify them. Yet, to develop and establish a standardized assessment among the stakeholders remains a big task.

Eating context. The eating context also influences the consumer's health perception of dried mango, e.g. the position of dried mango in the diet (Chapter 2, Table 6.3). Eating dried mango as a snack was perceived as healthier than potato chips or other non-fruit snack foods, but less healthy than fresh fruits, this result was in line with Jesionkowska et al. (2007). While eating it as part of a meal - e.g. in muesli, added to yoghurt or porridge - for some focus group participants it was perceived as healthier than adding honey or syrup. This implies dried mango was regarded as a healthier sugar replacement to sweeten these products.

Food products differ in calorie (sugar, protein, and fat) and other nutritional contents per portion of consumption. Regarding sugar intake, WHO (2015) strongly recommends a reduced intake of free sugars, including monosaccharides and disaccharides added to foods and beverages by the manufacturer, cook or consumer, and sugars naturally present in honey, syrups, fruit juices and fruit juice concentrates. The latter suggests that the natural fruit sugars in traditional dried fruits are not defined as 'free sugars". There are various types of dried fruit and dried fruit products 
in the market and its consumption is difficult to estimate, thus it is not wise to simplify the assessment of dried fruit - on e.g. its healthiness - only by the degree of processing.

Table 6.3 Eating context of dried fruit mentioned by participants during focus group study

\begin{tabular}{lccc}
\hline Eating context & Chinese & Indonesians & Dutch \\
\hline Activity & & & \\
On-the-go & $\bullet$ & $\bullet$ & $\bullet$ \\
Working/studying & $\mathbf{X}$ & $\bullet$ & $\bullet$ \\
Gathering with family or friends & $\bullet$ & $\bullet$ & $\bullet$ \\
During sports & $\bullet$ & $\bullet$ & $\mathbf{X}$ \\
Leisure time & $\bullet$ & $\bullet$ & $\mathbf{X}$ \\
Special activity: Spring festival & $\bullet$ & $\mathbf{X}$ & \\
Position in the diet & & & $\bullet$ \\
Snack & $\bullet$ & $\bullet$ & $\bullet$ \\
Substitute for candy & $\mathbf{X}$ & $\bullet$ & $\mathbf{X}$ \\
As part of a meal & $\bullet$ & $\bullet$ & $\mathbf{X}$ \\
Other: as a souvenir & & & \\
\hline
\end{tabular}

$\bullet=$ mentioned; $\mathbf{X}=$ did not mention.

When consumers assessed intrinsic quality, both product and process characteristics were actually considered as relevant for perceived healthiness. These characteristics were derived from the sensory characteristics of the products based on their experience and/or expectation, as described in our model referencing TFQM (Fig 2.1).

It is worth mentioning that the two examples of dried mango product concepts were made through collaboration between consumer scientists and food technologists (Fig 2.1). This supports the study of Jacobsen et al. (2014) that indeed internal collaboration and communication between various disciplines within the food industry is essential for successful product and process design. During the iterative interaction, it turned out to be a challenging process due to different nature of both disciplines. For instance, each discipline has its own terminologies, and methods or 
approaches for completing a project, that is, exploring consumers' perception for product and process design. A successful collaboration between disciplines along NPD requires serious efforts from both parties. Willingness to exchange knowledge and information, agreement on a joint nomenclature (terms), goals and methods for completing a project in an early stage, keeping an open communication and establishing a proper framework for scientific exchanges, just to mentioned some of the efforts (Knapp et al., 2015).

\subsubsection{Lessons learned from the consumer preference of dried mango}

Consumer preference is differently influenced by perceived or experienced intrinsic quality attributes e.g. colour, taste, texture (Banović et al., 2012; Grunert et al., 1996a). Some consumers can weigh a certain attribute to be more important than other attributes, and vice versa, which can be due to different product familiarity and health consciousness.

It is demonstrated that different cultural background can influence consumer preferences on both intrinsic quality attributes and levels. In dried mango, the attributes 'texture' and 'extra ingredients' are the two most important attributes among the three countries studied. When designing healthy dried mango (dried fruit), it might be 'crunchy and no extra ingredients' or 'chewy and no extra ingredients' depending on the intended market. A cross-cultural consumer segmentation for product and process design of dried mango can be used as a tailor-made approach for dried fruit and vegetable targeting different countries, depending on the identified key quality attributes and preference (Onwezen \& Bartels, 2011; Sparke \& Menrad, 2009). The results of this study could give information on the iterative process that can be applied for translating the needs of consumers' insights into the final products (Chapter 2).

Unfortunately, cultural differences and individual preferences (Pollard et al., 2002; Sijtsema, et al., 2012) as well as experience in eating dried fruit in general (Banović et al., 2012) are not studied in the conjoint study. These factors may influence consumption (e.g. associated with preference in choosing a food) thus contributing to the level of product familiarity. Therefore, the results of the conjoint study only show a general overview of consumer preferences toward intrinsic attributes of dried 
mango by the three respondent groups irrespective of their dried fruit eating habits, taste preference, and other specific factors.

In contrast to earlier findings, e.g. Hersleth et al. (2011) and Frez-Muñoz et al. (2016), the conjoint study is unable to demonstrate that the differences between groups are influenced by familiarity - described as ever/never ate the product and local availability - or by health consciousness. Therefore, it will be beneficial to further study other relevant aspects of familiarity, such as product knowledge, taste preference (Robertson et al., 2018; Sijtsema et al., 2012), while adding extrinsic quality attributes for a more holistic understanding (Frez-Muñoz et al., 2016; Lee \& Lou, 2011).

Fortunately, the rich data from the focus group study helps to shed light on what influenced the difference. In the focus group study, consumers from different groups differed in their eating contexts of dried fruit, as shown in Table 6.3. For example, dried fruits were consumed as part of a meal by the Chinese and Dutch participants, but this was not mentioned by the Indonesians. This might be interpreted that cultural differences and individual preference may have an association with preference in choosing dried mango, hence this could have been further investigated. It is also suggested to confirm the results using sensitivity analysis in a market simulator to estimate the impact of attributes (Orme, 2010); the simulation could have been used for simulating market shares of several alternatives of dried mango concepts in this early stages of NPD (Gil \& Sánchez, 1997).

Both consumer studies conducted in this thesis focused in capturing the vertical dimension of the food quality; sensory (taste and appearance), convenience (easy to be consumed), health and process (at primary production and processing level) (Grunert et al., 1996b) (Fig 2.1, Chapter 2). As for the horizontal dimension of the quality, which addresses expectation and experience and expectation, it is an interesting field to be further investigated to have a better understanding of how consumers assess a food. 


\subsubsection{Technological studies: Osmotic dehydration of mango}

\subsubsection{Selection of mango material}

Mango (Mangifera indica var. Kent) used in all experiments of this thesis (Chapter 4 and 5) was originated from Brazil. It is not assure that there is no variation due to regional differences in the experiments (Liguori et al., 2018) and a possible effect of the growing condition, e.g. soil type, cultivation technique. Using mango from different plantations in a systematic way could have given information on the effect of growing condition on the nutritional and sensory quality of mango as raw material for dried mango.

Intrinsic characteristics of mango differ among varieties, i.e. shape, texture, color, and nutrient content. Mango var. Kent is suitable for producing osmo-dehydrated mango, e.g. has sufficient fiber, a good texture, thus it is easy to handle and easy to eat. Regarding availability, Kent variety has an established supply chain, so it is available in its season and has good quality. This variety is quite expensive as raw material for dried mango because of its high value as table mango in the global market (FAO, 2019a). This variety, however, is one of the most commonly used in "conventional" dried mango production. It is commercially produced in South Africa for the global market, beside var. Keitt and to a lesser degree Tommy Atkins, which are more fibrous (Gerbaud, 2016). This can be interpreted that use of Kent variety could be also a profitable option for the production of specialty dried mango targeting a higher market price.

The intrinsic characteristics of mango change during ripening due to biochemical changes. These changes lead to tissue softening and also the skin and pulp colors change (Palafox-Carlos et al., 2012; Yashoda et al., 2006). This study showed that using unripe and ripe mango resulted in distinct nutritional, textural and sensory characteristics of the final osmo-dehydrated product (Chapter 4). However, the ripening selection during the experiment resulted in a notable loss of whole mango material because of the detrimental firmness measurement using a fruit penetrometer. In addition, the chosen cube shape in preparing the mango adds to the loss. Although the study did not focus on the yield, the proportion of the waste is not feasible in real practice. For further studies and at industrial scale, the loss from 
ripeness selection can be minimized by the use of rapid and non-destructive sorting technology such as based on near-infrared spectroscopy (Marques et al., 2016). While for the shape of mango, slices can be used.

Ripe mango var. Kent used in this thesis showed that it is a suitable fruit material to have minimal uptake of sucrose at $4 \mathrm{~h}$ OD (Chapter 5). A wide range of mango variety with different characteristics, size and ripening process are available. For the application of the results to other mango varieties, further investigation is required. Particularly, mango varieties - also the less commonly used varieties - which have similar features to be suitable for drying, and those containing a considerable amount of natural fruit sugar, unique mango flavor, high vitamin $C$ and other health-promoting compounds can be further investigated.

Fragmented experimental studies comparing the quality of dried mango between some mango varieties have been performed (Dissa et al., 2011; Mahayothee et al., 2007; Rankins et al., 2008). Dissa et al. (2011) found that mango var. Amelie and Brooks were suitable for direct solar drying, while Rankins et al. (2008) found mango var. Amelie and Kent to be suitable for a greenhouse-type solar drying. Mahayothee et al. (2007) found that two Thai mango varieties - Nam Dokmai and Chok Anan yielded an intermediate moisture mango with superior sensory acceptance and $\beta$ carotene content after a conventional tray drying. Nevertheless, research questions on the effect of both the variety and the ripeness of mango on the quality of different types of dried mango remain.

\subsubsection{Quality of dehydrated mango: application of innovative osmotic dehydration}

Being a simple process, osmotic dehydration (OD) was chosen to acquire osmodehydrated mango. OD, also called a "dewatering impregnation soaking process" is a partial water removal process that involves soaking of fruit in hypertonic (osmotic) salt or sugar or in a combined solution that simultaneously increases the soluble solid content of the fruit (Torreggiani, 1993). This less energy intensive technology compared to other drying technologies - facilitates minimal processing of fruit with partial retention of initial fruit sensory and nutritional quality characteristics (Ahmed et al., 2016; Ramya \& Jain, 2017). In this thesis, the experimental design of OD 
technology aimed at improving the process and maintaining the sensory (e.g. color and texture), and nutritional quality (e.g. sucrose, vitamin C) of osmo-dehydrated mango. This was done by applying pre-treatments - vacuum impregnation (VI) and high pressure (HP) - before osmotic dehydration and adding a texturizing agent pectin methylesterase (PME) in the presence of calcium. The technological study consisted of two parts: (1) effects of different processing conditions on quality changes during OD (Chapter 4); and (2) mathematical modeling to capture these quality changes to optimize the process (Chapter 5).

Based on the literature, some OD process variables were kept constant, namely, mild temperature (Shi \& Xue, 2009), fruit to osmotic solution ratio (Ciurzyńska et al., 2016; Tortoe, 2010), type of osmotic agent and its concentration (Silva et al., 2014), the calcium concentration (Van Buggenhout et al., 2008), as shown in Fig 6.3.

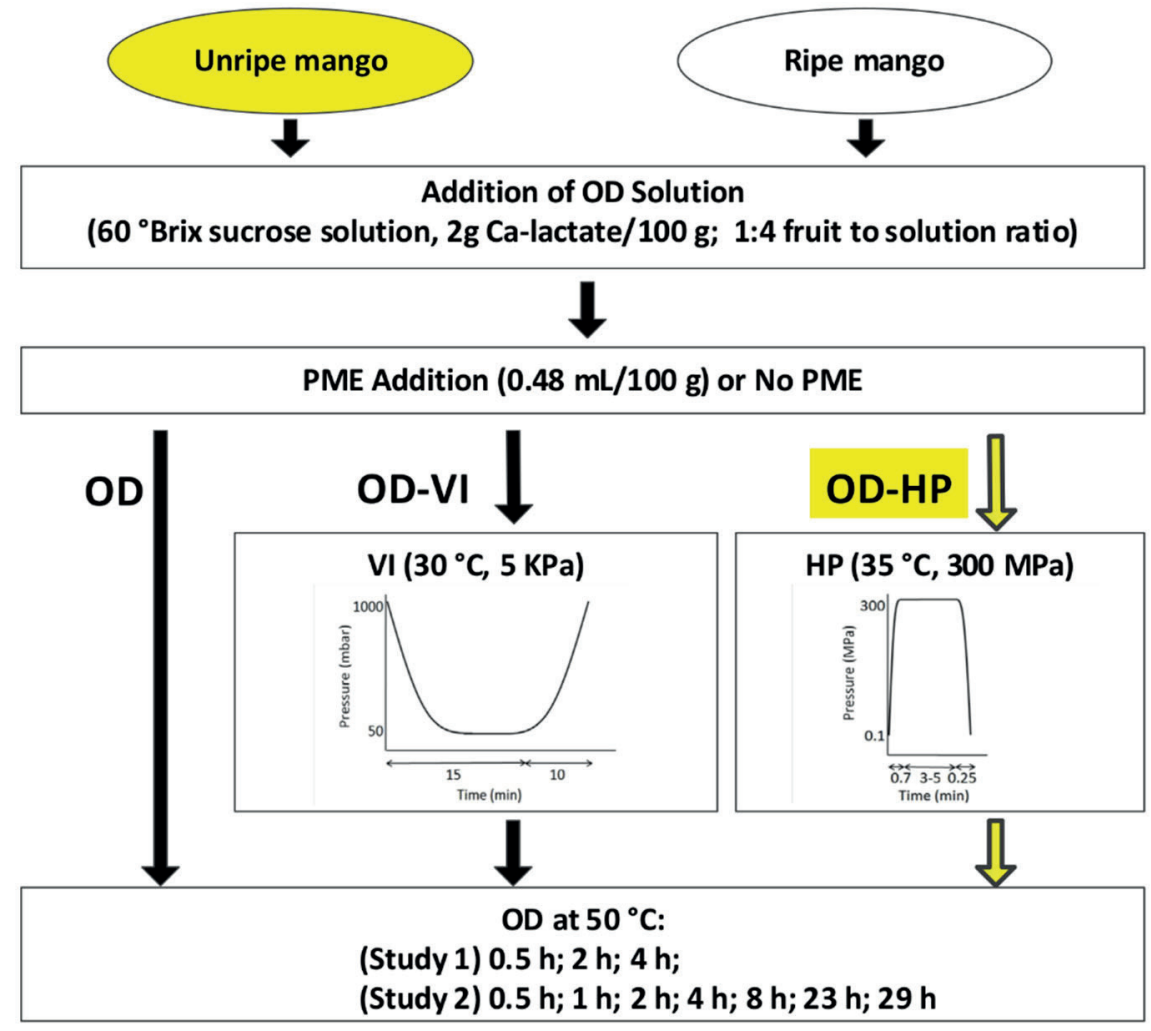

Fig 6.3 Experimental set up of the technological study consisting of two parts: Study 1 - Effect of OD processing conditions; Study 2 - mathematical modelling of OD quality changes. The yellow colored variables were only applied to Study 1 . 
Vacuum impregnation and high pressure were chosen for the pre-treatments because both technologies have been shown to enhance OD mass transfer and are highly potential to produce minimally processed fruits and vegetables (Ahmed et al., 2016; Huang et al., 2017) (Chapter 4 and 5, Fig 6.3).

Mango, as most fruits and vegetables, has a large number of pores (intercellular spaces) occupied by gas or fluid which give the possibility of being impregnated by external solutions (Fito et al., 2001). In this study, VI before OD (OD-VI) was employed to impregnate an external solution into mango. During OD-VI, the capillary impregnation and vacuum-induced impregnation occur simultaneously. Both impregnations expand internal gas in pores causing the gas partially flowing out of the pores (when vacuum is applied) and followed by compression sucking in the OD solution into the pores (Fito et al., 2001). Aside from the set-up of OD process variables, efficiency of $\mathrm{VI}$ is also influenced by factors associated with fruit tissue characteristics which are tissue structure (pore and size distribution), shape and size of the pores and capillary vessels (Chiralt \& Fito, 2003) (Fig 4.1). Ripe mango has a decrease in intercellular pore sizes and softer cellular structure (Brummell, 2006; Cantre et al., 2014). Therefore, as expected, OD-VI ripe mango had much lower impregnation (soluble solid gain, SSG), similar water loss (WL) resulting in a notable four to six-fold higher OD efficiency as compared to OD-VI unripe mango. Applying VI needs relatively cheaper initial investment cost compared to HPP and possible enrichment by adding probiotics or health promoting-compounds (e.g. flavonoids, calcium) in the osmotic solution could be done to produce a functional OD-VI mango (Betoret et al., 2012; Emser et al., 2017; Fito, Chiralt, Betoret, et al., 2001). Other than only for textural modification, the use of calcium lactate in this study has the potential to produce calcium-enriched OD-VI mango. For this functional purpose, the OD-VI mango should contain at least 10 percent more of the RDI for calcium per 100 $\mathrm{g}$ of food (FDA, 2019), but unfortunately it is not measured in this thesis.

High-pressure processing (HPP) is one of the most successful non-thermal technologies applied for minimally processed fruit and vegetable (Huang et al., 2017). $\mathrm{HP}$ pre-treatment was set at $300 \mathrm{MPa}$ for $5 \mathrm{~min}$ at a starting temperature of $35^{\circ} \mathrm{C}$. The decision was made based on the firmness, work of shear, and the water activity of mangoes after $2 \mathrm{~h} \mathrm{OD}$. In addition, this setting supports the maximum activity of 
PME - to create pectic gels with calcium - and inactivation of PG (Duvetter et al., 2006; Igual et al., 2013). For both unripe and ripe mango, OD-HP showed a similar but less pronounced effect as OD-VI on WL and SSG. This study suggests the application OD-HP without PME on unripe mango to produce candied mango with high SSG, the lowest WL and weight reduction, while minimizing color changes and maintaining fresh-like texture. However, from the real practice, applying HPP requires high initial investment costs in the equipment and slightly higher production costs as compared to traditional pasteurization. This makes the HPP products more expensive than non-HPP products with similar properties (Huang et al., 2017). Nevertheless, the use of HPP in this thesis provides insights that HPP is potential for producing value-added dried mango which has high value in international market, e.g. functional food by adding probiotics .

Commercial pectin methylesterase (PME) has been widely applied in fruit and vegetables processing. In OD plant products, added PME can de-methylate fruit pectin which can subsequently be bound by the available calcium into a calciumpectin gels and improve the fruit texture (Van Buggenhout et al., 2009). In this thesis, adding PME slightly improves the texture of OD mango (Chapter 3), but did not affect mass transfer nor to retain vitamin $C$ in mango during OD (Chapter 4). Increasing the concentration of added PME could be used to enhance the effect of added PME on textural attributes. Calcium L-lactate pentahydrate was used because it is a food grade ingredient and has higher solubility than other calcium salts (Fito et al., 2001). Although it is not the focus of these studies, the calcium gain should have been measured to have a more complete understanding of the mass transfer during OD.

When choosing an osmotic solution (OS) it is necessary to consider its specific effect during the $O D$ and on the final product quality. The osmotic agent costs, sensory compatibility and preservation action of the agents are among the factors considered. Sucrose is used due to its effectiveness, convenience and flavor. However, the $4 \mathrm{~h}$ OD mango of this study (Table 4.S1) could not yet be classified as an intermediate moisture food because it has $A_{w}>0.85$, though except OD-VI No PME, the moisture content have reached $50 \%$ (Ahmed et al., 2016). Mixed sucrose and salt solutions are one of the best choices of osmotic agents for the same reasons as that of sucrose 
(Tortoe, 2010). The mixture could have been used in OD mango to result in lower water activity $\left(A_{w}\right)$, although with a similar water loss compared to sucrose alone (Lenart \& Flink, 1984a). Thus it has the potential to produce an intermediate moisture mango. However, the lower $A_{w}$ was attributed to the extensive uptake of salt (Lenart \& Flink, 1984b), which could be a drawback for the sensory and health aspects of the product. Regarding the nutritional healthiness of sucrose, this ingredient indeed has been classified as added sugars and its intake for maximum $10 \%$ of total energy intake has been strongly recommended by WHO (WHO, 2015). However, it is worth to note that sucrose could be useful for OD of sour fruits like green immature mango, cape gooseberry, cranberry, and sour cherry.

Moreover, using a lower sucrose concentration for the osmotic solution (OS) will require longer time to reach a certain water loss and make the OD more costly and lower the OD efficiency. Moreover, a longer exposure to the OD process causes more vitamin $\mathrm{C}$ loss due to degradation (Chapter 5). Glucose has approximately twice the osmotic pressure at similar (weight) concentration of sucrose because it has nearly $50 \%$ molecular weight of sucrose. For this reason, replacing sucrose with glucose increases both solute penetration and water dehydration in the fruit tissue resulting in a higher sugar gain in the end product (Panagiotou et al., 1999). Additionally, due to the viscosity of the OS, a trade-off between the agitation speed and keeping the intactness of mango cubes was made, which might influence the homogeneity of the OS in the system.

Use of low or no-calorie as osmotic agents can be performed with, e.g. sorbitol, maltitol (Vilela et al., 2016). Sorbitol could be the best candidate to replace sucrose due to its potential to improve OD mass transfer at $25^{\circ} \mathrm{C}$ and $40{ }^{\circ} \mathrm{C}$ (Assis et al., 2017), but the textural and flavor characteristics of the sorbitol OD product deviate from that of sucrose (Vilela et al., 2016). Also, in a previous probiotic OD apple study, the use of a sucrose solution is preferred over that of sorbitol because of its efficiency in incorporating Lactobacillus plantarum in the $\mathrm{OD}$ apple and to obtain a longer viability during storage at $4^{\circ} \mathrm{C}$ (Emser et al., 2017). As an alternative to get the sensorial advantages of sucrose as an osmotic agent while limiting the sucrose gain, edible coatings - such as chitosan and carboxy methylcellulose (CMC) - could have been applied prior to OD (García et al., 2010; Jalaee et al., 2011). In these studies, 
use of $1 \%$ chitosan coating in OD papaya and $2 \%$ CMC in OD apple resulted in approx. twice more efficient than without coating, which were 2.3-3.5 and 2.5-3.8, respectively.

The results of this thesis show that $\mathrm{VI}$ and HP pre-treatments are able to produce OD mango featuring fresh-like texture and color (at $4 \mathrm{~h} \mathrm{OD),} \mathrm{Chapter} 4$. Also, this study has been able to demonstrate that these pre-treatments acted differently depend on intrinsic characteristics of food material, that is, the different ripeness of mango. The fruit tissue characteristics have been shown to influence the OD of fruit with different pre-treatments (Fig 4.1). The results of this study give insights in tailoring OD efficiency and achieving the desired quality of OD mango.

\subsubsection{Mathematical modelling}

The objectives of applying mathematical modelling in this thesis were to quantify the selection of processing methods and processing conditions to produce dried mango with specific quality characteristics to meet different consumer demands. In addition, modelling helps to gain mechanistic insight of the dehydration process and nutrient retention and can be used to optimize process conditions. Different models could have been used for these objectives. Mechanistic models have the advantage of yielding physical meaningful parameters and models that allow intra- and extrapolation when predicting conditions that have not been studied experimentally (Sarvan et al., 2014; Van Boekel, 2008). With empirical models this can easily result in inaccurate predictions. In this study mechanistic models have been used for describing the nutrient retention behavior. Truly mechanistic models for the mass transfer, could consist of spatial modelling of the diffusion and partitioning behavior of water and sugar through the fruit matrix inside and between the cells. Although such models could be interesting to apply they would have to consider the large degree of inhomogeneity of the fruit matrix at the microscopic scale, e.g. pectin content and composition (Sila et al., 2009). The added complexity of such models and its limited applicability in practice due to the large variation in raw material characteristics does not justify its use. Therefore, more general semi-mechanistic models were used for mass transfer modelling, with parameters that can be still be linked to the physical processes at the mesoscale. Previous studies had been 
demonstrated usefulness of the semi-mechanistic models, e.g., process-induced changes in glucosinolate content in Brassica vegetables (Nugrahedi et al., 2015), chlorophyll degradation in olives (Van Boekel, 2000).

Mathematical modeling as applied in this study is demonstrated to be a beneficial tool for describing the kinetics of mass transfer and vitamin $\mathrm{C}$ loss in mango during OD. In addition, the combination of the models can be used to optimize the process to improve the health aspects of OD mango. The kinetics of OD mass transfer was described by two commonly used empirical models, namely, the Peleg and Weibull models (Cunha et al., 2001; Peleg, 1988). Vitamin C loss during OD was described by a multiresponse model combining two mechanisms (1) degradation of vitamin C; and (2) leaching from mango cubes into the osmotic solution (OS) (Chapter 5, Fig 5.1). In order to formulate the mathematical equations of each mechanism, some assumptions were made. For instance, the leaching rate $r_{L}$ is proportional to the vitamin $C$ concentration difference between mango $T A A_{M}$ and the OD-solution $T A A_{S}$ (Sarvan et al., 2012). The degradation rate of vitamin $C$ both in mango and in the OS $r_{D}$ is described by a first-order reaction (Dermesonlouoglou et al., 2016; Katsoufi et al., 2017). Vitamin $C$ concentrations in time are described by combining the rate of leaching and that of degradation, correcting for the ratio in weights of OS to mango cubes - as they are changing during OD. This might be an oversimplification as explained in the earlier paragraph. Yet, this additional mechanism adds additional parameters to the model description.

The degradation rate of vitamin $\mathrm{C}$ in mango was found to be much faster than some other tropical fruits tested in high temperature conditions between 80-150 ${ }^{\circ} \mathrm{C}$ (Hiwilepo-van $\mathrm{Hal}$ et al., 2012). It is also worth to note that a high variation of vitamin $C$ content exists among mango varieties (Ribeiro \& Schieber, 2010). This suggests that further studies in the area of minimally processing of different varieties of mango such as optimizing a combined minimal processing technologies targeting for a certain product (i.e. no-added sugar calcium enriched dried mango using Kent variety and other varieties with similar features) is needed.

Regarding contribution of dried fruit consumption on the total carbohydrate intake, scenario 1 was taken for the estimation, as shown in Table 6.4. It is worth to note 
that the natural fruit sugars in traditional dried fruits are not defined as "free sugars" (WHO, 2015), and this sugars do not have Daily Value; while added sugar has a Daily Value of $50 \mathrm{~g}$ (FDA, 2016). From the OD optimization study (Chapter 5), OD with $\mathrm{PME}$ is favorable to produce $\mathrm{OD}$ mango with the lowest sugar uptake, highest vitamin $\mathrm{C}$ retention and shortest treatment time. While OD-VI with PME is favorable to produce sweeter OD mango with moderate vitamin C retention. In order to compare the estimated total carbohydrate intake from the dried mango consumption (Table 6.4) with that of fresh mango, one serving size (portion) of 40 gram product is used (FDA, 2016). A portion consumption of dried mango can give 1.5 to 2.5 -fold (3-5 \%DV) of total carbohydrate and about $20 \%$ less intake of vitamin C (10 \%DV) compared to that of fresh mango. It is worth to note that the actual serving size of fresh mango is $124 \mathrm{~g}$ (USDA, 2016), about three times the above mentioned. The contribution of dried mango consumption to total carbohydrate is considered as low (5\% DV or less in one serving) (FDA, 2016).

\subsection{Implications and prospective studies}

\subsubsection{Fruit ripeness and innovative osmotic dehydration: two important factors for tailoring product and process design of dried mango}

The use of ripeness of mango and innovative osmotic dehydration resulted in different quality of OD mango upon pre-treatments. This knowledge is valuable to tailor product and process design of dried mango. Osmo-dehydrated unripe mango resulted in a remarkable two to five-fold higher SSG compared to ripe mango for all treatments. Unripe mango pretreated with OD-VI had the lowest $\mathrm{WL}$ and the highest SSG, while OD-HP had a similar but less pronounced effect. This results is a useful information for further research to develop functional dried mango by innovative OD, e.g. incorporating prebiotics or probiotics compounds, partial replacement sucrose with low caloric solutes or the use of edible coatings in the unripe mango material. Relatedly, the optimized OD process using the mechanistic modelling approach is demonstrated to be valuable to explain the behavior of water, sucrose and vitamin $C$ in mango during OD. These useful results need to be formulated in a simple message in order to successfully introduce to small or medium dried mango industries. 


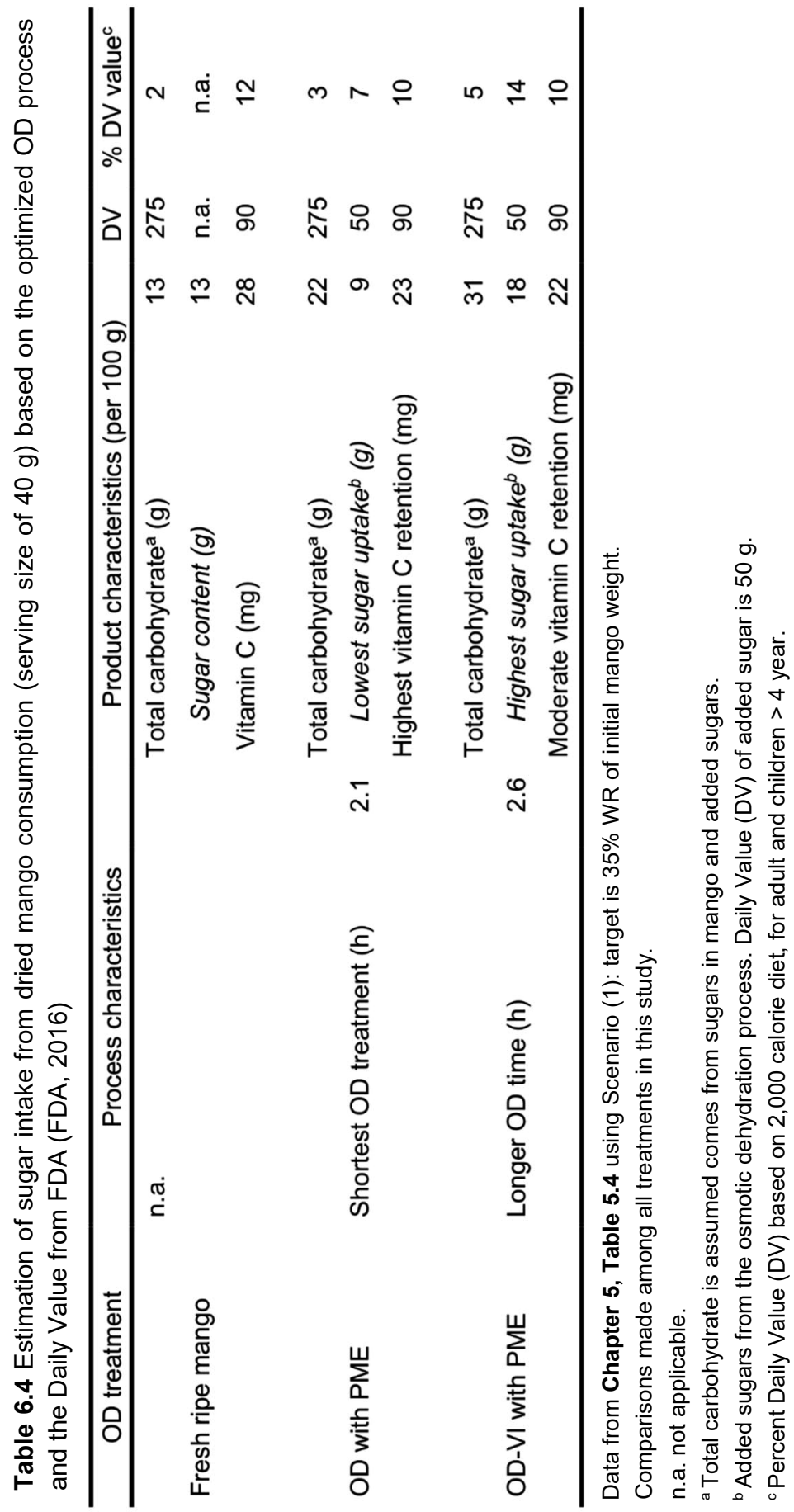


The approach in optimizing quality of osmo-dehydrated mango in this thesis can be extended as a model to other mango varieties or other climacteric fruits with unique sensory characteristics and beneficial health-promoting compounds.

\subsubsection{An interdisciplinary approach in product and process design: Potential benefits and overcome weak points}

Cultural context influences consumer preference of food products, as it is demonstrated that culture influences consumer preferences on both intrinsic quality attributes and levels. These results can give insights on how to inform consumers accurately regarding the newer technologies that can be used to produce their desired dried mango. Relatedly, a cross-cultural consumer segmentation for product and process design of dried mango can be used as a tailor-made approach for developing dried fruit and vegetables targeting different countries.

Improving the quality of food based on consumer-oriented NPD means that consumer insights should be well-translated into the final products along the product and process design - to drive the NPD. Consumers' health perception of other minimally processed fruit and vegetable is an interesting field to explore, given the knowledge about consumers' actual interpretation of healthy products. This knowledge gives insights and helps in understanding how consumers use different representation levels on healthy food from a concrete level (e.g. "the dried fruit contains minerals"), but also at a more abstract level (e.g. "dried fruit is a processed product") (Ronteltap et al., 2012). This study can be a basis to develop further studies on product and process design (PPD) of minimally processed fruits and vegetables.

Adding the ascribed interrelation into the Total Food Quality Model (TFQM) of Grunert (2005) and linking the consumer perception to this adapted model were demonstrated to be useful for product and process design. Iterative collaboration along the PPD is essential, thus further studies performing such a collaborative approach need to be tested for its effectiveness. For instance, to test, develop and optimize the translation of consumer insights in the later stages of the NPD by: 1) Quality Function Deployment (QFD) into several product concepts targeting certain consumer segments (Costa et al., 2000); 2) a descriptive sensory study involving end-user panels (Kemp et al., 2018). 
A collaboration between consumer scientists and food technologists was demonstrated to be useful in the early stages of NPD (Chapter 2). However, in this thesis, the demonstrated collaboration in the early stages of NPD was only at "one point' of the suggested iterative process along NPD. Although the interaction between only two disciplines along the NPD is not of practical reality, the demonstrated iterative process could serve as a model to assure the selected characteristics came from the consumers were effectively translated in the final products. If the collaboration did not take place, the translation of consumer insights into technical product and process specification could be inaccurate leading to failure of introducing new products to the market. Table 6.5 shows some possible benefits of collaboration between the two disciplines for product and process design.

Table 6.5 Possible benefits of collaboration between consumer scientists - food technologists in product and process design (PPD)

\begin{tabular}{|c|c|c|}
\hline \multicolumn{2}{|c|}{ Possible benefits of the collaboration for: } & \multirow{2}{*}{$\begin{array}{l}\text { Weak points that can } \\
\text { be overcome by } \\
\text { collaboration }\end{array}$} \\
\hline Consumer scientists & Food technologists & \\
\hline $\begin{array}{l}\text { Insights in the food value chain } \\
\text { regarding quality changes of } \\
\text { fresh material until it reaches } \\
\text { consumers }\end{array}$ & $\begin{array}{l}\text { Insights on which key quality } \\
\text { attributes and levels to create } \\
\text { healthy products based on } \\
\text { consumers' perceived benefit } \\
\text { and preference } \\
\rightarrow \text { may help in narrowing } \\
\text { down the generation and } \\
\text { selection of promising product } \\
\text { concepts }\end{array}$ & $\begin{array}{l}\text { - Time needed in } \\
\text { PPD to do "trial } \\
\text { and error" } \\
\rightarrow \text { can be avoided } \\
\text { - Working on to-be- } \\
\text { failed products } \\
\rightarrow \text { can be } \\
\text { minimized }\end{array}$ \\
\hline $\begin{array}{l}\text { - Insight in mechanisms taking } \\
\text { place during food processing } \\
\rightarrow \text { may lead to a more defined } \\
\text { consumer study } \\
\text { - Insights in how to involve } \\
\text { consumers in each step of } \\
\text { product and process design } \\
\rightarrow \text { may help in incorporating } \\
\text { product and process } \\
\text { characteristics along NPD }\end{array}$ & $\begin{array}{l}\text { - Insights on consumer } \\
\text { misconception and confusion of } \\
\text { a product } \\
\rightarrow \text { how to advice and deliver } \\
\text { clear messages to consumers } \\
\text { about the product }\end{array}$ & $\begin{array}{l}\text { - Inappropriateness } \\
\text { in product labelling } \\
\rightarrow \text { can be avoided }\end{array}$ \\
\hline
\end{tabular}




\subsection{Main conclusions}

Exploration of consumers' quality perception is relevant in early stages of product and process design. The insights of consumer perceptions required iterative interactions between consumer scientists and food technologists to achieve relevant product and process characteristics in the simultaneous design of the technical product and process specifications.

Consumers have different nutritional, texture, taste and colour preferences for dried mango among the studied countries.

Use of different ripeness of mango resulted in different quality of OD mango upon pre-treatments. Osmo-dehydrated unripe mango resulted in a remarkable two to five-fold higher SSG compared to ripe mango for all treatments.

The observed effects of $\mathrm{VI}$ and $\mathrm{HP}$ applied to unripe and ripe mango are valuable to tailor OD efficiency and achieve the desired quality of OD mango.

The combination of modelling the mass transfer and vitamin $\mathrm{C}$ retention was shown to be valuable to optimize sugar content, vitamin $C$ retention and processing time of OD mango.

Taken together, this thesis highlights the importance of consumer and food technological insights for improving the quality of osmo-dehydrated mango during product and process design. Application of the insights into product and process design requires collaboration between consumer scientists and food technologists for successful new product development.

\section{References}

Ahmed, I., Qazi, I. M., \& Jamal, S. (2016). Developments in osmotic dehydration technique for the preservation of fruits and vegetables. Innovative Food Science and Emerging Technologies, 34, 29-43. https://doi.org/10.1016/j.ifset.2016.01.003

Alasalvar, C., \& Shahidi, F. (2013). Composition, phytochemicals, and beneficial health effects of dried fruits: an overview. In C. Alasalvar \& F. Shahidi (Eds.), 
Dried Fruits: Phytochemicals and Health Effects (First Ed., p. 18). John Wiley \& Sons, Inc.

Alphonce, R., Temu, A., \& Almli, V. L. (2015). European consumer preference for African dried fruits. British Food Journal, 117(7), 1886-1902. https://doi.org/10.1108/BFJ-10-2014-0342

Artés, F., \& Allende, A. (2005). Minimal fresh processing of vegetables, fruits and juices. In Emerging Technologies for Food Processing (pp. 677-716). Elsevier Ltd. https://doi.org/10.1016/B978-012676757-5/50028-1

Asioli, D., Aschemann-Witzel, J., Caputo, V., Vecchio, R., Annunziata, A., Næs, T., \& Varela, P. (2017). Making sense of the "clean label" trends: A review of consumer food choice behavior and discussion of industry implications. Food Research International, 99(July), 58-71. https://doi.org/10.1016/j.foodres.2017.07.022

Assis, F. R., Morais, R. M. S. C., \& Morais, A. M. M. B. (2017). Mathematical Modelling of Osmotic Dehydration Kinetics of Apple Cubes. Journal of Food Processing and Preservation, 41(3). https://doi.org/10.1111/jfpp.12895

Banović, M., Fontes, M. A., Barreira, M. M., \& Grunert, K. G. (2012). Impact of product familiarity on beef quality perception. Agribusiness, 28(2), 157-172. https://doi.org/10.1002/agr.21290

Betoret, E., Sentandreu, E., Betoret, N., Codoñer-Franch, P., Valls-Bellés, V., \& Fito, P. (2012). Technological development and functional properties of an apple snack rich in flavonoid from mandarin juice. Innovative Food Science and Emerging Technologies, 16, 298-304. https://doi.org/10.1016/j.ifset.2012.07.003

Bleiweiss-Sande, R., Chui, K., Evans, E. W., Goldberg, J., Amin, S., \& Sacheck, J. (2019). Robustness of Food Processing Classification Systems. Nutrients, 11(6), 1344. https://doi.org/10.3390/nu11061344

Brummell, D. A. (2006). Cell wall disassembly in ripening fruit. Functional Plant Biology, 33(2), 103-119. https://doi.org/10.1071/FP05234

Bruns $\varnothing$, K., Verbeke, W., Olsen, S. O., \& Jeppesen, L. F. (2009). Motives, barriers and quality evaluation in fish consumption situations: Exploring and comparing heavy and light users in Spain and Belgium. British Food Journal, 111(7), 699716. https://doi.org/10.1108/00070700910972387

Bruseberg, A., \& McDonagh-Philp, D. (2002). Focus groups to support the industrial/product designer: A review based on current literature and designers' feedback. Applied Ergonomics, 33(1), 27-38. https://doi.org/10.1016/S00036870(01)00053-9

Cantre, D., Herremans, E., Verboven, P., Ampofo-Asiama, J., \& Nicolaï, B. (2014). Characterization of the 3-D microstructure of mango (Mangifera indica L. Cv. Carabao) during ripening using X-ray computed microtomography. Innovative Food Science and Emerging Technologies, 24, 28-39. https://doi.org/10.1016/j.ifset.2013.12.008

CBI. (2019a). Exporting dried tropical fruit to Europe. CBI - Centre for the Promotion 
of Imports from Developing Countries. https://www.cbi.eu/node/2767/pdf/

CBI. (2019b). What is the demand for processed fruit and vegetables in the European market? CBI - Centre for the Promotion of Imports from Developing Countries.

Chang, S. K., Alasalvar, C., \& Shahidi, F. (2016). Review of dried fruits: Phytochemicals, antioxidant efficacies, and health benefits. Journal of Functional Foods, 21, 113-132. https://doi.org/10.1016/j.jff.2015.11.034

Chiralt, A., \& Fito, P. (2003). Transport Mechanisms in Osmotic Dehydration: The Role of the Structure. Food Science and Technology International, 9, 179-186. https://doi.org/10.1177/108201303034757

Ciurzyńska, A., Kowalska, H., Czajkowska, K., \& Lenart, A. (2016). Osmotic dehydration in production of sustainable and healthy food. Trends in Food Science and Technology, 50, 186-192. https://doi.org/10.1016/j.tifs.2016.01.017

Costa, A. I. A., Dekker, M., \& Jongen, W. M. F. (2000). Quality function deployment in the food industry: A review. In Trends in Food Science and Technology (Vol. 11, Issues 9-10, pp. 306-314). https://doi.org/10.1016/S0924-2244(01)000024

Cunha, L. M., Oliveira, F. A. R., Aboim, A. P., Frías, J. M., \& Pinheiro-Torres, A. (2001). Stochastic approach to the modelling of water losses during osmotic dehydration and improved parameter estimation. International Journal of Food Science and Technology, 36(3), 253-262. https://doi.org/10.1046/j.13652621.2001.t01-1-00447.x

Dermesonlouoglou, E. K., Giannakourou, M., \& Taoukis, P. S. (2016). Kinetic study of the effect of the osmotic dehydration pre-treatment with alternative osmotic solutes to the shelf life of frozen strawberry. Food and Bioproducts Processing, 99(2004), 212-221. https://doi.org/10.1016/j.fbp.2016.05.006

Dissa, A. O., Bathiebo, D. J., Desmorieux, H., Coulibaly, O., \& Koulidiati, J. (2011). Experimental characterisation and modelling of thin layer direct solar drying of Amelie and Brooks mangoes. Energy, 36(5), 2517-2527. https://doi.org/10.1016/j.energy.2011.01.044

Duvetter, T., Fraeye, I., Sila, D. N., Verlent, I., Smout, C., Clynen, E., Schoofs, L., Schols, H., Hendrickx, M., \& Van Loey, A. (2006). Effect of temperature and high pressure on the activity and mode of action of fungal pectin methyl esterase. Biotechnology Progress, 22(5), 1313-1320. https://doi.org/10.1021/bp060079x

Emser, K., Barbosa, J., Teixeira, P., \& Bernardo de Morais, A. M. M. (2017). Lactobacillus plantarum survival during the osmotic dehydration and storage of probiotic cut apple. Journal of Functional Foods, 38, 519-528. https://doi.org/10.1016/j.jff.2017.09.021

FAO. (2019a). Major tropical fruits: Market review 2018. http://www.wipo.int/amc/en/mediation/rules

FAO. (2019b). Major tropical fruits: Statistical compendium 2018. 
FDA. (2016). $\%$ Daily Value. https://www.accessdata.fda.gov/scripts/InteractiveNutritionFactsLabel/pdv.ht $\mathrm{ml}$

Fito, P., Chiralt, A., Barat, J. M., Andrés, A., Martínez-Monzó, J., \& MartínezNavarrete, N. (2001). Vacuum impregnation for development of new dehydrated products. Journal of Food Engineering, 49(4), 297-302. https://doi.org/10.1016/S0260-8774(00)00226-0

Fito, P., Chiralt, A., Betoret, N., Gras, M., Cháfer, M., Martínez-Monzó, J., Andrés, A., \& Vidal, D. (2001). Vacuum impregnation and osmotic dehydration in matrix engineering: Application in functional fresh food development. Journal of Food Engineering, 49(2-3), 175-183. https://doi.org/10.1016/S02608774(00)00220-X

Frez-Muñoz, L., Steenbekkers, B. L. P. A., \& Fogliano, V. (2016). The choice of canned whole peeled tomatoes is driven by different key quality attributes perceived by consumers having different familiarity with the product. Journal of Food Science, 81(12), S2988-S2996. https://doi.org/10.1111/17503841.13539

García, M., Díaz, R., Martínez, Y., \& Casariego, A. (2010). Effects of chitosan coating on mass transfer during osmotic dehydration of papaya. Food Research International, 43(6), 1656-1660. https://doi.org/10.1016/j.foodres.2010.05.002

Gerbaud, P. (2016). Dried mango: A developing diversification niche. FruitTrop Magazine, 244, 30-33. https://www.fruitrop.com/en/Articles-bysubject/Economic-analyses/2016/Dried-mango

Gil, J. M., \& Sánchez, M. (1997). Consumer preferences for wine attributes: a conjoint approach. British Food Journal, 99(1), 3-11.

Grunert, K. G. (2005). Food quality and safety: consumer perception and demand. European Review of Agricultural Economics, 32(3), 369-391. https://doi.org/10.1093/eurrag/jbi011

Grunert, K. G., Hartvig Larse, H., Madsen, T. K., \& Baadsgaard, A. (1996a). Analysing consumers at the individual level. In Market orientation in food and agriculture (pp. 75-111). Kluwer Academic Publisher.

Grunert, K. G., Hartvig Larse, H., Madsen, T. K., \& Baadsgaard, A. (1996b). Market orientation in food and agriculture. Kluwer Academic Publisher. https://doi.org/10.1007/978-1-4613-1301-4

Hayashi, H. (1989). Drying Technologies of Foods -Their History and Future. Drying Technology, 7(2), 315-369.

Hersleth, M., Lengard, V., Verbeke, W., Guerrero, L., \& Næs, T. (2011). Consumers' acceptance of innovations in dry-cured ham: Impact of reduced salt content, prolonged aging time and new origin. Food Quality and Preference, 22(1), 3141. https://doi.org/10.1016/j.foodqual.2010.07.002

Hiwilepo-van Hal, P., Bosschaart, C., van Twisk, C., Verkerk, R., \& Dekker, M. (2012). Kinetics of thermal degradation of vitamin $\mathrm{C}$ in marula fruit (Sclerocarya birrea subsp. caffra) as compared to other selected tropical fruits. LWT - Food 
Science and Technology, 49(2), 188-191. https://doi.org/10.1016/j.Iwt.2011.12.038

Huang, H. W., Wu, S. J., Lu, J. K., Shyu, Y. T., \& Wang, C. Y. (2017). Current status and future trends of high-pressure processing in food industry. Food Control, 72(Part A), 1-8. https://doi.org/10.1016/j.foodcont.2016.07.019

Igual, M., Sampedro, F., Martínez-Navarrete, N., \& Fan, X. (2013). Combined osmodehydration and high pressure processing on the enzyme stability and antioxidant capacity of a grapefruit jam. Journal of Food Engineering, 114(4), 514-521. https://doi.org/10.1016/j.jfoodeng.2012.09.006

INC. (2018). Nuts \& Dried Fruits: Statistical Yearbook 2018/2019. https://www.nutfruit.org

International Food Information Council Foundation. (2010). Understanding Our Food Communication Tool Kit: Leader Guide. www.Foodlnsight.org

Jacobsen, L. F., Grunert, K. G., Søndergaard, H. A., Steenbekkers, B., Dekker, M., \& Lähteenmäki, L. (2014). Improving internal communication between marketing and technology functions for successful new food product development. In Trends in Food Science and Technology (Vol. 37, Issue 2, pp. 106-114). Elsevier Ltd. https://doi.org/10.1016/j.tifs.2014.03.005

Jalaee, F., Fazeli, A., Fatemian, H., \& Tavakolipour, H. (2011). Mass transfer coefficient and the characteristics of coated apples in osmotic dehydrating. Food and Bioproducts Processing, 89(4), 367-374. https://doi.org/10.1016/j.fbp.2010.09.012

Jervis, S. M., Ennis, J. M., \& Drake, M. A. (2012). A Comparison of Adaptive ChoiceBased Conjoint and Choice-Based Conjoint to Determine Key Choice Attributes of Sour Cream with Limited Sample Size. Journal of Sensory Studies, 27(6), 451-462. https://doi.org/10.1111/joss.12009

Jesionkowska, K., Konopacka, D., Płocharski, W., Sijtsema, S., \& Zimmermann, K. (2007). What do Polish and Dutch consumers think about dried fruit and products with them - Creative group discussions as a means of recognition consumers' perceptions. Polish Journal of Natural Sciences, Supplement No.4, 169-175.

Katsoufi, S., Lazou, A. E., Giannakourou, M. C., \& Krokida, M. K. (2017). Mass transfer kinetics and quality attributes of osmo-dehydrated candied pumpkins using nutritious sweeteners. Journal of Food Science and Technology, 54(10), 3338-3348. https://doi.org/10.1007/s13197-017-2786-2

Keast, D. R., O'Neil, C. E., \& Jones, J. M. (2011). Dried fruit consumption is associated with improved diet quality and reduced obesity in US adults: National Health and Nutrition Examination Survey, 1999-2004. Nutrition Research. https://doi.org/10.1016/j.nutres.2011.05.009

Kemp, S. E., Hort, J., \& Hollowood, T. (2018). Descriptive Analysis in Sensory Evaluation (S. E. Kemp, J. Hort, \& T. Hollowood (eds.)). John Wiley \& Sons, Ltd. https://doi.org/10.1002/9781118991657

Knapp, B., Bardenet, R., Bernabeu, M. O., Bordas, R., Bruna, M., Calderhead, B., 
Cooper, J., Fletcher, A. G., Groen, D., Kuijper, B., Lewis, J., Mclnerny, G., Minssen, T., Osborne, J., Paulitschke, V., Pitt-Francis, J., Todoric, J., Yates, C. A., Gavaghan, D., \& Deane, C. M. (2015). Ten simple rules for a successful cross-disciplinary collaboration. PLoS Computational Biology, 11(4), e1004214. https://doi.org/10.1371/journal.pcbi.1004214

Lee, M., \& Lou, Y.-C. (2011). Consumer Reliance On Intrinsic And Extrinsic Cues In Product Evaluations: A Conjoint Approach. Journal of Applied Business Research (JABR), 12(1), 21. https://doi.org/10.19030/jabr.v12i1.5833

Lenart, A., \& Flink, J. M. (1984a). Osmotic concentration of potato. I. Criteria for the end-point of the osmosis process. International Journal of Food Science \& Technology, 19(1), 45-63. https://doi.org/10.1111/j.1365-2621.1984.tb00326.x Lenart, A., \& Flink, J. M. (1984b). Osmotic concentration of potato. II. Spatial distribution of the osmotic effect. International Journal of Food Science \& Technology, 19(1), 65-89. https://doi.org/10.1111/j.1365-2621.1984.tb00327.x Liguori, G., Sortino, G., Gianguzzi, G., Inglese, P., \& Farina, V. (2018). Evaluation of quality attributes and consumer preference of fresh or imported mangoes in Italy. AIMS Agriculture and Food, 3(4), 426-440. https://doi.org/10.3934/agrfood.2018.4.426

Liu, Y., Wang, Z., \& Zhang, J. (2015). Dietary Chinese herbs: Chemistry, pharmacology and clinical evidence. In Dietary Chinese Herbs. Springer. https://doi.org/10.1007/978-3-211-99448-1

Mahayothee, B., Neidhart, S., Carle, R., \& Mühlbauer, W. (2007). Effects of variety, ripening condition and ripening stage on the quality of sulphite-free dried mango slices. European Food Research and Technology, 225(5-6), 723-732. https://doi.org/10.1007/s00217-006-0475-x

Marques, E. J. N., De Freitas, S. T., Pimentel, M. F., \& Pasquini, C. (2016). Rapid and non-destructive determination of quality parameters in the 'Tommy Atkins' mango using a novel handheld near infrared spectrometer. Food Chemistry, 197(Part B), 1207-1214. https://doi.org/10.1016/j.foodchem.2015.11.080

Monteiro, C. A., Levy, R. B., Claro, R. M., de Castro, I. R. R., \& Cannon, G. (2010). A new classification of foods based on the extent and purpose of their processing. Cadernos de Saude Publica, 26(11), 2039-2049. https://doi.org/10.1590/S0102-311X2010001100005

Monteiro CA, Cannon G, Levy R, Moubarac JC, Jaime P, Martins AP, Canella D, Louzada M, Parra D, R. C. (2016). NOVA. The star shines bright. World Nutrition, 7(1), 28-38.

Mossine, V. V, Mawhinney, T. P., \& Giovannucci, E. L. (2019). Dried Fruit Intake and Cancer: A Systematic Review of Observational Studies. Advances in Nutrition, 8, 1-14. https://doi.org/10.1093/advances/nmz085

Nielsen. (2017). On-The-Go Produce Snacking: A Billion Dollar Industry and Growing.

Nugrahedi, P. Y., Verkerk, R., Widianarko, B., \& Dekker, M. (2015). A Mechanistic 
Perspective on Process-Induced Changes in Glucosinolate Content in Brassica Vegetables: A Review. Critical Reviews in Food Science and Nutrition, 55(6), 823-838. https://doi.org/10.1080/10408398.2012.688076

Olayanju, J. B. (2019). Perspectives on the Future of Snacking. Forbes. https://www.forbes.com

Onwezen, M. C., \& Bartels, J. (2011). Which perceived characteristics make product innovations appealing to the consumer? A study on the acceptance of fruit innovations using cross-cultural consumer segmentation. Appetite, 57(1), 5058. https://doi.org/10.1016/j.appet.2011.03.011

Orme, B. K. (2010). Getting Started with Conjoint Analysis: Strategies for Product Design and Pricing Research (2nd ed.). Research Publishers LLC.

Palafox-Carlos, H., Yahia, E., Islas-Osuna, M. A., Gutierrez-Martinez, P., RoblesSánchez, M., \& González-Aguilar, G. A. (2012). Effect of ripeness stage of mango fruit (Mangifera indica L., cv. Ataulfo) on physiological parameters and antioxidant activity. Scientia Horticulturae, 135, 7-13. https://doi.org/10.1016/J.SCIENTA.2011.11.027

Panagiotou, N. M., Karathanos, V. T., \& Maroulis, Z. B. (1999). Effect of osmotic agent on osmotic dehydration of fruits. Drying Technology, 17(1-2), 175-189. https://doi.org/10.1080/07373939908917524

Pasha, I., Saeed, F., Sultan, M. T., Khan, M. R., \& Rohi, M. (2014). Recent Developments in Minimal Processing: A Tool to Retain Nutritional Quality of Food. Critical Reviews in Food Science and Nutrition, 54(3), 340-351. https://doi.org/10.1080/10408398.2011.585254

Peleg, M. (1988). An Empirical Model for the Description of Moisture Sorption Curves. Journal of Food Science, 53(4), 1216-1217. https://doi.org/10.1111/j.13652621.1988.tb13565.x

Perera, C. O. (2005). Selected Quality Attributes of Dried Foods. Drying Technology, 23(4), 717-730. https://doi.org/10.1081/DRT-200054180

Pollard, J., Kirk, S. F. L., \& Cade, J. E. (2002). Factors affecting food choice in relation to fruit and vegetable intake: a review. Nutrition Research Reviews, 15(2), 373-387. https://doi.org/10.1079/NRR200244

Poti, J. M., Mendez, M. A., Ng, S. W., \& Popkin, B. M. (2015). Is the degree of food processing and convenience linked with the nutritional quality of foods purchased by US households? The American Journal of Clinical Nutrition, 101(6), 1251-1262. https://doi.org/10.3945/ajcn.114.100925

Qiu, L., Zhang, M., Tang, J., Adhikari, B., \& Cao, P. (2019). Innovative technologies for producing and preserving intermediate moisture foods: A review. Food Research International, 116, 90-102. https://doi.org/10.1016/j.foodres.2018.12.055

Ramya, V., \& Jain, N. K. (2017). A Review on Osmotic Dehydration of Fruits and Vegetables: An Integrated Approach. Journal of Food Process Engineering, 40(3), 1-22. https://doi.org/10.1111/jfpe.12440

Rankins, J., Sathe, S. K., \& Spicer, M. T. (2008). Solar Drying of Mangoes: 
Preservation of an Important Source of Vitamin A in French-Speaking West Africa. Journal of the American Dietetic Association, 108(6), 986-990. https://doi.org/10.1016/j.jada.2008.03.013

Ratti, C. (2009). Advances in Food Dehydration (D.-W. Sun (ed.); First Edit). CRC Press.

Ribeiro, S. M. R., \& Schieber, A. (2010). Bioactive compounds in mango (Mangifera indica L.). Bioactive Foods in Promoting Health, 507-523. https://doi.org/10.1016/B978-0-12-374628-3.00034-7

Robertson, J., Ferreira, C., \& Botha, E. (2018). The influence of product knowledge on the relative importance of extrinsic product attributes of wine. Journal of Wine Research, 29(3), 159-176. https://doi.org/10.1080/09571264.2018.1505605

Rodgers, S. (2016). Minimally Processed Functional Foods: Technological and Operational Pathways. In Journal of food science (Vol. 81, Issue 10, pp. R2309-R2319). Blackwell Publishing Inc. https://doi.org/10.1111/17503841.13422

Ronteltap, A., Sijtsema, S. J., Dagevos, H., \& de Winter, M. A. (2012). Construal levels of healthy eating. Exploring consumers' interpretation of health in the food context. Appetite, 59(2), 333-340. https://doi.org/10.1016/j.appet.2012.05.023

Sadler, Michèle Jeanne. (2016). Dried fruit and dental health. International Journal of Food Sciences and Nutrition, 67(8), 944-959. https://doi.org/10.1080/09637486.2016.1207061

Sadler, Michele Jeanne, Gibson, S., Whelan, K., Ha, M. A., Lovegrove, J., \& Higgs, J. (2019). Dried fruit and public health-what does the evidence tell us? International Journal of Food Sciences and Nutrition, 70(6), 675-687. https://doi.org/10.1080/09637486.2019.1568398

Sarvan, I., Verkerk, R., \& Dekker, M. (2012). Modelling the fate of glucosinolates during thermal processing of Brassica vegetables. LWT - Food Science and Technology, 49(2), 178-183. https://doi.org/10.1016/j.Iwt.2012.07.005

Sarvan, I., Verkerk, R., Van Boekel, M., \& Dekker, M. (2014). Comparison of the degradation and leaching kinetics of glucosinolates during processing of four Brassicaceae (broccoli, red cabbage, white cabbage, Brussels sprouts). Innovative Food Science and Emerging Technologies, 25(C), 58-66. https://doi.org/10.1016/j.ifset.2014.01.007

Shi, J., \& Xue, S. J. (2009). Application and Development of Osmotic Dehydration Technology in Food Processing. In C. Ratti (Ed.), Advances in Food Dehydration (pp. 187-208). CRC Press. https://doi.org/10.1201/9781420052534-13

Siddiqui, W., Chakraborty, I., Ayala-Zavala, J. F., \& Dhua, R. S. (2011). Advances in minimal processing of fruits and vegetables: a review. Journal of Scientific \& Industrial Research, 70, 823-834.

Sijtsema, S. J., Reinders, M. J., Hiller, S. R. C. H., \& Dolors Guàrdia, M. (2012). Fruit 
and snack consumption related to sweet, sour and salty taste preferences. British Food Journal, 114(7), 1032-1046. https://doi.org/10.1108/00070701211241608

Sijtsema, S. J., Zimmermann, K., Cvetković, M., Stojanovic, Z., Spiroski, I., Milosevic, J., Mora, C., Butigan, R., Mugosa, B., Esteve, M., \& Pohar, J. (2012). Consumption and perception of processed fruits in the Western Balkan region. LWT - Food Science and Technology, 49(2), 293-297. https://doi.org/10.1016/j.Iwt.2012.07.025

Sijtsema, S., Linnemann, A., Van Gaasbeek, T., Dagevos, H., \& Jongen, W. (2002). Variables influencing food perception reviewed for consumer-oriented product development. Critical Reviews in Food Science and Nutrition, 42(6), 565-581. https://doi.org/10.1080/20024091054256

Sila, D. N., Van Buggenhout, S., Duvetter, T., Fraeye, I., De Roeck, A., Loey, A. Van, \& Hendrickx, M. (2009). Pectins in Processed Fruits and Vegetables: Part IIStructure-Function Relationships. Comprehensive Reviews in Food Science and Food Safety, 8, 86-104.

Silva, K. S., Fernandes, M. A., \& Mauro, M. A. (2014). Osmotic Dehydration of Pineapple with Impregnation of Sucrose, Calcium, and Ascorbic Acid. Food and Bioprocess Technology, 7(2), 385-397. https://doi.org/10.1007/s11947013-1049-0

Sloan, A. E. (2018). Produce: New Priorities and Preferences. Food Technology. https://www.ift.org/news-and-publications/food-technology-magazine

Sparke, K., \& Menrad, K. (2009). Cross-European and Functional Food-Related Consumer Segmentation for New Product Development. Journal of Food Products Marketing, 15(3), 213-230. https://doi.org/10.1080/10454440902908142

Tan, K. Y. M., van der Beek, E. M., Kuznesof, S. A., \& Seal, C. J. (2016). Perception and understanding of health claims on milk powder for children: A focus group study among mothers in Indonesia, Singapore and Thailand. Appetite, 105, 747-757. https://doi.org/10.1016/j.appet.2016.06.034

Torreggiani, D. (1993). Osmotic dehydration in fruit and vegetable processing. Food Research International, 26, 59-68. https://doi.org/10.1016/09639969(93)90106-S

Tortoe, C. (2010). A review of osmodehydration for food industry. African Journal of Food Science, 4(6), 303-324. http://www.academicjournals.org/ajfs

USDA. (2016). USDA National Nutrient Database for Standard Reference, Release 28. USDA \#09176 Mangos, raw. https://www.mango.org/mango-nutrition/

Van Boekel, M. A. J. S. (2000). Kinetic modelling in food science: A case study on chlorophyll degradation in olives. Journal of the Science of Food and Agriculture, $\quad 80(1), \quad 3-9 . \quad \mathrm{https}: / /$ doi.org/10.1002/(SICl)10970010(20000101)80:1<3::AID-JSFA532>3.0.CO;2-3

Van Boekel, M. A. J. S. (2008). Kinetic modeling of food quality: A critical review. Comprehensive Reviews in Food Science and Food Safety, 7(1), 144-158. 
https://doi.org/10.1111/j.1541-4337.2007.00036.x

Van Buggenhout, S., Sila, D. N., Duvetter, T., Van Loey, A., \& Hendrickx, M. (2009). Pectins in processed fruits and vegetables: Part III - Texture engineering. Comprehensive Reviews in Food Science and Food Safety, 8(2), 105-117. https://doi.org/10.1111/j.1541-4337.2009.00072.x

Van Buggenhout, Sandy, Grauwet, T., Van Loey, A., \& Hendrickx, M. (2008). Use of pectinmethylesterase and calcium in osmotic dehydration and osmodehydrofreezing of strawberries. European Food Research and Technology, 226(5), 1145-1154. https://doi.org/10.1007/s00217-007-0643-7

Van Esterik, P. (2008). Food culture in Southeast Asia. Greenwood Press.

van Kleef, E., van Trijp, H. C. M., \& Luning, P. (2005). Consumer research in the early stages of new product development: A critical review of methods and techniques. Food Quality and Preference, 16(3), 181-201. https://doi.org/10.1016/j.foodqual.2004.05.012

Vilela, A., Sobreira, C., Abraão, A. S., Lemos, A. M., \& Nunes, F. M. (2016). Texture Quality of Candied Fruits as Influenced by Osmotic Dehydration Agents. Journal of Texture Studies, 47(3), 239-252. https://doi.org/10.1111/jtxs.12177

WHO. (2015). Guideline: Sugars intake for adults and children. https://www.who.int/nutrition/publications/guidelines/sugars_intake/en/

Willett, W., Rockström, J., Loken, B., Springmann, M., Lang, T., Vermeulen, S., Garnett, T., Tilman, D., DeClerck, F., Wood, A., Jonell, M., Clark, M., Gordon, L. J., Fanzo, J., Hawkes, C., Zurayk, R., Rivera, J. A., De Vries, W., Majele Sibanda, L., ... Murray, C. J. L. (2019). Food in the Anthropocene: the EATLancet Commission on healthy diets from sustainable food systems. The Lancet, 393(10170), 447-492. https://doi.org/10.1016/S0140-6736(18)317884

Wyatt, S. L. (2018). New and Emerging SnackingTrends. https://www.iriworldwide.com/IRI/media/2018-New-and-Emerging-Snack-

Trends_SNAXPO.pdf

Yashoda, H. M., Prabha, T. N., \& Tharanathan, R. N. (2006). Mango ripening: Changes in cell wall constituents in relation to textural softening. Journal of the Science of Food and Agriculture, 86(5), 713-721. https://doi.org/10.1002/jsfa.2404 


\section{Summary}

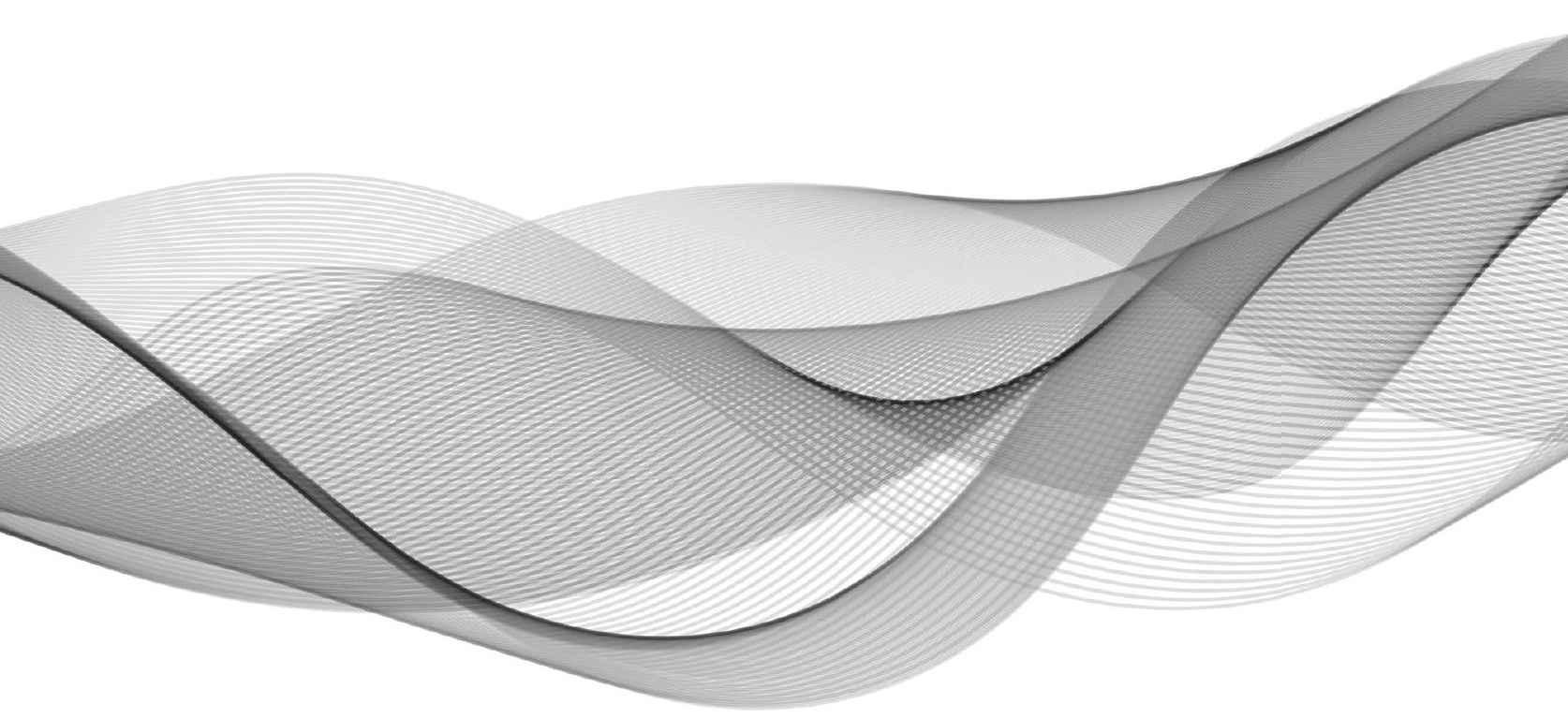





\section{Background}

Processing of mango can alter consumers' perception of the final dried mango quality. In order to optimize the dried mango quality by product and process design, consumer's insights on perceived product quality should be taken into account. The insights, which can consist of both product and process characteristics, should be transformed into useful input for designing food products. Previous consumer perception studies were focused on sensory, convenience and health aspects, and their interrelation with consumer perception, but less on that of process, particularly processing technology. In particular, there were no studies taking into account various drying technologies and the pre-treatments which can differently affect the intrinsic characteristics of dried mango and thus consumer perception.

\section{Aim}

The general objective of this thesis is to gain insights into consumer perceptions of dried mango and to connect them to quality attributes of this product, in order to achieve technological optimization during product and process design. An interdisciplinary approach is used to achieve knowledge about the effect of processing on dried mango quality and how this is perceived by consumers. This was accomplished by (i) exploring consumers' health perception among different cultures and demonstrating its relevance for product and process design in the early stages of new product development; (ii) studying consumer preference of dried mango among different cultures to add value to dried mango products; (iii) studying the effect of pre-treatment with vacuum impregnation (VI), high pressure (HP), and adding pectin methylesterase (PME) with calcium in combination with ripeness on the quality of dried mango; (iv) mathematical modelling of the kinetics of osmotic dehydration of mango to optimize water loss, sugar uptake, vitamin $\mathrm{C}$ retention and treatment time.

\section{Results}

Consumers' health perception of a fruit product is relevant to gain insights for product and process design since health is one of the important consumer's choice motives. Chapter 2 describes the exploration of consumers' health perception across cultures and the transformation into technical product and process specifications to be applied in the early stages of new product development. Dried mango was used as a case study, and a focus group approach was used with participants from three countries (The Netherlands, China, and Indonesia). Themes relating to health perception emerged from this study, namely nutrition, naturalness, taste, and wellbeing, which were all expressed on different levels of abstractness. Participants' health perception of dried mango varied and is related to (1) the product category with which it is compared, e.g. candy or fresh fruit; and (2) the eating context, e.g. position in the diet either as a snack or a meal. Moreover, it was shown that 
consumer insights in the health perception of a product not only relate to product characteristics but also to processing and its characteristics. Application of these insights into product and process design was performed through iterative interdisciplinary interactions between consumer scientists and food technologists. The transformation of consumers' perception into technical product and process specifications was demonstrated through an illustrative example of two product concepts of natural dried mango. This transformation suggests that iterative interactions are necessary to achieve relevant product and process characteristics to be used in the simultaneous development of the technical product and process specifications based on consumer perceptions.

A subsequent quantitative consumer study to compare the perception of key intrinsic quality attributes and preferences of dried mango between consumers with different familiarity and health consciousness is presented in Chapter 3 . This study involved respondents from three countries (The Netherlands, China, and Indonesia). The information gathered through an Adaptive Choice-Based Conjoint Analysis (ACBC) is useful to support consumer-oriented product development of dried mango. Texture, taste and colour preferences of dried mango attributes differed between the three countries studied. The most important attribute for the Dutch and Chinese respondents was 'free from extra ingredients' as they preferred a "more pure" dried mango product, while Indonesians considered texture as the most important attribute, preferring a crispier dried mango product. Familiarity with dried mango and health consciousness do not influence consumer preference of intrinsic attributes of dried mango. Different preferences of intrinsic attributes of dried mango between the studied respondent groups are related to cultural differences.

Intrinsic quality characteristics' changes in osmo-dehydrated mango due to osmotic dehydration (OD) with different pre-treatments were shown in Chapter 4. This study presents the effects of pretreatment with vacuum impregnation (VI), high pressure (HP) and addition of pectin methylesterase (PME) with calcium on the quality of osmo-dehydrated mango (Mangifera indica var. Kent) of different levels of ripeness. The use of unripe mango in OD showed two to five-fold higher soluble solid gain (SSG) compared to ripe mango for all treatments. Unripe mango pretreated with ODVI showed the lowest water loss (WL) and the highest SSG. The OD-HP treatment had a similar but less pronounced effect as OD-VI on the parameters WL and SSG. Addition of the cell wall modifying enzyme PME increased OD efficiency for the treatments high pressure as well as vacuum impregnation, but only for ripe mango. Colour is an important quality attribute for dried mango. Overall, the applied settings for OD treatments appeared to be suitable for preservation of colour quality of mango. Hue $\left(h^{*}\right)$ values were generally preserved and colour intensity $\left(C^{*}\right)$ was maintained or only slightly increased in both ripeness levels in all treatments. Lightness $\left(L^{*}\right)$ was greatly reduced in unripe mango but stable in ripe mango. In general, adding PME slightly increases the effect on texture in terms of firmness. This study thus 
demonstrates that using different levels of ripeness of mango resulted in different quality of osmo-dehydrated mango upon pretreatments with calcium.

In a follow-up study, the effects of vacuum impregnation (VI) pretreatment and PME addition on the kinetics of mass transfer and vitamin $C$ loss during osmotic dehydration of mango were studied (Chapter 5). The water loss (WL) and weight reduction (WR) were modelled by the Weibull's model, while soluble solid gain (SSG) was better described by Peleg's model. VI increases SSG indicated by a 55\% lower value of the equilibrium constant $\left(k_{2}\right)$ in the Peleg model. Vitamin $C$ loss was described by a multiresponse model incorporating both degradation and leaching processes into the osmotic solution (OS). Degradation of vitamin $\mathrm{C}$ was found to be the most important mechanism during osmo-dehydration of mango. The pretreatments have no significant effect on degradation and leaching rate constants of vitamin $\mathrm{C}$. The combined modelling of the mass transfer and vitamin $\mathrm{C}$ retention was shown to be valuable in optimizing the OD process design to improve the health-promoting value of OD mango (e.g. sugar content, vitamin $\mathrm{C}$ ) and reducing the processing time.

\section{Conclusions}

Exploring consumers' quality perception is relevant in the early stages of product and process design of dried mango. Obtained insights on these consumer perceptions require iterative interactions between consumer scientists and food technologists to achieve relevant product and process characteristics and simultaneously design the technical product and process specifications. Consumers in the studied countries have different nutritional, texture, taste and colour preferences for dried mango. This study provides useful insights for food manufacturers into the significance of key intrinsic quality attributes for developing dried mango.

The use of unripe mango in osmotic dehydration showed a higher soluble solid gain (SSG) compared to ripe mango for all pretreatments. Unripe mango pretreated with OD-VI had the lowest water loss and the highest SSG, while OD-HP had a similar but less pronounced effect. The observed effects of $\mathrm{VI}$ and HP applied to unripe and ripe mango are valuable to tailor $O D$ efficiency and achieve the desired quality of $O D$ mango. The combination of modelling the mass transfer and vitamin $\mathrm{C}$ retention was shown to be valuable to optimize sugar content, vitamin $C$ retention and reducing the processing time of OD mango.

Overall, insights provided by this thesis can be used to optimize product and process design to improve the quality of dried fruit. However, a collaboration between consumer scientists and food technologists is required to apply the insights for successful new product development. 



\section{Samenvatting}

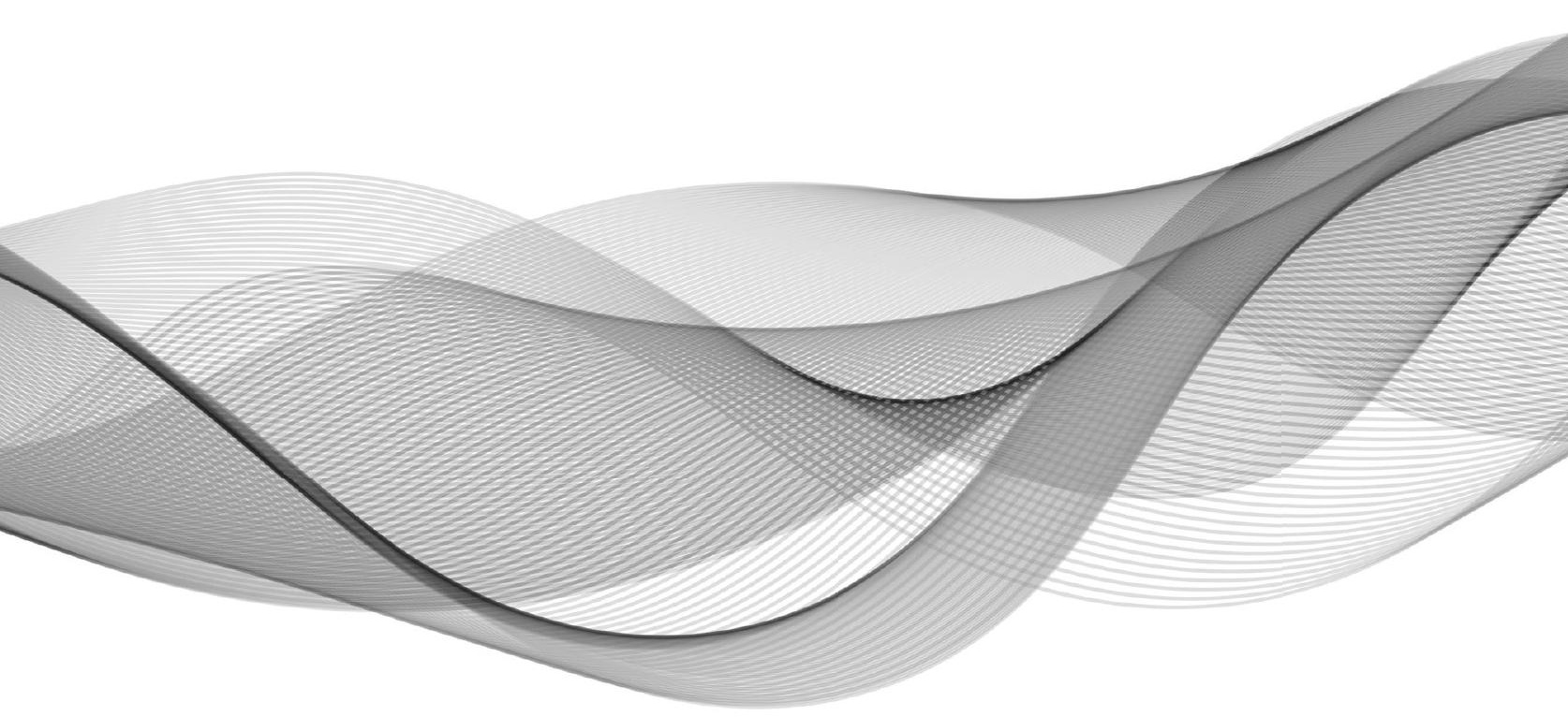





\section{Achtergrond}

Het bewerken van verse mango tot gedroogde mango heeft een effect op verschillende kwaliteitsattributen en kan daarmee de kwaliteitsperceptie van consumenten beïnvloeden. Inzicht in deze kwaliteitsperceptie is wenselijk en dient meegenomen te worden tijdens de ontwikkeling van nieuwe producten en productieprocessen, om een optimale afstemming te hebben op de wensen en behoeften van consumenten. Eerdere consumentenstudies waren vooral gericht op sensorische kenmerken, gemak en gezondheidsaspecten van voedingsmiddelen en hun samenhang met consumentenperceptie, maar er was veel minder aandacht voor het productieproces en met name de verwerkingstechnologie. Tot nu toe zijn er nauwelijks studies gedaan naar de consumentenperceptie van diverse technologieën van drogen en gerelateerde voorbehandelingen van mango en de mogelijke invloed op kwaliteitskenmerken.

\section{Doelstelling}

Het doel van dit proefschrift is inzicht te verkrijgen in consumentenpercepties van gedroogde mango en deze te relateren aan kwaliteitsattributen van dit product, om te komen tot een technologische optimalisatie tijdens product- en procesontwerp. Door een interdisciplinaire benadering is kennis verkregen over het effect van technologische processen op de kwaliteit van gedroogde mango en de wijze waarop dit door consumenten wordt ervaren. Dit is bereikt door: i) het verkennen van de gezondheidsperceptie van consumenten in verschillende culturen en het aantonen van de relevantie ervan voor zowel product- als procesontwerp in een vroeg stadium van productontwikkeling; ii) het bestuderen van consumentenpercepties van gedroogde mango in verschillende culturen, om waarde te kunnen toevoegen aan gedroogde mango producten; iii) het bestuderen van het effect van voorbehandeling van mango met vacuümimpregnatie $(\mathrm{VI})$, hoge druk (HP) en het toevoegen van pectine methylesterase (PME) bij verschillende rijpheid op de kwaliteit van de gedroogde mango; iv) het wiskundig modelleren van de kinetiek van osmotische dehydratie van mango om het waterverlies, suikeropname, vitamine $C$ retentie en de behandelduur te optimaliseren.

\section{Resultaten}

Inzicht in de gezondheidsperceptie van een fruitproduct door consumenten is relevant voor product- en procesontwerp, aangezien gezondheid een van de belangrijkste motieven is voor voedselkeuze.

Hoofdstuk 2 beschrijft de verkenning van de gezondheidsperceptie van consumenten in verschillende culturen en het belang van de vertaling van deze percepties in technische product- en processpecificaties tijdens de beginfase van het productontwikkelingsproces. In focusgroep discussies met deelnemers uit 3 verschillende landen (Nederland, China en Indonesië) is gedroogde mango gebruikt 
als casus. Uit dit onderzoek kwam een aantal thema's naar voren die relevant zijn voor gezondheidsperceptie, namelijk voedingswaarde, natuurlijkheid, smaak en welzijn Men sprak hierover op verschillende abstractieniveaus.

De gezondheidsperceptie van gedroogde mango varieerde tussen de deelnemers en is afhankelijk van (1) de productcategorie waarmee men gedroogde mango vergelijkt, nl. snoep of vers fruit; en (2) de context waarin men gedroogde mango eet, bijvoorbeeld de plaats van het product in het totale voedingspatroon (wordt het gegeten als een snack of als onderdeel van een maaltijd). Bovendien lieten de resultaten zien dat de gezondheidsperceptie niet alleen wordt gerelateerd aan productkenmerken, maar ook aan het bewerkingsproces en de kenmerken daarvan. Door iteratieve interdisciplinaire interacties tussen consumentenwetenschappers en levensmiddelentechnologen zijn deze inzichten vertaald naar product- en procesontwerpen. De vertaalslag van consumentenpercepties naar technische product- en processpecificaties is ter illustratie uitgewerkt voor 2 productconcepten van natuurlijke, gedroogde mango. Deze concepten laten zien dat deze iteratieve interacties nodig zijn om gelijktijdig tot relevante product- en proceskenmerken te komen, die op hun beurt leiden tot product- en processpecificaties, gebaseerd op consumenteninzichten.

Hoofdstuk 3 beschrijft de kwantitatieve vervolgstudie waarin de perceptie van belangrijke intrinsieke kwaliteitsattributen en voorkeuren voor gedroogde mango werd vergeleken voor groepen consumenten, die varieerden in bekendheid met het product en in het gezondheidsbewust zijn. In deze studie participeerden respondenten uit drie landen (Nederland, China en Indonesië). De resultaten verkregen via een 'Adaptive Choice-Based Conjoint Analysis' (ACBC) ondersteunen consument-georiënteerde productontwikkeling van gedroogde mango. De voorkeur voor kwaliteitsattributen textuur, smaak en kleur varieerde tussen de drie landen. Voor Nederlandse en Chinese respondenten was het belangrijkste kenmerk 'zonder extra ingrediënten'; zij prefereren een meer natuurlijke, pure gedroogde mango. Voor de Indonesische respondenten was de textuur het belangrijkste kenmerk; zij prefereren een knapperige textuur voor gedroogde mango. Het bekend zijn met gedroogde mango en het gezondheidbewust zijn bleken niet van invloed op de voorkeur voor intrinsieke kwaliteitsattributen. De verschillen in voorkeuren tussen de verschillende respondentengroepen zijn voornamelijk gerelateerd aan cultuurverschillen.

Hoofdstuk 4 beschrijt de veranderingen in intrinsieke kwaliteitsattributen als gevolg van osmotische dehydratie (OD) bij verschillende voorbehandelingen van mango. De resultaten van deze studie laten het effect zien van voorbehandeling met vacuüm impregnatie (VI), hoge druk (HP) en het toevoegen van pectine methylesterase (PME) en calcium op de kwaliteit van osmotisch-gedehydrateerde mango (Mangifera indica var. Kent) met verschillende rijpheid. Voor alle bestudeerde voorbehandelingen resulteert OD van onrijpe mango in twee tot vijf keer hogere 
oplosbare vaste stof opbrengst (SSG) vergeleken met rijpe mango. OD van onrijpe mango, voorbehandeld met $\mathrm{VI}$ laat het laagste waterverlies en de hoogste vaste stof opbrengst zien. De behandeling met OD-HP heeft een vergelijkbaar, maar minder duidelijk effect. Toevoeging van het celwand modificerende enzym PME verhoogt de efficiëntie van OD bij een voorbehandeling met zowel HP als VI, maar alleen voor rijpe mango. Kleur is een belangrijk kwaliteitsattribuut voor gedroogde mango. In het algemeen blijft de kleur van mango in alle toegepaste behandelingen goed behouden. De waarden voor kleurtint (Hue; $h^{*}$ ) en kleurintensiteit $\left(C^{*}\right)$ bleven gelijk of werden iets groter voor beide rijpheidsstadia en voor alle behandelingen. De waarde voor Helderheid $\left(L^{*}\right)$ verminderde substantieel voor onrijpe mango, maar bleef gelijk voor rijpe mango. In het algemeen heeft de toevoeging van PME een iets groter effect op de textuur (m.n. de stevigheid). Deze studie laat zien dat een verschillende rijpheid van mango resulteert in een verschillende kwaliteit van osmotisch gehydrateerde mango bij voorbehandelingen met calcium.

In een vervolgstudie (Hoofdstuk 5) werd het effect van voorbehandeling met vacuüm impregnatie $(\mathrm{VI})$ en toevoeging van $\mathrm{PME}$ op de kinetiek van de massaoverdracht en het verlies aan vitamine $C$ tijdens OD bestudeerd. Het waterverlies (WL) en de gewichtsreductie (WR) zijn gemodelleerd met een Weibull model. Terwijl de toename in oplosbare vaste stof beschreven werd met een Peleg model. VI vergroot de toename van de oplosbare vaste stof (SSG) wat resulteerde in een $55 \%$ lagere waarde voor de evenwichtsconstante $\left(k_{2}\right)$ in het Peleg model. Vitamine $\mathrm{C}$-verlies is beschreven met een multiresponse model dat zowel de afbraak als het uitlekken in de osmotische oplossing (OS) meeneemt. De afbraak van vitamine $\mathrm{C}$ blijkt het belangrijkste mechanisme bij $\mathrm{OD}$ van mango. De voorbehandelingen hebben geen significant effect op de afbraak en het uitlekken van vitamine $C$. Het gecombineerd modelleren van massaoverdracht en vitamine Cbehoud bleek waardevol te zijn bij het optimaliseren van het OD proces, om op die manier de gezondheid bevorderende waarde van gedroogde mango (i.c. suikergehalte, vitamine $\mathrm{C}$ ) te verbeteren en de bewerkingstijd te verkorten.

\section{CONCLUSIES}

Inzicht in de kwaliteitsperceptie van consumenten is relevant in de beginfase van product- en procesontwikkeling van gedroogde mango. Het verkrijgen van deze inzichten vergt een iteratieve interactie tussen consumentenwetenschappers en levensmiddelentechnologen om tot relevante product- en proceskenmerken te komen en deze tegelijkertijd te vertalen naar technische product- en processpecificaties. Consumenten in de bestudeerde landen hebben verschillende voorkeuren voor de voedingswaarde, textuur, smaak en kleur van gedroogde mango. Deze studie biedt waardevolle inzichten voor voedselproducenten in de betekenis van enkele belangrijke kwaliteitsattributen voor de ontwikkeling van gedroogde mango. 
Het gebruik van onrijpe mango voor osmotische dehydratie (OD) resulteert voor alle typen voorbehandelingen in een hogere oplosbare vaste stof opbrengst in vergelijking tot rijpe mango. Onrijpe mango, voorbehandeld met VI had bij OD het laagste waterverlies en de hoogste oplosbare vaste stof opbrengst, terwijl een voorbehandeling met HP een vergelijkbaar, doch minder uitgesproken effect had. De waargenomen effecten van VI en HP, toegepast op zowel onrijpe als rijpe mango, zijn waardevol om de OD efficiëntie te vergroten en de gewenste kwaliteit van ODgedroogde mango te bereiken. Het gecombineerd modelleren van massaoverdracht en vitamine $C$ retentie is waardevol om het suikergehalte, de vitamine $C$ retentie en de bewerkingsduur van osmotisch gedehydrateerde mango te optimaliseren.

De inzichten verkregen in dit proefschrift kunnen gebruikt worden om product- en procesontwikkeling van gedroogd fruit te optimaliseren en de kwaliteit ervan te verbeteren. Echter, samenwerking tussen consumentenwetenschappers en levensmiddelentechnologen is hierbij essentieel om deze inzichten toe te passen voor het succesvol ontwikkelen van nieuwe producten. 
Ringkasan

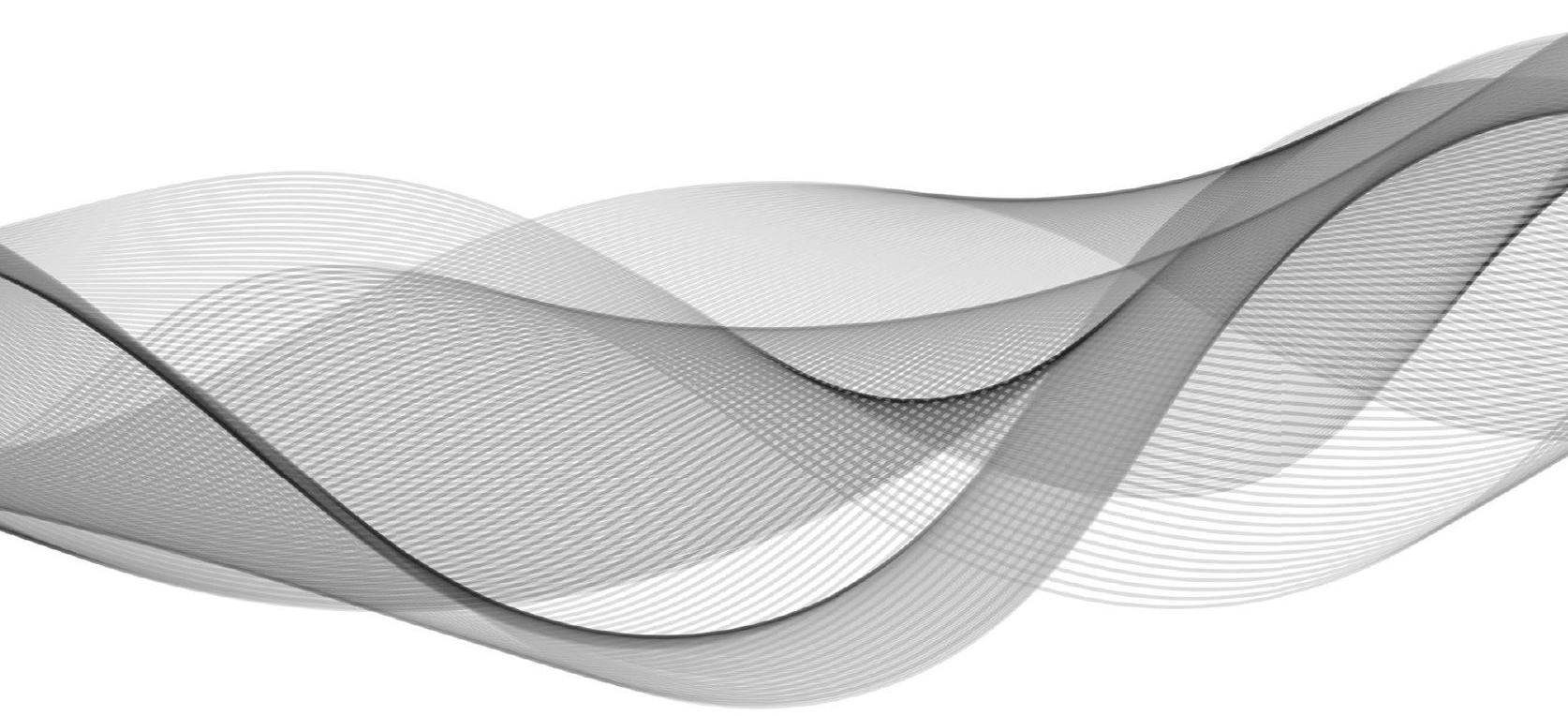





\section{Latar Belakang}

Pengolahan mangga dapat mengubah persepsi konsumen terhadap mutu akhir mangga kering. Guna mengoptimalkan mutu mangga kering dengan disain produk dan proses, wawasan konsumen tentang persepsi mutu produk harus dipertimbangkan. Wawasan, yang dapat terdiri dari karakteristik produk dan proses, harus ditransformasi menjadi input yang berguna untuk mendisain produk pangan. Studi persepsi konsumen yang ada berfokus pada aspek sensori, kenyamanan dan kesehatan, dan keterkaitannya dengan persepsi konsumen, namun kurang pada aspek proses, khususnya teknologi pengolahan. Tidak ada studi yang mempertimbangkan berbagai teknologi pengeringan dan perlakuan awal yang dapat mempengaruhi karakteristik intrinsik mangga kering secara berbeda-beda dan dengan demikian mempengaruhi persepsi konsumen.

\section{Tujuan}

Tujuan umum dari tesis ini adalah untuk mengeksplorasi wawasan konsumen dan mengaitkannya dengan optimalisasi teknologi mutu produk bagi disain produk dan proses mangga kering. Pendekatan interdisipliner digunakan untuk memperoleh pengetahuan tentang pengaruh pengolahan terhadap mutu mangga kering dan bagaimana pengaruh ini dipersepsi oleh konsumen. Hal ini dicapai dengan (i) mengeksplorasi persepsi kesehatan konsumen dengan latar belakang budaya yang berbeda dan menunjukkan relevansinya untuk disain produk dan proses pada tahap awal pengembangan produk baru; (ii) mempelajari preferensi konsumen mangga kering di antara budaya yang berbeda untuk menambah nilai produk mangga kering; (iii) mempelajari pengaruh perlakuan awal dengan impregnasi vakum (VI), tekanan tinggi (HP), dan menambahkan pektin metilesterase (PME) dikombinasi dengan kemasakan mangga terhadap mutu mangga kering; (iv) pemodelan matematis kinetika dehidrasi osmosis mangga untuk mengoptimalkan kehilangan air, serapan (uptake) gula, retensi vitamin $\mathrm{C}$ dan durasi perlakuan.

\section{Hasil}

Persepsi kesehatan konsumen tentang produk buah relevan untuk mendapatkan wawasan mengenai disain produk dan proses karena kesehatan merupakan salah satu motif penting dalam pilihan konsumen. Bab 2 menjelaskan eksplorasi persepsi kesehatan konsumen lintas budaya dan transformasinya menjadi spesifikasi teknis produk dan proses untuk diterapkan pada tahap awal pengembangan produk baru. Mangga kering digunakan sebagai studi kasus, dan pendekatan focus group digunakan dengan melibatkan peserta dari tiga negara (Belanda, Cina, dan Indonesia). Tema terkait persepsi kesehatan yang muncul dari studi ini, yaitu nutrisi, kealamian, rasa, dan kesejahteraan, yang semuanya diekspresikan pada tingkat abstraksi yang berbeda. Persepsi kesehatan dari peserta terhadap mangga kering bervariasi dan terkait dengan (1) kategori produk yang dibandingkan, misalnya: permen atau buah segar; dan (2) konteks makan, misalnya: posisi dalam diet 
sebagai camilan atau makanan utama. Selain itu, hasil menunjukkan bahwa wawasan konsumen dalam mempersepsikan kesehatan suatu produk tidak hanya terkait dengan karakteristik produk tetapi juga dengan pengolahan dan karakteristiknya. Penerapan wawasan ini ke dalam disain produk dan proses dilakukan melalui interaksi interdisipliner secara berulang antara ahli ilmu konsumen dan ahli teknologi pangan. Transformasi persepsi konsumen menjadi spesifikasi teknis produk dan proses ditunjukkan melalui contoh ilustratif berupa dua konsep produk mangga kering alami. Transformasi ini menunjukkan bahwa interaksi berulang diperlukan untuk memperoleh karakteristik produk dan proses yang relevan dalam pengembangan simultan dari spesifikasi teknis produk dan proses berdasarkan persepsi konsumen.

Sebuah studi konsumen lanjutan secara kuantitatif untuk membandingkan persepsi atribut mutu intrinsik utama dan preferensi terhadap mangga kering antara konsumen dengan tingkat familiarity dan health consciousness yang berbeda disajikan dalam Bab 3. Studi ini melibatkan responden dari tiga negara (Belanda, Cina, dan Indonesia). Informasi yang dikumpulkan melalui Adaptive Choice-Based Conjoint Analysis (ACBC) berguna untuk mendukung pengembangan produk berorientasi konsumen terhadap mangga kering. Preferensi terhadap atribut tekstur, rasa dan warna mangga kering berbeda antar ketiga negara tersebut. Atribut terpenting untuk responden Belanda dan Cina adalah 'bebas dari bahan tambahan' karena mereka lebih suka produk mangga yang "lebih murni". Sementara orang Indonesia menganggap tekstur sebagai atribut terpenting dan lebih memilih produk mangga kering yang renyah. Familiarity dengan mangga kering dan health consciousness tidak mempengaruhi preferensi konsumen terhadap atribut intrinsik mangga kering. Perbedaan preferensi terhadap atribut intrinsik mangga kering antar kelompok responden yang diteliti berkaitan dengan perbedaan budaya.

Perubahan karakteristik mutu intrinsik mangga setelah dehidrasi osmosis (mangga OD) dengan berbagai perlakuan awal dipaparkan pada Bab 4. Studi ini menyajikan pengaruh perlakuan awal dengan impregnasi vakum (VI) dan tekanan tinggi (HP) dan menambahkan pektin metilesterase (PME) dengan kalsium pada mutu mangga setelah dehidrasi osmosis (Mangifera indica var. Kent) dari kemasakan yang berbeda. Penggunaan mangga belum masak dalam OD menunjukkan serapan padatan terlarut (SSG) yang lebih tinggi dua hingga lima kali lipat dibandingkan dengan mangga masak untuk semua perlakuan. Mangga yang belum masak yang diberi perlakuan OD-VI menunjukkan kehilangan air terendah (WL) dan SSG tertinggi. Perlakuan OD-HP menunjukkan pengaruh yang sama namun dengan tingkat yang lebih kecil dari OD-VI pada parameter WL dan SSG. Penambahan enzim PME meningkatkan efisiensi OD untuk perlakuan tekanan tinggi serta impregnasi vakum, tetapi hanya terjadi pada mangga yang masak. Warna adalah atribut mutu yang penting untuk mangga kering. Secara keseluruhan, pengaturan yang diterapkan untuk perlakuan-perlakuan OD tampaknya sesuai untuk 
mempertahankan mutu warna mangga. Nilai hue $\left(h^{*}\right)$ umumnya tetap dan intensitas warna $\left(C^{*}\right)$ tetap atau hanya sedikit meningkat pada kedua tingkat kemasakan pada semua perlakuan. Lightness $\left(L^{*}\right)$ sangat berkurang pada mangga yang belum masak tetapi stabil pada mangga yang masak. Secara umum, penambahan PME sedikit meningkatkan pengaruh pada tekstur dalam hal firmness dan work of shear. Dengan demikian studi ini menunjukkan bahwa penggunaan mangga dengan tingkat kemasakan yang berbeda menghasilkan mutu mangga OD yang berbeda setelah diberi berbagai perlakuan awal dan dengan kalsium.

Sebagai studi lanjutan, pengaruh perlakuan awal impregnasi vakum (VI) dan penambahan PME terhadap kinetika perpindahan massa dan kehilangan vitamin $\mathrm{C}$ diteliti selama dehidrasi osmosis mangga (Bab 5). Kehilangan air (WL) dan pengurangan berat (WR) dimodelkan dengan model Weibull, sementara serapan padatan terlarut (SSG) dijelaskan lebih baik oleh model Peleg. VI meningkatkan SSG yang ditandai oleh nilai konstanta kesetimbangan $\left(k_{2}\right) 55 \%$ lebih rendah dalam model Peleg. Kehilangan vitamin $\mathrm{C}$ dijelaskan oleh model multiresponse yang menggabungkan proses degradasi dan pelindian ke dalam larutan osmotik (OS). Hasil menunjukkan bahwa degradasi merupakan mekanisme yang paling penting selama dehidrasi osmosis mangga. Perlakuan awal tidak memiliki pengaruh signifikan pada degradasi dan konstanta laju pelindian vitamin C. Pemodelan yang mengkombinasikan transfer massa dan retensi vitamin $C$ terbukti dapat mengoptimalkan disain produk dan proses OD untuk meningkatkan nilai pemacu kesehatan dari mangga OD (misalnya: kadar gula, vitamin $\mathrm{C}$ ) dan mempersingkat waktu pengolahan.

\section{Kesimpulan}

Mengeksplorasi persepsi konsumen pada tahap awal produk dan desain proses mangga kering adalah hal yang relevan. Wawasan yang diperoleh mengenai persepsi konsumen ini memerlukan interaksi berulang antara ahli ilmu konsumen dan ahli teknologi pangan guna memperoleh karakteristik produk dan proses yang relevan dalam disain simultan dari spesifikasi teknis produk dan proses. Konsumen di ketiga negara yang diteliti memiliki preferensi gizi, tekstur, rasa dan warna yang berbeda terhadap mangga kering. Studi ini memberikan wawasan yang bermanfaat bagi produsen pangan mengenai pentingnya atribut mutu intrinsik utama dalam mengembangkan produk mangga kering.

Penggunaan mangga yang belum masak dalam dehidrasi osmosis menunjukkan serapan padatan terlarut (SSG) yang lebih tinggi dibandingkan dengan mangga masak untuk semua perlakuan. Mangga belum masak dengan perlakuan OD-VI memiliki kehilangan air (WL) terendah dan SSG tertinggi, sementara perlakuan ODHP memiliki pengaruh yang serupa tetapi kurang menonjol. Pengaruh VI dan HP pada mangga yang belum masak dan yang masak sangat berguna untuk mengatur efisiensi OD dan mencapai mutu mangga OD yang diinginkan. Pemodelan yang 
mengkombinasikan transfer massa dan retensi vitamin $C$ terbukti bermanfaat untuk mengoptimalkan kadar gula, retensi vitamin $\mathrm{C}$ dan mengurangi durasi pengolahan mangga OD.

Secara keseluruhan, wawasan yang dihasilkan oleh tesis ini dapat digunakan untuk mengoptimalkan disain produk dan proses untuk meningkatkan mutu buah kering. Namun, kolaborasi antara ahli ilmu konsumen dan ahli teknologi pangan diperlukan untuk menerapkan wawasan ini sehingga mencapai keberhasilan dalam pengembangan produk baru. 


\section{Acknowledgements}



The long journey to the fruitful accomplishment of this dissertation was possible with the valuable support, guidance, and partaking of several individuals.

l'd like to express my sincere gratitude to my $\mathrm{PhD}$ supervision team. My promotor, Vincenzo Fogliano, although we did not have many meetings, each meeting, and communication we had always brought fruitful results. I appreciate your support, expertise, up-building criticism, and valuable inputs in directing the PhD project until it can be finalized. My amazing supervisors, Matthijs Dekker and Ruud Verkerk, thank you for helping me, started from our first meeting in Semarang and administering my DIKTI scholarship, I received it and went to the Netherlands. Ruud, you offered to pick me up when I arrived in NL for this PhD, it was so kind of you, though I kindly refused it since I already had a friend helping me. Matthijs, I remember your warm welcome when I came into Axis building for the first time, asking me if I would like to have a cup of tea or coffee. To you both, I really appreciate your continuous support, encouragement, inspiration, and the space given to me to learn and to grow during the whole process of this $\mathrm{PhD}$ journey.

I am also grateful to Bea Steenbekkers and Siet Sijtsema for your expertise, encouragement, patience, valuable suggestions, and co-supervising students in the qualitative consumer study of this thesis, a new-to-me field I decided to jump into. A special thanks to Bea also for keep providing your support for the subsequent quantitative consumer study.

My heartiest appreciation for the help extended to me goes also to all Food Quality and Design (FQD) staff, viz. Frans Lettink, Charlotte van Twisk, Xandra Bakkerde Haan, Erik Meulenbroeks, Geert Meijer, Mike Beijer, Anita Linnemann, Teresa Oliviero, Lysanne Hoksbergen, Kimberley Boss, Corine van Huenen. A special thanks also go to my (ex)fellow PhD colleagues for all the support and nice memories we shared. To Probo, thanks for my first meeting with Matthijs and Ruud during their work visit to Indonesia. To my ex-office mates, Liya, Lina, Fahui, Klementina, and Grace, you were my PhD buddies during my first years. To Grace and Lucia, for sharing your experience, opinion, and suggestions on the qualitative and quantitative consumer study, respectively. To Ana, thank you so much for being such a great buddy, you were also there in the last days of my thesis submission with your helping hands. Juliet, Ruth, Faith, James, Mostafa, Ana, Elisa, and Marianna, thank you so much for the nice conversations we had during our cheerful "late lunch". I also appreciate my (ex)fellow PhD and post-doc colleagues and friends, viz. Mary Luz, Daylan, Radhika, Ruben, Elisa, Renske, Ilario, Geraldine, Andrijana, Chunyue, Sara, Folachodé, Sidney, Shingai, Ayusta, Mohammed, Li Wang, Alim, Furahisha, Julie, Fabiola, Femke, Jonna, Annelies, Eva, Hannah, Zhijun, Lijiao, Ling Xiong, Yuzheng, Yajing, Jing, Jilu, Onu, Folake, Pieter, Moheb, Oluranti, Naomi, Ningjing, Arianne, Yao Chen, Sergio, Aracelli, Dario, Domenico, Sara, Anna, and many others I could not mention by name. Thanks to 
you all for the nice shared moments and comradery atmosphere. To my paranymphs, James Ledo (FQD) and Novita Dhian Naomi (HNE), thank you so much!

I also want to thank Bea, Matthijs, Ruud, and Femke for the samenvatting, this experience motivates me to learn Dutch even more.

I thank Harry Baptist (FPH), Jarno Gieteling (FPE), Jos Sewalt, Jaap Hulstein, Nam-Phuong Hua, Ariette Matser, and Mariette Helmond (FBR), and Rob van Dam (Logistics AFSG officer) for all the support.

I thank all my BSc and MSc thesis students (Guizhao Hu, Peter van Grunsven, José Luis Ordóñez Alarcón, Martijn van Oirschot, Stefani Amanda Harmani, Changyun Zhang, Lingqi Kong, Yu Shen, Dangyiqi Wu, Stella Alinneshia, Claire Setjadiningrat, and Stefani Hartono) I supervised during my PhD, for your commitment and helpful contributions. To all FG participants and respondents of my consumer studies, thank you so much!

I would like to express my appreciation to Nature's Pride company for providing fresh mango for the investigations.

I would like to appreciate the management of Soegijapranata Catholic University (SCU): the honorable rectors and the members, for all the support and provision during this PhD journey. My appreciation also goes to Pak Budi Widianarko, for your motivation to study abroad, support, guidance, and inspiration, since I was an undergraduate student in 1996 and during my time as a junior lecturer and researcher in SCU. Bu Tina and Bu Rini, thank you for sharing your PhD experience and inspiration. To all (ex)Food Tech SCU colleagues: Pak Probo, Bu Inne, Bu Tina, Bu Rini, Bu Rika, Bu Novita, Bu Linda, Bu Laksmi, Bu Nik, Pak Sum, Pak Budi, Bu Tika, Bu Les, Pak Han, Pak Sol, Pak Pri, Bu Endah, Pak Lyk, Pak Agus, Bu Susy, Bu Tuti, Pak Andre, Pak Joko, and Pak Kas. Thank you for your support, prayers, and for cheering me up, not to mention the help of all lecturers who filled the gap during this PhD study. To all my colleagues in SCU, deans, admins, and everyone, thank you very much for your support!

A special thanks to Ir. Sumardianto (CV. Piramida Kreasi Mandiri) for all the support. I also appreciate Siska Hudaja for the cover design of this thesis. To Mbak Amik, thank you for the useful information regarding printing the thesis and the on-line defence, and of course for being our Semarangs friends together with Ayusta.

Untuk Tante Joyce, terimakasih sudah menjadi teman dan keluarga, dan untuk bantuan serta perhatiannya buat kami sekeluarga. To all Indonesian PhD colleagues and families in Wageningen and my international friends, thank you for your support and the nice shared memories.

Terimakasih kepada teman-teman di Persekutuan Kristus ekklesia di Wageningen (PKedW) a.I. Febi, Silvia, Hugo, Tya, Karin, Naomi, Mary, Adi, Enid, dan semua teman di Persekutuan Doa (PD) Wageningen, serta semua teman yang pernah 
berjumpa di persekutuan, a.I. Fani, Beta, Siska, Nawang, Tannie, dan Ahun. Untuk Pdt. Anton dan Bu Isti, terimakasih untuk pelayanan, doa, dan kasih persaudaraan yang boleh ada. Terima kasih sudah menjadi sahabat, saudara, dan keluarga, di dalam kasih bersekutu, berdoa, memuji, menyanyi dan bersukacita bersama. Saya sungguh bersyukur atas persekutuan kita. Semoga kebersamaan kita ini tidak hanya di dunia tetapi hingga selama-lamanya.

Ibu, Bapak (1947-2019), Mas Iko dan keluarga, Dik Robert dan keluarga di Semarang, terimakasih banyak untuk dukungan, perhatian dan bantuan kalian sehingga saya boleh jadi seperti saya sekarang ini. Khususnya Mas Iko, Mbak Aya dan Dik Robert terimakasih sudah menjaga dan merawat Bapak (alm.) dan hingga sekarang merawat Ibu. Bapak dan Ibu, Mbah Bu, Bu Ena dan Mas Heru di Ungaran, terimakasih sudah membantu merawat Ehre dan Naomi saat mereka hanya dengan Ayahnya atau tanpa kami. Juga Dik Lia dan keluarga, serta Tatis dan keluarga, terimakasih sudah menjaga dan menemani Bapak dan Ibu Ungaran. Untuk seluruh keluarga besar, terimakasih untuk dukungan dan doa kalian.

I cannot find words to express my gratitude to my husband, Moediartianto (Anto), my lovely daughters, Ehre Christi Anantya and Naomi Gracia Anantya, thank you for your love, patience, encouragements and prayers during my $\mathrm{PhD}$ journey. Terimakasih juga untuk kesabaran dan pengertian kalian selama kita terpisah fisik di masa satu setengah tahun pertama PhD ini. Saya bersyukur kita boleh bersatu lagi dan bersama-sama menjalani suka duka di negeri kincir angin ini.

If you have not been acknowledged in this thesis, I apologize for that, please rest assured that my appreciation is the same to you as to those mentioned above!

May 2020

Wageningen, the Netherlands 



\section{About the author}

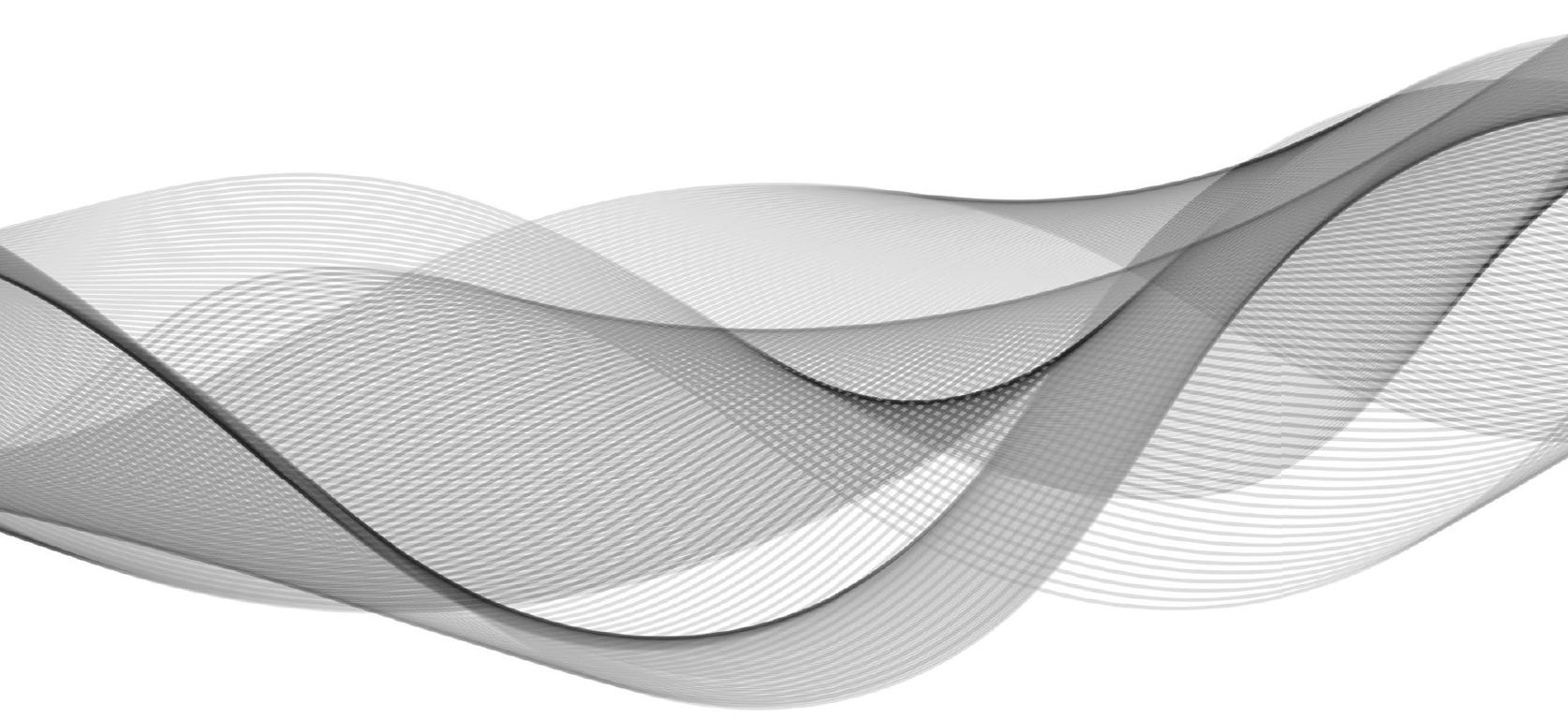





\section{Curriculum vitae}

Ita Sulistyawati was born in Semarang, Central Java-Indonesia on May $14^{\text {th }}, 1978$. In 2001, she obtained a BSc degree in Food Technology at Soegijapranata Catholic University (SCU), Indonesia. During her BSc study, she was awarded Jan Tinbergen Fellowship (NUFFIC) to perform a research on trace metals in an edible cockle Anadara granosa at Vrije Universiteit, Amsterdam. Upon completion of her BSc degree, she became an assistant lecturer in SCU for Food Quality, Food Safety and Food Waste Processing courses and a junior researcher. In 2002-2004,

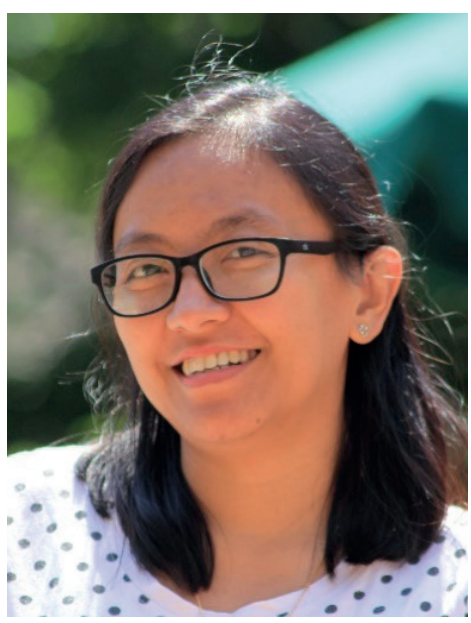
she received STUNED scholarship to pursue her MSc study in Urban Environmental Management at Wageningen University - IHS Rotterdam. She enrolled as a Ph.D. fellow at Food Quality and Design group of Wageningen University and Research in 2014, funded by Directorate General of Research, Science, Technology and Higher Education (DG-RSTHE), Indonesia. From 2001 to date, she has been working at the Department of Food Technology SCU. Her interest includes food quality and design, consumer perception, and food safety. 


\section{Publications}

\section{Full papers}

Sulistyawati, I., Verkerk, R., Fogliano, V., \& Dekker, M. (2020). Modelling the kinetics of osmotic dehydration of mango: optimizing process conditions and pretreatment for health aspects. Journal of Food Engineering, 280, 109985.

Sulistyawati, I., Sijtsema, S., Dekker, M., Verkerk, R., \& Steenbekkers, B. (2019). Exploring consumers' health perception across cultures in the early stages of new product development: Dried mango as a case study. British Food Journal, 121(9), 2116-2131.

Sulistyawati, I., Dekker, M., Fogliano, V., \& Verkerk, R. (2018). Osmotic dehydration of mango: Effect of vacuum impregnation, high pressure, pectin methylesterase and ripeness on quality. $L W T, 98,179-186$.

\section{Submitted paper}

Sulistyawati, I., Dekker, M., Verkerk, R., \& Steenbekkers, B. Consumer Preference for Dried Mango Attributes: A Conjoint Study among Dutch, Chinese and Indonesian consumers.

\section{Posters}

Sulistyawati, I., Verkerk, R., Dekker, \& M. Fogliano, V. (2017). Influence of high pressure, vacuum impregnation and pectin methylesterase with calcium on quality parameters of osmo-dehydrated mango. $31^{\text {st }}$ EFFoST International Conference, 1316 November 2017, Sitges, Spain.

Sulistyawati, I., Steenbekkers, B., \& Sijtsema, S. (2016). Exploring Chinese and Indonesian consumers' perception of dried tropical fruits - a cross national study. The $2^{\text {nd }}$ Asian Sensory and Consumer Research Symposium, 15-17 May 2016, Shanghai, China. 


\section{Overview of completed training activities}

\section{Discipline specific courses and activities}

Applied statistics
Advance food analysis
Multivariate analysis for food
data/scientists
Sensory perception and food
preference: Affective drivers on
food choice
SENSEAsia 2016
The $2^{\text {nd }}$ International Conference
on Sustainable Global Agriculture
\& Food (ICSAF)
Wageningen Indonesia Scientific
Expose (WISE) 2016
Indonesian PhD Symposium (part
of Wageningen UR 99th years
Anniversary)
Microscopy and spectroscopy in
food and plant sciences
31 st EFFOST International
Conference

VLAG, Wageningen 2014

VLAG, Food Chemistry, Organic 2015

Chemistry-WUR, FP7 EC Project

QSAFFE

VLAG, Wageningen 2016

VLAG \& Human Nutrition, $\quad 2016$

Wageningen

Elsevier, Shanghai 2016

Soegijapranata Catholic University \& 2016

Assumption University \& Saigon

Technology University, Semarang

WUR \& Indonesian PhD Association 2016

of WUR, Wageningen

WUR, Wageningen 2017

VLAG \& EPS, Wageningen

2017

EFFoST \& IUFoST \& Elsevier, Sitges 2017

\section{General courses and activities}

Competence assessment

WGS, Wageningen 2014

Data management

WGS, Wageningen 2014

VLAG PhD Week

VLAG, Baarlo

2015

Project \& time management

WGS, Wageningen

2015

Systematic approaches to

WGS, Wageningen

2015

reviewing literature

PhD workshop carousel

WGS, Wageningen

2015

Reviewing a scientific paper

WGS, Wageningen

2015

Techniques for writing and

WGS, Wageningen

2016

presenting a scientific paper

Scientific writing

WGS, Wageningen

2016 
About the author

\section{Optional courses and activities}

Writing VLAG PhD proposal

FQD

2014

$\mathrm{PhD}$ and student colloquia

FQD

2014-2019

PhD Trip: Thailand-Singapore

FQD

2014

Wageningen PhD Symposium 2015

Wageningen PhD Council

2015

Organizing Committee member

VLAG PhD Council member

VLAG PhD Council

2015-2017 

The research described in this thesis was financially supported by the Directorate General of Resources for Science, Technology and Higher Education, Indonesia (DIKTI).

Cover design by S. Hudaja (all images courtesy of www.freepik.com/uis_molinero, topntp26, mrsiraphol)

Lay out by I. Sulistyawati

Printed by Digiforce/Proefschriftmaken.nl

Copyright @ 2020 I.Sulistyawati 


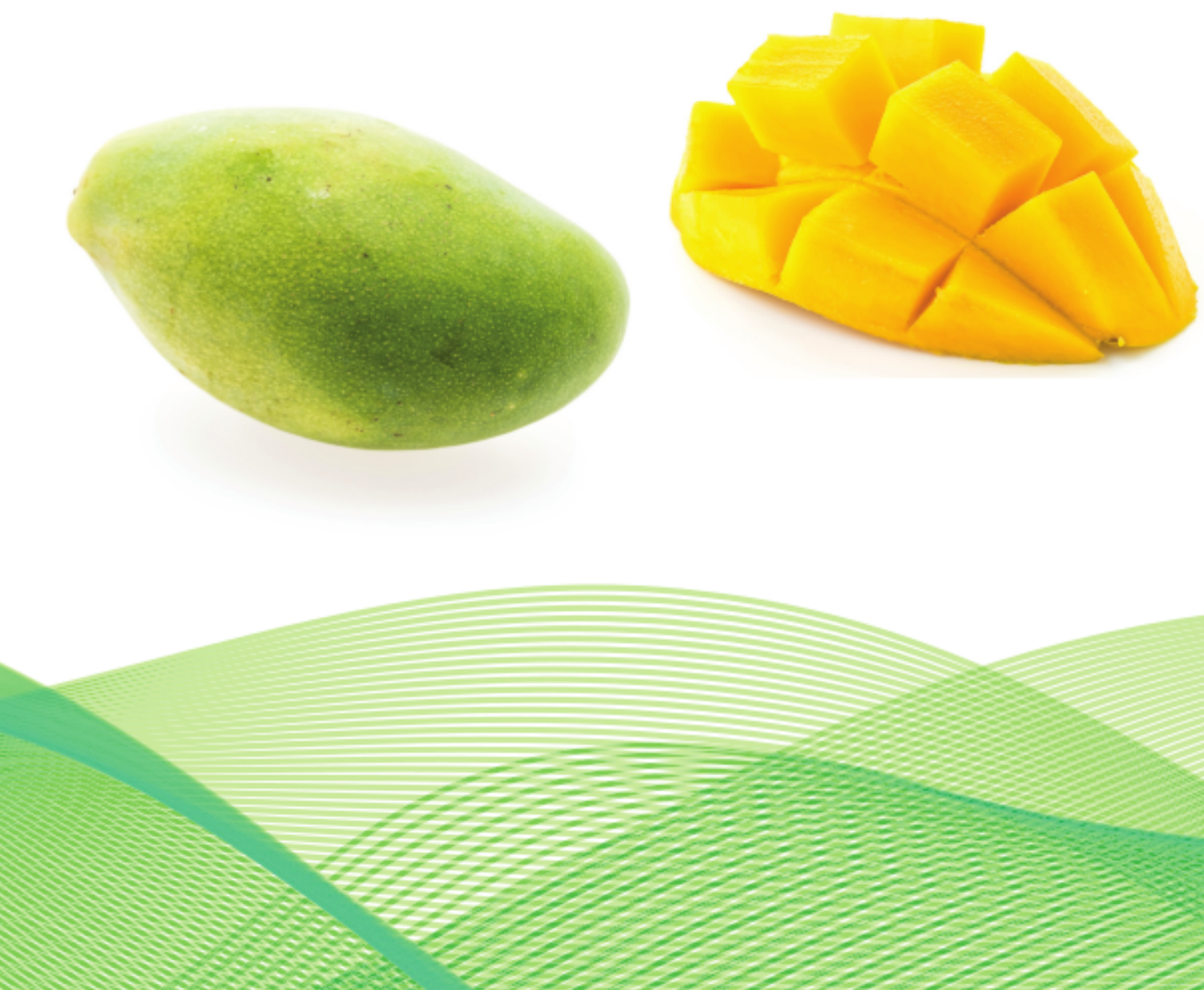

Sn-
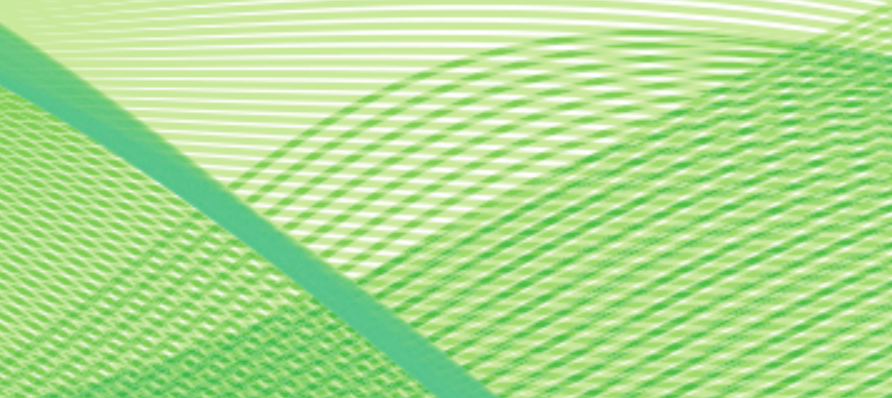

S

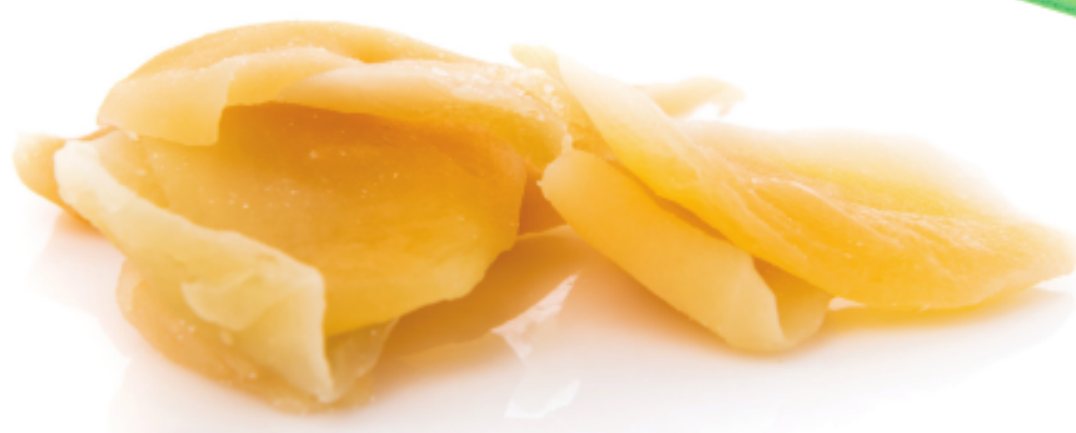

